\title{
Zur Expression und Funktion von Prm3: ein ungewöhnliches Protamin
}

\author{
Dissertation \\ zur Erlangung des Doktorgrades \\ der Mathematisch-Naturwissenschaftlichen Fakultäten \\ der Georg-August-Universität zu Göttingen
}

vorgelegt von

Dagmara Boińska

aus Toruń, Polen

Göttingen 2002 
D 7

Referent: Prof. Dr. W. Engel

Korreferent: PD Dr. S. Hoyer-Fender

Tag der mündlichen Prüfung: 
$\begin{array}{ll}\text { Inhaltverzeichnis } & 1\end{array}$

$\begin{array}{ll}\text { Abkürzungen } & 7\end{array}$

$1 \quad$ Einleitung 10

$\begin{array}{lll}1.1 & \text { Mechanismen der Spermatogenese } & 10\end{array}$

1.2 Die Organisation und Expression des Protamin Gen Clusters 12

$\begin{array}{lll}1.3 & \text { Ziele der vorliegenden Arbeit } & 14\end{array}$

$2 \quad$ Material und Methoden 16

$\begin{array}{lll}2.1 & \text { Chemikalien und Enzyme }\end{array}$

$\begin{array}{lll}2.2 & \text { Gebrauchswaren } & 19\end{array}$

$2.3 \quad$ Sterilisation 19

$2.4 \quad$ Puffer und Stammlösungen 20

$2.5 \quad$ Medien und Zusätze 27

$\begin{array}{lll}\text { 2.5.1 } & \text { Medien für Bakterien } & 27\end{array}$

$\begin{array}{lll}\text { 2.5.2 Medien für Hefen } & 27\end{array}$

2.5.3 Medien für die Zellkultur 28

2.6 Verwendete Bakterien-, Hefestämme, eukaryotische Zellinien 29

2.6.1 Bakterienstämme 29

2.6.2 Hefestämme 29

2.6.3 Eukaryotische Zellinien 30

$2.7 \quad$ Synthetische Oligonukleotide 30

$2.8 \quad$ Verwendete Vektoren, Gensonden und Antikörper 31

2.8.1 Vektoren für Standardklonierungen 31

2.8.2 Expressionsvektoren 31

2.8.3 Fertige Konstrukte 32

2.8.4 Antikörper 32

2.8.5 Gensonden und Klone 33

$2.9 \quad$ Mausstämme 33

2.10 Methoden zur Isolierung von Nukleinsäuren 34

2.10.1 Isolierung von genomischer DNA aus Geweben 34

2.10.2 Präparation von Plasmid-DNA $\quad 34$

$\begin{array}{lll}2.10 .3 & \text { Isolierung von DNA aus Agarosegelen }\end{array}$ 
2.10.4 Isolierung von Gesamt-RNA 35

2.11 Konzentrationsbestimmung von Nukleinsäuren 36

$2.12 \quad$ Polymerase-Kettenreaktion (PCR) 36

2.13 Enzymatische Modifikation von DNA 37

$\begin{array}{lll}\text { 2.13.1 Restriktionsspaltungen } & 37\end{array}$

$\begin{array}{lll}\text { 2.13.2 Auffüllreaktion } & 37\end{array}$

2.13.3 Dephosphorylierung von Vektor-DNA 38

$\begin{array}{lll}2.13 .4 & \text { Ligation } & 38\end{array}$

2.13.5 Radioaktive „Random prime“-Markierung von Nukleinsäuren 38

2.14 Gelelektrophorese von Nukleinsäuren 39

2.14.1 Horizontale Agarosegelelektrophorese 39

2.14.2 Denaturierende Agarosegelelektrophorese 39

2.15 Transfertechniken von Nukleinsäuren 40

2.15.1 Dot-Blotting 40

2.15.2 Southern-Blotting 41

2.15.3 Northern-Blotting 41

2.16 Hybridisierung mit radioaktiv markierten DNA-Sonden 42

2.17 Klonierung von DNA-Fragmenten 42

2.17.1 Herstellung kompetenter $\boldsymbol{E}$. coli-Zellen $\quad 42$

2.17.2 Transformation kompetenter Bakterien 43

$\begin{array}{lll}2.18 & \text { Sequenzanalyse }\end{array}$

$\begin{array}{lll}2.19 & \text { Isolierung von Proteinen } & 44\end{array}$

2.19.1 Gesamtproteinisolierung aus kultivierten Zellen $\quad 44$

2.19.2 Extraktion der Gesamtproteine aus Geweben 45

2.19.3 Extraktion von Kernproteinen aus Geweben. 45

2.19.4 Isolierung von zytoplasmatischen Proteinen aus Gewebe 46

2.19.5 Isolierung der Proteine für die Isoelektrische Fokussierung (IEF) 46

$2.20 \quad$ Proteinanalysen (Proteinbiochemische Techniken) 46

2.20.1 SDS-PAGE 46

2.20.2 Zwei-dimensionale Elektrophorese mit immobilisierten

$\begin{array}{ll}\text { pH-Gradienten } & 47\end{array}$

2.20.2.1 Durchführung des IEFs 48

2.20.2.2 Äquilibrierung der IPG-Streifen und SDS-PAGE für IEF 48

2.20.3 Coomassie-Färbung 49 
2.20.4 Acetonfällung von Proteinen 49

2.20.5 Dialyse von Proteinlösungen 49

2.20.6 Bestimmung von Proteinkonzentrationen 50

2.21 Expression von rekombinantem Protein in S. cerevisiae 51

2.21.1 Induktion der Proteinexpression und Aufschluß der Hefezellen 51

2.21.2 Aufreinigung von rekombinantem Protein 52

2.22 Immunodetektion $\mathbf{5 2}$

2.22.1 Aufreinigung monospezifischer Antikörper 52

2.22.1.1 Aufreinigung monospezifischer Antikörper mittels Western-BlotVerfahren

2.22.1.2 Aufreinigung monospezifischer Antikörper mittels Affinitäts-Säulen 53

2.22.2 Immunoblots

2.22.2.1 Transfer von Proteinen auf Nitrocellulose 54

2.22.2.2 Transferkontrolle mit Ponceau Rot 54

2.22.2.3 Immunodetektion $\mathbf{5 5}$

2.22.3 ELISA (,Enzyme linked immuno-absorbant-assay“)

2.23 Histologische Techniken 56

2.23.1 Fixierung des Gewebes 56

2.23.2 Vorbehandlung der Objektträger $\quad 57$

2.23.3 Herstellung der Testis-Paraffinschnitte $\quad 57$

2.23.4 Immunlokalisierung von Proteinen in Paraffinschnitten $\quad 58$

2.23.5 Akrosomenfärbung 59

2.24 Zellbiologische Methoden

2.24.1 Kultivierung eukaryotischer Zellen 59

2.24.2 Isolierung und Kultivierung primärer Fibroblasten 59

2.24.3 Einfrieren eukaryotischer Zellen $\quad 60$

2.24.4 Transfektion eukaryotischer Zellen $\quad 60$

2.24.5 Zelluläre Lokalisation von GFP-Prm3 Fusionsproteinen in NHI3T3 Zellen $\quad 62$

2.24.6 Immunodetektion des Prm3-Proteins in der P3/3T3 Zellinie 62

2.24.7 Nachweis der apoptotischen Wirkung des Prm3-Proteins. Trypan

Blau Färbung $\quad 63$

$\begin{array}{lll}2.24 .8 & \text { ES-Zellen } & 63\end{array}$

$\begin{array}{lll}\text { 2.24.8.1 } & \text { Kultivierung embryonaler Stammzellen }\end{array}$ 
2.24.8.2 Elektroporation und Selektion von ES-Zellen $\quad 63$

$\begin{array}{lll}\text { 2.24.8.3 Gewinnung von ES-Zellklonen } & 64\end{array}$

$\begin{array}{lll}\text { 2.24.8.4 DNA-Extraktion aus ES-Zellen } & 64\end{array}$

$\begin{array}{lll}\text { 2.24.8.5 Herstellung von Chimären } & 64\end{array}$

2.25 Quantitativer Nachweis von Reporter Enzymen 65

2.25.1 Luciferase-,Assay“6 65

2.25.2 $\beta$-Galactosidase- „Assay“6 66

$2.26 \quad$ Yeast-Two-Hybrid Screening $\quad 66$

2.26.1 Klonierung des "Bait" Proteins $\quad 68$

2.26.2 Beschreibung der Maus Testis pGAD-Bank 68

2.26.3 Herstellung von Lachsspermien-DNA-Lösung 69

2.26.4 Transformation von pGBT9-Prm3 im kleinen Ansatz 69

2.26.5 Transformation der pGAD10/ cDNA-Bibliothek im großen Ansatz 69

$\begin{array}{lll}\text { 2.26.6 Selektion relevanter Transformanten } & \mathbf{7 0}\end{array}$

2.26.7 $\quad \beta$-Galaktosidase-Filter-Assay $\quad 70$

2.26.8 Verifikation positiver Klone durch Erzeugung von Segreganten 70

2.26.9 Isolierung des AD-Plasmids aus Hefezellen und Klon-Analyse $\quad 71$

2.26.10 Hefe „Mating“6 71

2.27 Mammalian-Two-Hybrid System 72

$\begin{array}{lll}\text { 2.27.1 } & \text { Luminometrische Messungen }\end{array}$

$\begin{array}{lll}2.28 & \text { Erzeugung transgener Mäuse } & 74\end{array}$

2.28.1 Vorbereiten der DNA zur Mikroinjektion $\quad 74$

2.28.2 Zucht der Mäuse mit Doxycyklinabhängigem Transaktivator 75

$3 \quad$ Ergebnisse $\quad 76$

3.1 Untersuchungen zur Expression des Prm3-Gens bei der Maus 76

3.1.1 Organspezifische Expression des Prm3-Gens 76

3.1.2 Expression des Prm3-Gens während der Testis-Entwicklung $\begin{array}{ll}\text { der Maus } & 77\end{array}$

3.2 Analyse der Prm3-Expression auf Protein-Ebene 79

3.3 Bestimmung des isoelektrischen Punktes des Prm3-Proteins 82

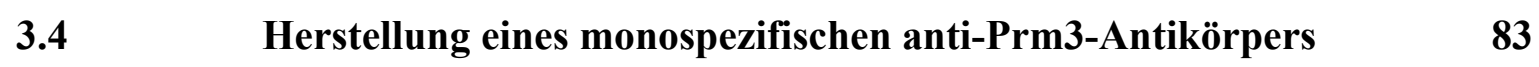

$\begin{array}{lll}\text { 3.4.1 Herstellung des GST/Prm3-Fusionsproteins } & 84\end{array}$ 
3.4.2 Gewinnung von Antikörpern gegen das Maus Prm3-Protein $\quad 84$

3.5 Immunohistochemische Färbungen auf Testisschnitten 85

3.6 Der Versuch der Zuordnung der Expression des Prm3-Proteins zu $\begin{array}{ll}\text { Spermatogenese Stadien } & 87\end{array}$

3.7 Subzelluläre Lokalisation des Prm3-Proteins in Säugerzellen $\quad 88$

3.7.1 Subzelluläre Lokalisation des Prm3-Proteins als

$\begin{array}{lr}\text { GFP-Fusionsprotein } & \mathbf{8 8}\end{array}$

3.7.2 Computergestützte Voraussage der subzellulären Lokalisation des Prm3- Proteins $\quad 90$

3.7.3 Subzelluläre Lokalisation des Prm3-Proteins in stabil transfizierten Zellen $\quad 90$

3.7.4 Westernblot-Analyse zur Lokalisation des Prm3-Protein 92

3.8 Induktion von Apoptose durch Prm3-Expression 92

3.9 Suche nach Prm3-Interaktionspartnern mit Hilfe des "Yeast-Two-Hybrid-Systems" 94

3.9.1 Klonierung des Prm3-Gens in den pGBT9-Vektor 95

$\begin{array}{lll}\text { 3.9.2 Transaktivierungstest } & 95\end{array}$

3.9.3 Bestimmung der Transformationseffizienz und der Anzahl $\begin{array}{ll}\text { der getesteten Klone } & 95\end{array}$

3.9.4 Identifikation von HIS3-positiven Hefetransformanten 96

3.9.5 $\quad \beta$-Galaktosidase-Test der HIS3-positiven-Transformanten $\quad 96$

3.9.6 Screening einer YTH-Testis-cDNA-Bank durch Hefe "Mating" 97

3.9.7 Identifizierung der cDNA-Klone $\quad 98$

3.9.8 Verifikation positiver Klone durch Segregation 98

3.10 Mammalian-Two-Hybrid-System 99

$\begin{array}{lll}\text { 3.10.1 } & \text { Transfektion der NIH/3T3-Fibroblasten }\end{array}$

$\begin{array}{lll}3.11 & \text { Expression-Studien des Klons } 96 & 101\end{array}$

3.12 Induzierbare Expression von Prm3 in transgenen Mäusen 103

$\begin{array}{lll}\text { 3.12.1 Klonierung des TRE-Prm3-Konstrukts } & 104\end{array}$

3.12.2 Transgene Tet-Responder Linien für TRE/Prm3 105

3.12.3 Test auf Regulierbarkeit der TRE-Prm3-Linien durch Transfektion von primären Ohrfibroblasten 106 
3.12.4 Transgene Maus für den Tetracyclin-abhängigen

Transaktivator tTA

108

3.12.5 Analyse der doppelt transgenen Tiere TRE/Prm3//CMV/tTA 109

3.12.6 Act/tTA-Aktivator-Linien 110

3.12.7 Expressionsanalysen in Act/tTA transgenen Mäusen durch

Northern-Blot-Analysen

3.12.8 Untersuchungen der Act/tTA-transgenen Mäuse

auf der Proteinebene

3.12.9 Western-Blot Analysen der doppelt transgenen Tiere

TRE/Prm3//Act45

3.12.10 Immundetektion des Prm3-Proteins auf Testis- und

Epididymisschnitten doppelt transgener Tiere TRE/Prm3//Act45 114

3.13 Homologe Rekombination des Prm3-Gens 115

3.13.1 Herstellung eines Prm3-Knock-out-Konstrukts 116

3.13.2 Herstellung von homolog rekombinierten ES-Zellen 120

$\begin{array}{lll}\text { 3.13.3 Generierung von Prm3-defizienten Mäusen } & 121\end{array}$

4 Diskussion

122

4.1 Prm3 und die Protamin/Transitionsprotein-Familie: ein Vergleich

4.1.1 Vergleichende Analyse von mRNA- und Proteinexpression

von Prm3 und anderen Mitgliedern der Protamin-Familie

122

4.1.2 Interspezies-Variabilität der Prm3-Expression

4.1.3 Interspezies-Vergleich der Prm3-5' flankierenden Region

und Vergleich mit anderen Protamin-Genen $\quad 128$

4.2 Charakterisierung des Prm3-Proteins 130

4.2.1 Versuche zur subzellulären Lokalisation von Prm3 131

4.2.2 Überlegungen zur Funktion von Prm3 131

4.3 Versuche zur Manipulation der Prm3 Expression in der Maus 133

4.3.1 Effekt von aberranter Expression 133

4.3.2 Knockout Modele für spermatogenesespezifische Gene 136

$5 \quad$ Zusammenfassung 139

$\begin{array}{lll}6 & \text { Literaturverzeichnis } & 141\end{array}$ 


\section{Abkürzungen}

\begin{tabular}{|c|c|}
\hline A & Ampère \\
\hline A & Purinbase Adenin \\
\hline Abb. & Abbildung \\
\hline Amp & Ampicillin \\
\hline AP & Alkalische Phosphatase \\
\hline APS & Ammoniumperoxodisulfat \\
\hline ATP & Adenosintriphosphat \\
\hline $\mathrm{Bp}$ & Basenpaare \\
\hline BCIP & 5-Brom-4-Chlor-3-Indolylphosphat \\
\hline bzw. & beziehungsweise \\
\hline BSA & Rinderserumalbumin \\
\hline $\mathrm{C}$ & Pyrimidinbase Cytosin \\
\hline${ }^{\circ} \mathrm{C}$ & Grad Celsius \\
\hline ca. & circa \\
\hline $\mathrm{cfu}$ & „,colony forming units“ \\
\hline CHAPS & 3-[(3-Cholamidopropyl)-dimethylammonio]-1-propansulfonat \\
\hline $\mathrm{Ci}$ & Curie \\
\hline cDNA & komplementäre DNA \\
\hline СТP & Cytidintriphosphat \\
\hline d- & desoxy \\
\hline dATP & Desoxyadenosintriphosphat \\
\hline $\mathrm{Da}$ & Dalton \\
\hline DAPI & 4,6-diamidino-2-phenylindole dihydrochloride \\
\hline $\mathrm{dCTP}$ & Desoxycytidintriphosphat \\
\hline dd- & didesoxy \\
\hline dest. & Destilliert \\
\hline d.h. & das heißt \\
\hline DEPC & Diethylpyrocarbonat \\
\hline dGTP & Desoxyguanosintriphosphat \\
\hline DMEM & „Dulbeccos modified eagle medium“ \\
\hline DMF & Dimethylformamid \\
\hline DNA & Desoxyribonukleinsäure \\
\hline DNase & Desoxyribonuklease \\
\hline dNTP & Desoxynukleotidtriphosphat \\
\hline DTT & Dithiotreitol \\
\hline dTTP & Desoxythymidintriphosphat \\
\hline E.coli & Escherichia coli \\
\hline EDTA & Ethylendiamintetraessigsäure \\
\hline EGTA & Ethylenglycol-bis (ß-Aminoethylether)-Tetraacetat \\
\hline EGFP & $\begin{array}{l}\text { verstärkt grün-fluoreszierendes Protein „, enhanced green } \\
\text { fluorescent protein““ }\end{array}$ \\
\hline ELISA & „Enzyme linked immuno-absorbant-assay“ \\
\hline ES & Embryonale Stamm- \\
\hline EST & $\begin{array}{l}\text { Sequenzierter Abschnitt einer cDNA „, expressed sequence } \\
\text { Tag“ }\end{array}$ \\
\hline et al. & et alteres \\
\hline $\mathrm{EtBr}$ & Ethidiumbromid \\
\hline Fa. & Firma \\
\hline FITC & Fluorescein-5-isothiocyanat \\
\hline
\end{tabular}




\begin{tabular}{|c|c|}
\hline FKS & fetales Kälberserum \\
\hline g & Gramm \\
\hline G & Purinbase Guanin \\
\hline GST & Glutathion-S-Transferase \\
\hline $\mathrm{h}$ & Stunde(n) \\
\hline $\mathrm{HEF}$ & human elongation factor \\
\hline HSV & Herpes simplex-Virus \\
\hline IEF & isoelektrische Fokussierung \\
\hline IPTG & Isopropyl- $\beta$-thiogalactopyranosid \\
\hline $\mathrm{k}$ & kilo- $\left(1 \times 10^{3}\right)$ \\
\hline $\mathrm{Kb}$ & Kilobasenpaare \\
\hline $\mathrm{KDa}$ & Kilodalton \\
\hline 1 & Liter \\
\hline LB & Luria Bertani \\
\hline Lsg. & Lösung \\
\hline $\mathrm{m}$ & milli- $\left(1 \times 10^{-3}\right)$ \\
\hline M & mega- $\left(1 \times 10^{6}\right)$ \\
\hline M & Molarität \\
\hline MCS & „multiple cloning site” \\
\hline$\mu$ & mikro- $\left(1 \times 10^{-6}\right)$ \\
\hline $\min$ & Minute(n) \\
\hline mRNA & „messenger“ Ribonukleinsäure \\
\hline MTH & „Mammalian Two Hybrid System” \\
\hline $\mathrm{n}$ & nano- $\left(1 \times 10^{-9}\right)$ \\
\hline $\mathrm{NaAc}$ & Natriumacetat \\
\hline NBT & Nitroblau-Tetrazolium \\
\hline neo & Neomycin-Resistenzgen \\
\hline Nr. & Nummer \\
\hline $\mathrm{nt}$ & Nukleotide \\
\hline OD & Optische Dichte \\
\hline $\mathrm{p}$ & pico- $\left(1 \times 10^{-12}\right)$ \\
\hline PAA & Polyacrylamid \\
\hline p.A. & per analysi \\
\hline PAGE & Polyacrylamidgelelektrophorese \\
\hline PBS & Phosphatgepufferte Salzlösung \\
\hline pc & post coitum \\
\hline PEG & Polyethylenglykol \\
\hline PCR & Polymerasekettenreaktion (,polymerase chain reaction“) \\
\hline $\mathrm{pH}$ & $\begin{array}{l}\text { negativer dekadischer Logarithmus der } \mathrm{H}^{+} \text {- } \\
\text { Ionenkonzentration }\end{array}$ \\
\hline RE & Restriktionsendonukleasen \\
\hline RNA & Ribonukleinsäure \\
\hline RNase & Ribonuklease \\
\hline RT & Raumtemperatur \\
\hline SDS & Natriumdodecylsulfat \\
\hline $\mathrm{S}$ & Svedberg \\
\hline S & Sekunden \\
\hline $\mathrm{T}$ & Pyrimidinbase Thymidin \\
\hline TAE & Tris-Acetat-EDTA-Puffer \\
\hline TBE & Tris-Borat-EDTA-Puffer \\
\hline TBS & Trisgepufferte Salzlösung \\
\hline
\end{tabular}




$\begin{array}{ll}\text { TE } & \text { Tris-EDTA (-Puffer) } \\ \text { TEMED } & \text { Tetramethylethylendiamin } \\ \text { TK } & \text { Thymidin-Kinase } \\ \text { Tris } & \text { Tris- (hydroxymethyl) aminomethan } \\ \text { Tween 20 } & \text { Polyoxyethylensorbitanmonooleat } \\ \text { U } & \text { Unit (Einheit der Enzymaktivität) } \\ \text { U } & \text { Pyrimidinbase Uridin } \\ \text { u.a. } & \text { unter anderem } \\ \text { üN } & \text { über Nacht } \\ \text { UTR } & \text { nicht translatierte Region } \\ \text { UV } & \text { Ultraviolett } \\ \text { V } & \text { Volt } \\ \text { Vol } & \text { Volum } \\ \text { v/v } & \text { Volumen pro Volumen } \\ \text { W } & \text { Watt } \\ \text { w/v } & \text { Gewicht pro Volumen } \\ \text { x g } & \text { Vielfaches der Erdbeschleunigung } \\ \text { YTH } & \text { Yeast Two Hybrid System } \\ \text { z.T } & \text { zum Teil } \\ \text { 2D } & \text { zwei-dimensionale Elektrophorese }\end{array}$




\section{$1 \quad$ Einleitung}

\subsection{Mechanismen der Spermatogenese}

Jedes reife Spermatozoon, das befähigt ist, eine Eizelle zu befruchten, hat seinen Ursprung in einer von 10 bis 100 primordialen Keimzellen, die im frühen Embryo gebildet werden. Damit jedoch aus einer undifferenzierten Keimzelle ein hochspezialisiertes Spermium entsteht, sind komplexe morphologische und physiologische Prozesse nötig. Am Anfang der embryonalen Entwicklung durchlaufen die Keimzellen zahlreiche mitotische Teilungen und wandern vom Hinterdarmepithel über die dorsalen Mesenterien in die Gonadenleiste ein. Nach weiteren mitotischen Proliferationsteilungen differenzieren sie dort letztlich zu den Gonocyten, aus denen die Spermatogonien hervorgehen. Hier beginnt die eigentliche Spermatogenese, ein komplexer Differenzierungsprozess, der sich in drei Phasen gliedert: 1) Die Proliferationsphase, die gekennzeichnet ist durch zahlreiche mitotische Zellteilungen der TypA Spermatogonien, 2) die meiotische Phase, in der das genetische Material der Spermatocyten rekombiniert und halbiert wird und 3) die Spermiogenese, in der, ausgehend von den haploiden Spermatiden, das befruchtungsfähige Spermatozoon entsteht. Der gesamte Prozess dauert bei der Maus 34,5 Tage.

Im Vergleich zu anderen Entwicklungsprozessen beim Säuger ist relativ wenig über die molekularen Mechanismen bekannt, welche die Spermatogenese kontrollieren. In deren Verlauf kommt es zu dramatischen morphologischen und biochemischen Veränderungen, bedingt durch spezifische Änderungen der Genexpression. Jede der oben genannten Phasen ist gekennzeichnet durch eine Reihe von Genen, die nur zu diesem Zeitpunkt exprimiert werden. Stellvertretend sollen hier genannt sein: c-kit in den Spermatogonien (Yoshinaga et al., 1991), Mak während der meiotischen Reduktionsteilung (Matsushime et al., 1990) sowie Calspermin (Wu und Means, 2000) und die Protamine (Kleene et al., 1985; Yelick et al., 1987) während der postmeiotischen Phase. Darüberhinaus unterliegt die Spermatogenese einer stringenten hormonellen Regulation, an der sowohl die testikulären somatischen Zellen (Leydig- und Sertoli-Zellen) als auch das zentrale Nervensystem sowie die Schilddrüse beteiligt sind. Insbesondere während der Spermiogenese, also der morphologischen und funktionellen Differenzierung des Spermiums, läuft eine Anzahl hochspezialisierter Prozesse ab, die zu den 
augenfälligsten Arten der Zelldifferenzierung gehören: die Anlage und Organisation des Spermienschwanzes, die Ausbildung des Akrosoms, die Kondensation des Chromatins im Spermatidenkern. Letztere ist durch eine zweistufige Substitution der somatischen Histone durch keimzellspezifische basische Nucleoproteine, die Transitionsproteine und Protamine, gekennzeichnet. In der ersten Stufe werden in den frühen elongierenden Spermatiden die somatischen Histone gegen die Transitionsproteine Tnp1 (Stadium XII) und Tnp2 (Stadium X) ersetzt. In den späten elongierten Spermatiden (Stadium VI, Schritt 15 elongierende Spermatiden) werden diese dann durch Protamine ersetzt, die Arginin-, Lysin- und Cysteinreiche, also hoch basische Nucleoproteine darstellen.

Das haploide männliche Genom erlangt bei diesem Vorgang eine spezielle sog. "doughnut"förmige Chromatinstruktur (Allen et al., 1993; Sassone-Corsi, 2002), die sich deutlich von der klassischen Nucleosomen - Struktur (Mills et al., 1977) unterscheidet. Die Protamine binden mit ihrer zentralen Polyarginin Region innerhalb der großen Furche der DNA-Doppelhelix. Die Protamin-DNA Komplexe eines DNA-Fadens passen sich genau an die große Furche einer nächsten DNA-Doppelhelix an und werden so Seite an Seite im Spermien-Nucleus verpackt (Balhorn, 1982). In den Protamin-DNA-Komplexen sind auf diese Weise viel größere DNA-Subunits (ca. $50 \mathrm{~kb}$ ) enthalten als in den Histon-DNA-Komplexen der somatischen Zellen. Sie sind darüberhinaus miteinander stark über van der Waal-Kräften verbunden (Ward (1993). Die Kondensierung des Chromatins erreicht hierbei einen extremen Zustand, wobei die DNA im Spermien-Nucleus auf lediglich 5\% des Volumens des Kerns einer somatischen Zelle komprimiert wird.

Der Beginn der Spermiogenese ist zudem durch eine massive Zunahme der transkriptionalen Aktivität charakterisiert. TBP (TATA-binding Protein) und die RNA II Polymerase sind in frühen runden Spermatiden in viel größerer Menge als in somatischen Zellen akkumuliert (Schmidt et al., 1995; Sassone-Corsi, 1997). Weiter wird in den frühen haploiden Stadien eine ganze Batterie von postmeiotischen Genen aktiviert, die für die weitere Differenzierung der Keimzellen essentiell sind. Auch für die Proteine, die zu einem späteren Zeitpunkt der Spermiogenese bzw. der frühen Embryogenese (nach erfolgreicher Befruchtung) benötigt werden, erhöht sich massiv die Zahl der korrespondierenden Transkripte in runden Spermatiden. Der Grund hierfür ist eine Inaktivierung des Transkriptionsapparates und damit der mRNA-Synthese während der nächsten Schritte der Spermiogenese. Dieser Prozess läuft parallel zur Kondensation des Kerns. Im vollständig kondensierten Chromatin findet keine 
Transkription mehr statt (Meistrich, 1989). Auch innerhalb des Nucleolus, dem Ort der rRNA-Transkription, Reifung und Prozessierung des prä rRNA und Zusammenbaus mit ribosomalen Proteinen, wird ab dem Stadium der elongierenden Spermatiden die Transkriptionsaktivität zunehmend eingestellt. In den elongierten Spermatiden wird der Nucleolus abgebaut (Biggiogera et al., 1994).

Die prozessierten Transkripte werden bis zum späteren Zeitpunkt der Translation im Zytoplasma in Form von Ribonukleoprotein-Partikel (RNPs) gelagert (Balhorn et al., 1984; Kleene et al., 1984). Obwohl die postranskriptionale Kontrolle das wichtigste Werkzeug zur Regulation der Genaktivität während der Spermatogenese darstellt, ist bis heute wenig über die Mechanismen der temporären Reprimierung sowie späteren Aktivierung dieser mRNAs bekannt. Die Translation der gelagerten und vor der Degradation geschützten mRNAs wird durch spezifische zytoplasmatische Proteine reguliert, die sowohl innerhalb der kodierenden Sequenz als auch an regulatorische Sequenzmodule im 5'- und 3'-nichttranslatierten Bereich (UTRs) der betreffenden mRNAs binden. Verschiedene mRNA-bindende Proteine sind mittlerweile identifiziert worden: Protamine 1 RNA-binding Protein (Prbp) (Lee et al., 1996; Zhong et al., 1999), Spermatid perinuclear RNA-binding Protein (Spnr) (Pires-da Silva et al., 2001; Coolidge und Patton, 2000) oder Testis Brain RNA-binding Protein (Tb-rbp) (Kwon und Hecht, 1991). Von diesen konnte bislang lediglich für MSY4 überzeugend gezeigt werden, das es eine Funktion bei der Regulation, Speicherung und Translation Spermatidenspezifischer Transkripte hat (Giogini et al., 2002).

\subsection{Die Organisation und Expression des Protamin Gen Clusters}

Drei von vier der bei der Maus bekannten Gene, deren Genprodukte an der Kondensierung des Chromatins während der Spermatogenese beteiligt sind, sind in einem etwa $8 \mathrm{~Kb}$ großen Bereich auf dem langen Arm des Chromosoms 16 lokalisiert (Schlüter et al., 1992). Es sind dies die Gene für Protamin 1 (Prm1), Protamin 2 (Prm2) sowie Transitionsprotein 2 (Tnp2). Diese enge Kopplung ist bei allen daraufhin untersuchten Spezies zu beobachten: Prm1, Prm2 und Tnp2 des Menschen liegen in einem $13 \mathrm{~Kb}$ großen Bereich an der Spitze des kurzen Armes von Chromosom 16 (Schlüter et al., 1992), der Ratte auf Chromosom 10 (Adham et 
al., 1991) und auch beim Rind sind diese drei Gene innerhalb eines ca.13 Kb großen Bereichs lokalisiert.

Die Protamine bilden den Hauptbestandteil der DNA-bindenden Proteine in den reifen Spermatozen der Maus (ca. 95\%). Ihre zeitlich und räumlich korrekte Expression ist von großer Bedeutung für die Spermien-Differenzierung und die Fertilität. So verursacht eine vorgezogene Expression des Prm1-Proteins eine vorzeitige Chromatin-Kondensierung. Abhängig von der Kopienzahl des Transgens verursacht dies einen Arrest der Spermiogenese im Stadium der runden oder elongierenden Spermatiden (Lee, 1995).

Die Phosphorylierung von Protaminen scheint ebenfalls eine wichtige Rolle bei der Chromatinkondensierung zu spielen. Prm2 wird durch Camk4 $\left(\mathrm{Ca}^{2+} /\right.$ calmodulin-dependent protein kinase IV) phosphoryliert. Männliche Mäuse mit einer Deletion im Camk4-Gen sind infertil, wobei die Spermatogenese zunächst bis zum Stadium XII ungestört verläuft. Ab diesem Zeitpunkt ist die aufeinanderfolgende Ablagerung der Spermiogenese-spezifischen DNA-bindenden Proteinen unterbrochen (Wu et al., 2000). Das Prm2-Vorläuferprotein kann nicht zum reifen Prm2 prozessiert werden. Hierdurch unterbleibt der Austausch von Tnp2 gegen Prm2. Es resultiert eine deutliche Reduktion der Spermienzahl.

Prm2 scheint also eine wichtige Rolle bei Mensch (de Yebra, 1998) und Maus (Cho, 2001) zu spielen. Interessanterweise wird Prm2 in verschiedenen Spezies in sehr unterschiedlichem Ausmaß benutzt. In einigen Arten sind Prm2 Transkripte nicht nachweisbar. In Spezies, in denen Transkripte nachgewiesen wurden, variiert der Anteil von Prm2 am Gesamt-Protamin von $2-75 \%$.

Zwischen den Genloci für Prm2 und Tnp2 wurde zunächst mithilfe von Computer-SequenzAnalysen und später experimentell (u.a. durch Northern Blot-Hybridisierungen) ein weiteres Gen identifiziert, welches Protamin3 (Prm3) genannt wurde (Schlüter, 1995) (Abb.1). Das Expressionsmuster des Prm3-Gens der Ratte wurde nachfolgend detailliert untersucht. Das $0,4 \mathrm{~Kb}$ große Transkript wird spezifisch in runden und elongierenden Spermatiden exprimiert und kann erstmals in 23 Tage alten Tieren detektiert werden, also zum gleichen Zeitpunkt wie Prm1 (Hecht et al., 1986). 


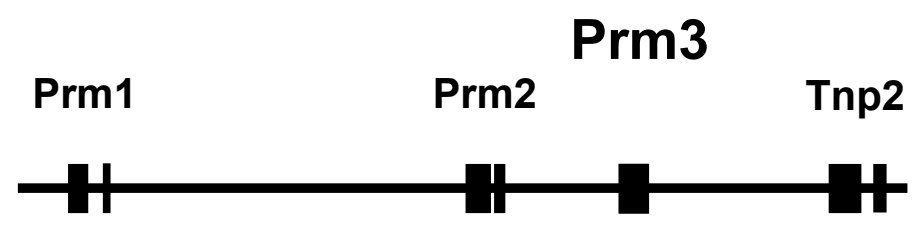

$1 \mathrm{~kb}$

Abb. 1: Schematische Darstellung des Maus Protamine Gene Clusters.

Das Prm3-Gen unterscheidet sich jedoch in einigen Aspekten von den anderen Genen des Clusters. Erstens findet sich innerhalb der Sequenz für Prm3 kein Intron und zweitens scheint diese Sequenz für ein saures Protein zu kodieren. Inmitten eines Gen-Clusters, dessen Mitglieder durch eine Duplikation der ursprünglichen Prm1-Sequenz entstanden sein sollen (Nelson und Krawetz, 1993), ist die Gegenwart eines intronlosen Gens bemerkenswert. Die übrigen Gene des Clusters (Prm1, Prm2 und Tnp2) besitzen alle eine einheitliche Struktur. Es existieren zwei Exons (wobei die kodierende Region fast ausschließlich im 5' Exon liegt), die für extrem basische Proteine codieren. Das Prm3-Gen hingegen kodiert für ein Protein, dessen isoelektrischer Punkt nach theoretischer Überlegung bei pH 4.3 liegt (Schlüter, 1996) und somit einen sauren Charakter besitzt. Daher stellt sich hier nun die berechtigte Frage, ob Prm3 tatsächlich ein Protamin darstellt bzw. im Rahmen der Kondensation von genetischem Material funktionell aktiv ist oder ob dem Prm3-Protein eine hiervon abweichende Funktion zukommt.

\subsection{Ziele der vorliegenden Arbeit}

Mit dieser Arbeit sollte das Protamin3-Gen im Vergleich zu den bekannten Protaminen charakterisiert werden. Es sollte ein detailliertes Expressionsmuster der Prm3-Gens und des zugehörigen Proteins in der Spermatogenese der Maus analysiert werden, sowie die zelluläre und subzelluläre Lokalisation des Prm3-Proteins aufgeklärt werden. Um die möglichen 
Funktionen des Prm3-Proteins zu beleuchten, sollte nach Bindungspartnern für das Prm3Protein gesucht werden.

Einen zweiten Aspekt bildeten die Untersuchungen im lebenden Organismus. Es sollte sowohl eine Maus mit Null-Mutation (Knock-out für Prm3) als auch eine Mauslinie mit einer aberranten Expression von Prm3 geschaffen werden. Für letzteren Ansatz sollte Prm3 sowohl in Keimzellen zeitlich vorgezogen induzierbar als auch in somatischen Zellen exprimiert werden. Bei einer solchen aberranten Expression können Rückschlüsse auf die Eigenschaften und Funktionen von Prm3 gezogen werden. 


\section{Material und Methoden}

\subsection{Chemikalien und Enzyme}

Chemikalien und Lösungsmittel, die nicht gesondert aufgeführt sind, wurden von der Firma Carl Roth (Karlsruhe) in p.A. Qualität bezogen.

Acrylamid/Bisacrylamid (40\%; 29:1)

Agar

Agarose

Ampicillin

Aprotinin

Bacto-Tryptone

Bacto-Yeast-Extrakt

BCIP

Bio-Lyte, pH 3-10

BigDye ${ }^{\circledR}$ Terminator Cycle Sequencing Ready Reaktion Kit

Bromphenolblau

BSA

CHAPS

Coomassie-Brilliant Blau R250

Dextransulfat

Diethylpyrocarbonat

Dimethylformamid

Dithiothreitol

DMEM

DNase I (RNase-frei)

dNTPs

Doxycyclin

DYEnamic ET-Terminator-Mix

EDTA
Amresco, Cleveland, USA

Fluka, Deisenhofen

Peq-Lab, Erlangen

Fluka

Sigma, Deisenhofen

Difco, Detroit, USA

Difco

Roth, Karlsruhe

Amersham Pharmacia Biotech, Freiburg

Applied Biosystems, Weiterstadt

Fluka

Biomol, Hamburg

Biomol

Fluka

Amresco

Sigma

Sigma

Biomol

PAN, Aidenbach

Epicentre, Wisconsin, USA

Invitrogen, Karlsruhe

Sigma

Amersham Pharmacia

ICN, Aurora, USA 
EGTA

Endo Free Plasmid Maxi Kit

Ethidiumbromid

Ficoll 400

FKS

Formaldehyd

Formamid

G418

$\mathrm{D}(+)$-Galactose

Glasperlen (0,25-0,5 mm)

Glucose (Dextrose)

Glutamin (200 $\mathrm{mM}$ in $\mathrm{H}_{2} \mathrm{O}$ )

Glutathion (reduziert)

Glutathione Sepharose 4B

Glycerin

Glycylglycin Puffersubstanz

Harnstoff

HCG (Choriongonadotropin, human)

Hefe Stickstoffbasis ohne Aminosäuren

Hygromycin B

Immobiline Dry Strips pH 3-10

Iodacetamid

Kanamycin

Klenow-DNA-Fragment

Lachs-Spermien-DNA

Lectin

Leupeptin

D-Luciferin (freie Säure, synth.)

Megaprime ${ }^{\circledR}$ DNA Labeling Kit

$\beta$-Mercaptoethanol

Mineralöl

myo-Inositol

NBT
Sigma

Qiagen, Hilden

Merck, Darmstadt

Fluka

PAN

Roth

Merck

Calbiochem-Novabiochem, La Jolla, USA

Fluka

Roth

Becton Dickinson, Cockeysville, USA

PAN

Fluka

Amersham Pharmacia Biotech

ICN

Biomol

ICN

Organon, Oberschleißheim

Difco

Calbiochem-Novabiochem

Amersham Pharmacia Biotech

Sigma

Sigma

MBI, St. Leon-Rot

Sigma

Calbiochem

Sigma

PJK, Kleinblittersdorf

Amersham Pharmacia Biotech

Serva, Heidelberg

Sigma

BBL

Roth 
Orange G

PBS (ohne $\mathrm{Ca}^{2+}, \mathrm{Mg}^{2+}$ )

Penicillin, Streptomycin (10000U, $10 \mathrm{mg} / \mathrm{ml}$ )

Pepstatin

Phenol

PMSF

Polyethylenglycol 6000

Polyvinylpyrrolidon

Poly $(\mathrm{dI} * \mathrm{dC})$

Ponceau-Rot

Protease Inhibitor Cocktail (Mammaliagewebe)

Proteinase K

Radioaktiv markierte dCTP

$$
\left[\alpha^{32 \mathrm{p}}\right] \mathrm{dCTP}(3000 \mathrm{Ci} / \mathrm{mmol})
$$

Readiprime $^{\mathrm{TM}}$ II Random Prime

Labeling System

Restriktionsenzyme

RNA-Längestandard 0.29-9.5 Kb

RNase Inhibitor

Roticlear

Rotifect

RPMI

SDS

Select Peptone

Superfect

T4-DNA-Ligase

Taq-DNA-Polymerase

TEMED

Triton X

Trypsin/EDTA $(0,05 / 0,02 \%$ ig in PBS)

Tween 20

Yeast Nitrogen Base w/o aa

Zellkulturmedien
Sigma

PAN

PAN

Sigma

Biomol

Sigma

Serva

Sigma

ICN

Fluka

Sigma

Roth

Amersham Pharmacia Biotech

Amersham Pharmacia Biotech

Eurogentec, Invitrogen, MBI

Invitrogen

MBI

Roth

Roth

PAN

ICN

Invitrogen

Qiagen

MBI

Biometra Göttingen; Invitrogen, Roche

Serva

Serva

PAN

Merck

Difco

PAN 


\section{$2.2 \quad$ Gebrauchswaren}

Affinitätssäulen HiTrap affinity

Columns, NHS-aktiviert

Aufreinigungssäule MicroSpin ${ }^{\mathrm{TM}}$ S-200 HR

Blottingpapier GB 003

Centrisart I

Dialyseschläuche

Einmalfilter Minisart NMI

Hybond C Membran

Mikrotiterplatten NUNCLONTM

Objektträger SuperFrost* Plus

Peel-A-Way Einbettungsformen

Röntgenfilme Hyperfilm ${ }^{\mathrm{TM}}$ MP

Sterilfilter

Turbo-Blot-Apparatur
Amersham Pharmacia Biotech

Amersham Pharmacia Biotech

Schleicher \& Schüll, Dassel

Satorius, Göttingen

Serva

Sartorius

Amersham Pharmacia Biotech

Nunc

Schütt, Göttingen

Polysciences

Amersham Pharmacia Biotech

Satorius

Schleicher \& Schuell

Sonstige Plastik-Einwegartikel wurden von den Firmen Krannich und Schütt (Göttingen), Eppendorf (Hamburg), Greiner (Frickenhausen), Nunc (Wiesbaden) oder Sarstedt (Sarstedt) bezogen.

\subsection{Sterilisation}

Die Sterilisation erfolgte für $20 \mathrm{~min}$ bei $120^{\circ} \mathrm{C}$ und $10^{5}$ Pascal im Dampfdruckautoklaven (Webeco, Bad Schwartau) oder durch Sterilfiltration (Porengröße 0,2 $\mu \mathrm{m}$ ). Gebrauchswaren wurden autoklaviert oder für $5-10 \mathrm{~h}$ bei $200^{\circ} \mathrm{C}$ hitzesterilisiert. 


\subsection{Puffer und Stammlösungen}

Puffer und Lösungen wurden nach Sambrook et al. (1989) hergestellt. Die Chemikalien wurden den Erfordernissen entsprechend in bidestilliertem oder deionisiertem Wasser gelöst und nach Bedarf autoklaviert oder sterilfiltriert. Für die Arbeiten mit RNA wurden die Puffer, sofern sie kein Tris enthielten, üN mit 0,1\% DEPC inkubiert und anschließend autoklaviert. Tris-Puffer wurden in RNase-freien Gefäßen mit DEPC behandeltem Wasser angesetzt. Puffer von Enzymen und gebrauchsfertigen „Kits“ wurden, wie vom Hersteller in den Beipackzetteln angegeben, benutzt. Ihre Zusammensetzung ist hier nicht mehr aufgeführt.

AP-Puffer

$\begin{array}{ll}100 \mathrm{mM} & \text { Tris/Cl (pH 9,5) } \\ 100 \mathrm{mM} & \mathrm{NaCl} \\ 5 \mathrm{mM} & \mathrm{MgCl}_{2}\end{array}$

Äquilibrierungspuffer 1

6 M Harnstoff

(2-D-Elektrophorese)

$30 \%$ Glycerin

$2 \% \mathrm{SDS}$ in $0,05 \mathrm{M}$ Tris/ $\mathrm{HCl}, \mathrm{pH} 8,8$

$1 \%$ DTT

Äquilibrierungspuffer 2

6 M Harnstoff

(2-D-Elektrophorese)

$30 \%$ Glycerin

$2 \% \mathrm{SDS}$ in $0,05 \mathrm{M}$ Tris/ $\mathrm{HCl}, \mathrm{pH} 8,8$

$260 \mathrm{mM}$ Jodacetamid

BCIP-Stammlösung

$50 \mathrm{mg} / \mathrm{ml}$ in Dimethylformamid

Coomassie-Lösung

$30 \%$ (v/v) Methanol

$10 \%(\mathrm{v} / \mathrm{v})$ Essigsäure

0,05\% (w/v) Coomassie-Brilliant Blau R250

Denhardt's Lsg.

1\% (w/v) Ficoll 400

$1 \%(\mathrm{w} / \mathrm{v})$ Polyvinylpyrrolidon

$1 \%(\mathrm{w} / \mathrm{v}) \mathrm{BSA}$ 
Coomassie-Entfärber

Diethanolaminpuffer

Elutionspuffer

(Fusionsproteinisolierung)

Elutionspuffer

(Aufreinigung vonAntikörper

mittels Western-Blot)

Elutionspuffer

(Affinitäts-Säule)

E-Puffer $(10 \mathrm{x})$

Extraktionspuffer

(Gesamtprotein)

Fixiergemisch

(Bouin'sches Fixativ)

Formamid-Stopmix

Gewebe-Lysis-Puffer
$30 \%(\mathrm{v} / \mathrm{v})$ Methanol

$10 \%(\mathrm{v} / \mathrm{v})$ Essigsäure

$10 \mathrm{mM}$ Diethanolamin $\mathrm{pH} 9,5$

$0,5 \mathrm{mM} \mathrm{MgCl}_{2}$

$10 \mathrm{mM}$ reduziertes Glutathion

50 mM Tris- $\mathrm{HCl}, \mathrm{pH} 8,0$

3 M KSCN

$0.1 \%$ BSA in $1 x$ PBS

$3 \mathrm{M} \mathrm{MgCl}_{2}$

in $1 x$ PBS

$300 \mathrm{mM} \mathrm{NaH}{ }_{2} \mathrm{PO}_{4}(\mathrm{pH} 7,0)$

$50 \mathrm{mM}$ EDTA

100 mM Kaliumphosphat (pH 7,8)

$1 \mathrm{mM}$ DTT (direkt vor Gebrauch zugegeben)

0,2\% (v/v) Triton X-100 (Lysis von Zellkulturen)

$1 \%(\mathrm{v} / \mathrm{v})$ Triton X-100 (Lysis von Geweben)

15 Vol Pikrinsäure (gesättigt in $\mathrm{H}_{2} \mathrm{O}$ )

5 Vol Formaldehyd

1 Vol Essigsäure

95\% (v/v) Formamid

$50 \mathrm{mM}$ EDTA

0,05\% (w/v) Bromphenolblau

$0,05 \%(\mathrm{w} / \mathrm{v})$ Xylenxyanol

$100 \mathrm{mM} \mathrm{NaCl}$ 


$\begin{array}{ll}\text { (Isolierung genomischer DNA) } & 100 \mathrm{mM} \text { Tris/HCl } \\ & 10 \mathrm{mM} \text { EDTA } \\ & 0,5 \%(\mathrm{w} / \mathrm{v}) \mathrm{SDS} \\ & 0,5 \mathrm{mg} / \mathrm{ml} \text { Proteinase K }\end{array}$

Gewebe-Lysis-Puffer

(Gesamtproteinpuffer)

Glycylglycinpuffer (pH 7,8)

Hybridisierungslösung

IEF-Lysispuffer

Kernproteinpuffer A

Kernproteinpuffer B
$20 \mathrm{mM}$ Tris $\mathrm{pH} 7.5$

$1 \mathrm{mM}$ EDTA

$1 \%$ SDS

$25 \mathrm{mM}$ Glycylglycin

$15 \mathrm{mM} \mathrm{MgSO}_{4}$

4 mM EGTA

10\% (w/v) Dextransulfat

$5 \mathrm{x}$ Denhardt's

$5 \times \mathrm{SSC}$

$0,5 \%$ SDS

9 M Harnstoff

$1 \%$ DTT

2\% CHAPS

0,8\% Bio-Lyte, $\mathrm{pH}$ 3-10

nicht über $30^{\circ} \mathrm{C}$ erhitzt

Aliquots bei $-70^{\circ} \mathrm{C}$, gelagert

0,6\% (v/v) Nonidet P40

10 mM HEPES (pH 7,9)

$150 \mathrm{mM} \mathrm{NaCl}$

2 mM EDTA

$25 \%$ (v/v) Glycerol

20 mM HEPES (pH 7,9) 
Lachs-Spermien-DNA

Lagerungspuffer

Luciferase-Reaktionspuffer

Luciferin (Stocklösung)

Luciferin-Injektionslösung

NBT-Stammlösung

PBS (pH 7,2)

PBST

Ponceau-Lösung

Protease-Inhibitor-Mix

\section{$1,2 \mathrm{mM} \mathrm{MgCl} 2$ \\ 0,2 mM EDTA}

$100 \mu \mathrm{g} / \mathrm{ml}$

$0.05 \mathrm{M} \mathrm{Na}_{2} \mathrm{HPO}_{4}$

$0.1 \%$ Natriumazid $\mathrm{pH} 7.0$

$165 \mu 1$ Glycyglycinpuffer (25 mM, pH 7,8)

$35 \mu 1$ Kaliumphosphat (100 mM, pH 7,8)

2,5 $\mu 1$ DTT (100 mM)

$2,5 \mu 1 \mathrm{ATP}(200 \mathrm{mM})$

10 mg D-Luciferin (freie Säure)

$55 \mathrm{mg}$ DTT

$37,5 \mathrm{ml}$ Glycylglycin-Puffer (25 mM, pH 7,8)

(Aliquots bei $-70^{\circ} \mathrm{C}$, lichtgeschützt gelagert)

$1 \mathrm{ml}$ Luciferin Stocklösung

$4 \mathrm{ml}$ Glycylglycinpuffer (25 mM, pH 7,8)

$80 \mu 1 \mathrm{DTT}(0,5 \mathrm{M})$

$75 \mathrm{mg} / \mathrm{ml}$ in $70 \%$ (v/v) Dimethylformamid

$137 \mathrm{mM} \mathrm{NaCl}$

$2,7 \mathrm{mM} \mathrm{KCl}$

$10 \mathrm{mM} \mathrm{Na}_{2} \mathrm{HPO}_{4}$

$1,8 \mathrm{mM} \mathrm{KH}_{2} \mathrm{PO}_{4}$

PBS $+0,02-0,1 \%$ Tween 20

$0,1 \%(\mathrm{w} / \mathrm{v})$ in $5 \%(\mathrm{v} / \mathrm{v})$ Essigsäure

$100 \mathrm{mM}$ TLCK 
(Hefe, 1:200)

Protease-Inhibitor-Mix

(Eukaryoten)

PufferA

(Aufreinigung monospezifischer

Antikörper)

PufferB

(Aufreinigung monospezifischer Antikörper)

Puffer A

(Zytoplasmatische Proteine)

Puffer B

(Zytoplasmatische Proteine)

Puffer D

(Zytoplasmatische Proteine)
$100 \mathrm{mM}$ TPCK

$100 \mathrm{mM}$ p-Aminobenzamidin- $\mathrm{HCl}$

$100 \mathrm{mM}$ o-Phenantrolin

100 mM PMSF

$1 \mathrm{mM}$ DTT

$1 \mathrm{mM}$ PMSF

2 mM Benzamidin

$5 \mu \mathrm{g} / \mathrm{ml}$ Aprotinin

$5 \mu \mathrm{g} / \mathrm{ml}$ Leupeptin

$5 \mu \mathrm{g} / \mathrm{ml}$ Pepstatin

0,5 M Ethanolamin

$0,5 \mathrm{M} \mathrm{HCl} \mathrm{pH} 8,3$

$0,1 \mathrm{M} \mathrm{NaAc}$

$0,5 \mathrm{M} \mathrm{NaCl} \mathrm{pH} 4$

10 mM HEPES pH 7.9

$1.5 \mathrm{mM} \mathrm{MgCl}_{2}$

$10 \mathrm{mM} \mathrm{KCl}$

$0.5 \mathrm{mM}$ PMSF

$0.5 \mathrm{mM}$ DTT

0.3 M HEPES pH 7.9

1.4 $\mathrm{M}$ oder $2 \mathrm{M} \mathrm{KCl}$

$0.3 \mathrm{mM} \mathrm{MgCl}_{2}$

20 mM HEPES pH 7.90.

$1 \mathrm{M} \mathrm{KCl}$

0.2 mM EDTA 
$20 \%$ Glycerol

$0.5 \mathrm{mM}$ PMSF

$0.5 \mathrm{mM}$ DTT

Rehydratisierungslösung

8 M Harnstoff

$10 \mathrm{mM}$ DTT

$1 \%$ CHAPS

0,25\% Bio-Lyte $\mathrm{pH} 3-10$

SDS-PAGE Probenpuffer

0,25 M Tris/HCl $\mathrm{pH} 6,8$

$7 \%$ SDS

$30 \%$ Glycerol

0,3\% Bromphenolblau

$15 \% \beta$-Mercaptoethanol (frisch zusetzen)

SDS-PAGE Sammelgelpuffer (2 x) 0,25 M Tris/HCl ( $\mathrm{pH} 6,8)$

$0,2 \%$ SDS

SDS PAGE Trenngelpuffer $(4 \mathrm{x}) \quad 1,5 \mathrm{M}$ Tris/HCl $(\mathrm{pH} 8,8)$

$0,4 \%$ SDS

SDS PAGE Laufpuffer $(10 \mathrm{x}) \quad 250 \mathrm{mM}$ Tris/HCl

2,5 M Glycin

$1 \%$ SDS

Semi-dry Transferpuffer

$25 \mathrm{mM}$ Tris/ $\mathrm{HCl}(\mathrm{pH} 8,3)$

150 mM Glycin

$10 \%(\mathrm{v} / \mathrm{v})$ Methanol

$20 \times \operatorname{SSC}(\mathrm{pH} 7,0)$

$3 \mathrm{M} \mathrm{NaCl}$

0,3 M Tri-Natriumcitrat 
$20 \times \operatorname{SSPE}(\mathrm{pH} 7,0)$

TBS

TFB1 (pH 5,0)

TFB2 (pH 7)

Towbin Protein-Transferpuffer

(Towbin et al., 1979)

X-Gal-Stammlösung

Z-Puffer

Z-Puffer/X-Gal-Lösung
0,02 M EDTA

$0,2 \mathrm{M} \mathrm{NaH}_{2} \mathrm{PO}_{4}$

$3,6 \mathrm{M} \mathrm{NaCl}$

$100 \mathrm{mM}$ Tris/HCl

$0,9 \%(\mathrm{w} / \mathrm{v}) \mathrm{NaCl}$

$15 \%$ (v/v) Glycerol

$30 \mathrm{mM}$ KAc

$50 \mathrm{mM} \mathrm{MnCl}_{2}$

$100 \mathrm{mM} \mathrm{RbCl} l_{2}$

$10 \mathrm{mM} \mathrm{CaCl}_{2}$

10 mM NaMOPS

$10 \mathrm{mM} \mathrm{RbCl}_{2}$

$75 \mathrm{mM} \mathrm{CaCl}_{2}$

$25 \mathrm{mM}$ Tris $/ \mathrm{HCl}$

192 mM Glycin

$20 \%(\mathrm{w} / \mathrm{w})$ Methanol

$0,1 \%(w / v)$ SDS

$20 \mathrm{mg} / \mathrm{ml} \mathrm{X-Gal} \mathrm{N,N-Dimethylformamid}$

$16,1 \mathrm{~g} / 1 \mathrm{Na}_{2} \mathrm{HPO}_{4} \times 7 \mathrm{H}_{2} \mathrm{O}$

$5,5 \mathrm{~g} / 1 \mathrm{NaH}_{2} \mathrm{PO}_{4} \times \mathrm{H}_{2} \mathrm{O}$

$0,75 \mathrm{~g} / 1 \mathrm{KCl}$

$0,246 \mathrm{~g} / 1 \mathrm{MgSO}_{4} \times 7 \mathrm{H}_{2} \mathrm{O}$

pH 7.0

$100 \mathrm{ml} \mathrm{Z-Puffer}$

0,27 ml ß-Mercaptoethanol

1,67 ml X-Gal-Stammlösung 


\subsection{Medien und Zusätze}

\subsubsection{Medien für Bakterien}

LB (Luria-Bertani)-Medium (pH 7,5)

Zusätze zur Selektion:

Agarplatten enthielten 1,5\% (w/v) Agar
10 g/1 Trypton

$5 \mathrm{~g} / 1$ Hefeextrakt

$10 \mathrm{~g} / 1 \mathrm{NaCl}$

Ampicillin $(0,1 \mathrm{mg} / \mathrm{ml})$

Kanamycin $(0,05 \mathrm{mg} / \mathrm{ml})$

\subsubsection{Medien für Hefen}

YPD-Medium

20 g/1 Pepton

$10 \mathrm{~g} / 11$ Hefeextrakt

$2 \%(\mathrm{w} / \mathrm{v})$ Glucose

$30 \mathrm{mg} / \mathrm{l}$ Adeninhemisulfat

18 g/l Agar (bei festem Nährmedium) pH 5.8

SC-Medium

1,5 g/l Hefe Stickstoffbasis

$5 \mathrm{~g} / 1$ Ammoniumsulfat

$1 \mathrm{~g} / 1$ myo-Inositol

$2 \%(\mathrm{w} / \mathrm{v})$ Glucose

$18 \mathrm{~g} / \mathrm{l}$ Agar (bei festem Nährmedium) pH 5.8

SD-Medium

6,7 g/l Hefe-Stickstoffbasis ohne Aminosäuren $2 \%$ Glucose

1 fach konzentrierte Mangel-Nährlösung

$18 \mathrm{~g} / \mathrm{l}$ Agar (bei festem Nährmedium) pH 5.8 
(bei Verwendung von Histidin-Selektivmedium zusätzlich 3-Amino-1,2,4-Triazol in einer Endkonzentration von $10 \mathrm{mM}$ )

Mangel-Nährlösung (10fach konzentriert):

In Abhängigkeit vom gewünschten Selektionsmedium wurden von den folgenden Komponenten eine oder mehrere weggelassen.

$300 \mathrm{mg} / \mathrm{l} \mathrm{L}-$ Isoleucin

$1500 \mathrm{mg} / \mathrm{l} \mathrm{L}-$ Valin

200 mg/l L-Arginin-HCl

200 mg/l L-Histidin-HCl-Monohydrat

$1000 \mathrm{mg} / \mathrm{l} \mathrm{L-Leucin}$

300 mg/l L-Lysin-HCl

$200 \mathrm{mg} / \mathrm{l} \mathrm{L-Methionin}$
2000 mg/l L-Threonin

$500 \mathrm{mg} / \mathrm{l}$ L-Phenylalanin

200 mg/l L-Tryptophan

$300 \mathrm{mg} / 1 \mathrm{~L}-$ Tyrosin

200 mg/l Adenin-Hemisulfat

$200 \mathrm{mg} / 1$ Uracil

\subsubsection{Medien für die Zellkultur}

Medien und Zusätze zur Anzucht eukaryotischer Zellen wurden als sterile Lösungen bezogen (PAN, Aidenbach). Zur Kultivierung primärer Fibroblasten sowie verschiedener Tumorzellinien wurden folgende Medien benutzt:

- DMEM (Dulbecco`s „modified Eagle medium”): 4,5 g/l Glucose, 3,7 g/1 NaHCO 3

- RPMI 1640: mit 3,7 g/1 $\mathrm{NaHCO}_{3}$

Medienzusätze zur Kultivierung: $\quad 10 \% \quad(\mathrm{v} / \mathrm{v}) \quad$ FKS， L-Glutamin $\quad(2-4 \mathrm{mM})$, Penicillin (200 U/ml, Streptomycin $(0,2 \mathrm{mg} / \mathrm{ml})$

Medienzusätze zur Lagerung in $\mathrm{N}_{2}: 20 \%$ (v/v) FKS, 10\% (v/v) DMSO 


\subsection{Verwendete Bakterien-, Hefestämme, eukaryotische Zellinien}

\subsubsection{Bakterienstämme}

Escherichia coli

HB101 (Bolivar und Beckmann, 1979)

JM109 (Messing, 1983)

DH5 $\alpha$ (Hanahan, 1983)

\subsubsection{Hefestämme}

Sacharomyces cerevisiae

Stamm RH2191 Genotyp: MAT $\alpha$ pra1, prb1, prc 1, cps1, ura3 45

Im Yeast Two Hybrid System wurden folgende Stämme benutzt:

\begin{tabular}{|c|c|c|c|c|}
\hline Stamm & Genotyp & Reportergene & $\begin{array}{l}\text { Transforma- } \\
\text { tionsmarker }\end{array}$ & Referenz \\
\hline Y187 & $\begin{array}{l}\text { MATa, ura3- 52, his3-200, ade } \\
\text { 2- 101, trp 1-901, leu 2- 3, 112, } \\
\text { gal4A, met-, gal80DA URA3 :. } \\
\text { GAL1 } 1_{U A S}-G A L 1_{T A T A}-l a c Z, \\
\text { MEL1 }\end{array}$ & lacZ, MELI & $\operatorname{trp} 1$, leu2 & $\begin{array}{l}\text { Harper et al., } \\
1993\end{array}$ \\
\hline AH109 & $\begin{array}{l}\text { MATa, trp1-901, leu2-3, 112, } \\
\text { ura3-52, his3-200, gal4A, } \\
\text { gal80A, LYS2 }: \text { GAL1 GAL2 }_{U A S^{-}} \\
\text {GAL2 }{ }_{T A T A^{-}} \text {ADE2, } \\
\text { URA3::MEL1 }{ }_{U A S^{-}} \text {MEL1 } 1_{T A T A^{-}} \\
\text {lacZ }\end{array}$ & $\begin{array}{l}\text { HIS3, ADE2, } \\
\text { lacZ, MEL1 }\end{array}$ & $\operatorname{trp} 1$, leu2 & $\begin{array}{l}\text { James et al., } \\
\text { 1996; }\end{array}$ \\
\hline CG-1945 & $\begin{array}{l}\text { MATá, ura3-52, his3-200, lys2- } \\
\text { 801, trp 1-901, ade2-101, leu 2- } \\
\text { 3, gal4-452, gal80-538, } \\
\text { URA3::(GAL4 } 17 \text { mere) } 3-C Y C 1- \\
\text { lacZ }\end{array}$ & HI3, lacZ & $\operatorname{trp} 1$, leu2 & $\begin{array}{l}\text { Bartel et al., } \\
1993\end{array}$ \\
\hline
\end{tabular}




\subsubsection{Eukaryotische Zellinien}

$\mathrm{NIH} / 3 \mathrm{~T} 3$

Embryofibroblasten; „NIH Swiss Mouse“, kontaktinhibiert

ATCC, Rockville, USA

(Kulturbedingungen: DMEM, $37^{\circ} \mathrm{C}, 5 \% \mathrm{CO}_{2}$ )

$\mathrm{P} 3 / 3 \mathrm{~T} 3$

Stabile Linie der NIH/3T3 Fibroblasten mit der Prm3-kodierenden Sequenz unter Kontrolle des zinkabhängigen Metallothionin-Promotors, (Kulturbedingungen: DMEM $+50 \mu \mathrm{M}$ Hygromycin, $37^{\circ} \mathrm{C}, 5 \% \mathrm{CO}_{2}$ )

Kämper 2001, Institut für Humangenetik, Göttingen

\subsection{Synthetische Oligonukleotide}

Die verwendeten Oligonukleotide wurden von den Firmen NAPS (Göttingen) oder Carl Roth (Karlsruhe) bezogen. Verschiedene standardmäßig eingesetzte Oligonukleotide, die komplementär zu Phagenpromotorsequenzen wie T3 oder T7 sind, sind nicht aufgeführt.

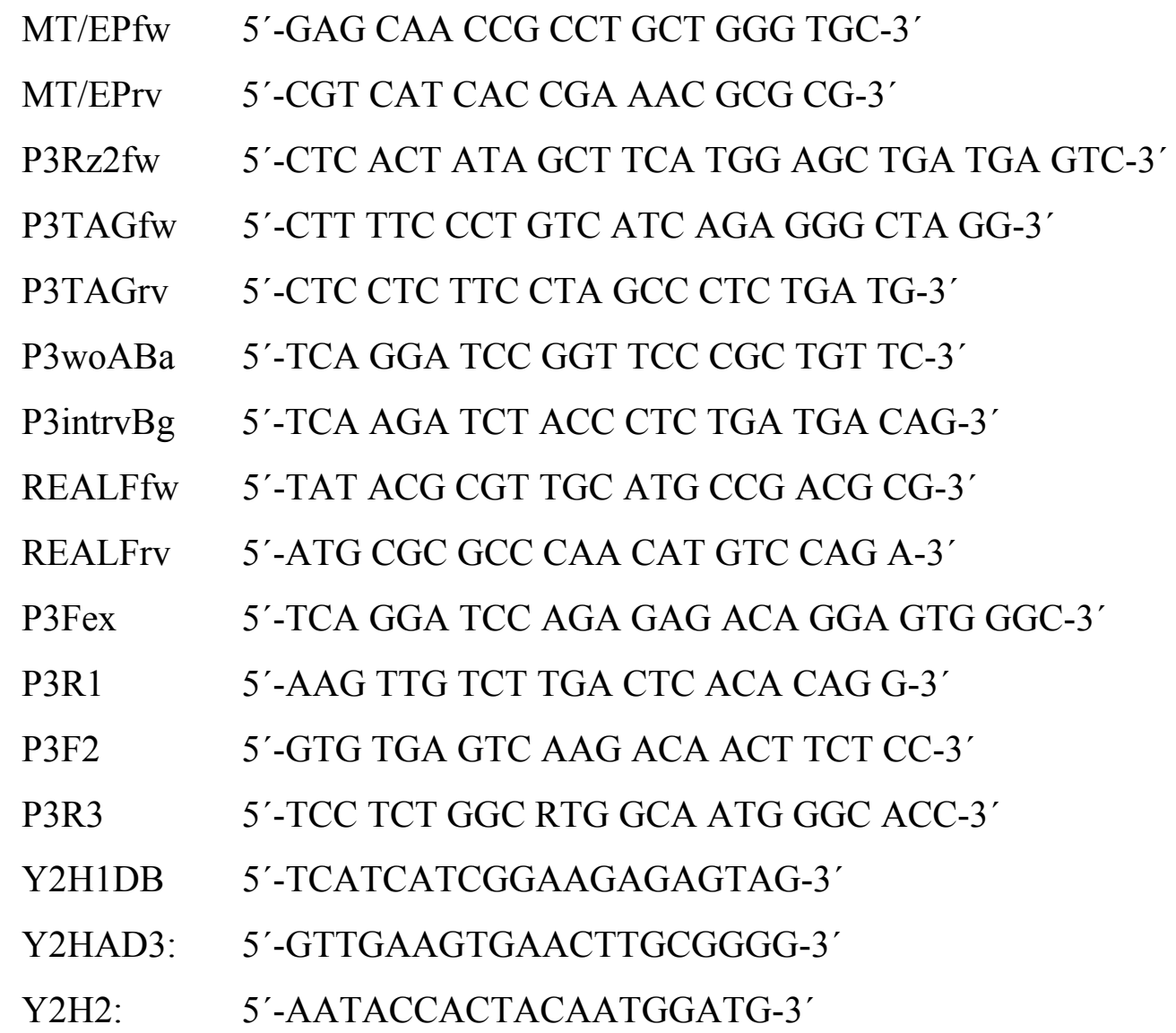


pVPFlag5.1865'-CGC TAG ACG ATT TCG ATC TG-3'

pMDBD.803 5'-TCA TCA TCG GAA GAG AGT AG-3'

ftTA2 5'-AAG TAA AGT GAT TAA CAG CGC-3'

rtTA2 5'- CTA CCC ACC GTA CTC GTC-3'

pTKneo R 5'-GCG CGA ATT CGA TGA TCC TGA ACG GC-3'

pTKneo R2 5'-CAG AGG TTA CGG CAG TTT GTC-3'

P3KOF3(3') 5'-AAC GAG GAG AAG GAG AAG AAG-3'

P3KOR3(3') 5'-AAC CAG AGG GAG AAA GGG AAA-3'

SacIIKOF $\quad$ 5'-TTT TCC GCG GTT TTG GTT TTG CTT TGG TTA-3'

NotIKOR 5'-AAA AGC GGC CGC GGA ATG ATT GGG GTA GAG TA-3'

ClaKOF 5'-AAG AGT CTC CAT CGA TCT CTC TTG GTC TCC-3'

(Eco) KOR 5'-TCT GAA GAA TTC CCT CTC ACC ACC CAT GCA-3'

\subsection{Verwendete Vektoren, Gensonden und Antikörper}

\subsubsection{Vektoren für Standardklonierungen}

Bluescript ${ }^{\circledR}$ SK II Stratagene, La Jolla, USA

pUC 18, $19 \quad$ Norander et al., 1983

pGEM®-T Easy Promega, Wisconsin, USA

pGL3®-basic Promega

\subsubsection{Expressionsvektoren}

$\begin{array}{ll}\text { pGBT9 } & \text { Clontech, Heidelberg } \\ \text { pGAD 10 } & \text { Clontech } \\ \text { pACT2 } & \text { Clontech } \\ \text { pM1 (pM2) } & \text { Sadowski et al., } 1992 \\ \text { pVP-FLAG 5 } & \text { Tsan et al., 1997 } \\ \text { pCMV-ßGal } & \text { Clontech } \\ \text { pEGFP-C1 } & \text { Clontech } \\ \text { pMT/EP } & \text { Burfeind et al., } 1996 \\ \text { pTK-Hyg } & \text { Clontech }\end{array}$


pYGEX-2T

abgeleitet von pGEX, Stratagene (Hefe Derivat des Startagene pGEX)

pTet-Off Clontech

pTRE Clontech

pTKneo Dr. N. Brose, MPI für Experimentelle Medizin, Göttingen

\subsubsection{Fertige Konstrukte}

\author{
GAL4-LUC \\ pGAL4/STAT2 \\ pM1/BR-304 \\ pVP-HA/B202-NB \\ pBSC/Prm3 \\ pBSC/Prm3 $\varnothing$
}

Gerhard Behre, München

Gerhard Behre, München

Richard Bear, University of Texas, Dallas

Richard Bear, University of Texas, Dallas

Gregor Schlüter, Institut für Humangenetik, Göttingen

Martin Kämper, Institut für Humangenetik, Göttingen

\subsubsection{Antikörper}

\begin{tabular}{|l|l|l|}
\hline Antikörper & Verwendung & Bezugsquelle \\
\hline $\begin{array}{l}\text { anti } \alpha \text {-Tubulin (monoklonal, } \\
\text { aufgereinigt) }\end{array}$ & $\begin{array}{l}\text { Kontrollantikörper zum } \\
\text { Abgleich der Proteinmengen } \\
\text { auf Western-Blot }\end{array}$ & Fa. Sigma \\
\hline $\begin{array}{l}\text { anti GST (IgG, aufgereinigt } \\
\text { aus polyklonalem Serum, } \\
\text { Kaninchen) }\end{array}$ & $\begin{array}{l}\text { Nachweis der Glutathion S- } \\
\text { Transferase }\end{array}$ & $\begin{array}{l}\text { Fa. Santa Cruz, Santa Cruz, } \\
\text { Delaware, USA }\end{array}$ \\
\hline $\begin{array}{l}\text { anti-Prm3 (aufgereinigt aus } \\
\text { polyklonalem Serum, } \\
\text { Kaninchen) }\end{array}$ & Nachweis des Prm3 Proteins & Kämper, 2001 \\
\hline $\begin{array}{l}\text { anti Tet-Repressor (TET02, } \\
\text { monoklonaler IgG1 Mix) }\end{array}$ & $\begin{array}{l}\text { Nachweis des Tet- } \\
\text { Transaktivators }\end{array}$ & Fa. MoBiTec, Göttingen \\
\hline
\end{tabular}




\subsubsection{Gensonden und Klone}

\begin{tabular}{|c|c|c|}
\hline Sonde & Eigenschaften & Herkunft/Referenz \\
\hline TRE & $\begin{array}{l}\text { „Tet responsive element“"(CMV-Promotor und } \\
\text { tet-Operator Sequenzen): Nachweis auf Dot- } \\
\text { und RNA-Blots }\end{array}$ & $0,6 \mathrm{~Kb}$ XhoI/SacI aus pTRE \\
\hline hEF 2 & Kontrollhybridisierung von RNA-Blots & $\begin{array}{l}\text { BamHI/BglII (1,6 Kb } \\
\text { Fragment aus pHEF2 } \\
\text { (Rapp et al., 1987) }\end{array}$ \\
\hline $\mathrm{X} 04$ & Genotypisierung von ES-Zellen und Chimeren & $\begin{array}{l}\text { 0,4 Kb XhoI Fragment aus 5' } \\
\text { Ende des SOCS-1 Gens }\end{array}$ \\
\hline Prm3 & $\begin{array}{l}\text { Prm3-cDNA, Nachweis der Transkripte auf } \\
\text { RNA-Blots }\end{array}$ & $\begin{array}{l}\text { BamHI/NotI aus pBSC } \\
\text { (Schlüter, Diss. 1996) }\end{array}$ \\
\hline tTA & $\begin{array}{l}\text { cDNA des reversen Tet-Transaktivators; } \\
\text { Nachweis auf Dot- und RNA-Blots }\end{array}$ & $\begin{array}{l}\text { EcoRI/BamHI Fragment aus } \\
\text { pTet-Off }\end{array}$ \\
\hline neo & $\begin{array}{l}\text { Neomycin-Resistenzgen: } \\
\text { Kontrollhybridisierung von ES-Blots }\end{array}$ & $\begin{array}{l}\text { 830Bp EcoRI/XbaI Fragment } \\
\text { aus pTKneo }\end{array}$ \\
\hline GAPDH & Kontrollhybridisierung von RNA-Blots & $\begin{array}{l}\text { PCR Produkt mit Primer } \\
\text { GAPDHF und GAPDHR auf } \\
\text { der Maus cDNA }\end{array}$ \\
\hline $28 \mathrm{~S}$ & Kontrollhybridisierung von RNA-Blots & $\begin{array}{l}\text { PCR Produkt mit Primer } \\
\text { ER1F und ER1R auf E.coli } \\
\text { cDNA }\end{array}$ \\
\hline
\end{tabular}

\subsection{Mausstämme}

Die verwendeten Mäuse der Stämme FVB und NMRI stammten aus institutseigenen Beständen, dem Max-Planck-Institut für experimentelle Medizin (Göttingen) oder wurden von der Firma Charles River (Hannover) bezogen. 
Die CMV/tTA Linie wurde bei Jackson Laboratory gekauft (STOCK TgN(tTAhCMV)3Uh, Nr.003271), die Act/tTA-Linien wurden von Herrn Dr. Antonio Servadio (Universität Padua, Italien) zur Verfügung gestellt.

Die Haltungsbedingungen bestanden aus einem zwölfstündigen Hell-Dunkel-Rhythmus bei $22^{\circ} \mathrm{C}$ und $55 \pm 5 \%$ relativer Luftfeuchtigkeit. Tierfutter wurde von der Firma ssniffSpezialdiäten (Soest) bezogen.

\subsection{Methoden zur Isolierung von Nukleinsäuren}

\subsubsection{Isolierung von genomischer DNA aus Geweben}

(Laird et al., 1991)

Frisches oder tiefgefrorenes Gewebe $(0,1-1 \mathrm{~g})$ wurde zerkleinert und üN in 10 Vol GewebeLysis Puffer bei $56^{\circ} \mathrm{C}$ unter Schütteln inkubiert. Die Proteine wurden einmal mit $1 \mathrm{Vol}$ Phenol und einmal mit 1 Vol Phenol/Chloroform $(1: 1)$ extrahiert. Die DNA wurde mit 1 Vol Isopropanol aus der wäßrigen Phase gefällt, abzentrifugiert und das DNA Pellet einmal mit $70 \%$ igem Ethanol gewaschen und in Wasser ( 0,3 bis $3 \mathrm{ml})$ üN bei $56^{\circ} \mathrm{C}$ gelöst.

\subsubsection{Präparation von Plasmid-DNA}

Plasmide wurden in E. coli unter Selektionsbedingungen vermehrt. Die „Minipräparation“ aus kleinen Kulturvolumina zur Testung einzelner Klone erfolgte nach Sambrock et al., (1989). Die Plasmidpräparationen erfolgten nach dem Prinzip der alkalischen Lyse mit anschließender Phenol/Chloroform Extraktion. Einzelne Bakterienklone wurden in $8 \mathrm{ml} \mathrm{LB}-$ Medium üN kultiviert. 1,5 ml dieser Kulturen wurden abzentrifugiert und die Bakterien in $100 \mu 1$ GET-Lösung resuspendiert. Nach der alkalischen Lyse durch Zugabe von $200 \mu 1$ $0,2 \mathrm{M} \mathrm{NaOH} / 1 \%$ SDS wurden der Zelldebris und das SDS mit $150 \mu \mathrm{KAc}$ Puffer präzipitiert. Der nach dem anschließenden Zentrifugieren (20 min, $15000 \mathrm{x} \mathrm{g}, 4^{\circ} \mathrm{C}$ ) erhaltene Überstand wurde mit $700 \mu 1$ Phenol/Chloroform extrahiert, die DNA aus der abgenommenen wäßrigen Phase mit $1 \mathrm{ml}$ Ethanol ausgefällt. Nach dem Waschen mit $800 \mu 170 \%$ igem Ethanol wurde das Pellet getrocknet und in $40 \mu 1 \mathrm{H}_{2} 0$ gelöst. $16 \mu 1$ der DNA Lösung genügten für den anschließenden Testverdau des Plasmids. 
Plasmid-DNA im Größenmaßstab 50-200 $\mu \mathrm{g}$ wurde mit Hilfe von DNA-Affinitätssäulen (Qiagen Plasmid Midi-Kit) erhalten. Mit $50 \mu 1$ aus einer Vorkultur wurden $100 \mathrm{ml}$ selektives LB Medium angeimpft und üN kultiviert. $50 \mathrm{ml}$ Kultur wurden abzentrifugiert und gemäß den Angaben des Herstellers lysiert, ohne Kaliumdodecylsulfat-Präzipitat und Zelldebris auf die äquilibrierten Säulen gegeben, gewaschen und eluiert. Die DNA wurde mit Isopropanol ausgefällt, einmal mit 70\%igem Ethanol gewaschen, luftgetrocknet und in Wasser (50-200 $\mu 1)$ gelöst.

\subsubsection{Isolierung von DNA aus Agarosegelen}

(Vogelstein und Gillispie, 1979)

Die Isolierung von DNA-Restriktionsfragmenten erfolgte mit Hilfe von Glasmilch. Entsprechende Kits wurden von Genomed (Bad Oeynhausen) oder Bio 101 (vertrieben über Dianova, Hamburg) bezogen. Diese Methode beruht auf der reversiblen Bindung von Nukleinsäuren an Glaspartikel, abhängig von der Ionenstärke der Lösungsmittel. Die gewünschte Bande wurde unter UV-Licht (354 nm) aus dem Agarosegel (TAE-Puffer) geschnitten und in $3 \mathrm{Vol} 6 \mathrm{M} \mathrm{NaI}$ bei $55^{\circ} \mathrm{C}$ gelöst. Je nach DNA Menge wurden 5-25 $\mu$ l einer 1:1 Glasmilch $/ \mathrm{H}_{2} \mathrm{O}$ Suspension zugegeben und 20 min bei $4^{\circ} \mathrm{C}$ inkubiert. Die Glaspartikel mit den gebundenen DNA-Fragmenten wurden abzentrifugiert (50 s, $5000 \mathrm{x} \mathrm{g}$ ), einmal mit $800 \mu 1$ $6 \mathrm{M} \mathrm{NaI}$ und zweimal mit „New-Wash“ (enthält 70\% Ethanol, die genaue Zusammensetzung ist nicht veröffentlicht) gewaschen. Nach kurzem Abdampfen des restlichen Ethanols an der Luft wurde die DNA zweimal mit 15-50 $\mu 1 \mathrm{H}_{2} \mathrm{O}$ von der Glasmilch eluiert und 5-10\% des Eluats auf einem Testgel kontrolliert.

\subsubsection{Isolierung von Gesamt-RNA}

(modifiziert nach Chomczynski und Sacchi, 1987)

RNA wurde mit Hilfe des sog. "Tri-Reagent" (Sigma, Deisenhofen) isoliert. Zum schnellen Zellaufschluß wird hierbei eine Mischung aus Phenol und Guanidinthiocyanat benutzt. Frische oder bei $-70^{\circ} \mathrm{C}$ gelagerte Gewebe wurden in einem Glas/Glas-Potter in 5-10 Vol TriReagent bei Raumtemperatur aufgeschlossen, mit 0,1 Vol 1-Brom-3-chlorpropan gemischt (15 s Vortex) und nach einer Inkubationszeit von $10 \mathrm{~min}$ zentrifugiert (15 min, $5000 \mathrm{xg}$, 
$4^{\circ} \mathrm{C}$ ). Ab diesem Schritt wurde mit sicher RNase-freien Materialien und Lösungen gearbeitet. Die RNA wurde aus der wäßrigen Phase mit 0,5 Vol (bezogen auf das Tri-Reagent Volumen) Isopropanol gefällt, zentrifugiert (15-30 min, $5000 \mathrm{x} \mathrm{g}, 4^{\circ} \mathrm{C}$ ), zweimal mit $800 \mu 175 \%$ igem Ethanol gewaschen und in $\mathrm{H}_{2} \mathrm{O}$ gelöst.

\subsection{Konzentrationsbestimmung von Nukleinsäuren}

Die Konzentration der aus Gelextraktionen erhaltenen Mengen an DNA wurden im Vergleich mit Proben bekannter Konzentration auf Agarosegelen abgeschätzt. Dazu wurden verschiedene Volumina aus den Elutionslösungen neben einem DNA Standard aufgetragen, der definierte Mengen an DNA/Bande enthielt (Smart-Ladder, Eurogentec, Seraing, Belgien). Die der Größe nach entsprechende Bande wurde mit Hilfe der Ethidiumbromidfärbung mit den eluierten DNAs verglichen. Die DNA Konzentrationen von Midi-Präparationen und von isolierter Gesamt RNA wurde im Spektralphotometer bestimmt (Biophotometer, Eppendorf). Unter Annahme einer $\mathrm{OD}_{260}$ von 1 einer dsDNA Lösung von $50 \mathrm{ng} / \mu \mathrm{l}$ (bzw. $40 \mathrm{ng} / \mu \mathrm{l}$ für RNA) wurden die Konzentrationen nach Abzug des Hintergrundes des Lösungsmittels $\left(\mathrm{H}_{2} \mathrm{O}\right)$ berechnet. Die zusätzlich angegebenen Quotienten $\mathrm{OD}_{260 / 280}$ und $\mathrm{OD}_{260 / 230}$ spiegeln die Protein- bzw. Salzkontamination wieder und sollten $>1,8$ bzw. $>2,0$ sein.

\subsection{Polymerase-Kettenreaktion (PCR)}

(Saiki et al., 1985)

Die Möglichkeit der in vitro-Amplifikation definierter DNA-Fragmente wurde in dieser Arbeit zur Einführung von Schnittstellen in DNA-Fragmente, zur Vervielfältigung von zu klonierenden oder zu transkribierenden DNA-Fragmenten und zur DNA-Sequenzierung eingesetzt. Die Reaktionen wurden in „Thermocyclern“ der Firmen Perkin-Elmer, Überlingen (Thermal Cycler Typ 480), oder MWG-Biotech, München (Typ Primus), durchgeführt. Die Zyklusprofile und besonderen Zusammensetzungen der verschiedenen Anwendungen sind in den jeweiligen Abschnitten des Ergebnisteils angegeben. Soweit nicht anders vermerkt, bestand die Zusammensetzung einer PCR aus 1 x Reaktionspuffer (vom Hersteller der jeweils verwendeten Taq-Polymerase), 10 pmol jeden Primers, 0,2 mM dNTP und ca. 1 pg Plasmid oder 0,5-1 $\mu$ g genomische DNA als Template. Die Reaktionsansätze, die in 0,5 ml Cups im 
Perkin-Elmer „Thermocycler“ durchgeführt wurden, mußten mit Mineralöl als Verdunstungsbarriere überschichtet werden, da dieser Gerätetyp nicht über einen beheizten Deckel verfügt. Es wurden Taq-DNA-Polymerasen verschiedener Hersteller eingesetzt. In der Regel wurden sog. Hot-Start Polymerasen verwendet. Diese Polymerasen enthalten Modifikationen, die eine Aktivierung des Enzyms im ersten Denaturierungsschritt verursachen (z.B. Abfall eines aktivitätshemmenden Antikörpers durch Erhitzen, wie bei „Platinum Taq-Polymerase“, Fa. Gibco). Ansonsten wurde die Reaktion erst nach Ablauf des ersten Denaturierungsschrittes durch Zugabe der Polymerase gestartet. Für PCRs, deren Amplifikate nachfolgend kloniert werden sollten, wurde Pwo- (Roche Diagnostics, Mannheim) oder Pfu-Polymerase (Stratagene, La Jolla) benutzt, deren Fehlerraten aufgrund ihrer ,proof-reading“-Aktivität erheblich reduziert ist.

\subsection{Enzymatische Modifikation von DNA}

\subsubsection{Restriktionsspaltungen}

Doppelsträngige DNA wurde durch Restriktionsendonukleasen (RE) verschiedener Hersteller gespalten. In der Regel wurde 2-10 U (1 U spaltet $1 \mu \mathrm{g} \lambda$-DNA in einer Stunde) RE pro $\mu \mathrm{g}$ DNA eingesetzt. Wegen des zur Enzymlösung zugesetzten Glycerols sollte das Volumen an eingesetztem Enzym nicht 1/10 des Reaktionsvolumens überschreiten. Für den simultanen Verdau mit zwei verschiedenen REs wurde ein für beide Enzyme kompatibler Puffer eingesetzt. Die Inkubation erfolgte je nach Herkunft der REs bei den vom Hersteller angegebenen Temperaturen. Falls eine Inaktivierung erforderlich war, wurden hitzesensitive Enzyme für $10 \mathrm{~min}$ bei $70^{\circ} \mathrm{C}$ inaktiviert.

\subsubsection{Auffüllreaktion}

Durch die Behandlung mit dem Klenow-Fragment der E. coli DNA Polymerase I oder TaqPolymerasen mit ,proof-reading“ Aktivität wurden 5'-überhängende Enden von DNAFragmenten zu stumpfen (,blunt ends“) aufgefüllt. Die Reaktionen wurden in Volumina von $20 \mu 1$ durchgeführt, wobei jeweils ca. $1 \mu \mathrm{g}$ DNA modifiziert werden konnte. Die genaue Zusammensetzung und die Bedingungen der Reaktion richteten sich nach den Angaben des 
Herstellers des verwendeten Enzyms. Wegen der hohen Stabilität der Polymerasen mußte die so behandelte DNA mit einer Phenol/Chloroform Extraktion mit anschließender Ethanolfällung oder über Agarosegelelektrophorese mit anschließender Glasmilchelution aufgereinigt werden.

\subsubsection{Dephosphorylierung von Vektor-DNA}

Wenn Vektor-DNA nach Restriktionsspaltung kompatible Enden enthielt, wurde die DNA vor der Ligation mit alkalischer Phosphatase behandelt, um die 5'-Phosphatgruppen zu entfernen und eine Religation des Vektors ohne Einbau des gewünschten Fragments zu verhindern. Zur Dephosphorylierung wurde $1 \mathrm{U}$ alkalische Phosphatase aus Kälberdarm pro $10 \mu \mathrm{g}$ DNA zum abgeschlossenen Restriktionsverdau gegeben und für $20 \mathrm{~min}$ bei $37^{\circ} \mathrm{C}$ inkubiert. Zur Entfernung der Enzyme wurde die DNA über ein Agarosegel mit anschließender Glasmilch-Prozedur aufgereinigt (s. 2.10.3).

\subsubsection{Ligation}

Die Ligation von Vektor-DNA (geschnitten und dephosphoryliert) mit DNA-Fragmenten wurde in dem vom Hersteller angegebenen Puffersystem der T4-Ligase in $10 \mu 1$ Ansätzen durchgeführt. In der Regel wurden 0,1-1 $\mu \mathrm{g}$ Vektor-DNA mit einem molaren Überschuß an DNA-Fragmenten ligiert. Die Ligation erfolgte unter Verwendung von 1 U T4-Ligase üN bei $16^{\circ} \mathrm{C}$.

\subsubsection{Radioaktive „Random prime“-Markierung von Nukleinsäuren}

(Feinberg und Vogelstein, 1983)

Für die radioaktive Markierung von Sonden zur Hybridisierung von Dot- und Northern-Blots wurden doppelsträngige DNA-Fragmente (50-150 ng in $46 \mu \mathrm{H}_{2} \mathrm{O}$ ) für $5 \mathrm{~min}$ in einem kochenden Wasserbad denaturiert und anschließend auf Eis abgekühlt. $\mathrm{Zu}$ diesen einzelsträngigen Templates wurden $40 \mu \mathrm{Ci}(4 \mu \mathrm{l})\left[\alpha^{32} \mathrm{P}\right] \mathrm{dCTP}$ (Amersham) gegeben. Mit diesem Ansatz wurden die an eine Glasmatrix gebundenen Komponenten des „Ready-to-goDNA-labeling-System“ (Fa. Amersham Pharmacia Biotech) gelöst. Der getrocknete „Ready- 
to-go“ Reaktionsansatz enthält Oligo(dN) $)_{9}$-Primer, Reaktionspuffer, Klenow-DNA Polymerase und nichtmarkierte Nukleotide (dATP, dGTP und dTTP). Der $50 \mu 1$ Ansatz wurde 45 min bei $37^{\circ} \mathrm{C}$ inkubiert und danach mit Ethanol gefällt. Das Pellet wurde an der Luft getrocknet, in $200 \mu \mathrm{l}$ Wasser aufgenommen und bis zur weiteren Verwendung eingefroren.

\subsection{Gelelektrophorese von Nukleinsäuren}

\subsubsection{Horizontale Agarosegelelektrophorese}

Testgele zur Kontrolle von Restriktionsverdaus, Gele für Restriktionskartierungen oder für Insertisolierungen wurden in „Horizon 11.14“ Gelkammern (Fa. GIBCO BRL) gegossen. Je nach Größe der zu trennenden Fragmente wurde 0,5 bis 3\% (w/v) Agarose zugesetzt. Gele für die Auftrennung genomischer DNA (0,8\% w/v Agarose) wurden in vertikalen Gelkammern (Fa. Ochs, Lenglern) gegossen. Je nach Anwendung wurde 0,5 x TBE- oder 1 x TAE- Puffer eingesetzt. Nach dem Lösen der Agarose durch mehrmaliges kurzes Aufkochen des Ansatzes wurde die Lösung auf ca. $50^{\circ} \mathrm{C}$ abgekühlt. Kurz vor dem Gießen des Gels wurde Ethidiumbromid in einer Endkonzentration von $0,1 \mu \mathrm{g} / \mathrm{ml}$ zugesetzt. Die Größenbestimmung der DNA-Fragmente erfolgte über den Vergleich mit EcoRI/HindIII geschnittener $\lambda$ DNA oder der $1 \mathrm{~Kb}$-Ladder als Längenstandards. Die Proben wurden vor dem Einfüllen in die Taschen des Gels mit ca. 20 \% Stopmix beschwert.

\subsubsection{Denaturierende Agarosegelelektrophorese}

(nach Sambrock et al., 1989)

Für die Auftrennung von RNA wurden 1\%ige Gele verwendet, die in Vertikalkammern (Glasgerätebau Ochs, Lenglern) gegossen wurden. Da RNA einzelsträngig ist und Sekundärstrukturen ausbilden kann, die das Verhalten der RNA in der Elektrophorese beeinflussen, wurde die Gelelektrophorese unter denaturierenden Bedingungen durchgeführt, die durch Zugabe von Formaldehyd eingestellt wurden. Nach dem Gießen eines Gelsockels, der 2\% (w/v) Agarose in 1 x E-Puffer enthielt, wurde das eigentliche RNA-Gel vorbereitet: 


$\begin{array}{lll}\text { RNA-Gele } & 1,25 \mathrm{~g} & \text { Agarose } \\ 87,5 \mathrm{ml} & \mathrm{H}_{2} \mathrm{O} \\ & 12,5 \mathrm{ml} & 10 \times \text { E-Puffer }\end{array}$

Nach dem vollständigen Lösen der Agarose durch mehrmaliges kurzes Aufkochen wurden unter dem Abzug $25 \mathrm{ml}$ einer 37\%igen Formaldehydlösung zugegeben und das Gel auf den bereits festen Sockel gegossen.

Die RNA Proben wurden vor dem Auftragen auf das Gel mit je

$$
\begin{aligned}
& 3 \mu 110 \times \text { E-Puffer } \\
& 4 \mu 1 \text { Formaldehyd (37\%) } \\
& 30 \mu 1 \text { Formamid }
\end{aligned}
$$

versetzt, 10 min bei $75^{\circ} \mathrm{C}$ denaturiert und anschließend auf Eis abgekühlt. Die Proben wurden mit 0,2 Vol Stopmix (enthielt 200 ng Ethidiumbromid) versetzt und auf das Gel aufgetragen. Die Elektrophorese wurde bei $4^{\circ} \mathrm{C}$ und 50 bis $90 \mathrm{~V}$ durchgeführt. Während des Gellaufs (ca. 3-4 h) wurden die Puffer der inneren (Kathode) und äußeren Kammer (Anode) durch umpumpen vermischt, um den Aufbau von $\mathrm{pH}$ - und Salzgradienten zu verhindern und einen gleichmäßigen Spannungsabfall über die Gelstrecke zu gewährleisten.

\subsection{Transfertechniken von Nukleinsäuren}

\subsubsection{Dot-Blotting}

Zur Analyse transgener Tiere wurde genomische DNA aus der Schwanzspitze isoliert und punktförmig auf eine Nitrozellulosemembran transferiert. Dazu wurde eine mit 2 x SSC angefeuchtete Nitrozellulosemembran in eine Vakuum-Kammer (Minifold, Schleicher \& Schüll, Dassel) eingesetzt und zur Äquilibrierung $100 \mu 120$ x SSC über das angelegte Vakuum durch die einzelnen Öffnungen gesogen. 2-10 $\mu \mathrm{g}$ der $\mathrm{zu}$ analysierenden DNA wurden mit $\mathrm{H}_{2} \mathrm{O}$ auf ein Volumen von $30 \mu \mathrm{l}$ gebracht, 10 min bei $95^{\circ} \mathrm{C}$ denaturiert und durch Zugabe von $150 \mu \mathrm{l}$ eiskaltem 20 x SSC schockgekühlt. Die DNA-Lösungen wurde in die Öffnungen der Vakuum-Kammer pipettiert und durch die Membran gesogen, auf der die DNA haften blieb. Nach dem Nachspülen der Kammer mit weiteren $100 \mu 120$ x SSC wurde der Blot entnommen, in 2 x SSC gespült und die DNA durch „Crosslinking“ der feuchten 
Membran (Stratalinker ${ }^{\mathrm{TM}} 1800$ mit 120 mJ, Fa. Stratagene) oder Backen der luftgetrockneten

Membran $\left(2 \mathrm{~h}, 80^{\circ} \mathrm{C}\right)$ fixiert. Beide Methoden sollen eine irreversible Bindung der Nukleinsäuren an die Nitrocellulosemembran gewährleisten.

\subsubsection{Southern-Blotting}

(Southern, 1975)

Mit Hilfe des Southern-Transfers wurden DNA-Fragmente aus Agarosegelen (2.14.1) auf Nitrocellulose- oder Nylonmembranen übertragen. Nach einer Elektrophorese wurde das Gel für $2 \times 30 \mathrm{~min}$ in Denaturierungslösung überführt und anschließend für 2 x 30 min in Neutralisierungslösung behandelt. Der Transfer der DNA auf die Membran erfolgte mit der Turbo-Blot-Apparatur (Schleicher \& Schuell, Dassel) nach dem Protokoll des Herstellers. Nach dem Transfer wurden die Membranen zum Entfernen möglicher Gel- und Salzreste kurz in zweimal SSC gewaschen und feucht unter UV-Licht (120 mJ, UV Stratalinker ${ }^{\mathrm{TM}}$ 1800, Fa. Stratagene) oder nach dem Trocknen für $2 \mathrm{~h}$ bei $80^{\circ} \mathrm{C}$ durch „Backen“ fixiert.

\subsubsection{Northern-Blotting}

Nach der Auftrennung von RNA (2.14.2) wurden die denaturierenden Agarosegele unter UVLicht photographiert (Videodokumentation, Fa. Intas, Göttingen) und anschließend sofort einem Kapillarblot zur Übertragung der RNA auf eine Nitrocellulosemembran (Hybond C, Amersham) unterzogen. Das Gel wurde mit Plastikfolie umgrenzt auf ein Filterpaper (Typ GB003, Schleicher \& Schüll, Dassel) gelegt, dessen Enden in 20 x SSC eintauchten. Ein Flüssigkeitstransfer war so nur durch das Gel möglich. Eine der Gelgröße entsprechende Nitrocellulosemembran wurde mit 2 x SSC angefeuchtet und luftblasenfrei auf dem Gel ausgebreitet. Darüber wurden zwei Stück Filterpapier und mehrere Lagen Handtuchpapier zur Flüssigkeitsaufnahme ausgebreitet. Zur Verstärkung des Flüssigkeitstransfers wurde der Aufbau beschwert. Während der Transferzeit von 10-20 h wird die DNA durch die diffundierende Salzlösung aus dem Gel auf die Unterseite der Membran übertragen. Nach dem Transfer wurden die Membranen zum Entfernen möglicher Gel- und Salzreste kurz in zweimal SSC gewaschen und feucht unter UV-Licht (120 mJ, UV Stratalinker ${ }^{\mathrm{TM}}$ 1800, Fa. Stratagene) oder nach dem Trocknen für $2 \mathrm{~h}$ bei $80^{\circ} \mathrm{C}$ durch „Backen“ fixiert. 


\subsection{Hybridisierung mit radioaktiv markierten DNA-Sonden}

Die Nitrocellulosefilter wurden in 2 x SSC äquilibriert und mit der nicht beladenen Fläche luftblasenfrei an die Wandung des mit 2 x SSC gefüllten Hybridisierungsröhrchens gedrückt. Der Puffer wurde durch 15 ml Hybridisierungslösung (Yang et al., 1993) oder KPL-Lösung ersetzt, die $150 \mu \mathrm{l}$ denaturierte Lachspermien-DNA $(10 \mathrm{mg} / \mathrm{ml}, 5 \mathrm{~min} \mathrm{im}$ kochenden Wasserbad erhitzt und auf Eis abgekühlt) enthielt. Die Prähybridisierung erfolgte zur Absättigung unspezifischer Bindungen für $1-4 \mathrm{~h}$ bei $65^{\circ} \mathrm{C}$ im Rollofen (Bachhofer, Reutlingen). Zur spezifischen Hybridisierung wurde dann die Sonde mit weiteren $150 \mu 1$ Lachsspermien-DNA wie oben beschrieben denaturiert und nach dem schnellen Abkühlen direkt in die Hybridisierungslösung gegeben. Die Hybridisierung erfolgte üN unter denselben Bedingungen wie die Prähybridisierung.

Zum Waschen der Membranen wurde die Hybridisierungslösung mit Sonde abgegossen (gegebenenfalls zur erneuten Verwendung verwahrt) und die Filter je nach gewünschter Stringenz in den Hybridisierungsröhrchen mehrfach mit jeweils $100 \mathrm{ml}$ Waschlösung $(0,2 \mathrm{x}$ SSC mit 0,1\% SDS) unter den Bedingungen der Hybridisierung im Rollerofen solange gewaschen, bis keine deutliche Abnahme der Radioaktivität mehr zu messen war. Die getrockneten Membranen wurden in Folie eingeschweißt und zur Auswertung mit einem Röntgenfilm bei $-70^{\circ} \mathrm{C}$ (Autoradiographiekassette mit Verstärkermembran) oder mit einer Phospho-Imagermembran (Kodak, Rochester, NY) bei RT exponiert.

\subsection{Klonierung von DNA-Fragmenten}

Zur Vervielfältigung von DNA-Fragmenten und zur Expression von cDNAs wurden diese in verschiedene Plasmidvektoren eingebaut und in kompetente Bakterien oder in Hefen transformiert.

\subsubsection{Herstellung kompetenter $E$. coli-Zellen}

(Dagert und Ehrlich, 1979)

Einzelkolonien der verschiedenen E. coli Stämme wurden in $50 \mathrm{ml}$ LB-Medium üN zu einer Vorkultur angezogen. Mit $5 \mathrm{ml}$ dieser Vorkultur wurden $100 \mathrm{ml}$ frisches, auf $37^{\circ} \mathrm{C}$ 
vorgewärmtes LB-Medium angeimpft. Die Bakterien wurden bis zu einer $\mathrm{OD}_{600}$ von 0,5-0,6 kultiviert, dann bei $4^{\circ} \mathrm{C} 10 \mathrm{~min}$ mit $1500 \mathrm{xg}$ zentrifugiert. Das Pellet wurde in eiskaltem TFB1-Puffer resuspendiert und für 90 min auf Eis inkubiert. Nach erneutem Abzentrifugieren wurde das Pellet in $4 \mathrm{ml}$ eiskaltem TFB2-Puffer resuspendiert. Die Zellen wurden in 150 $\mu 1$ Aliquots in flüssigem Stickstoff schockgefroren und bei $-70^{\circ} \mathrm{C}$ gelagert.

\subsubsection{Transformation kompetenter Bakterien}

(Hanahan, 1983)

Zur Aufnahme von Plasmid-DNA durch kompetente Bakterien wurden diese langsam auf Eis aufgetaut. Der Ligationsansatz oder 50 ng Plasmid-DNA wurden mit $15 \mu 1$ kompetenten Zellen 20 bis 40 min auf Eis inkubiert. Danach wurden die Zellen $20-30 \mathrm{~s}$ auf $37^{\circ} \mathrm{C}$ erwärmt und wieder auf Eis abgekühlt, in $600 \mu 1$ LB-Medium oder SOC-Medium aufgespült und bei $37^{\circ} \mathrm{C}$ inkubiert. Nach $1 \mathrm{~h}$ wurden 50-200 $\mu 1$ des Transformationsansatzes auf LB-Agarplatten ausgestrichen, die der Resistenz des transformierten Plasmids entsprechende selektive Agenzien enthielten. Einzelkolonien zeigten sich nach einer Bebrütung üN bei $37^{\circ} \mathrm{C}$.

\subsection{Sequenzanalyse}

(modifiziert nach Sanger et al., 1977)

Die nichtradioaktiv durchgeführten Sequenzreaktionen wurden nach einem modifizierten Kettenabbruchverfahren durchgeführt. Die Sequenzabbruchreaktion wurde als nichtradioaktive PCR („Dye Terminator“ Technik) mit Systemen von ABI oder Amersham Pharmacia Biotech durchgeführt. Dabei wird die doppelsträngige DNA denaturiert und ein Einzelstrang nach Anlagerung eines sequenzspezifischen Primers aufgefüllt, wobei die limitierte Zugabe von ddNTPs zu Synthesestops führt. Über die verschiedenfarbige Markierung der vier Didesoxynukleotide können diese nach Anregung mit einem Argonlaser an ihrer unterschiedlichen Fluoreszenz erkannt und über die Lauflänge im Sequenzgel ihrer Position in der zu sequenzierenden DNA-Probe zugeordnet werden. Neben den markierten ddNTPs enthält der „Dye Terminator“ Mix dNTPs, Reaktionspuffer sowie Ampli-Taq-DNAPolymerase. Vor der Sequenz-PCR wurden 10 pmol Primer und doppelsträngige PlasmidDNA oder ein über PCR amplifiziertes DNA-Fragment zugegeben und der Reaktionsansatz 
auf $11 \mu \mathrm{l}$ aufgefüllt. Einer Faustregel folgend wurde die Menge zu sequenzierender DNA in ng eingesetzt, die man nach der Division der Anzahl der Bp der DNA durch 5 erhält, also z.B. 400 ng eines $2 \mathrm{~Kb}$ Fragmentes. In einer Reaktion von $11 \mu 1$ wurden 3-4 $\mu$ l Dye-TerminatorMix eingesetzt. Die PCR durchlief standardmäßig 25 Zyklen mit $98^{\circ} \mathrm{C} / 30$ s Denaturierung, $50^{\circ} \mathrm{C} / 15 \mathrm{~s}$,Annealing“ und $60^{\circ} \mathrm{C} / 4$ min „Elongation“. Nach der PCR wurde der Ansatz auf ein Vol von $100 \mu 1$ gebracht und die DNA mit $15 \mu 12 \mathrm{M} \mathrm{NH}_{4} \mathrm{Ac}(\mathrm{pH} 4,5)$ und $450 \mu 1$ Ethanol gefällt. Der Gellauf zur Auswertung der Sequenzierung erfolgte in automatischen Sequenzern des Typs ABI PRISM 377 DNA-Sequencer (Perkin Elmer). Die Sequenzgele enthielten 6,8\% Polyacrylamid und wurden mit Puffern (TBE) und Lösungen speziell für die FluoreszenzSequenzelektrophorese (Fa. Roth, Karlsruhe) angesetzt. Die DNA Pellets der Sequenzreaktion wurden in $4 \mu 1$ Formamid/EDTA (0,5 M EDTA, pH 8,0; 1:5 in Formamid) aufgenommen, aufgekocht und nach dem Abkühlen auf Eis auf das Gel aufgetragen, welches schon ohne Proben $1 \mathrm{~h}$ bei 1400 V im Vorlauf war. Nach dem Auftrag der Proben dauerte der Gellauf $14 \mathrm{~h}$ bei 1400 V. Die Fluoreszenz wurde durch das "Base-calling"-Programm des Sequenzers (Modell 373A, Applied Biosystem) in ein Elektropherogramm und schließlich die Basensequenz umgesetzt.

\subsection{Isolierung von Proteinen}

Alle Proteine wurden entweder frisch präpariert oder die Gewebe nach dem Einfrieren in flüssigem Stickstoff bis zu der Präparationzeit bei $-70^{\circ} \mathrm{C}$ aufbewahrt. Nach der Isolierung wurden die erhaltenen Proteine aliquotiert und bei $-70^{\circ} \mathrm{C}$ gelagert oder bis zur Verwendung maximal 2 Tage auf Eis aufbewahrt.

\subsubsection{Gesamtproteinisolierung aus kultivierten Zellen}

Gesamtproteine aus kultivierten Zellen und Geweben wurden zum immunologischen Nachweis in der Western-Blot Prozedur und zur Verwendung in Reportergen-Assays isoliert. Der einzige Unterschied betrifft die Zusammensetzung des Extraktionspuffers (s. 2.4).

Die bei Transfektionsexperimenten verwendeten adhärenten Zellen wurden 24-48 h nach der Transfektion einmal mit PBS gewaschen, das PBS sorgfältig entfernt und die Zellen je nach Größe der Kulturschale und der zu erwartenden Reportergenaktivität mit Extraktionspuffer 
überschichtet und 5 min bei RT inkubiert. Für die so durchgeführte Lyse der Zellen wurden z.B. $75-150 \mu 1$ je Schale einer 12-Well Platte (Costar®, Fa. Corning, New York) oder bis zu $1 \mathrm{ml}$ für eine $100 \mathrm{~mm}$ Kulturschale verwendet. Anschließend wurden die Zellextrakte in 1,5 ml Reaktionsgefäße überführt, Zelltrümmer durch Zentrifugation pelletiert (5 min, 12000 x g, $4^{\circ} \mathrm{C}$ ) und ein Aliquot des Überstandes im entsprechenden Test auf Luciferase- oder $\beta$ Galactosidaseaktivität gemessen.

\subsubsection{Extraktion der Gesamtproteine aus Geweben}

Frisches oder tiefgefrorenes Gewebe $(0,05-0,2 \mathrm{~g})$ wurde in 1-2 $\mathrm{ml}$ Gewebe-Lysis-Puffer in einem Glas/Teflon Homogenisator (Belco, USA) mit rotierendem Pistill im Kühlraum homogenisiert. Nach den 30 Stößen bei 1000rpm wurde das Homogenat in 15 ml Falcon oder 1,5ml Cups umgefüllt und für 10 x $5 \mathrm{~s}$ mit einem Ultraschallstab (Ultraturrax Branson, Soest, Niederlande) sonifiziert. Schließlich wurden die Gewebetrümmer abzentrifugiert (4000 x g, $\left.10 \mathrm{~min}, 4^{\circ} \mathrm{C}\right)$. Der Proteinüberstand wurde aliquotiert.

\subsubsection{Extraktion von Kernproteinen aus Geweben.}

(Deryckere und Gannon, 1994, modifiziert)

Frisch präparierte Organe $(0,1-0,2$ g) wurden auf Eis in PBS gewaschen, in $2 \mathrm{ml}$ Kernproteinpuffer A aufgenommen und mit einem Glas/Glas-Potter homogenisiert. Nach der Überführung in $10 \mathrm{ml}$ Zentrifugenröhrchen wurden größere Gewebereste und Zelldebris durch vorsichtige Zentrifugation $\left(50 \mathrm{~s}, 800 \mathrm{x} \mathrm{g}, 4^{\circ} \mathrm{C}\right)$ sedimentiert. Der Überstand wurde $10 \min \left(4000 \mathrm{x} \mathrm{g}, 4^{\circ} \mathrm{C}\right)$ zentrifugiert und die pelletierten Zellkerne in $100-300 \mu \mathrm{l}$ Kernproteinpuffer B resuspendiert. Die osmotische Lyse der Kerne erfolgte während einer 20minütigen Inkubation auf Eis (mehrmaliges Aufschütteln). Die Ansätze wurden in 1,2 ml Reaktionsgefäße überführt und hochmolekulare Bestandteile (incl. DNA) durch kurzzeitige Zentrifugation (5 min, $7000 \mathrm{x}$ g) sedimentiert. Der die Kernproteine enthaltende Überstand wurde aliquotiert und gelagert. 


\subsubsection{Isolierung von zytoplasmatischen Proteinen aus Gewebe.}

Frisch präparierte Testes wurden auf Eis in PBS gewaschen, in $1 \mathrm{ml}$ Puffer A aufgenommen und in einem Glas/Glas-Potter homogenisiert. Größere Gewebereste und Zelldebris wurden durch Zentrifugation $\left(10 \mathrm{~min}, 800 \mathrm{x} \mathrm{g}, 4^{\circ} \mathrm{C}\right)$ sedimentiert. Der Überstand hier von wurde nach der Zugabe von 0,11 Vol des Puffer B $1 \mathrm{~h}\left(45000 \mathrm{x}\right.$ g, $\left.4^{\circ} \mathrm{C}\right)$ zentrifugiert. Der neue Überstand wurde 2-4 h gegen 20 Vol des Puffer D dialysiert. Nach der kurze Zentrifugation (2 min, 4000 x g) wurden die Proteine schließlich aliquotiert.

\subsubsection{Isolierung der Proteine für die Isoelektrische Fokussierung (IEF)}

Der entscheidende Schritt für die IEF ist die Proteinvorbereitung. Die Proben sollten komplett gelöst, denaturiert und reduziert werden, störende Substanzen (z.B. Lipide, Nukleinsäuren oder Salze) müssen entfernt sein. Allerdings führt jede zusätzliche Manipulation zur Gefahr der Proteinmodifikation.

Die in den Experimenten der vorliegenden Arbeit verwendeten Proteine wurden mit $9 \mathrm{M}$ Harnstoff-Puffer (IEF-Lysis-Puffer) (siehe 2.4) homogenisiert und sonifiziert (2.19.2). Schließlich wurden die Gewebetrümmer abzentrifugiert $\left(100000\right.$ x g $\left.60 \mathrm{~min}, 15^{\circ} \mathrm{C}\right)$. Der Proteinüberstand wurde aliquotiert.

\subsection{Proteinanalysen (Proteinbiochemische Techniken)}

\subsubsection{SDS-PAGE}

Proteine werden in Anwesenheit von reduzierenden Agenzien (DTT und $\beta$-Mercaptoethanol) und SDS aufgekocht, wobei die natürlichen Ladungen der Probe durch die negativen Ladungen des SDS maskiert werden und so eine Auftrennung der nun gleich geladenen Proteine nach ihrer Größe gewährleistet wird. Die große Trennleistung der Diskelektrophorese wird über Diskontinuitäten im pH-Wert und in der Porengröße erreicht, die aus der Kombination eines großporigen Sammelgels (4\% Polyacrylamid) zur Konzentrierung der Probe auf eine schmale Startzone und eines feinporigen Trenngels (10$15 \%$ Polyacrylamid) resultieren. Es wurden diskontinuierliche Gele in PHASE- 
Minigelkammern mit Trennlängen von ca. $70 \mathrm{~mm}$ gegossen oder vorgefertigte Gele des NuPAGE $^{\text {TM }}$ Elektrophorese Systems (NOVEX, San Diego) benutzt. In der Regel wurden Trenngele mit $10 \%$ Polyacrylamid (29:1) gegossen (1x Trenngelpuffer, 0,1\% APS und 0,1 \% TEMED zur Polymerisierung). Um bei selbst gegossenen Gelen eine glatte Oberfläche des Trenngels zu erhalten, wurden diese direkt nach dem Gießen mit Butanol überschichtet. Das Butanol wurde nach dem vollständigen Polymerisieren des Trenngels mit Wasser abgespült, danach das 4\%ige Sammelgel gegossen und der Kamm luftblasenfrei eingesetzt. Die Proteinproben wurden mit 0,25 Vol Probenpuffer versetzt, 10 min bei $70^{\circ} \mathrm{C}$ inkubiert, auf Eis abgekühlt und danach auf das Gel aufgetragen. Die Elektrophorese erfolgte bei 40 $100 \mathrm{~V}$, und zwar solange bis der mitlaufende gefärbte Proteinstandard (SeeBlue ${ }^{\text {TMPlus2, }}$ NOVEX) eine genügende Auftrennung der Proben anzeigte.

\subsubsection{Zwei-dimensionale Elektrophorese mit immobilisierten pH-Gradienten}

(Görg, 1998)

Die zwei-dimensionale Elektrophorese ist eine Methode der Proteinanalyse, bei der die Proteine nach ihrer Molekulargröße und ihrem Ladungszustand aufgetrennt werden. In der ersten Dimension werden die Proteine durch eine isoelektrische Fokussierung (IEF) nach ihrem Isoelektrischen Punkt (pI) aufgetrennt. Eine SDS-PAGE trennt die Proteine in der zweiten Dimension nach ihrer Größe.

In der hier verwendeten Version wurde die Fokussierung in einem immobilisierten $\mathrm{pH}$ Gradient (IPG) auf kommerziell erhältlichen vorgefertigten IEF-Streifen durchgeführt. Der Gradient wird durch Kopolymerisation von Immobilinen ${ }^{\circledR}$ (Acrylamidderivate mit puffernden Carboxyl- oder Aminogruppen) mit Acrylamid-Monomeren erzeugt. Im Gegensatz zu früher verwendeten Ampholyten sind Immobiline ${ }^{\circledR}$ keine amphoteren Substanzen, sondern in Abhängigkeit der puffernder Gruppe schwache Säuren oder Basen mit definiertem pKs-Wert. Der pH-Gradient entsteht durch eine kontinuierliche Veränderung des Immobiline ${ }^{\circledR}-$ Mischungsverhältnisses während des Gelgießens. Je nach Eigenschaften der Proteine sind IPG-Streifen mit verschiedenen $\mathrm{pH}-$ Bereichen erhältlich.

Im elektrischen Feld bewegt sich jedes geladene Protein in Richtung der Elektrode mit der komplementären Ladung, aber nur zu der Stelle, die seinem elektrischen Punkt (pI) entspricht. In diesem Punkt ist die Ladung des Proteins gleich Null, es bewegt sich nicht mehr im elektrischen Feld. Auf diese Weise bleiben die Proteine in diesem pH Bereich fixiert. 


\subsubsection{Durchführung des IEFs}

Die IPG-Streifen wurden vor Beginn der Fokussierung 12-16 Stunden rehydratisiert. Die Rehydratisierungslösung wurde in den Einsatz der PROTEAN ${ }^{\circ}$ IEF-Cell pipettiert und ein Streifen wurde nach dem Abziehen der Schutzfolie luftblasenfrei mit der Gelseite nach unten auf die Rehydratisierungslösung gelegt. Die Menge der Rehydratisierungslösung war von der Streifenlänge abhängig und betrug $125 \mu \mathrm{l}$ für $70 \mathrm{~mm}$ und $200 \mu \mathrm{l}$ für $110 \mathrm{~mm}$ lange Streifen.

Die vorbereitete Probe (2.19.5) konnte nach beendeter Rehydratisierung auf den Streifen aufgetragen werden oder (gelöst in der Rehydratisierungslösung) am Anfang des Rehydratisierungsprozeßen pipettiert werden. Die optimale Proteinkonzentration für die Fokussierung (wenn nach der abgeschlossenen Rehydratisierung pipettiert) beträgt ca. 1-5 $\mu \mathrm{g} / \mu \mathrm{l}$. Bei einer analytischen 2D-Elektrophorese wurde auf $70 \mathrm{~mm}$ und auf $110 \mathrm{~mm}$ lange IPG-Streifen ( $\mathrm{pH}$ 3-10) ca. 5 bzw. $10 \mu \mathrm{g}$ Protein aufgetragen. Sowohl während der Rehydratisierung als auch während der eigentlichen Fokussierung wurden die Streifen mit 2-3 ml Silikonöl bedeckt. Dies soll die Austrocknung der Streifen und die Auskristallisation des Harnstoffs verhindern.

Die Fokussierung verlief in der Bio-Rad PROTEAN ${ }^{\circledR}$ IEF-Cell ${ }^{\mathrm{TM}}$ bei folgenden Bedingungen:

\begin{tabular}{lllll} 
Temperatur & \multicolumn{2}{c}{$20^{\circ} \mathrm{C}$} \\
Stromstärke & \multicolumn{2}{c}{$0,05 \mathrm{~mA} /$ Streifen } & \\
Volts & IPG3-10/7cm & IPG3-10/11cm & IPG3-6/7cm & IPG3-6/11cm \\
$200 \mathrm{~V}$ & $1 \mathrm{~h}$ & $1 \mathrm{~h}$ & $1 \mathrm{~h}$ & $1 \mathrm{~h}$ \\
$500 \mathrm{~V}$ & $1 \mathrm{~h}$ & $1 \mathrm{~h}$ & $1 \mathrm{~h}$ & $1 \mathrm{~h}$ \\
$500-4000 \mathrm{~V}$ & $30 \mathrm{~min}$ & $30 \mathrm{~min}$ & $30 \mathrm{~min}$ & $30 \mathrm{~min}$ \\
$4000 \mathrm{~V}$ & $1,5 \mathrm{~h}$ & $2 \mathrm{~h}$ & $2 \mathrm{~h}$ & $2,5 \mathrm{~h}$
\end{tabular}

Nach beendeter Fokussierung wurden die Streifen sofort weiter verarbeitet oder in einer Plastikfolie bei $-70^{\circ} \mathrm{C}$ gelagert (max. 9-12 Monate).

\subsubsection{2 Äquilibrierung der IPG-Streifen und SDS-PAGE für IEF}

Nach der IEF wurde der IEF-Streifen horizontal auf ein SDS-PAGE-Gel gelegt und die Proteine werden in der 2. Dimension aufgetrennt. Um einen optimalen Proteintransfer aus 
dem IPG-Streifen in das SDS-PAA-Gel zu erzielen, mußten die fokussierten Proteine mit SDS beladen werden. Der IPG-Streifen wurde 2x10 min in den Äquilibrierungspuffern 1 und 2 (2.4) geschüttelt. Äquilibrierungspuffer-1 enthält 1\% DTT (w/v), Äquilibrierungspuffer-2 $260 \mathrm{mM}$ Jodacetamid. Anschließend wurde der IPG-Streifen kurz in Laufpuffer geschwenkt, seitlich auf die Gelkante des SDS-Gels gelegt und mit heißer Agarose fixiert. Die SDSPAGE-Elektrophorese wurde nach Standardprotokoll (2.20.1) durchgeführt.

Nach der Elektrophorese wurde das Gel geblottet (2.22.2.1) und mit anti-Prm3-Antiserum entwickelt (2.22.2.3).

\subsubsection{Coomassie-Färbung}

(Weber und Osborn, 1969, modifiziert)

SDS-PAGE Gele wurden zwecks Proteinfärbung 1-3 h in Coomassie Brilliant Blau Färbelösung geschwenkt. Anschließend wurden die Gele bis zur Entfärbung des Hintergrundes in Entfärbelösung geschwenkt. Dabei wurde der Entfärber mehrfach gewechselt. Benutzter Entfärber wurde über Aktivkohle regeneriert. Die zur An- und Entfärbung benötigte Zeit konnte, wenn nötig durch Erwärmen auf $45^{\circ} \mathrm{C}$ auf die Hälfte reduziert werden. Zur Lagerung wurden die gefärbten Gele in Folie eingeschweißt, bei $4^{\circ} \mathrm{C}$ oder auf einem Filterpapier getrocknet bei Raumtemperatur aufbewahrt.

\subsubsection{Acetonfällung von Proteinen}

Proteinproben konnten, wenn eine Volumenreduzierung nötig war, über Acetonfällung aufkonzentriert werden. Hierzu wurden $4 \mathrm{Vol}$ Aceton (vorgekühlt auf $-20^{\circ} \mathrm{C}$ ) zugegeben. Nach $1 \mathrm{~h}$ bei $-20^{\circ} \mathrm{C}$ wurden die ausgefallenen Proteine $30 \mathrm{~min}$ bei $10.000 \mathrm{x}$ g zentrifugiert und die erhaltenen Pellets einmal mit 80\%igem Aceton gewaschen.

\subsubsection{Dialyse von Proteinlösungen}

Die Dialyseschläuche (Fa. Serva) wurden vor dem Gebrauch in folgenden Lösungen ausgekocht:

$$
\mathrm{Na}_{2} \mathrm{CO}_{3}(2 \%, \mathrm{w} / \mathrm{v})
$$


$\operatorname{EDTA}(2 \mathrm{mM})$

$\mathrm{H}_{2} \mathrm{O}$ dest.

Anschließend wurden die Schläuche autoklaviert und bei $4^{\circ} \mathrm{C}$ in $\mathrm{H}_{2} \mathrm{O}$ aufbewahrt. Die Dialyse erfolgte unter Rühren bei $4^{\circ} \mathrm{C}$ gegen ein 1000 faches Puffervolumen für ca. $12 \mathrm{~h}$. Für kleine Volumina $(<3 \mathrm{ml})$ wurden Dialyse-Cassetten der Fa. Pierce (Slide-A-Lyzer ${ }^{\circledR}$ Dialysis Cassette) gemäß Firmenprotokoll verwendet.

\subsubsection{Bestimmung von Proteinkonzentrationen}

(Bradford, 1976)

Coomassie Brilliant Blue G250 wird durch Bindung an Protein vom kationischen in den anionischen Zustand überführt und absorbiert in diesem Zustand Licht mit einer Wellenlänge von $595 \mathrm{~nm}$ (der kationische Zustand absorbiert bei $470 \mathrm{~nm}$ ). Das vorgefertigte BradfordReagenz (Roti ${ }^{\circledR}$-Quant, Fa. Roth) enthält den Farbstoff Coomassie Brilliant Blue G250 unter Zusatz von Ethanol und $\mathrm{H}_{3} \mathrm{PO}_{4}$ gelöst in $\mathrm{H}_{2} \mathrm{O}$. Für die Verwendung in Mikrotiterplatten wurden wie vom Hersteller angegeben $2 \mathrm{Vol}$ des Reagenz mit 5,5 $\mathrm{Vol} \mathrm{H}_{2} \mathrm{O}$ verdünnt. Pro Messung wurden dann $200 \mu 1$ verdünntes Reagenz zu $50 \mu 1$ der vorgelegten Standards und verdünnten Proben gegeben. Alle Absorptionsmessungen wurden immer auf eine Eichgerade mit BSA (BSA gelöst in $\mathrm{H}_{2} \mathrm{O}: 0 ; 10 ; 20 ; 40 ; 60 ; 80 ; 100 \mu \mathrm{g} / \mathrm{ml}$ ) bezogen. Nach 5 min Inkubation bei RT wurde die $\mathrm{OD}_{595}$ in einem Mikrotiterplatten-Photometer (Microplate Reader 450, Biorad Laboratories, München) gemessen. Alle Messungen wurden in Doppelbestimmungen durchgeführt. Zur Auswertung wurde die $\mathrm{OD}_{595}$ für jede Probe gegen die eingesetzte Proteinmenge aufgetragen. Bei der Messung von Proben, die mit Hilfe von Glycerin, Triton X 100 oder SDS enthaltenden Lysispuffern erhalten wurden, mußte beachtet werden, das diese Reagenzien ab einer bestimmten Konzentration das Anfärbeverhalten von Coomassie Blue beeinflussen (siehe Produktprotokoll). 


\subsection{Expression von rekombinantem Protein in S. cerevisiae}

Der Hefe-Stamm RH2191, der das Maus Prm3-Gen exprimiert, wurde von Dr. Martin Kämper zur Verfügung gestellt (Kämper, 2001). Als Expressionsvektor wurde in diesem System pYGEX-2T benutzt, ein Vektor, der das Glutathion S-Transferase (GST) Fusionssystem zur Expression und Aufreinigung eines Fusionsproteins in E.coli (pGEX, Fa. Stratagene) auf Hefe überträgt. Dazu wurde der ursprüngliche Vektor pGEX um einen Replikationsstartpunkt für Hefe $(2 \mu)$ und einen Selektionsmarker (URA3) ergänzt, sowie der Promotor durch einen Galaktose-induzierbaren Hefepromotor ersetzt.

\subsubsection{Induktion der Proteinexpression und Aufschluß der Hefezellen}

Der Hefestamm RH2191 wurde zunächst aus dem Glycerolstock heraus auf eine selektive Agarplatte (Minimalmedium: SC) ausgestrichen. Nach dem Anwachsen der Hefen (2-3 Tage) wurde Zellmaterial zum Animpfen einer Vorkultur $(200 \mathrm{ml})$ abgenommen und diese üN kultiviert. Die Hauptkulturen (21) wurden mit 10\% ihres Volumens aus der Vorkultur angeimpft und ebenfalls üN kultiviert. Am nächsten Tag wurden die Zellen abzentrifugiert (1000 x g, $1 \mathrm{~min})$ und die Zellpellets wurden mit PBS gewaschen, um Glucosereste des verwendeten SC-Mediums zu entfernen. Die Zellen wurden erneut abzentrifugiert und wieder in derselben Menge SC-Medium aufgenommen, die jetzt 2\% (w/v) Galactose als einzige CQuelle enthielt. Die Induktion durch Galactose erfolgte mindestens 8 h, konnte aber auch üN durchgeführt werden.

Nach der Induktion des Fusionsproteins wurden die Kulturen abzentrifugiert (1000 x g, $15 \mathrm{~min}, 4^{\circ} \mathrm{C}$ ) und einmal in PBS gewaschen. Die Pellets wurden in $20 \mathrm{ml}$ PBS (enthielt $10 \%$ (v/v) Glycerol, $100 \mu \mathrm{l}$ Hefe-Protease Inhibitor) sowie $10 \mathrm{ml}$ Glasperlen $(\varnothing 0,5 \mathrm{~mm})$ aufgenommen. Der Aufschluß der Zellen erfolgte durch Schütteln für $15 \mathrm{~min}$ bei $4^{\circ} \mathrm{C}$, anschließender Zugabe von 1,5\% Sarkosyl und 2\% Triton X-100 und erneutem kurzem Schütteln (2 min). Die Zugabe der Tenside zu Anfang des Aufschlusses ist nicht von Vorteil, da durch die entstehende Schaumbildung das Zerschlagen der Zellen durch die Glasperlen behindert wird. Die Glasperlen und Zellfragmente wurden durch Zentrifugation (2000 x g, $15 \mathrm{~min}, 4^{\circ} \mathrm{C}$ ) von den freigesetzten Proteinen getrennt. 
Die Aufreinigung des rekombinanten Proteins erfolgte über die Bindung des GST-Anteils an Sepharose gekoppeltes Glutathion, das Substrat der Glutathion S-Transferase. Die verwendete Glutathion Sepharose 4B (Pharmacia) wurde zur Konservierung in 20\% Ethanol geliefert und mußte vor der Verwendung mit PBS äquilibriert werden. Nach den Angaben des Herstellers bindet $1 \mathrm{ml}$ eines 50\%igen Gemisches der äquilibrierten Sepharose $5 \mathrm{mg}$ GST. Um $1 \mathrm{ml}$ des Gemisches $\mathrm{zu}$ erhalten, wurden $1,33 \mathrm{ml}$ der Ethanol enthaltenden Sepharose vorsichtig abzentrifugiert (500 x g, $5 \mathrm{~min}$ ), der Überstand verworfen und das Pellet vorsichtig in $10 \mathrm{ml}$ kaltem PBS $\left(4^{\circ} \mathrm{C}\right)$ resuspendiert, die Sepharose erneut abzentrifugiert und in $1 \mathrm{ml}$ PBS aufgenommen. Die äquilibrierte Glutathion Sepharose (1 ml, 50\% (w/v) Sepharose) wurde zu dem aus 21 Hefekultur erhaltenen Proteinaufschluß gegeben. Die Bindung des GST-Anteils des Fusionsproteins an die Glutathionreste der Agarose erfolgte innerhalb von 30-45 min wobei die Lösung in langsamer Bewegung gehalten wurde. Nach der Bindungsreaktion wurde die Sepharose abzentrifugiert $\left(500 \mathrm{x} \mathrm{g}, 5 \mathrm{~min}, 4^{\circ} \mathrm{C}\right)$ und der Überstand abgetrennt. Zur Entfernung nichtgebundener Proteine aus dem Sepharosepellet wurde dieses 5-10 x mit $10 \mathrm{ml}$ eiskaltem PBS gewaschen. Nach dem letzten Zentrifugationsschritt wurde das Pellet in $1 \mathrm{ml}$ Elutionspuffer vorsichtig aufgeschwemmt und 10 min bei RT inkubiert. Zur Sedimentation der Sepharosematrix wurde erneut zentrifugiert (500 x g, 5 min, RT). Die Elution der Matrix erfolgte dreimal in $1 \mathrm{ml}$ Lösung mit reduziertem Glutathion. Die Elutionsfraktionen wurden jeweils mittels SDS-PAGE auf ihren Proteingehalt getestet.

\subsection{Immunodetektion}

2.22.1 Aufreinigung monospezifischer Antikörper

\subsubsection{Aufreinigung monospezifischer Antikörper mittels Western-Blot-} Verfahren

Das vorhandene polyklonale Serum gegen Prm3 wurde aufgereinigt, um die Spezifität des Serums zu erhöhen. Hierzu wurde das rekombinante Prm3-GST-Fusionsprotein aus Hefezellen (2.21.4) mittels PAGE aufgetrennt und auf eine Hybond C-Membran transferiert. 
Nach dem Transfer wurden schmale Randstreifen vom Filter abgetrennt und mittels WesternBlot-Verfahren entwickelt, um die Höhe der Fusionsproteinbande festzustellen. Der entprechende Teil des Filters wurde ausgeschnitten, mit $200 \mu \mathrm{l}$ des polyklonalen Antiserums inkubiert, 3x 10 min in PBT gewaschen und zur Elution der monospezifischen Antikörper 15 min mit $1 \mathrm{ml}$ Elutionslösung mit dem Vortexer kräftig geschüttelt. Nach Waschschritten in PBS wurde der Filterstreifen erneut mit dem Antiserum inkubiert. Die eluierten Antikörper wurden in ein Centrisart-Röhrchen überführt und durch Zentrifugtion bei $4^{\circ} \mathrm{C}$ und $2500 \mathrm{x} \mathrm{g}$ konzentriert, wobei der Elutionspuffer in den inneren Stempel übertritt und der Antikörper durch die Membran im Außenröhrchen zurückgehalten wird. Der Überstand wurde verworfen, die Restflüssigkeit mit PBS auf das Ausgangsvolumen aufgefüllt und erneut zentrifugiert. Dieser Vorgang wurde so oft wiederholt, bis das KSCN vollständig aus der Antikörperlösung entfernt war (3-4x). Die Antikörperlösung wurde mit $0.2 \% \mathrm{NaN}_{3}$ versetzt und bei $4^{\circ} \mathrm{C}$ gelagert.

\subsubsection{Aufreinigung monospezifischer Antikörper mittels Affinitäts-Säulen}

Aktivierte N-Hydroxysuccinimid (NHS) Sepharose-Säulen (HiTrap affinity columns, Amersham Pharmacia Biotech) können kovalent Liganden mit primären Aminogruppen binden. So konnte das GST-Prm3 Protein, das zur Immunisierung von Kaninchen eingesetzt wurde, an die Säule gebunden und zur Aufreinigung des Immunserums verwendet werden. Das zur Vermeidung der Deaktivierung von NHS-Gruppen bei der Lagerung zugegebene Isopropanol wurde direkt vor der Verwendung mit 3x $2 \mathrm{ml} 1 \mathrm{mM} \mathrm{HCl}\left(4^{\circ} \mathrm{C}\right)$ ausgewaschen. Die Lösung wurde mit Hilfe einer Spritze und eines Adapters auf die Säule appliziert. Um die Matrix nicht irreversibel zu komprimieren, wurde für diesen und alle weiteren Schritte eine Flussrate von maximal $1 \mathrm{ml} / \mathrm{min}$ eingehalten. $2 \mathrm{ml}$ des GST-Prm3 in einer Konzentration von $5 \mu \mathrm{g} / \mathrm{ml}$ in Bindungspuffer wurden auf eine Säule gegeben und diese $4 \mathrm{~h}$ bei $4^{\circ} \mathrm{C}$ inkubiert. Durch eine Behandlung mit 3 x 2 ml Puffer A, 3x 2 ml Puffer B, 3 x ml Puffer A, Inkubation bei RT für $30 \mathrm{~min}, 3 \times 2 \mathrm{ml}$ Puffer B, $3 \times 2 \mathrm{ml}$ Puffer A und nochmals $3 \times 2 \mathrm{ml}$ Puffer B wurden die überzähligen aktiven Gruppen, die keinen Liganden gebunden hatten, deaktiviert und unspezifisch gebundene Liganden ausgewaschen. Die Lagerung der Säulen erfolgte im Lagerungspuffer. Vor der Verwendung für die Aufreinigung von Antikörpern wurde der Lagerungspuffer mit $3 \mathrm{ml}$ PBS und $3 \mathrm{ml}$ Elutionspuffer ausgewaschen. Anschließend wurde die Säule mit $10 \mathrm{ml}$ PBS äquilibriert und $2 \mathrm{ml}$ des mit PBS 1:4 verdünnten Antiserums 
appliziert. Die Serum/PBS-Lösung wurde mehrmals über die Matrix gepumpt. Die Säule wurde 7 x mit $1 \mathrm{ml}$ PBS gewaschen, und die Antikörper wurden mit 2ml Elutionspuffer eluiert. Das Eluat wurde wie unter 2.20.5 beschrieben entsalzt. Die Säulen wurden mit 7x 1 $\mathrm{ml}$ PBS reäquilibriert und bis zur weiteren Verwendung in Lagerungspuffer bei $4^{\circ} \mathrm{C}$ aufbewahrt.

\subsubsection{Immunoblots}

\subsubsection{Transfer von Proteinen auf Nitrocellulose}

Nach der elektrophoretischen Auftrennung mittels SDS-PAGE wurden die Proteine über ein elektrisches Feld auf eine Nitrozellulosemembran (Hybond C) transferiert. Für diesen sog. „Western-Blot“ wurde entweder die Methode des „Tank-“ (Bio-Rad, München) oder des „Semi-Dry-Blots“ (Fast Blot, Fa. Biometra, Göttingen) verwendet. Für beide Transferarten wurde ein sog. „Immunoblot-Sandwich“ vorbereitet, dessen Größe von der Gelgröße abhängt und in dem das PA-Gel luftblasenfrei Kontakt zur Nitrozellulose hat. Im Falle des Tank-Blots wurden zwei in Towbin-Puffer getränkte Filterpapiere (GB 003, Fa. Schleicher \& Schüll, Dassel), im Falle des Semi-Dry-Blots je drei Filterpapiere in Semi-Dry-Puffer getränkt und auf beide Seiten des Sandwichs gelegt. Das fertige Sandwich wurde dann entweder in die Tank-Transfer-Kassette eingebaut und in die mit Towbin-Puffer gefüllte Tank-Blot Apparatur eingehängt oder zwischen die Elektroden des Semi-Dry Blotters gelegt. Bedingt durch die gebundenen negativen Ladungen des SDS werden die Proteine in Richtung der Anode transferiert. Der Transfer im Tank-System erfolgte meist üN bei $4^{\circ} \mathrm{C}$ und eingestellten 10 $15 \mathrm{~V}$. Der Semi-Dry-Transfer erfolgte bei RT für ca. $1 \mathrm{~h}$ mit voreingestellten $5 \mathrm{~mA} / \mathrm{cm}^{2}$, wobei auch bei Ansteigen der Spannung während des Transfers die Leistungsaufnahme des Gerätes nicht höher als $10 \mathrm{~W}$ sein sollte.

\subsubsection{Transferkontrolle mit Ponceau Rot}

Die reversible Anfärbung von Proteinen mit Ponceau-Rot erlaubt eine qualitative Abschätzung der Transfereffizienz ohne eine Beeinflussung einer später erfolgenden Immunodetektion. Ponceau S bildet ein komplettes Profil der transferierten Proteine mit einem Detektionslimit von 1-2 $\mu \mathrm{g}$ ab. Der wenige Minuten gefärbte Blot wurde in Wasser bis 
zur Sichtbarwerdung der Proteinbanden entfärbt, das Bandenmuster dokumentiert. In den folgenden Inkubationsschritten mit PBS oder TBS wurde die Färbung der Membran vollständig entfernt.

\subsubsection{Immunodetektion}

Unspezifische Bindungsstellen auf der Membran wurden durch Inkubation der Filter (üN bei $4^{\circ} \mathrm{C}$ oder $2 \mathrm{~h}$ bei RT) in Block-Puffer (TBS oder PBS mit 10\% FKS (v/v)) abgesättigt. Danach wurden die Filter einmal im verwendeten Puffersystem (TBS oder PBS) gewaschen und mit dem primären Antikörper inkubiert (üN bei $4^{\circ} \mathrm{C}$ oder $2 \mathrm{~h}$ bei RT). Der Antikörperansatz enthielt 5\% FKS, die Verdünnung des Antikörpers oder Antiserums richtete sich nach seiner Konzentration und der Konzentration des zu detektierenden Proteins. Das polyklonale anti-Prm3-Antiserum wurde in der Regel in einer Verdünung von 1:100 eingesetzt. Ungebundene Antikörper wurden nach der Inkubation durch Waschen (3 x 10 min TBS/PBS mit 0,05-0,1\%(v/v) Tween-20, einmal nur mit Puffer) entfernt. Die Membran wurde nun für $1 \mathrm{~h}$ mit dem mit Alkalischer Phosphatase konjugierten sekundären Antikörper (Ziege-anti-Maus oder Ziege-anti-Kaninchen; 1:10.000 verdünnt) inkubiert. Nach erneutem Abwaschen ungebundener Antikörper wurde die Membran 1-5 min im Reaktionspuffer der Alkalischen Phosphatase (AP-Puffer) äquilibriert. Die Färbereaktion, bei der an Stellen mit gebundener Alkalischer Phosphatase wasserunlösliche violette Kristalle ausfallen, wurde durch AP-Puffer gestartet, der $66 \mu \mathrm{NBT}$ und $33 \mu 1$ BCIP in $5 \mathrm{ml}$ Gesamtvolumen enthielt. Die Färbereaktion wurde abgedunkelt gehalten, fortwährend kontrolliert und konnte durch Waschen der Filter in Wasser abgestoppt werden.

\subsubsection{ELISA (,Enzyme linked immuno-absorbant-assay“)}

Ein anderer Weg, die Anwesenheit eines Proteins nachzuweisen, ist der ELISA, der darüber hinaus eine näherungsweise Quantifizierung des gesuchten Proteins erlaubt. Im Rahmen dieser Arbeit wurde ein ELISA für die quantitativen Vergleiche der Prm3-Expression in transgenen Mäusen benutzt.

Alle ELISA Versuche wurden in 96-well Mikrotiterplatten (Nunc) durchgeführt. Die Polystyreneoberfläche der Platten bindet auf nichtkovalente Weise ungefähr $200 \mathrm{ng} / \mathrm{well}$ 
Proteinen. Wenn eine maximale Binding erforderlich ist, sollten die Proteinen mindestens in 10-fachem Überschu $\beta$ pipetiert werden $(2 \mu \mathrm{g} / \mathrm{well}, 20 \mu \mathrm{g} / \mathrm{ml})$.

Zur Quantifizierung der Prm3-Expression in transgenen Tieren mussten zunächst primäre Fibroblastenkulturen aus Ohrspitzen angelegt werden. Diese wurden dann zur Induktion der Prm3-Expression mit dem Tet-Transaktivator transfiziert, üN mit Doxycyclin behandelt und am nächsten Tag mit Lysis-Puffer lysiert. Die Proteine (40 $\mu \mathrm{g}$ gelöst in $200 \mu \mathrm{l}$ PBS) wurden in die erste well-Zeile auf der Mikrotiterplatte pipettiert. Die Antigenlösungen wurden dann in 1:2 Schritten titriert, so da $\beta$ in der untersten Zeile noch eine Verdünung von 1:128 vorlag. Nach zweistündiger Bindung (RT) wurden unspezifische Bindungsstellen mit $200 \mu \mathrm{l}$ 5\% Blockierungslösung (Milchpulver in PBS) abgesättigt. Danach wurden die wells 2 x mit $200 \mu \mathrm{l}$ PBS gewaschen und mit $100 \mu \mathrm{l}$ Antiserum in 5\% Milchpulverlösung inkubiert. Ungebundene Antikörper wurden durch zweimaliges Waschen mit PBS entfernt. $100 \mu 1$ des verdünnten Zweitantikörpers (Ziege-anti-Kaninchen, AP-gekoppelt, 1:10.000 in 5\%iger Blockierungs-lösung) wurde in jedes well pipettiert. Nach viermaligem Waschen mit PBS wurden die Proteine 2 x mit Diethanolamin-Puffer gewaschen. Anschließend wurde das im Diethanolamin-Puffer gelöste Substrat PNPP (p-nitrophenyl phosphate, $10 \mathrm{mg}$ in $10 \mathrm{ml}$ ) zugegeben. Die Farbreaktion wurde regelmäßig kontrolliert und durch Zugabe von $100 \mu 1$ 0,5M TE gestoppt. Unmittelbar danach wurde die Platte bei $405 \mathrm{~nm}$ in einem Mikrotiterplatten-Photometer (MR580 MICROELISA ${ }^{\circledR}$ AUTOREADER) analysiert. Alle Inkubationen wurden entweder $2 \mathrm{~h}$ bei RT oder üN bei $4^{\circ} \mathrm{C}$ in einer feuchten Kammer durchgeführt. Zur Auswertung wurde die $\mathrm{OD}_{405 \mathrm{~nm}}$ gegen die Titrationsstufe des Antigens aufgetragen.

\subsection{Histologische Techniken}

\subsubsection{Fixierung des Gewebes}

Das frisch präparierte Material wurde direkt in das Bouin'sches Fixativ gegeben und je nach Größe des Präparats für eine Stunde bis zu 2 Tagen bei RT fixiert. Mit Hilfe einer aufsteigenden Alkoholreihe (50\%, 70\%, 90\% und 96\%) wurde das Gewebe entwässert. Um den Ethanol vor der Einbettung in das Paraffin vollständig zu entfernen, wurde das Gewebe üN in Methylbenzoat inkubiert. Für die Einbettung wurde das Paraffin im Wasserbad bei $58^{\circ} \mathrm{C}$ geschmolzen. Die Einbettung bestand aus mehreren Schritten, die sämtlich bei $58^{\circ} \mathrm{C}$ 
durchgeführt wurden. Für die Entfernung des Methylbenzoats wurde das Gewebe zweimal mit Benzol und zweimal in einem 1:1 Benzol/Paraffin-Gemisch jeweils für $1 \mathrm{~h}$ inkubiert. Zur vollständigen Durchdringung des Gewebes mit dem Paraffin wurde das Präparat anschließend zweimal für $1 \mathrm{~h}$ in Paraffin inkubiert. Im Anschluss daran wurde die auf $58^{\circ} \mathrm{C}$ temperierte Einbettungsform etwa zur Hälfte mit geschmolzenem Paraffin gefüllt, das Gewebe in die Form überführt und mit Paraffin aufgefüllt. Nach der Aushärtung üN wurde der Paraffinblock aus der Form genommen und bei $4^{\circ} \mathrm{C}$ gelagert.

\subsubsection{Vorbehandlung der Objektträger}

Die Objektträger wurden $20 \mathrm{~min}$ in $0,1 \mathrm{M} \mathrm{HCl}$ gekocht und danach 2 mal 5 min in $\mathrm{H}_{2} \mathrm{O}$ gewaschen. Anschließend wurden sie für $30 \mathrm{~min}$ in $96 \%$ Ethanol gelegt, getrocknet und üN in 1x Denhardt's Lsg. (2.4) inkubiert. Nach 20minütiger Fixierung in Ethanol/Eisessig (3:1) wurden die Objektträger in einer absteigenden Alkoholreihe (96\%, 70\%, 50\%, 30\% Ethanol, je $5 \mathrm{~min}$ ) rehydriert und üN bei $70^{\circ} \mathrm{C}$ in $1 \%$ Organosilan $(\mathrm{pH} \mathrm{3,4)} \mathrm{inkubiert.} \mathrm{Schließlich}$ wurden sie 5 mal 5 min in $\mathrm{H}_{2} \mathrm{O}$ gewaschen und üN bei $100^{\circ} \mathrm{C}$ gebaken. In diesem Zustand können die beschichteten Objektträger bis zu 6 Monate aufbewahrt werden.

Die Aktivierung der Objektträger erfolgte in 10\% Glutaraldehyd in PBS, pH 7,0, für 30 min Anschließend wurden sie 5 min in $\mathrm{H}_{2} \mathrm{O}$ gewaschen, bevor die Aktivierung in $0,1 \mathrm{M}$ Natriumm-Perjodat 15 min unter dem Abzug stabilisiert wurde. Schließlich wurden die Objektträger 3 mal 5 min in PBS gewaschen und üN bei $42^{\circ} \mathrm{C}$ getrocknet. Im aktivierten Zustand können die Objektträger mindestens 8 Wochen verwendet werden.

\subsubsection{Herstellung der Testis-Paraffinschnitte}

Die Paraffinblöcke mit dem fixierten Gewebe wurden zu Quadern geeigneter Größe zurechtgeschnitten und in das Mikrotom (JUNG RM 2035, Leica) eingespannt. Die Schnittdicke betrug 5-7 $\mu \mathrm{m}$. Mit Hilfe eines feinen Pinsels wurden die Schnitte auf $58^{\circ} \mathrm{C}$ warmes Wasser gelegt, mit einem Objektträger aufgenommen und getrocknet. Bis zur weiteren Verwendung wurden die Schnitte bei $4^{\circ} \mathrm{C}$ gelagert. 


\subsubsection{Immunlokalisierung von Proteinen in Paraffinschnitten}

Zunächst wurden die Testisschnitte 2 x $10 \mathrm{~min}$ in Roticlear deparaffiniert, in einer absteigenden Alkoholreihe (96\% EtOH für 2 mal 10 min, 70\%, 50\%, 30\% Ethanol für je 5 min) rehydriert und in $\mathrm{H}_{2} \mathrm{O}$ (2 min), PBS (2 mal $\left.10 \mathrm{~min}\right)$ PBT (5-50 min) gespült. Die überschüssige Flüssigkeit wurde abgesaugt, und unspezifische Bindungsstellen wurden 30 min mit 50-100 $\mu 1$ 5\% Ziegen- oder Schaf-Normalserum in PBT abgesättigt. Danach wurde erneut überschüssige Flüssigkeit mit einem Filterpapier abgesaugt. Auf das Präparat wurde gereinigtes Prm3 Antiserum (1:40 verdünnt) gegeben und $2 \mathrm{~h}$ in einer feuchten Kammer mit PBS als Puffer inkubiert. Unspezifische Antikörper-Bindungen wurden in PBT 4 x 5 min abgewaschen. Der Zweitantikörper (Ziege-anti-Kaninchen-AP, Ziege-anti-Kaninchen-cy3 oder Schaf-anti-Kaninchen-FITC) wurde entsprechend den Katalog-Empfehlungen in PBT verdünnt. Pro Objektträger wurden 50-100 $\mu$ l Antikörperlösung eingesetzt. Nach $2 \mathrm{~h}$ Inkubation in einer feuchten Kammer wurden nicht gebundene Antikörper 4 x 5 min in PBT ausgewaschen.

Für die Alkalische Phosphatase- (AP)-Detektion wurde das Gewebe für 2 min in AP-Puffer umgepuffert bevor $50 \mu 1$ Färbelösung auf den Schnitt gegeben wurden. Die Farbreaktion erfolgte unter einem Deckglas und wurde regelmäßig unter dem Mikroskop kontrolliert. Durch Eintauchen der Objektträger in TE-Puffer wurde die Reaktion gestoppt. Danach wurden die Präparate kurz in $\mathrm{H}_{2} \mathrm{O}$ gewaschen und luftgetrocknet. Vor dem Auflegen eines Deckglases wurde ein Tropfen „Vectashield Mounting Medium“ mit DAPI (4,6-diamidino-2phenylindole dihydrochloride) (Boehringer, Mannheim) auf die Zellen gegeben. DAPI bindet spezifisch an DNA und emittiert nach Anregung mit UV-Licht von $360 \mathrm{~nm}$ blaues Licht einer Wellenlänge von $460 \mathrm{~nm}$, so da $\beta$ die blau fluoreszierenden Zellkerne sich gut vom Zytoplasma abgrenzen lassen.

Bei der Verwendung anti-FITC oder anti-cy3 Antikörper wurden die Präparate nach 2stündiger Inkubation nur $4 \times 5 \mathrm{~min}$ in PBT gewaschen, luftgetrocknet und mit DAPIVectashield bedeckt. Die Präparate wurden hierbei dunkel gehalten. 


\subsubsection{Akrosomenfärbung}

Um die Spermiogenese-Stadien sicherer zu identifizieren, wurde das Akrosom angefärbt. Dies erfolgte durch eine Inkubation der Testisschnitte mit FITC-konjugiertem Erdnuß-Lectin. Nach dem letzten Waschschritt wurde der Objektträger mit der Lectinlösung 20 min inkubiert. Schließlich wurde er 4 x 10 min gewaschen, luftgetrocknet und mit DAPI gegengefärbt.

\subsection{Zellbiologische Methoden}

\subsubsection{Kultivierung eukaryotischer Zellen}

Alle hier verwendeten Zellen wuchsen adhärend in beschichteten Gewebekulturschalen. Die Zellen wurden im entsprechenden Medium bei $37^{\circ} \mathrm{C}$ und zur Einstellung eines physiologischen $\mathrm{pH}-$ Wertes (alle Medien enthielten $\mathrm{NaHCO}_{3}$ ) bei $5 \% \mathrm{CO}_{2}$ kultiviert. Die Zellen wurden geteilt, bevor eine 100\%ige Konfluenz erreicht wurde. Zum Passagieren wurden die Zellen nach Abnahme des Kulturmediums zweimal mit $\mathrm{Ca}^{2+} / \mathrm{Mg}^{2+}$-freier PBSLösung gewaschen und in Trypsin/EDTA-Lösung solange inkubiert, bis sich alle Zellen vom Boden der Kulturschale gelöst hatten. Zum Abstoppen der Trypsin-Wirkung wurden die Zellen in Kulturmedium aufgenommen. 5-10\% dieser Zellsuspension wurden zur Weiterkultur in der benutzten oder in einer neuen Kulturschale gleicher Größe verwendet.

\subsubsection{Isolierung und Kultivierung primärer Fibroblasten}

Zum Nachweis der Doxycyclin-induzierbaren Expression von transgenen Konstrukten in Mäusen wurden narkotisierten Tieren kleine Gewebestücke der Ohrmuschel entnommen. Die Gewebe wurden kurz in 70\%igem Ethanol gewaschen, getrocknet und in einer Kulturschale ( $830 \mathrm{~mm}$ ) in RPMI-Medium unter Zusatz von Collagenase Typ IV (10 mg/ml) $2 \mathrm{~h}$ unter $\mathrm{CO}_{2}$ inkubiert. Danach wurde das Gewebestück mit zwei sterilen Pinzetten in möglichst kleine Stückchen zerzupft. Nach weiterer Inkubation in der Collagenase üN wurden die Gewebestücke mehrmals durch eine Pipette aufgezogen, in ein Zentrifugenröhrchen überführt und abzentrifugiert (10 min, $1000 \mathrm{xg}$, RT). Das Zellpellet wurde in RPMI-Kulturmedium 
resuspendiert und in neue Kulturschalen überführt. Die Zellen wurden so lange kultiviert und geteilt, bis genügend Zellen für eine Transfektion vorhanden waren. Dies war in der Regel nach 1-2 Wochen der Fall.

\subsubsection{Einfrieren eukaryotischer Zellen}

Alle Zellinien wurden zur Lagerung in flüssigem Stickstoff eingefroren. Die Zellen wurden während der stärksten Wachstumsphase zweimal mit PBS gewaschen und trypsinisiert. Die losgelösten Zellen wurden zur Inaktivierung des Trypsins in Medium mit FKS aufgenommen und abzentrifugiert ( $3 \mathrm{~min}, 900 \mathrm{x} \mathrm{g}, 4^{\circ} \mathrm{C}$ ), der Überstand wurde verworfen. Das Pellet wurde in vorgekühltem Einfriermedium aufgenommen. Aus einer $10 \mathrm{ml} \mathrm{Kulturflasche} \mathrm{mit} \mathrm{einer}$ Konfluenz von etwa 80\% lassen sich vier Kryoröhrchen mit einem Volumen von 1,8 ml befüllen. Für die Lebensfähigkeit der Zellen ist langsames Einfrieren erforderlich. Die Zellen wurden deshalb zunächst bei $-20^{\circ} \mathrm{C}$ für $2 \mathrm{~h}$ gefroren, dann $\ddot{\mathrm{N}}$ bei $-70^{\circ} \mathrm{C}$ gehalten (Lagerung bei $-70^{\circ} \mathrm{C}$ ist abhängig vom Zelltyp für mehrere Monate möglich) und später in flüssigen Stickstoff gelagert. Zum Auftauen wurden die Röhrchen schnell aus dem Stickstoff in ein $37^{\circ} \mathrm{C}$ Wasserbad überführt. Nach dem Schmelzen wurde der Inhalt des Röhrchens in eine kleine Kulturflasche mit $6 \mathrm{ml}$ vorgewärmtem Kulturmedium gegeben. Nach dem Anwachsen der Zellen (über Nacht) wurde das noch DMSO enthaltende Medium gegen frisches Kulturmedium ausgetauscht. Eine Transfektion frisch aufgetauter Zellen war erst nach drei bis vier Passagen möglich.

\subsubsection{Transfektion eukaryotischer Zellen}

Die Transfektion eukaryotischer Zellen erfolgte zum qualitativen Nachweis oder zur quantitativen Bestimmung von Reportergenaktivität. Für die Transfektion der verschiedenen Zelltypen wurden unterschiedliche Transfektionsreagenzien verwendet. Transfektionsreagenzien komplexieren DNA, sie schirmen die negativen Ladungen ab und ermöglichen dem positiv geladenen DNA/Reagenz-Komplex auf z. T. nicht genau aufgeklärte Weise den Eintritt in die Zelle und weiter in den Kern. Monokationische Lipide wie z.B. DOTAP (Roche Diagnostics, Mannheim) oder polykationische Lipide wie Roti-Fect (Carl Roth, Karlsruhe) ermöglichen eine Fusion des Komplexes mit der Zellmembran, während DNA-Komplexe mit 
Substanzen wie Superfect (Qiagen, Hilden) sich an negativ geladene Rezeptoren der Säugetierzellmembran binden, wonach dieser Komplex dann aktiv in die Zelle eingeschleust wird.

Für jede Zellinie muß das beste Verhältnis von Transfektionsreagenz und DNA ermittelt werden. $\mathrm{Zu}$ beachten ist aber, daß Transfektionsreagenzien unterschiedlich toxisch auf verschiedene Zellen wirken, was auch bei ansonsten sehr guter Transfektionseffizienz die Menge der DNA im Transfektionsansatz limitiert. Für die Transfektionsexperimente wurden nur Zellen benutzt, die sich in einer logarithmischen Wachstumsphase befanden. Zellen, die zu lange konfluent sind, lassen sich schwerer transfektieren als schnell wachsende (häufig und rechtzeitig passagierte) Zellen. Die Anzahl der Passagen lag zwischen 5 und 25. Die Anzahl der Passagen wurde ab Ankunft der Zellen gezählt. Früheste erhältliche Passagen von NIH/3T3 Zellen sind laut ATCC-Katalog (American Type Culture Collection) erst ab einer Passagenzahl von ca. 120 (ab Primärkultur) erhältlich. Zu oft passagierte Zellen können ihre Morphologie und damit ihre Transfektionsbereitschaft verändern. Zur Transfektion wurden die Zellen einen Tag vor der DNA-Aufnahme in die entsprechende Kulturschalen ausgesät, so daß am folgenden Tag eine Konfluenz von 50-70\% erreicht wurde. Die Transfektion erfolgte weitgehend nach den Herstellerangaben. Für verschiedene Ziele wurden folgende Transfektions-Parameter vervendet:

\begin{tabular}{|l|l|l|l|}
\hline Zelltyp & $\begin{array}{l}\text { Kulturgröße } \\
(\mu \mathrm{g} \text { DNA/Schale })\end{array}$ & $\begin{array}{l}\text { Nachweis/ } \\
\text { Verwendung }\end{array}$ & $\begin{array}{l}\text { Reagenz } \\
(\mu 1 / \mu \mathrm{g} \text { DNA })\end{array}$ \\
\hline NIH/3T3 & 12 Well $(0,25-1,2 \mu \mathrm{g})$ & Luciferase-Assay & Roti-Fect $(3 \mu \mathrm{l} / \mu \mathrm{g})$ \\
\hline NIH/3T3 & $\begin{array}{l}\text { Flaskette glass slide } \\
(1-2 \mu \mathrm{g})\end{array}$ & GFP-Transfektion & Roti-Fect $(3 \mu \mathrm{l} / \mu \mathrm{g})$ \\
\hline NIH/3T3 & $\begin{array}{l}6 \mathrm{~cm}(4-8 \mu \mathrm{g} \text { DNA }) \\
10 \mathrm{~cm}(10 \mu \mathrm{g} \text { DNA })\end{array}$ & $\begin{array}{l}\text { Northern- Western- } \\
\text { Blot }\end{array}$ & Superfect $(5 \mu \mathrm{l} / \mu \mathrm{g})$ \\
\hline primäre Fibroblasten & $6 \mathrm{Well}(4-5 \mu \mathrm{g})$ & $\begin{array}{l}\text { Western-Blot } \\
\text { ELISA }\end{array}$ & Superfect $(5 \mu \mathrm{l} / \mu \mathrm{g})$ \\
\hline
\end{tabular}


Die Dauer der Inkubation mit den DNA-Komplexen betrug 2-4 h. Die Ernte der Proteine erfolgte 20-48 h nach dem Abstoppen der Transfektion durch Ersetzen des Ansatzes mit frischem Kulturmedium.

\subsubsection{Zelluläre Lokalisation von GFP-Prm3 Fusionsproteinen in NHI3T3 Zellen}

GFP-Fusionsproteine ermöglichen es, die intrazelluläre Lokalisation eines Proteins näher zu charakterisieren. Das „green fluorescent protein“ (GFP) stammt aus der Qualle Aequorea victoria. Nach Anregung mit 490-nm-UV-Licht emittiert das GFP Licht einer Wellenlänge von ungefähr $500 \mathrm{~nm}$ und fluoresziert grün. Die Gensequenz dieses Proteins wurde leicht abgewandelt in einen eukaryotischen Expressionsvektor (pEGFP) integriert. Wird der Vektor pEGFP in Säugetierzellen transfiziert und exprimiert, verteilt sich das GFP gleichmäßig in allen Kompartimenten der Zelle. Wird hingegen die codierende Sequenz eines Gens im richtigen Leserahmen in den Vektor kloniert, entscheidet der zugefügte Genabschnitt über die intrazelluläre Lokalisation des GFP-Fusionsproteins.

Um die zelluläre Lokalisation des Prm3-Protein zu untersuchen, wurde die komplette cDNA in den pEGFP-C1-Vektor kloniert und zur Kontrolle sequenziert, um den Leserahmen zu überprüfen.

Die NIH/3T3-Zellen wurden in Zellkulturflaschen, die auf einem Objektträger befestigt sind (sogenannte „Flaskette glass slide“) (Nunc, Wiesbaden), ausplattiert und transfiziert (s. 2.24.4). Die fluoreszensmikroskopische Detektion des GFP-Fusionsproteins wurde ca. $24 \mathrm{~h}$ später durchgeführt. Dazu wurde zunächst die Zellkulturflasche vom Objektträger abgelöst und dieser dann für 10 min in ein Methanolbad überführt, wodurch die Zellen fixiert wurden. Anschließend wurden die Zellen an der Luft getrocknet und mit DAPI gegengefärbt. Die Zellen wurden anschließend unter einem Fluoreszenzmikroskop (BX-60, Olympus) betrachtet.

\subsubsection{Immunodetektion des Prm3-Proteins in der P3/3T3 Zellinie}

Die Zellen wurden bis zu einer 60-80\%igen Konfluenz auf Objektträger mit angehefteter Kulturflasche („Flaskette glass slide“) in serumhaltigen DMEMs (Gibco BRL, Karlsruhe) kultiviert. Anschließend wurden die Zellen $3 x$ in PBS gewaschen und in 4\%igem Paraformaldehyd im PBS für 8 min fixiert. Es folgten ein erneutes dreimaliges Waschen in 
PBS, eine 10minütige Inkubation der Zellen in 0.5\%igem TritonX100 und der nächste Waschschritt. Im Anschluss wurden die Zellen 10 min in 10\% BSA geblockt, erneut mit PBS gewaschen und mit Prm3 Anti-Serum (1:40 in 5\%BSA) 1 h bei RT inkubiert. Nach einem Waschschritt (3x10 min) in PBS mit 0,1\% Tween 20 folgte eine 30minütige Inkubation mit einem anti-FITC oder anti-cy3 Zweitantikörper. Die Zellen wurden dreimal mit PBS mit 0,1\% Tween 20 gewaschen und mit DAPI gegengefärbt. Als Negativkontrolle wurden die Zellen der gleichen Prozedur unterzogen, aber ohne eine Inkubation mit dem primären Antikörper. Die Zellen wurden anschließend unter einem Fluoreszenzmikroskop (BX-60, Olympus) ausgewertet.

\subsubsection{Nachweis der apoptotischen Wirkung des Prm3-Proteins. Trypan Blau Färbung}

Für die mikroskopische Untersuchung wurden die Prm3-NIH3T3 Zellen mit Trypan Blau gefärbt. Die sterbenden Zellen färben sich hierbei blau. Die Zellen wurden zunächst für 2 x 10 min in PBS gewaschen und mikroskopisch (BX-60, Olympus) begutachtet.

\subsubsection{ES-Zellen}

\subsubsection{Kultivierung embryonaler Stammzellen}

Damit sich die ES-Zellen in der Kultur nicht differenzieren, wurden zwei Maßnamen getroffen. Zum einen wurden die ES-Zellen auf einer Schicht Fibroblastenzellen kultiviert, die durch Mitomycinbehandlung an weiteren Zellteilungen gehindert wurden. Zum anderen war im ES-Medium LIF enthalten, das eine Differenzierung der Zellen verhindert. Die Zellen wurden bei $37^{\circ} \mathrm{C}$ und hoher Luftfeuchte bei $5 \% \mathrm{CO}_{2}$-Begasung inkubiert.

\subsubsection{Elektroporation und Selektion von ES-Zellen}

ES-Zellen einer voll bewachsenen $10 \mathrm{~cm}$ Petrischale wurden trypsiniert und vereinzelt. Die Zellen wurden zweimal mit PBS gewaschen, 5 min bei $200 \mathrm{x} \mathrm{g}$ abzentrifugiert und in $600 \mu 1$ PBS resuspendiert. $100 \mu \mathrm{g}$ DNA $(0,5 \mu \mathrm{g} / \mu \mathrm{l}$ in PBS) wurde hinzugegeben, gemischt, in eine GenePulser-Küvette (Biorad, München) überführt und für $5 \mathrm{~min}$ auf Eis inkubiert. Die 
Transfektion erfolgte mit dem BioRad GenePulser bei $240 \mathrm{~V}$ und $500 \mu \mathrm{Fd}$. Anschließend wurden die Zellen weitere 20 min auf Eis inkubiert, in $30 \mathrm{ml}$ ES-Medium aufgenommen und in zwei $10 \mathrm{~cm}$ Petrischalen ausplattiert.

\subsubsection{Gewinnung von ES-Zellklonen}

Transfektierte ES-Zellen wurden jeweils 4 Tage mit Selektionsmedium I und II behandelt. Die Zugabe von Neomycin bewirkt, daß nur solche Zellen wachsen können, die das transfektierte Plasmid mit dem Gen für die Neomycin-Resistenz in das Genom integriert haben. Die Zugabe von Gancyclovir bewirkt, daß Zellen, die das Thymidinkinase $(t k)$-Gen tragen, absterben. Es sollten also nur die ES-Zellen überleben, bei denen das $t k$-Gen nicht in das Genom integriert ist. Nach der Selektion wurden die Einzelklone in 24-well-Platten überführt und weitere drei Tage kultiviert. Danach wurden die Klone geteilt, ein Teil wurde eingefroren, der andere Teil wurde für die DNA-Präparation verwendet.

\subsubsection{DNA-Extraktion aus ES-Zellen}

Die ES-Einzelklone wurden für die DNA-Präparation lysiert. Zu den Zellen wurde 500 $\mu 1 /$ well ES-Lysispuffer hinzugefügt und üN bei $37^{\circ} \mathrm{C}$ inkubiert. Am nächsten Tag wurde in jedes well $500 \mu$ I Isopropanol hinzugefügt und 15 min bei RT auf einem Schüttler inkubiert. Dabei fiel die DNA als weißer Faden aus. Das Puffer/Isopropanol-Gemisch wurde vorsichtig abpipettiert und die DNA mit je $1 \mathrm{ml} 70 \%$ Ethanol gewaschen. Die DNA wurde in frische Reaktionsgefäße mit je $80 \mu 1$ TE-Puffer überführt, bei geöffnetem Deckel 10 min bei $65^{\circ} \mathrm{C}$ inkubiert, um Ethanolreste zu entfernen, und üN bei $4^{\circ} \mathrm{C}$ gelöst.

\subsubsection{Herstellung von Chimären}

Die Isolierung von 2.5 Tage alten Mausembryonen, die Injektion von rekombinanten ESZellen in die Embryonen und die Reimplantation der injizierten Blastocysten in pseudoschwangere Mäuse wurden von MitarbeiterInnen des Max-Planck-Instituts für Experimentelle Medizin, Göttingen, durchgeführt. Die ES-Zellen wurden aus Tieren des Mausstammes 129/SvJ isoliert, deren Fell eine braune Färbung aufweist (Agouti-Fellmarker). 
Die bei der Aggregation eingesetzten Blastocysten wurden aus dem C57BL-Stamm isoliert, dessen Mäuse eine schwarze Fellfärbung zeigen. Sind ES-Zellen an der Entwicklung der reimplantierten Embryonen involviert, können die chimären Tiere anhand einer gescheckten Fellfärbung identifiziert werden. Männliche Mäuse mit einem Chimerismus von mindestens $80 \%$ wurden auf die Stämme C57BL und 129/SvJ zurückgekreuzt.

\subsection{Quantitativer Nachweis von Reporter Enzymen}

Der quantitative Nachweis der Aktivität der Reporterenzyme Luciferase und $\beta$-Galactosidase erfolgte über die Messung von Lichtemissionsreaktionen in einem Luminometer (Typ LB 953, Fa. Berthold, Bad Wildbad). Das rekombinante Gen des Enzyms Luciferase aus dem Leuchtkäfer Photimus pyralis (de Wet et al., 1987) wird als Reportergen verwendet, da die auf die Oxidation des Käfer-Luciferins zurückzuführende Biolumineszenzreaktion gut nachgewiesen werden kann. Nach der Zugabe des Substrats durch das Luminometer startet die lichtemittierende Reaktion in $<1 \mathrm{~s}$ und ist bei einer Zugabe des Substrats im Überschuß über einen bestimmten Zeitraum proportional zur Luciferaseaktivität der Probe, was eine indirekte Bestimmung der Transkription des Reportergens erlaubt. In der ATP- und $\mathrm{Mg}^{2+}$ abhängigen Reaktion wird zunächst eine Acyl-AMP Zwischenstufe gebildet, die in Gegenwart von Sauerstoff zu Oxyluciferin oxidiert wird. Angeregtes Oxyluciferin fällt nachfolgend in den Grundzustand zurück, wobei ein Photon emittiert wird. Zur Normalisierung der Transfektionseffizienz wurde ein $\beta$-Galaktosidase exprimierender Vektor im Verhältnis 1:10 bis 1:20 zu dem zu testenden Konstrukt kotransfektiert. Durch die Verwendung von Chemilumineszenzsubstraten für die $\beta$-Galaktosidase ist die Aktivitätsmessung im Luminometer möglich, was den linearen Bereich der Detektion erhöht und die Sensitivität gegenüber dem früher benutzten kolorimetrischem Assay um den Faktor $5 \times 10^{5}$ steigert (Bronstein et al., 1994).

\subsubsection{Luciferase-,,Assay“}

(Ausubel et al., 1992)

Zur Bestimmung der Luciferaseaktivität wurden $200 \mu \mathrm{l}$ des Luciferase-Reaktionspuffers in Polystyrol Meßröhrchen (Fa. Sarstedt, Nürnbrecht) vorgelegt und 25-50 1 1 Zell- bzw. 
Gewebeextrakt zugegeben. Zum Starten der Lichtreaktion wurden $100 \mu 1$ der LuciferinInjektionslösung durch einen Injektor des Luminometers (AutoLumat LB953, Berthold) eingespritzt und die nachfolgende Lichtemission nach Verstreichen einer Vorlaufzeit von $20 \mathrm{~s}$ über weitere $20 \mathrm{~s}$ gemessen.

\subsection{2 $\beta$-Galactosidase- „Assay“}

(Jain und Magrath, 1991)

Die $\beta$-Galactosidaseaktivität wurde mit dem „Galacto-Light ${ }^{\mathrm{TM}}$-Kit“ (Fa. Tropix, Bedford, USA) gemessen. Das als Stocklösung vorliegende chemilumineszense Substrat Galacton wurde 1:100 mit dem gelieferten Reaktionspuffer verdünnt und $70 \mu 1$ in die Messröhrchen des Luminometers vorgelegt. In einem Abstand von 30 s wurden $5-10 \mu 1$ der Proben zum Substrat gegeben. Der Abstand von 30 s entsprach der Dauer einer Messung im Luminometer, zusammengesetzt aus $20 \mathrm{~s}$ Vorlaufzeit nach Injektion von $100 \mu 1$ des „Light Emission Accelerators" und $10 \mathrm{~s}$ Messintervall. Die Inkubationszeit mit Reaktionspuffer sollte für jede Probe identisch sein, da die Signalintensität von der Inkubationszeit abhängt. Nach dem Pipettieren der ersten Probe begann die Inkubationszeit von 30 - 60 min bei RT. Nach dieser Zeit wurden die Messungen gestartet.

\subsection{Yeast-Two-Hybrid Screening}

(Fields and Song., 1989)

Mit dem Yeast-Two-Hybrid-System ist es möglich, in vivo Protein-Protein-Interaktionen zu identifizieren. Das Yeast-Two-Hybrid-System wurde zur in vivo Identifizierung von Interaktionspartnern des Prm3-Proteins angewendet. Es basiert auf der Tatsache, da $\beta$ viele eukaryotische Transkriptionsfaktoren aus zwei funktionell unabhängigen Domänen bestehen, die physikalisch getrennt werden können. So enthält der GAL4-Transkriptionsaktivator der Hefe eine DNA-Bindungsdomäne (DNA-BD) und eine transkriptionsaktivierende Domäne (AD). Die DNA-BD erkennt und bindet an eine als UAS („upstream activating sequence“) bezeichnete Sequenz stromaufwärts von GAL4-responsiven Domänen. Die AD interagiert mit anderen Komponenten der Transkriptionsmaschinerie, die sich an der Initiation der Transkription beteiligen. Beide Domänen, die im Normalfall Teile eines einzigen Proteins 
sind, werden gleichermaßen zur Aktivierung eines Gens benötigt. Werden beide jedoch in derselben Zelle getrennt exprimiert, kommt es zu keiner direkten Interaktion von DNA-BD und $\mathrm{AD}$ und somit auch zu keiner Aktivierung GAL4-responsiver Gene. Zwei verschiedene Klonierungsvektoren wurden im Yeast-Two-Hybrid-System benutzt, um Fusionen dieser beiden GAL4-Domänen mit (Teilen von) Proteinen zu konstruieren, die auf eine Interaktion hin untersucht werden sollten. Dabei wurde das Köder („Bait“)-Protein Prm3 durch Integration der entsprechenden Gensequenz in den Vektor pGBT9 mit der GAL4-DNA-BD fusioniert. Die verwendete Testis-cDNA-Bank (Clontech, Heidelberg) war in den Vektor pGAD10 kloniert, um Fusionen von Proteinen, für die die cDNAs kodieren, mit der GAL4AD zu erhalten. Beide Plasmide wurden in den Hefestamm CG-1945 transformiert, in dem die Fusionsproteine exprimiert und in den Zellkern transportiert werden. Im Fall einer Interaktion von Prm3 mit einem in der cDNA-Bank kodierten Protein kommt es zu einer räumlichen Annährung zwischen der GAL4-DNA-BD und der GAL4-AD und damit zu einer funktionellen Rekonstitution des GAL4-Transkriptionsaktivators. Dieser ist daraufhin in der Lage, die Transkription von Reportergenen (lacZ und HIS3), die stromabwärts der GAL4Bindungsstellen lokalisiert sind, zu aktivieren, wodurch die Proteininteraktion detektierbar wird. (Abb. 2.1).
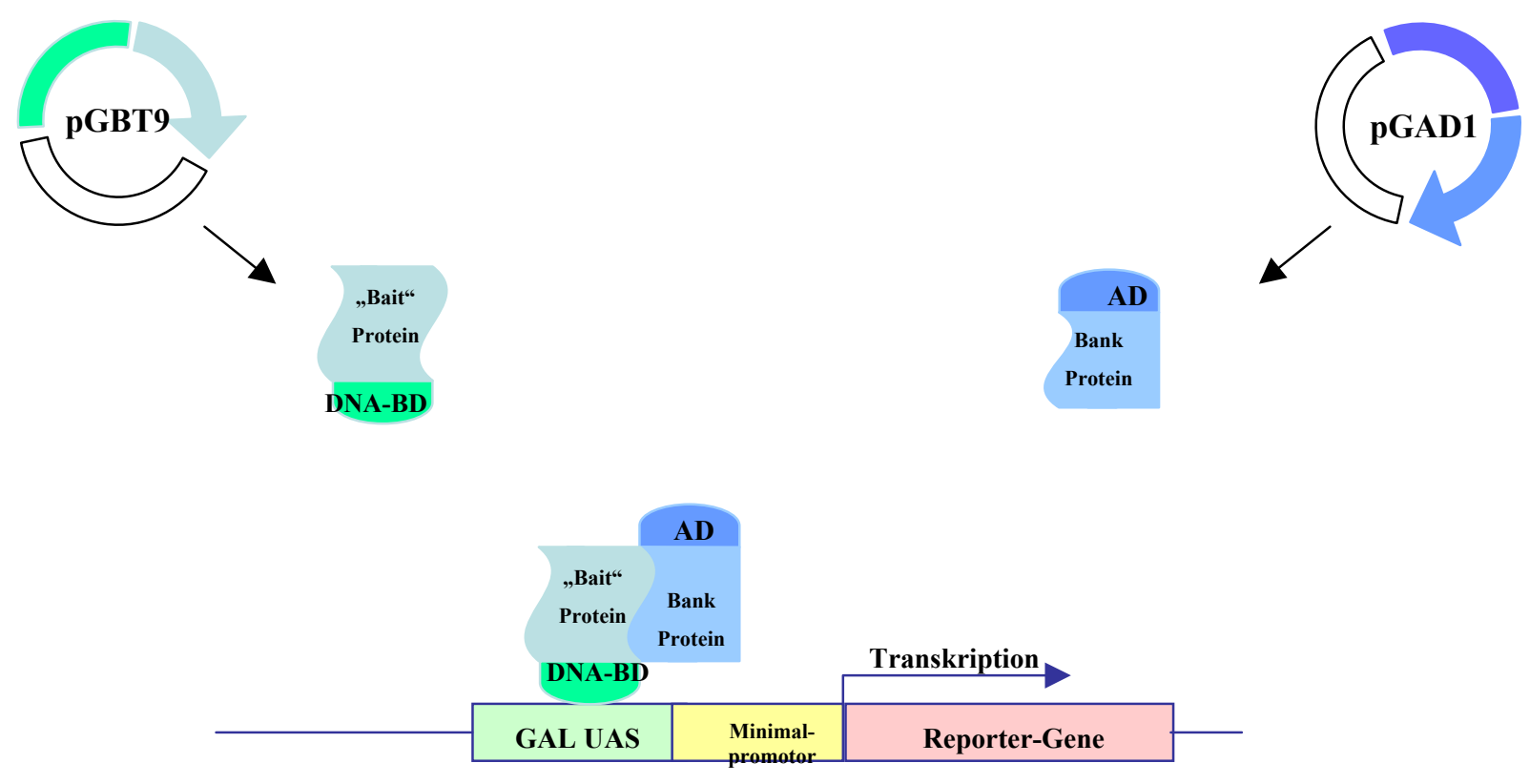

Abb. 2.1: Schematischer Ablauf des Yeast-Two-Hybrid-Systems. Die Interaktion zwischen Prm3 und einem Protein der Bibliothek rekonstituiert den GAL4-Transkriptionsaktivator, was zur Expression der Reportergene HIS3 und lacZ führt. 


\subsubsection{Klonierung des "Bait" Proteins}

Der komplette offene Leserahmen des Maus Prm3-Proteins wurde unter Beibehaltung des Leserahmens als Fusionskonstrukt an den C-Terminus der GAL4-DNA-Bindungsdomäne in den pGBT9-Vektor kloniert. Prm3 wurde auf diese Weise als Fusionsprotein mit der GAL4DNA-Bindungsdomäne exprimiert. Dieses Fusionsprotein ist allein nicht zur Aktivierung der Transkription GAL4-responsiver Gene fähig, was eine Grundvoraussetzung für das Funktionieren des Yeast-Two-Hybrid-Systems ist und zuvor überprüft wurde.

\subsubsection{Beschreibung der Maus Testis pGAD-Bank}

Maus Testis mRNA wurde mittels eines XhoI (dT)15-Primers in die entsprechenden cDNAs umgeschrieben. Die cDNAs wurden unidirektional über die Schnittstellen EcoRI und XhoI in den Vektor pGAD 10 kloniert und besitzen eine Größe von 0,4- ,.0 Kb (Ø 1,5 Kb). Die Anzahl unabhängiger Klone betrug 7 $\times 10^{6}$. Die Testis cDNA- Bank (Clontech, Heidelberg) wurde freundlicherweise von Frau Dr. Drabetd zur Verfügung gestellt.

\subsubsection{Herstellung von Lachsspermien-DNA-Lösung}

Die Lachsspermien-DNA (Sigma-Aldrich, Deisenhofen) wurde in $1 \times$ TE-Puffer gelöst. Durch Ultraschall-Stöße (1-2 min) wurde sie in Fragmente von ca. 1 bis $4 \mathrm{~Kb}$ zerkleinert. Nach einer Phenol-Chloroform-Extraktion und anschließender Ethanolfällung wurde die Lachsspermien-DNA in $1 \times$ TE-Puffer resuspendiert. Sie hatte eine Konzentration von $10 \mathrm{mg} / \mathrm{ml}$. Durch 20minütiges Kochen in einem Wasserbad wurde die DNA denaturiert. Anschließend wurde sie sofort auf Eis abgekühlt, um ein Renaturieren der DNA zu verhindern. Nach dem Aliquotieren wurde die Lachsspermien-DNA bei $-20^{\circ} \mathrm{C}$ aufbewahrt. Vor dem Gebrauch wurde sie ein zweites Mal durch Erhitzen (15 min) denaturiert und bis zur Verwendung auf Eis gehalten. 


\subsubsection{Transformation von pGBT9-Prm3 im kleinen Ansatz}

Es wurden $300 \mathrm{ml}$ YPD- Nährlösung mit $25 \mathrm{ml}$ einer Übernachtkultur des Hefestamms CG-1945 beimpft und $3 \mathrm{~h}$ bei $30^{\circ} \mathrm{C}$ inkubiert, wodurch eine OD 600 von 1,8 erzielt wurde. Nach Zellernte und Waschen mit sterilem Wasser wurde das Pellet in $1.5 \mathrm{ml}$ TE/Lithiumacetat-Lösung suspendiert. Für den Transformationsansatz wurden $10 \mu \mathrm{g}$ DNA mit $100 \mu \mathrm{g}$ hitzedenaturierter Lachsspermien-DNA-Lösung und $100 \mu \mathrm{l}$ Suspension der kompetenten Hefezellen vermischt, anschließend mit $600 \mu 1$ frisch angesetzter PEG/Lithiumacetat/TE-Lösung versetzt und für $30 \mathrm{~min}$ bei $30^{\circ} \mathrm{C}$ geschüttelt. Nach Zusatz von $70 \mu \mathrm{l}$ DMSO erfolgte ein Hitzeschock bei $42^{\circ} \mathrm{C}$ für $15 \mathrm{~min}$. Die so behandelten Zellen wurden auf Eis abgekühlt, pelletiert und in 0,5 ml TE-Puffer suspendiert. Von dieser Suspension wurden $100 \mu \mathrm{l}$ auf einem SD/-Trp- Selektivnährboden ausgestrichen und bei $30^{\circ} \mathrm{C}$ für 3-4 Tage inkubiert. Dieser Nährboden läßt nur Zellen wachsen, die durch Aufnahme des pGBT9 Plasmids Trp-autotroph geworden sind.

\subsubsection{Transformation der pGAD10/ cDNA-Bibliothek im großen Ansatz}

Die auf dem SD/-TRP-Nährboden herangewachsenen transformierten Hefezellen (CG-1945pGBT9/Prm3) wurden in der gleichen Weise kompetent gemacht wie im kleinen Ansatz, jedoch ist hier für die Transformation der cDNA-Bank das präparierte Volumen an Zellsuspension (ca. 2,2 ml) komplett verwendet worden.

Es wurden $100 \mu \mathrm{g}$ Plasmid-DNA eingesetzt, weil bei diesem Verhältnis von Zellen zu transformierter DNA-Menge die Transformationseffizienz in Vorversuchen einen Maximalwert erreicht hatte. Analog sind die Mengen der übrigen Komponenten des Transformationsansatzes erhöht worden.

Nach der Transformation wurden die Zellen zunächst $1 \mathrm{~h}$ bei $30^{\circ} \mathrm{C}$ in $14 \mathrm{ml} \mathrm{YPD-Nährlösung}$ inkubiert, danach in TE-Puffer gewaschen und schließlich in $6 \mathrm{ml}$ desselben Puffers resuspendiert, bevor sie in Volumenanteilen von $300 \mu \mathrm{l}$ auf $20 \mathrm{SD} /$-TRP-LEU-HISSelektivnährböden ausgestrichen und bei $30^{\circ} \mathrm{C}$ inkubiert wurden. Zur Kontrolle wurde $1 \mu 1$ der Transformationsmischung auf SD/-LEU- und auf SD/-LEU-TRP-Selektivnährböden ausgestrichen. 


\subsubsection{Selektion relevanter Transformanten}

Durch die Selektion sollten Transformanten identifiziert werden, in denen das DNABD/Prm3-Fusionsprotein mit einem AD-Fusionsprotein der Bibliothek interagiert. Da der verwendete Hefestamm CG-1945 zwei Reportergene (HIS3 und lacZ) besitzt, die beide unter der Kontrolle des GAL4-Transkriptionsaktivators stehen, jedoch verschiedene MinimalPromotoren haben, ist eine Doppelselektion der erhaltenen Cotransformanten möglich.

Das His-Gen verleiht eine Histidin-Autotrophie. Doppel-Transformanten können somit auf SD/-Leu-Trp-His-Nährböden wachsen. Zusätzlich sollten die His3 positiven-Klone eine $\beta$-Galaktosidase-Aktivität besitzen.

\subsection{7 $\beta$-Galaktosidase-Filter-Assay}

Für den $\beta$-Galaktosidase-Filter-Test, der die Expression des lacZ-Gens bzw. die Aktivität der $\beta$-Galaktosidase testet, wurden die auf SD/-LEU-TRP-His-Nährböden ausgestrichenen Kolonien mit einem sterilen Filterpapier von der Platte abgehoben und die Hefezellen durch dreimaliges Einfrieren des Filterspapiers in flüssigem Stickstoff und Auftauen bei RT permeabilisiert. Danach wurde der Filter auf einen zweiten Filter gelegt, der zuvor mit frisch angesetzer Z-Puffer/X-Gal-Lösung getränkt worden war, und bei $30^{\circ} \mathrm{C}$ inkubiert. Sofern eine Aktivierung des lacZ-Gens in diesen Zellen erfolgt, setzt die synthetisierte $\beta$-Galaktosidase das farblose Substrat X-Gal in ein blaues Produkt um.

\subsubsection{Verifikation positiver Klone durch Erzeugung von Segreganten}

Bei in der Selektion erhaltenen Klonen beruht die Aktivierung der Reportergene nicht auf einer Interaktion der beiden Fusionsproteine, sondern wird allein durch das AD-Fusionsprotein hervorgerufen. Dies sind falsch positive Klone. Deshalb wurden durch Elimination des DNA-BD-Plasmids (pGBT9-Prm3) Klone erzeugt, die nur noch das AD-Plasmid (pGAD10/cDNA-Klon) trugen. Dies wurde erreicht, indem die Klone zunächst einen Tag in SD-Leu-Nährlösung angezogen und anschließend (in einer $10^{-4}$-Verdünnung) auf SD/-Leu und zur Kontrolle auch auf SD/-Leu-Trp- Nährboden ausgestrichen wurden. Um Segreganten zu identifizieren, wurden daraufhin einzelne Kolonien vom SD/-Leu-Nährboden 
auf markierte Bereiche eines frischen SD/-Leu- und eines SD/-Leu-Trp-Nährbodens übertragen. Klone, die nur auf dem SD/-Leu-Nährboden heranwuchsen, enthielten lediglich das AD-Plasmid. Diese Klone wurden dann auf SD-Leu-His-Selektivnährböden ausgestrichen. Bei positiven Kandidaten durfte kein Wachstum auf diesen Platten erfolgen.

\subsubsection{Isolierung des AD-Plasmids aus Hefezellen und Klon-Analyse}

Nachdem die Interaktion eines AD-Fusionsproteins mit Prm3 durch die oben beschriebenen Verfahren bestätigt worden war, wurde das entsprechende AD-Plasmid (pGAD10) aus den Hefezellen isoliert. Dafür wurden die hergestellten Segreganten (2.26.8) herangezogen. Zwei ml SD-Leu-Selektivnährmedium wurde mit einer entsprechenden Kolonie angeimpft und üN bei $30^{\circ} \mathrm{C}$ und intensivem Schütteln inkubiert. Am nächsten Tag wurde $1,5 \mathrm{ml}$ in ein Reaktionsgefäß (Eppendorf) überführt und für $5 \mathrm{~s}$ bei $12000 \mathrm{x}$ g bei RT zentrifugiert (Eppendorf-Zentrifuge). Der Überstand wurde dekantiert und das Pellet in $200 \mu$ l Lyse-Puffer für Hefen resuspendiert. Anschließend wurden $200 \mu \mathrm{l}$ Phenol/Chloroform (1:1) sowie $0.3 \mathrm{~g}$ Glasperlen (Sigma) hinzugegeben und 2 min intensiv gevortext. Danach wurde der Ansatz zen-trifugiert (5 min, $12000 \mathrm{x}$ g, RT) und mit 2,5 Vol Ethanol und 1/10 Vol $3 \mathrm{M} \mathrm{NaAc}, \mathrm{pH}$ 5.2, gefällt, in 70\%igem Ethanol gewaschen und in $50 \mu 1 \mathrm{H}_{2} \mathrm{O}$ suspendiert. Anschließend wurde die isolierte Plasmid-DNA als Template in einer PCR Reaktion verwendet, unter Verwendung von zwei flankierenden vektorspezifischen Primern (Y2H2 und Y2HAD3). Das Amplifikat wurde in den pGEM-T-Vektor (Promega) einkloniert. Nach einer MiniPräparation sind die darin enthaltenen cDNA-Klone in beide Richtungen mit den plasmidspezifischen Primern SP6 und T7 sequenziert und anschließend mit dem BLASTProgramm (Altschul et al., 1990) analysiert worden.

\subsubsection{Hefe, ,Mating“6}

Der erste Durchgang des YTH-Screenings (Transformation der pGAD10-Bank in Prm3pGBT9-Zellen) brachte keine befriedigende Resultate, es wurden keine positiven Klone gefunden. Für das zweite Screening waren eine prätransformierte MATCHMAKER-TestiscDNA-Bank (Clontech) benutzt. In diesem System wurden die Testis-cDNAs in den Vektor pACT2 kloniert und in den Y187-MAT $\alpha$-Hefestamm prätransformiert. 
Das „Bait“-Protein (Prm3) wurde in den AH109-MATa Hefestamm transformiert, der einen geeignete „Mating“-Partner für den Stamm Y187-MAT $\alpha$ darstellt. Dieser Stamm bietet außer dem HIS3-Reporter zwei weitere Reporter-Gene: ADE2 (Adenin), als auch MEL1, das für $\alpha$ Galaktosidase kodiert. $\alpha$-Galaktosidase bietet eine einfache screening Möglichkeit, dieses Enzym wird aus den Zellen sekretiert, kann also dierekt auf X- $\alpha$-Gal Platten detektiert werden. Die positiven Hefeklone färben sich ohne zusätzlichen Indikationsmethoden blau. Alle vier Reporter-Gene sind unter Kontrolle der getrennten GAL4-Aktivierung-Sequenzen (UAS) und TATA-boxen, was eine sehr stringente Selektion bietet.

Die Prm3-pGBT9-AH109-Zellen wurden mit den Y187-Zellen der prätransformierten TestisBibliothek fusioniert.

Die, nach 22stündiger Inkubation entstehenden diploide Zellen, wurden auf Selektivnährböden ausgestrichen und bei $30^{\circ} \mathrm{C}$ inkubiert. Die weitere Selektion verlief wie in 2.26.8 und 2.26.9 beschrieben.

\subsection{Mammalian-Two-Hybrid System}

(Tsan et al., 1997)

Dem Mammalian-Two-Hybrid-System liegt prinzipiell die gleiche Verfahrensweise zugrunde wie dem Yeast-Two-Hybrid-System: Ein Transkriptionsaktivator, dessen DNA-Bindungsund Aktivierungsdomäne zuvor durch Manipulation getrennt wurde, wird durch die Interaktion zweier Proteine funktionell rekonstituiert und bewirkt die Transkription eines Reportergens, wodurch die Interaktion detektierbar wird. Im Gegensatz zum Hefesystem, bei dem man sich des physiologischen Transkriptionsaktivators GAL4 bedient, wird in den Säugetierzellen ein künstlich zusammengesetzter Transaktivator benutzt, der zum einen aus der DNA-Bindungsdomäne des GAL4-Proteins der Hefe und zum anderen aus der Transaktivierungsdomäne des VP16-Proteins des Herpes simplex-Virus besteht. Darüber hinaus besitzen Säugertierzellen kein Gen, das als Reportergen geeignet ist, so daß zu diesem Zweck das Luciferase-Gen, integriert in ein Plasmid, kotransfiziert werden muss. Dieses steht unter der Kontrolle der UAS-Sequenz, der Erkennungsstelle der GAL4-DNABindungsdomäne (Abb. 2). 


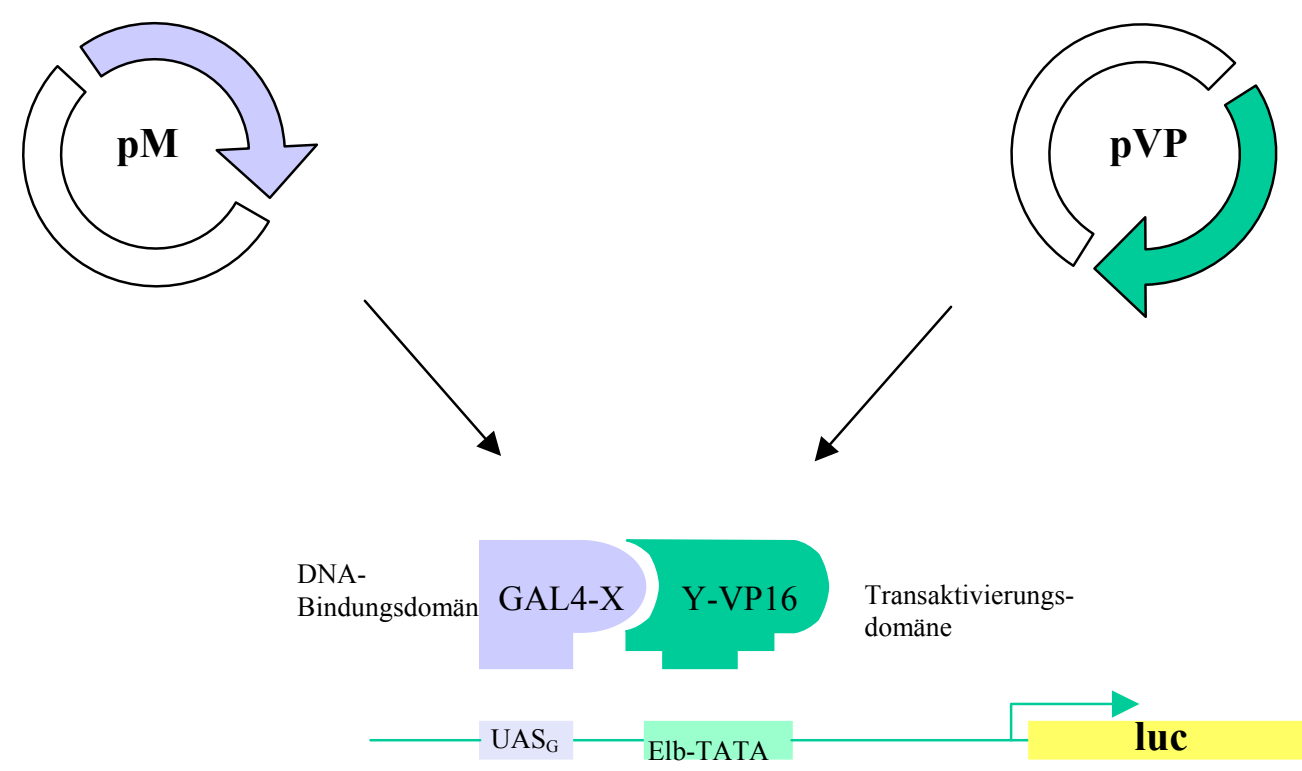

Abb. 2.2: Schematische Darstellung des Mammalian-Two-Hybrid-Systems. Der Transkriptionsaktivator besteht aus der GAL4 DNA-BD der Hefe sowie aus der Aktivierungsdomäne des VP16-Proteins des Herpes simplex Virus. Eine Interaktion zwischen Prm3 und einem Interaktionspartner rekonstituiert den Transkriptionsaktivator und aktiviert die Transkription des Luciferase-Reportergens, das sich stromabwärts der GAL4 Erkennungsstelle (UAS) und des verkürzten Promotors des Adenovirus E1b-Gens befindet.

Das Mammalian-Two-Hybrid System wurde angewendet, um Protein-Interaktionen, die im Yeast-Two-Hybrid-System identifiziert worden waren, zu verifizieren. Ein Screening auf unbekannte Proteine ist hier nicht möglich. Für die Transfektion mussten sowohl das Prm3 als auch die im Yeast-Two-Hybrid-System isolierten potentiellen Interaktionspartner in Säugetier-Expressionsvektoren umkloniert werden. Dabei wurde Prm3 hinter die VP16Aktivierungsdomäne und hinter die GAL4-DNA-Bindungsdomäne rekombiniert. Sämtliche Interaktionspartner wurden auch in pVP- und pM-Vektoren integriert.

\subsubsection{Luminometrische Messungen}

Zur Durchführung des Mammalian-Two-Hybrid-Systems wurden Maus NIH3T3Fibroblastenzellen mit den pVPFlag-Fusionskonstrukten und pM2- und GAL4-Luc transient transfiziert. Darüber hinaus wurden die Konstrukte GAL4/STAT2 sowie pM1/BR-304 und pVP-HA/B202-NB als Positivkontrollen verwendet. Das Konstrukt GAL4/STAT4 erlaubt die 
Expression eines funktionellen Transaktivators, bestehend aus der GAL4-DNABindungsdomäne und der STAT2-Aktivierungsdomäne. Bei der Plasmidkombination pM1/BR304 und pVP-HA/B202-NB interagieren die beiden Polypeptide BR-304 (Teil des BRCA1-Proteins) und B202-NB (Teil des BARD1-Proteins) und führen so DNABindungsdomäne (GAL4-DNA-BD in pM1) und Aktivierungsdomäne (Vp16 in PVP-HA) zusammen, wodurch das Luciferase-Reportergen aktiviert wird (Wu et al., 1996). Als Negativkontrollen wurden leere Vektoren transfiziert bzw. ein leerer Vektor in Kombination mit dem komplementären Partner mit Insert. Jede Transfektion wurde in drei Bestimmungen in 12-well Platten ausgeführt. Es wurden 60.000 Zellen pro well pipettiert und am folgenden Tag mit einer Mischung der beiden Bindungspartner (pM und pVP16 Derivate, Gal-4-luc, jeweils $0,4 \mu \mathrm{g})$ und CMV $B-G a l(0,1 \mu \mathrm{g})$ transfiziert.

Im Mammalian-Two-Hybrid-System, in dem das Luciferase-Gen als Reportergen verwendet wird, ist die Interaktion zweier Proteine anhand der Luciferase-Aktivität quantitativ nachweisbar. Durch Messung der ß-Galactosidase-Aktivität konnten die Luciferase-Aktivitäten verschiedener Ansätze trotz etwaiger Abweichungen der Transfektionseffizienz verglichen werden.

\subsection{Erzeugung transgener Mäuse}

Für die Erzeugung der pTRE-Prm3 transgenen Mäuse wurde die Mikroinjektion, d.h. die Einführung der DNA mit Hilfe einer feinen Glaskapillare in den männlichen Vorkern, verwendet. Nach der Superovulation wurden die befruchteten Eizellen isoliert und die DNA wurde in den männlichen Vorkern mikroinjiziert. Die überlebenden mikroinjizierten Oozyten wurden anschließend in die Eileiter eines scheinträchtigen Empfängertieres retransferiert. Die geborenen Mäuse wurden zum Nachweis der Integration der Fremd-DNA analysiert. Die Genotypisierung erfolgte mittels PCR unter Verwendung sequenzspezifischer Primer bzw. mittels genomischer Dot Blots.

Die Erzeugung transgener Mäuse erfolgte über den „Transgenen Service“ des Max-PlanckInstituts für experimentelle Medizin in Göttingen. Die Erzeugung transgener Mäuse wurde prinzipiell nach Hogan et al. (1986) durchgeführt. 


\subsubsection{Vorbereiten der DNA zur Mikroinjektion}

Laut Literatur (Brinster et al., 1985) integriert DNA in linearisierter Form am besten, die Beschaffenheit der Enden spielt dagegen für die Integrationseffizienz keine Rolle. Das Konstrukt enthaltende DNA-Fragment wurde über einen Verdau des Vektorrückgrats mit entsprechenden Restriktionsenzymen aus dem Plasmid freigesetzt und über ein Agarosegel (ohne EtBr) vom Vektorrückgrat getrennt. Da DNA-Mengen von $25 \mu \mathrm{g}$ verdaut wurden, wurden mehrere Taschen eines Gels beladen. Die äußeren Taschen erhielten dabei nur etwa 1/10 der DNA/Dye-Lösung. Nach dem Gellauf wurden diese Taschen und der DNALängenstandard ausgeschnitten und die Gelstücke im EtBr-Bad angefärbt. Nach dem Anfärben wurde das Gel zusammengesetzt und auf dem UV-Tisch die gesuchte Bande zwischen den angefärbten Bereichen ausgeschnitten. Die Elution der DNA erfolgte mit Glasmilch (siehe 2.10.3). Um nach der Gelelution jegliche verbliebenen Partikel zu entfernen, wurde das Eluat über kleine Mikrofilter (Fa. Millipore, Typ HY, 0,45 $\mu \mathrm{m}$ ) filtriert. Die Konzentration der DNA wurde über eine Anfärbung mit Etbr nach der Agarosegelelektrophorese bestimmt. Dazu wurden verdünnte Aliquots der DNA-Lösung aufgetragen und die Anfärbung mit der auf gleicher Höhe laufenden Bande eines Markers verglichen, die definierte DNA-Mengen enthielt. Zur Mikroinjektion wurde die Konzentration auf etwa $5 \mathrm{ng} / \mu 1$ mit 1 x Mikroinjektionspuffer verdünnt.

Alle weiteren Schritte wurden im MPI für experimentelle Medizin, Göttingen, durchgeführt.

\subsubsection{Zucht der Mäuse mit Doxycyklinabhängigem Transaktivator}

Die CMV/Tet-Off und Act-45/Tet-Off Tiere exprimieren den doxycyclinabhängigen tTA. Dieser ist konstitutiv aktiv. Um eine Suppression seiner Aktivität zu erreichen, wurde den Tieren sieben bis zehn Tage Dox in einer Konzentration von $2 \mathrm{mg} / \mathrm{ml}$ in das Trinkwasser gegeben (um die Lösung schmackhaft zu machen, wurde 1\% (w/v) Saccharose zugesetzt). Die Dox-Lösung wurde alle drei Tage erneuert. Laut Literaturangaben (Kistner et al., 1996) wird die volle Expression des Reportergens auf diese Weise nach $24 \mathrm{~h}$ in den meisten Organen induziert. Nach mindestens sieben Tagen Induktion wurden die Tiere abgetötet und die Gewebe wurden für die Protein-Isolierung verwendet. 


\section{Ergebnisse}

\subsection{Untersuchungen zur Expression des Prm3-Gens bei der Maus}

Zu Beginn der Arbeit war das Expressionsmuster des Prm3-Gens der Ratte bekannt. Dieses wird erst postnatal ab Tag 23 testisspezifisch exprimiert. Nach Hybridisierung von GesamtRNA aus verschiedenen Spermatogenese-Stadien mit der Prm3-Sonde erhielt man ein Signal in runden und elongierenden Spermatiden. Prm3-Expression wurde auch im Testis weiterer Spezies nachgewiesen: Pferd, Ziege, Pavian, Rind, Mensch und Maus. Bei Pferd und Mensch ist nur eine geringe Prm3-Expression nachweisbar (Schlüter, 1996).

Im Rahmen der vorliegenden Arbeit wurde das Prm3-Gen der Maus charakterisiert. Zunächst wurde die Expression des Maus Prm3-Gens mit Hilfe von Northern Blot-Experimenten untersucht.

\subsubsection{Organspezifische Expression des Prm3-Gens}

Durch Northern-Blots sollten die Transkriptgröße und das Expressionsmuster des Maus Prm3-Gens untersucht werden. Gesamt-RNA (je $20 \mu \mathrm{g}$ ) aus verschiedenen Organen der adulten Maus (Thymus, Testis, Ovar, Pankreas, Lymphknoten, Herz, Muskel, Epididymis, Lunge, Gehirn, Niere, Uterus, Darm und Milz) wurde nach Elektrophorese und Blot mit der radioaktiv markierten Prm3-Sonde (2.8.4) üN hybridisiert (2.16). Nach 20stündiger Exposition des Autoradiogramms zeigte sich ein Hybridisierungs-Signal für ein $330 \mathrm{Bp}$ großes testisspezifisches Transkript. In der RNA aus allen weiteren Organen konnten auch nach zweiwöchiger Exposition keine Prm3-Transkripte nachgewiesen werden.

Um die Integrität und Menge der untersuchten RNAs zu überprüfen, wurde das Gel mit EtBr angefärbt. Die Färbung des Gels mit EtBr vor dem Blot belegt die Integrität und gleichmäßige Beladung des Gels. 

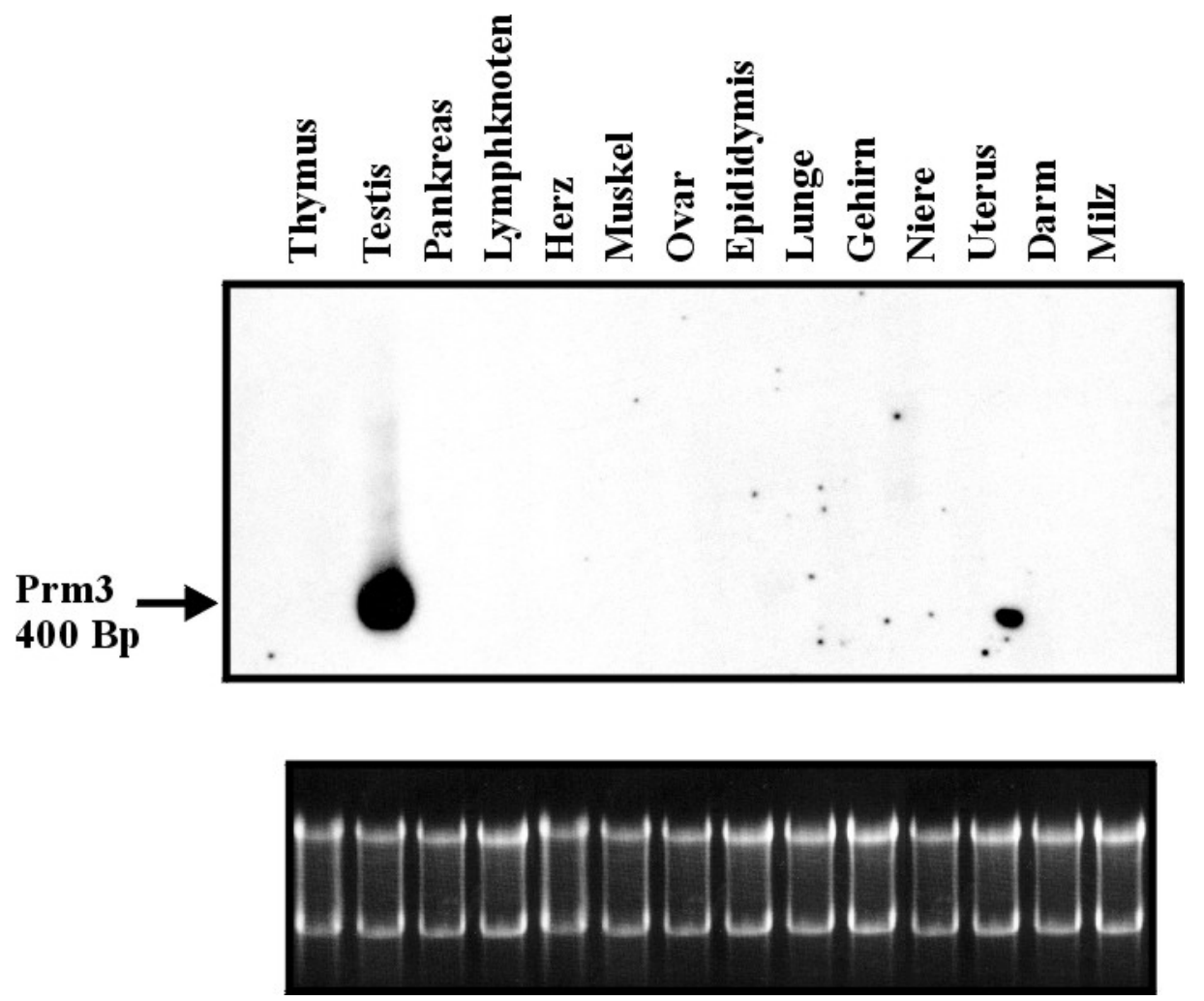

Abb. 3.1: Northern-Blot Analyse des Prm3-Gens mit RNA aus verschiedenen Mausgeweben.

Es wurden je $20 \mu \mathrm{g}$ Gesamt-RNA aus Thymus, Testis, Pankreas, Lymphknoten, Herz, Muskel, Ovar, Epididymis, Lunge, Gehirn, Niere, Uterus, Darm und Milz auf einem 1\%igen denaturierenden Agarosegel aufgetrennt und auf Nitrocellulose geblottet. Eine Expression des Prm3-Gens ist ausschließlich im Testis zu beobachten. Zur Kontrolle der RNA-Proben wurde das Gel mit EtBr angefärbt, um die 28S- und 18S-rRNAs sichtbar zu machen.

\subsubsection{Expression des Prm3-Gens während der Testis-Entwicklung der Maus}

Um zu untersuchen, in welchen Stadien der Testis-Entwicklung das Prm3-Gen aktiv ist, wurden Northern-Blot Hybridisierungen mit Gesamt-RNA aus Testis von 15 bis 25 Tage alten und adulten Mäusen durchgeführt.

Das Prm3-Transkript ist zuerst am Tag 20 nachweisbar. Die Intensität des Signals steigt bis Tag 25 und bleibt auf diesem Niveau während der weiteren Entwicklung. Um die Integrität und Menge der aufgetragenen RNAs zu überprüfen, wurde der Northern-Blot mit der cDNASonde des humanen Elongationsfaktors EF-2 nachhybridisiert. 


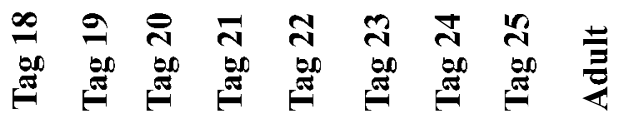

A

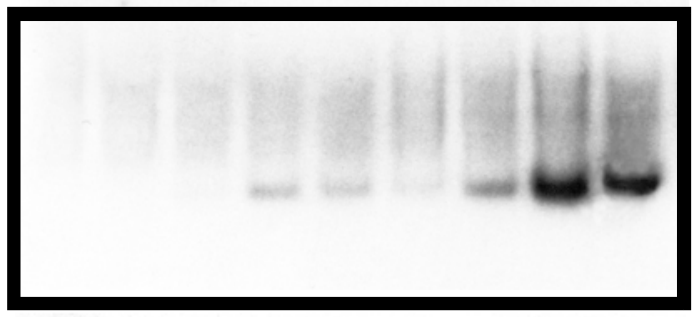

Prm3

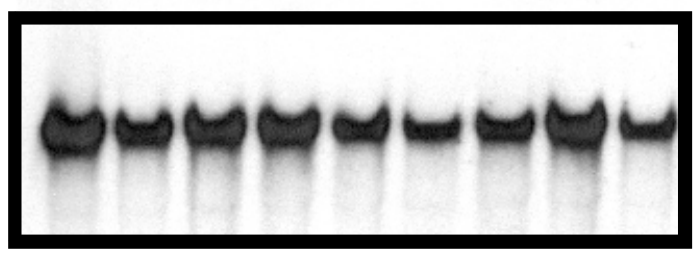

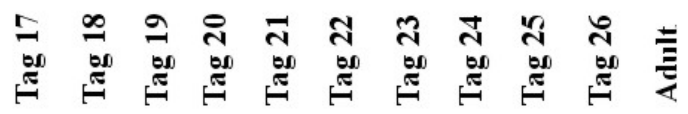

B

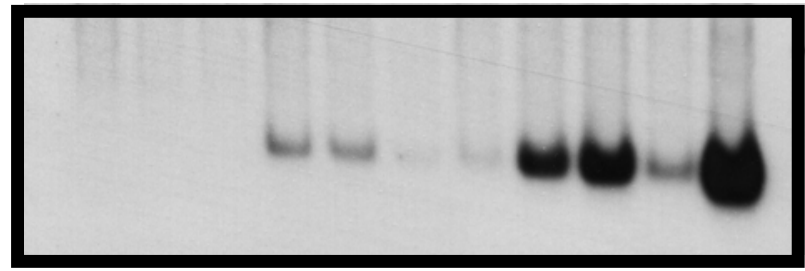

Prm3

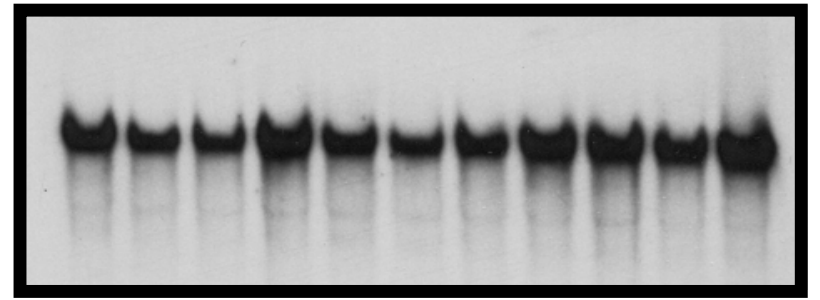

HEF

Abb. 3.2: Northern-Blot Analyse der Maus Prm3-Expression während der Testis-Entwicklung.

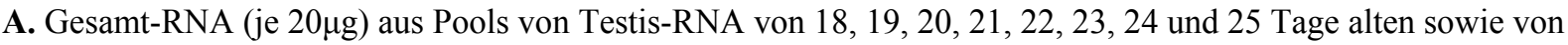
adulten Mäusen wurde nach denaturierender Gelelektrophorese und Blot auf Nitrocellulose mit der Prm3-Sonde hybridisiert. Die Expositionszeit des Autoradiogramms betrug 48 Stunden. Das Prm3-Signal ist ab Tag 20

sichtbar. Am Tag 23 sinkt die Prm3-Expression. Die Integrität und Menge der aufgetragenen RNAs wurde durch Nachhybridisierung mit der Sonde des humanen Elongationsfaktors EF-2 überprüft.

B. Unabhängige Wiederholung des Experiments. 
Zwischen den Tagen 22 und 23 zeigte sich eine Abnahme des Signals. Am Tag darauf ist das Prm3-Signal wieder stärker. Dieses Phänomen wurde reproduzierbar beobachtet. Dies ist gezeigt in Abb. 3.2A und in der unabhängigen Wiederholung 3.2B.

Für diese Experimente wurde RNA aus Testes von jeweils mindestens 6 Tieren gepoolt.

\subsection{Analyse der Prm3-Expression auf Protein-Ebene}

In Western-Blot Experimenten wurde die Prm3-Expression auf Proteinebene in verschiedenen Mausgeweben, im Rahmen der Testis-Entwicklung und in Testes verschiedener MausMutanten mit Störungen der Keimzelldifferenzierung untersucht.

Ein polyklonales Antiserum gegen ein Prm3-GST-Fusionsprotein wurde von Dr. Kämper zur Verfügung gestellt. In Vorversuchen wurde die optimale Verdünnung des Serums zur Verwendung im Western-Blot mit 1:100 bestimmt. Um die Vergleichbarkeit der aufgetragenen Proteinmengen $\mathrm{zu}$ demonstrieren, wurden alle Western-Blot-Membrane mit einem anti- $\alpha$-Tubulin-AK (1:2.000) nachgefärbt. Als Zweitantikörper dienten AP-gekoppelte Ziege-anti-Kaninchen (zur Detektion des Prm3-Antiserums) bzw. Ziege-anti-Maus (zur Detektion des anti-Tubulin-AKs) IgGs, jeweils 1:15.000 verdünnt. Die Entwicklung der Blots erfolgte mit NBT/BCIP.

Protein-Extrakte (je $100 \mu \mathrm{g}$ ) aus verschiedenen Organen der adulten Maus (siehe 2.19.3) Leber, Niere, Milz, Thymus, Testis, Gehirn - wurden in einer SDS-PAGE (2.20.1) aufgetrennt, auf Nitrocellulose geblottet (2.22.2.1) und mit dem Prm3-Antiserum detektiert (2.22.2.3). Eine Bande bei $14 \mathrm{kDa}$ ist ausschließlich im Testisextrakt nachweisbar (Abb. 3.3). Dieses Molekulargewicht entspricht dem aus dem offenen Leserahmen der Prm3-cDNA zu erwartenden Wert. 

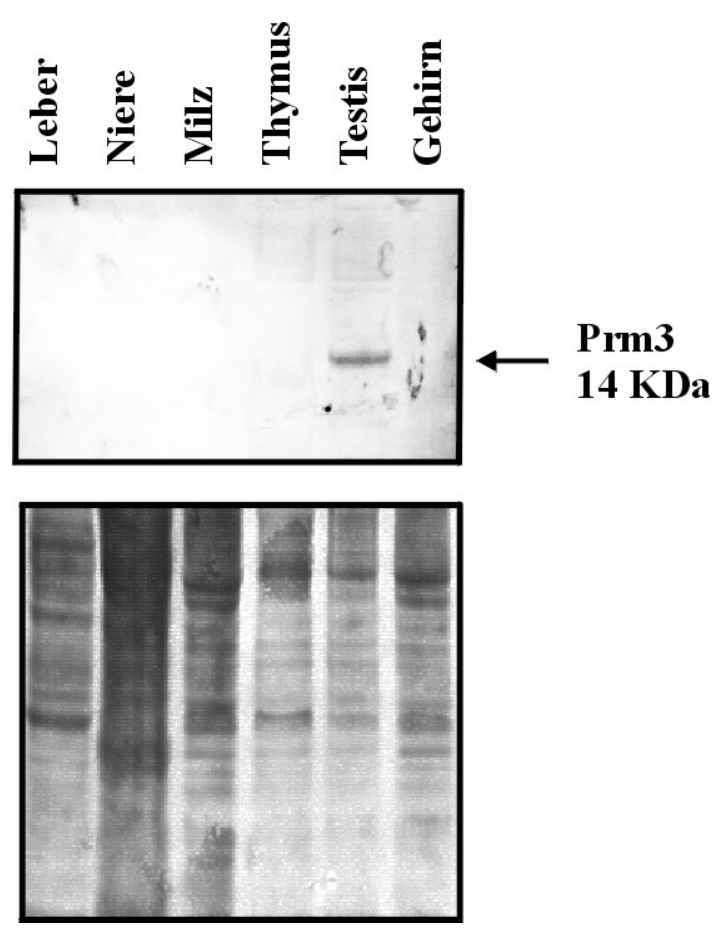

Abb. 3.3: Darstellung der testisspezifischen Prm3-Expression in der Maus im Western-Blot

Es wurden je $100 \mu \mathrm{g}$ Gesamt-Protein aus Leber, Niere, Milz, Thymus, Testis und Gehirn in einer 12\% SDSPAGE aufgetrennt und auf Nitrocellulose geblottet. Die Detektion des Antigens erfolgte mit 1:100 verdünntem Prm3-Antiserum und AP-gekoppeltem Ziege-anti-Kaninchen Zweitantikörper (1:15.000). Das Prm3-Protein ist ausschließlich in Testis nachzuweisen. Die Anfärbung des Gels mit Coomassie-Brilliant-Blau (unteres Bild) zeigt ähnliche Proteinmengen für jedes Gewebe.

Weiterhin wurde die Expression des Prm3-Proteins während der Testisentwicklung untersucht. Testesextrakte aus 24-30 Tage alten Mäusen wurden analysiert. Das Prm3-Protein konnte erst am Tag 25 beobachtet werden (Abb. 3.4).

Für die Untersuchung der Prm3-Expression bei verschiedenen Mutanten wurden jeweils $100 \mu \mathrm{g}$ Gesamt-Protein aus Testes der Mutanten W/W $\mathrm{v}, \mathrm{Tfm} / \mathrm{Y}$ olt/olt, qk/qk analysiert (Abb.3.5). Die W/Wv'-Mutante zeichnet sich durch das völlige Fehlen von Keimzellen aus. Bei olt/olt- und qk/qk-Mutanten läuft die Spermatogenese bis zu haploiden Spermatiden ab. Bei der Tfm/Y-Maus differenzieren die Spermatogonien bis zur meiotischem Prophase. Es konnte ein Prm3-Signal bei olt/olt und qk/qk-Mutanten nachgewiesen werden, nicht jedoch bei $\mathrm{Tfm} / \mathrm{Y}$ und $\mathrm{W} / \mathrm{W}^{\mathrm{V}}$ Mäusen. 


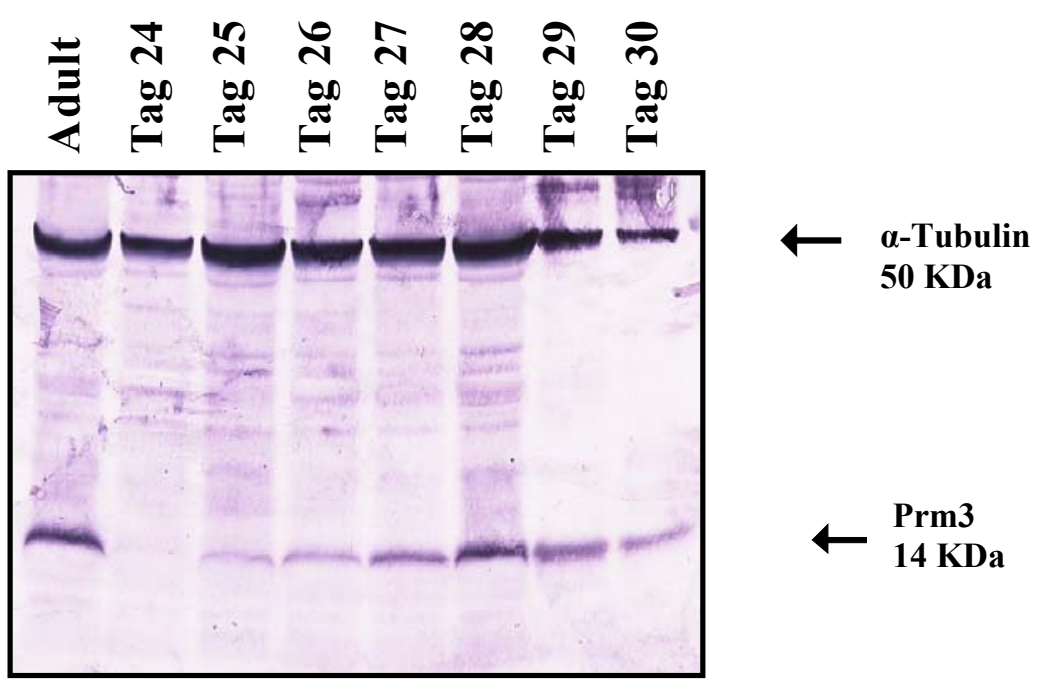

Abb. 3.4: Western-Blot Analyse der Prm3-Protein-Expression in der postnatalen Mausentwicklung.

Testis-Proteinextrakte von 24-30 Tage alten Mäusen wurden in einem SDS-PAGE aufgetrennt und auf Nitrocellulosemembran transferriert. Die Detektion erfolgte mit 1:100 verdünntem Prm3-Antiserum und APgekoppeltem Ziege-anti-Kaninchen Zweitantikörper (1:15.000). Das Prm3-Protein wird zuerst am Tag 25 detektiert. Zur Kontrolle der Protein-Proben wurde eine Immundetektion mit anti- $\alpha$-Tubulin (1:2000) und APgekoppeltem Ziege-anti-Maus Zweitantikörper (1:15.000) durchgeführt.

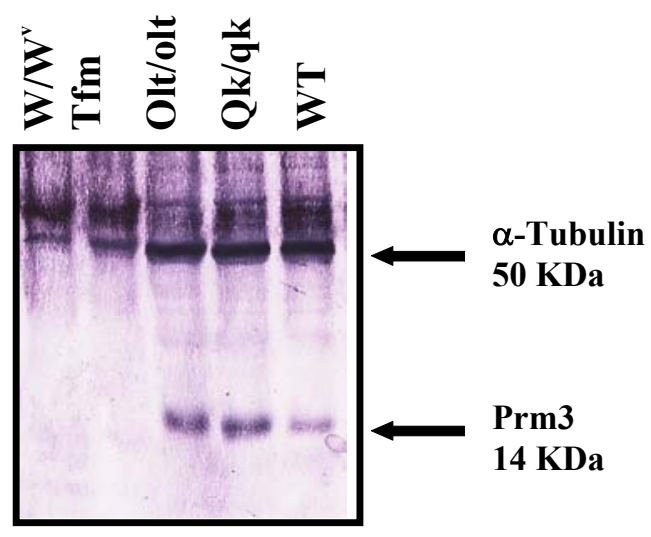

Abb. 3.5: Western-Blot Analyse der Expression des Prm3-Gens bei verschiedenen Maus-Mutanten mit Keimzelldefekten.

Jeweils $100 \mu \mathrm{g}$ Gesamt-Protein aus dem Testis verschiedener Maus-Mutanten (W/W, $\mathrm{v}$ Tfm/Y olt/olt, qk/qk) sowie von Wildtyp-Maus wurde mit Prm3-Antiserum (1:100) und AP-gekoppeltem Ziege-anti-Kaninchen Zweitantikörper (1:15.000) immunologisch detektiert. Zur Kontrolle der Protein-Proben wurde eine Immundetektion mit anti- $\alpha$-Tubulin $(1: 2.000)$ und AP-gekoppeltem Ziege-anti-Maus Zweitantikörper durchgeführt.

Um zu untersuchen, ob auch in den letzten Stadien der Spermien-Entwicklung Prm3-Protein anwesend ist, wurden sowohl Epididymis als auch Spermien-Extrakte getestet. Es wurde kein 
Prm3-Signal beobachtet (Abb. 3.6). Auch in menschlichem Testis-Gewebe konnte kein Signal für Prm3 detektiert werden (Abb. 3.6).

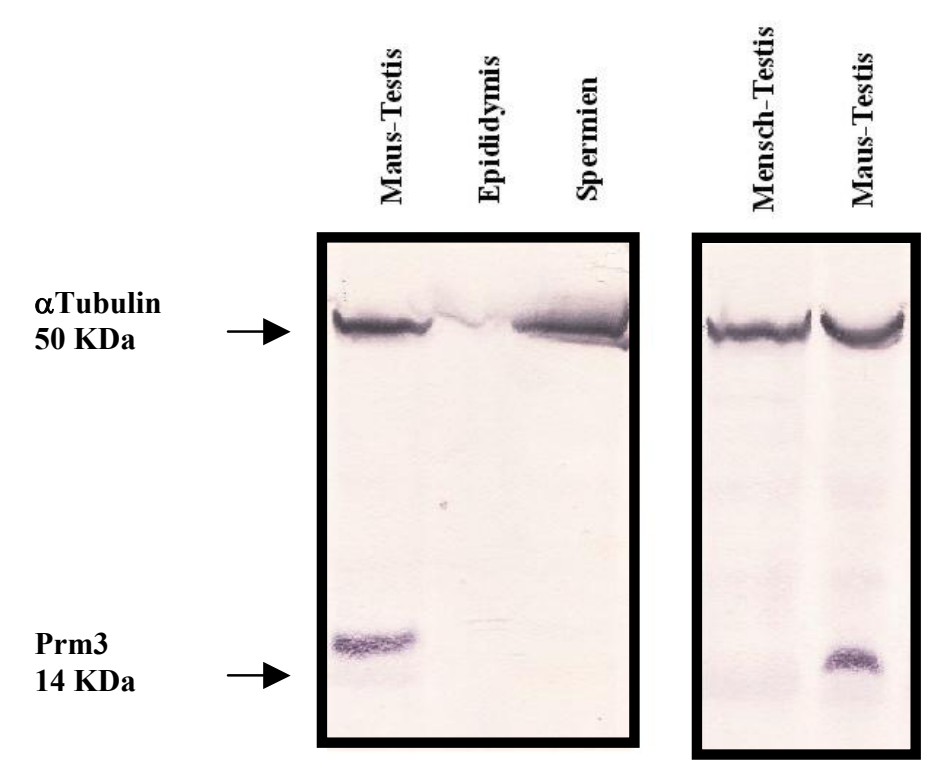

Abb. 3.6: Western-Blot Analyse der Expression des Prm3-Gens in Epididymis, Spermien-Extrakt der Maus und dem menschlichen Testis.

Jeweils $100 \mu \mathrm{g}$ Gesamt-Protein aus dem Epididymis (1) und Spermien (2) der Maus, Testis des Menschen (3) sowie von Wildtyp-Maus (WT) wurde mit Prm3-Antiserum (1:100) und AP-gekoppeltem Ziege-anti-Kaninchen Zweitantikörper (1:15000) immunologisch detektiert. Zur Kontrolle der Protein-Proben wurde eine Immundetektion mit anti- $\alpha$-Tubulin (1:2000) und AP-gekoppeltem Ziege-anti-Maus Zweitantikörper durchgeführt.

\subsection{Bestimmung des isoelektrischen Punktes des Prm3-Proteins.}

Die Prm3-cDNA codiert für ein saures, glutamat- und aspartatreiches Protein. Dies ist für ein Protein aus der Protamin-Familie sehr ungewöhnlich. Der saure Charakter des Prm3Moleküls sollte deshalb experimentell bestätigt werden. Hierfür wurde eine 2DElektrophorese mit nachfolgender Immunodetektion durchgeführt.

Die 2D-Elektrophorese wurde wie in Kapitel 2.20.2 beschrieben durchgeführt. Nach dem Transfer auf die Nitrocellulosemembran und immunologischer Detektion wurde ein spezifisches Signal im pH Bereich 4-5 sichtbar (Abb.3.7). Das Molekulargewicht des detektierten Signals lag auf der Höhe von $\sim 14 \mathrm{kDa}$. Dies entspricht dem Molekulargewicht 
des Prm3-Proteins. Zur Kontrolle wurde eine Außenspur des SDS-PAGE Gels mit Testisextrakt beladen. Das spezifische Prm3-Signal wurde auf gleiche Höhe sichtbar. Für diesen Versuch mußte affinitätsgereinigtes Antiserum benutzt werden.

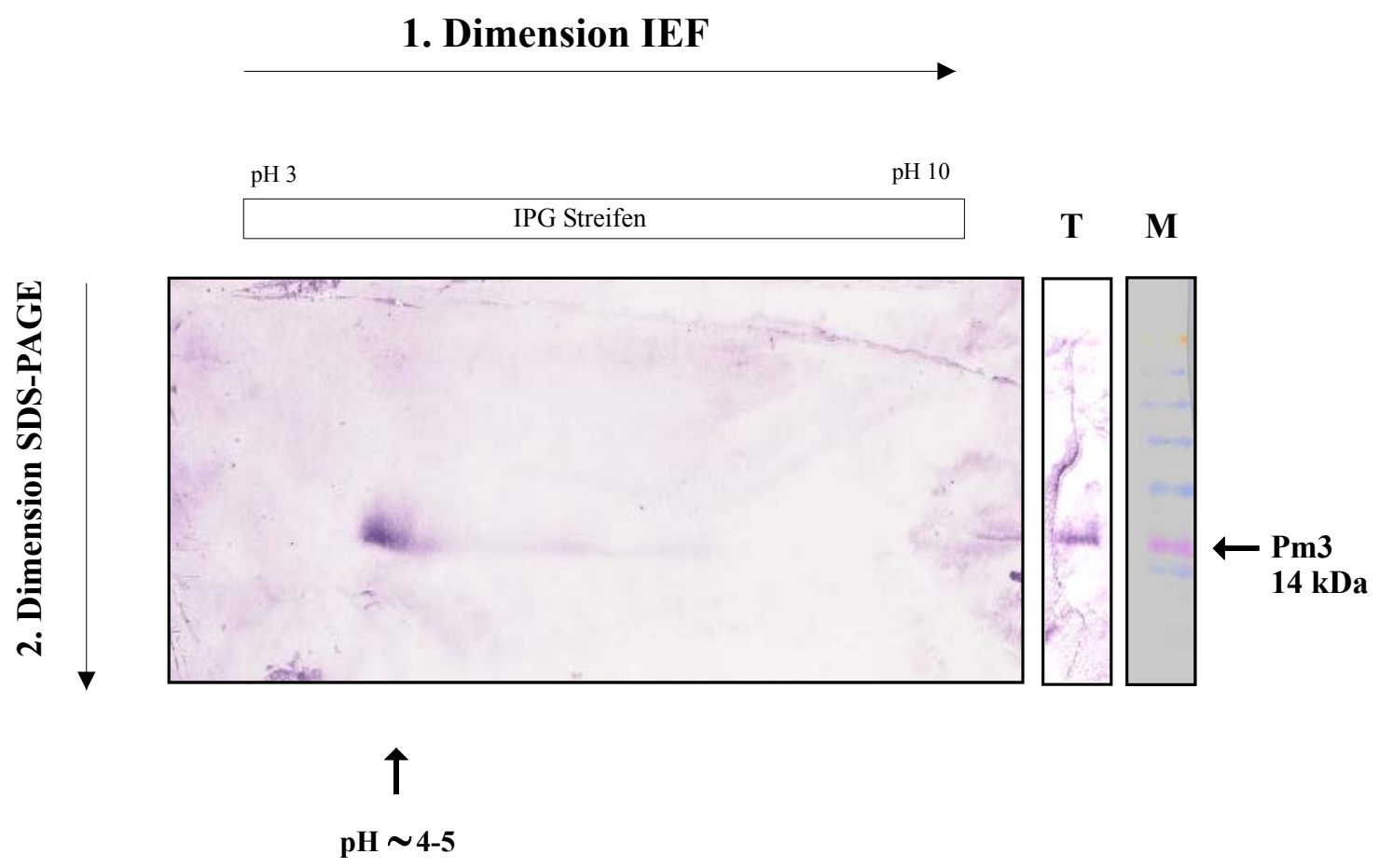

Abb. 3 .7: 2D-Elektrophorese von Maus Testisprotein und Immunodetektion von Prm3

Nach der isoelektrischen Fokussierung und SDS-PAGE wurden die Proteine auf Nitrocellulose transferriert und mit gereinigtem anti-Prm3 Antikörper detektiert. Das Signal befindet sich im pH Bereich 4-5 und bei $\sim 14$ kDa. Als Kontrolle wurde in der Außenspur der SDS-PAGE Testis-Gesamtprotein aufgetrennt (T). Die Größe der spezifischen Bande aus dem Testisextrakt entspricht der Größe des Signals nach dem 2D-Verfahren. M=Protein Marker

\subsection{Herstellung eines monospezifischen anti-Prm3-Antikörpers}

Das vorhandene Prm3-Antiserum (Kämper, 2001) konnte zwar in Western-BlotExperimenten verwendet werden, zeigte jedoch in immunohistochemischen Verfahren einen unakzeptablen Hintergrund. Deshalb wurde das Serum durch eine Affinitätschromatographie über GST-Prm3 aufgereinigt. 


\subsubsection{Herstellung des GST/Prm3-Fusionsproteins}

Ein Hefeklon zur Expression eines GST/Prm3-Fusionsproteins wurde von Dr. Kämper überlassen (Kämper, 2001). Anzucht des Stammes, Induktion und Aufreinigung des Proteins wurden wie in 2.21 beschrieben durchgeführt.

Die Abb. 3.8 zeigt Western-Blots für Aliquots der Waschfraktionen der GlutathionSepharose. $5 \mu$ jeder Fraktion wurden im Western-Blot analysiert. Bis zur dritten Elutionsfraktion konnte Fusionsprotein erhalten werden, dann nahm die Ausbeute deutlich ab. Die Ausbeute an rekombinantem Protein war insgesamt sehr gering. Im Durchschnitt wurden etwa 2-4 mg Fusionsprotein aus 41 Hefekultur isoliert.

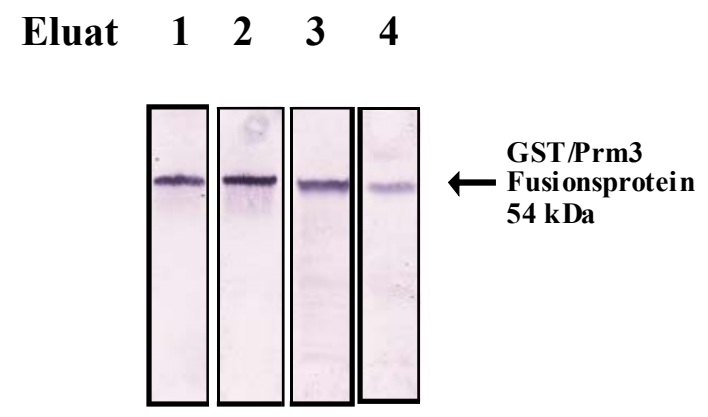

Abb. 3.8: Aufreinigung von rekombinantem Maus-Prm3 über Glutathion-Sepharose

Die Darstellung des Fusionsproteins GST-Prm3 ( 54 kDa) im Western-Blot erfolgte durch Detektion mit Prm3Antiserum. Aufgetragen sind je $5 \mu \mathrm{l}$ aus $1 \mathrm{ml}$ Eluat.

\subsubsection{Gewinnung von Antikörpern gegen das Maus Prm3-Protein}

Das aus dem Hefe-Rohextrakt gereinigte GST/Prm3-Protein konnte jetzt verwendet werden, um aus dem bereits vorhandenen Prm3-Antiserum monospezifische Antikörper aufzureinigen. Dies wurde mit zwei unterschiedlichen Methoden, dem Western-Blot-Verfahren und per Affinitätssäule, durchgeführt (2.22.1).

Die Abbildung 3.9 zeigt einen Vergleich der verschiedenen Antikörperpräparationen im Western-Blot. In den Spuren 2 und 3 wurde die Immundetektion mit gereinigtem Antikörper, in Spur 1 mit nichtgereinigtem Prm3-Antiserum durchgeführt. Es ist deutlich sichtbar, da $\beta$ die Spezifität der Detektion erhöht und der Hintergrund der Reaktion wesentlich reduziert wurde. 


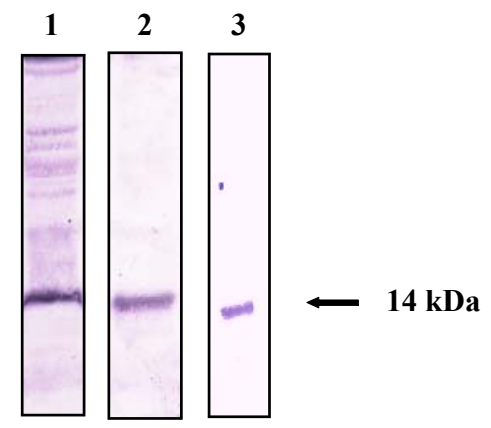

Abb. 3.9: Qualitätstest der gereinigten Antikörper.

Je Spur wurde $100 \mu \mathrm{g}$ Testis-Protein im SDS-PAGE aufgetrennt; Detektion mit nicht gereinigtem Antiserum (1), mit im Western-Blot-Verfahren aufgereinigtem (2) und mit Affinitätssäule aufgereinigtem Antikörper (3), alle Verdünnungen 1:100.

\subsection{Immunohistochemische Färbungen auf Testisschnitten}

Durch eine immunohistochemische Färbung sollte die zelluläre und subzelluläre Lokalisation des Prm3-Proteins im Testisgewebe bestimmt werden. Um eine Zuordnung der Signale zu den Entwicklungsstadien der Keimzelldifferenzierung zu ermöglichen, wurde parallel zur Immunodetektion eine Lektin-Färbung des Akrosoms (2.23.3) durchgeführt. Das Akrosom ist eine spermatiden- und spermienspezifische Struktur, die sich vom Golgi-Apparat ableitet und die lytischen Enzyme, die zur Durchdringung der Zona Pellucida nötig sind, enthält. Es ändert während der Spermienentwicklung seine Form in charakteristischer Weise, so da $\beta$ die entsprechenden Stadien leicht identifiziert werden können. Die Polysaccharide des Akrosoms lassen sich spezifisch mit Erdnußlektin anfärben. In Abb. 3.10 sind zwei Tubuli, einer mit runden, einer mit elongierenden Spermatiden dargestellt. Diese sind durch die Lektin-Färbung unterscheidbar: die Akrosomen der runden Spermatiden sind weniger gut entwickelt als die der elongierenden Spermatiden. Das Prm3-Signal kann ausschließlich in dem Tubulus mit elongierenden Spermatiden beobachtet werden. In Abb. 3.11 ist ein Tubulus mit elongierenden Spermatiden bei 600x Vergrößerung dargestellt. Das Prm3-Signal ist im inneren Bereich des Lumens, in dem sich elongierende Spermatiden befinden, sichtbar. 
A
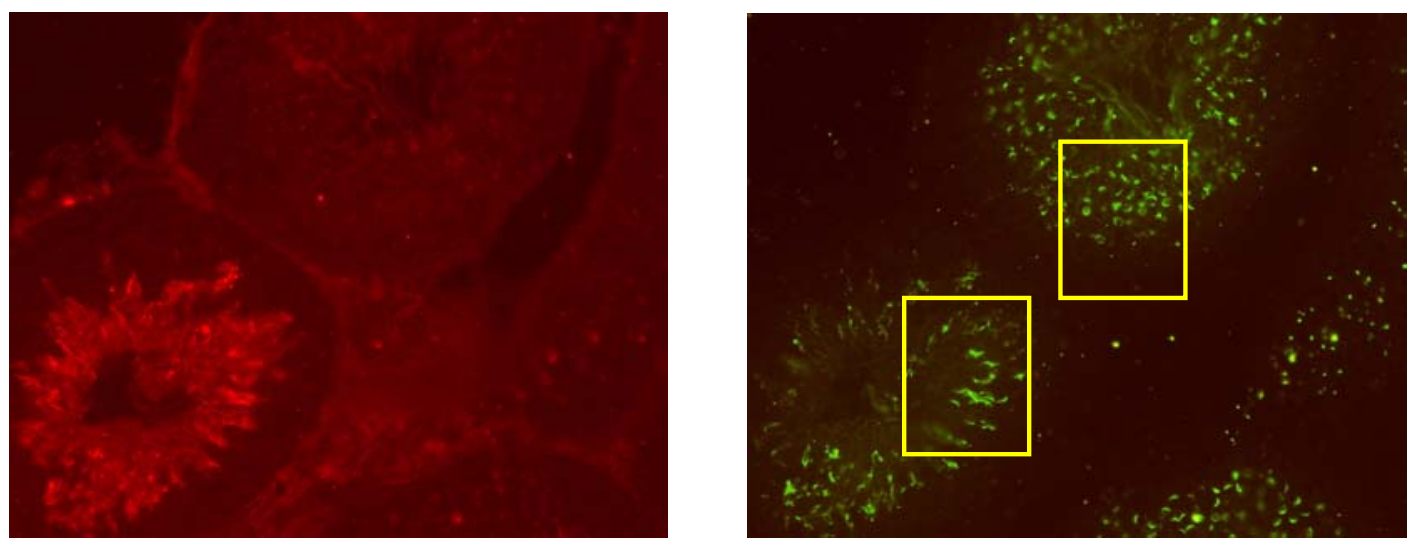

B
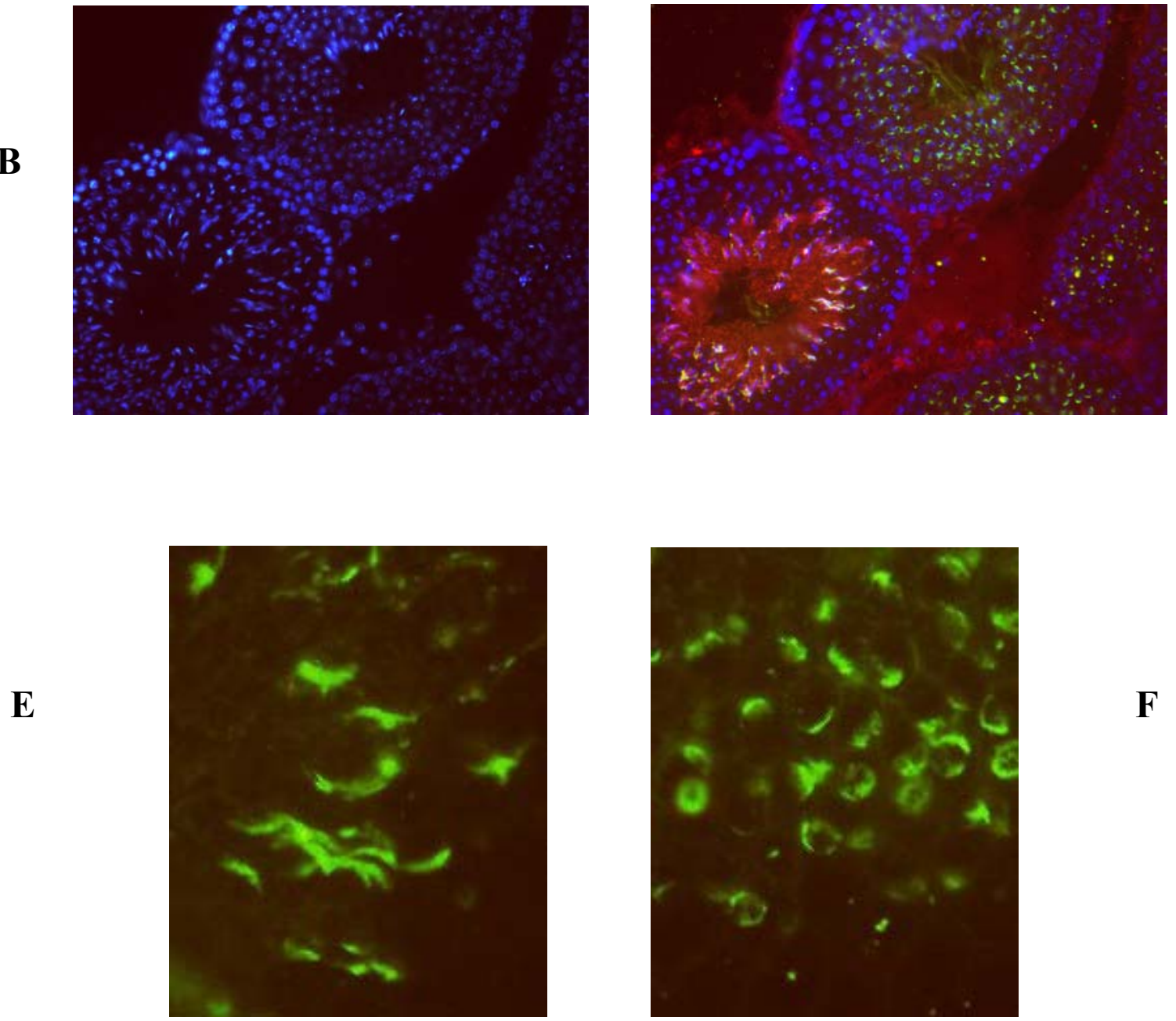

Abb. 3.10: Immunfärbung des Prm3-Proteins auf Testisschnitten.

A Immunfärbung mit dem monospezifischen Prm3-Antikörper und mit cy3-gekoppeltem Schaf-anti-Kaninchen Zweitantikörper (1:100). B Akrosomfärbung mittels FITC- (Fluorescein Isothiocyanate)-markiertem ErdnußLektin. C DAPI-Gegenfärbung der Kerne. D übereinander gelegte Bilder A, B und C. Das Protein konnte ausschließlich im Zytoplasma der elongierenden Spermatiden (siehe Lektin-Färbung) beobachtet werden. Die Bilder $\mathbf{E}$ und $\mathbf{F}$ stellen vergrößerte Abschnitte des Bildes $\mathbf{C}$ dar. Ein Unterschied zwischen dem Akrosom der elongierenden $\mathbf{E}$ und runden $\mathbf{F}$ Spermatiden ist deutlich sichtbar. 

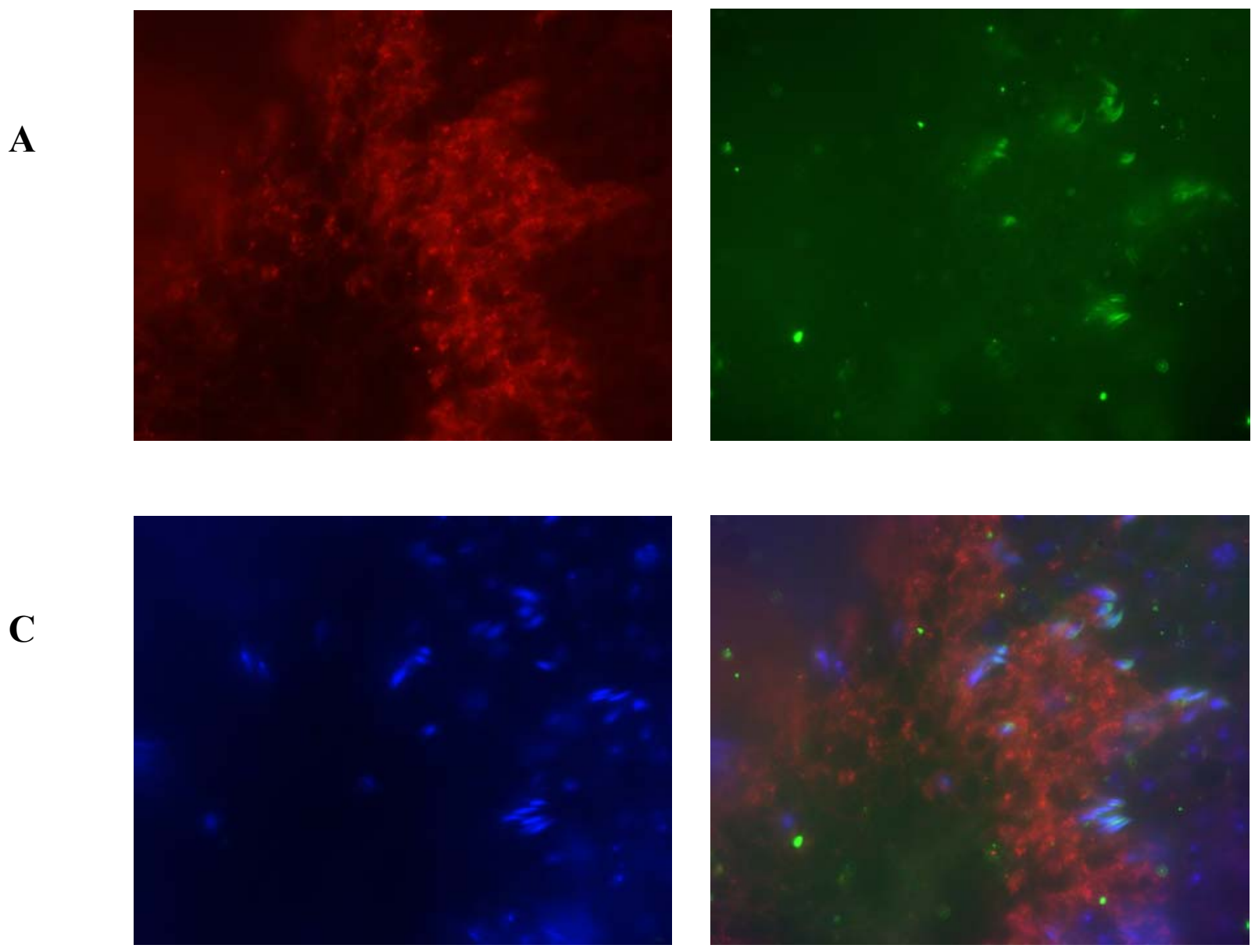

Abb. 3.11: Immunfärbung des Prm3-Proteins auf Testisschnitten (600x Vergrößerung).

A Immunfärbung mit dem monospezifischen Prm3-Antikörper und mit cy3-gekoppeltem Schaf-Anti-Kaninchen Zweitantikörper (1:100). B Akrosomfärbung mittels FITC-markiertem Erdnuß-Lektin. C DAPI-Gegenfärbung der Kerne. D übereinander gelegte Bilder A, B und C. Das Protein konnte ausschließlich im Zytoplasma der elongierenden Spermatiden (siehe Lektin-Färbung) beobachtet werden.

\subsection{Der Versuch der Zuordnung der Expression des Prm3-Proteins zu Spermatogenese Stadien}

Neben Fluoreszenz-markierten Zweitantikörpern wurden auch Alkalische Phosphatase- (AP)gekoppelte Antikörper zur Detektion des Prm3-Signals in Gewebeschnitten benutzt.

Mit diesem Verfahren lassen sich die Zellen, in denen die Färbung auftritt, lichtmikroskopisch besser identifizieren. Prm3-Signale konnten in den Tubuli der Stadien IX (3. Zyklus) bis VII (4. Zyklus) (entspricht Spermatiden-Stadien 9 bis 16) detektiert werden (Abb.3.12). 
Stadium

IX
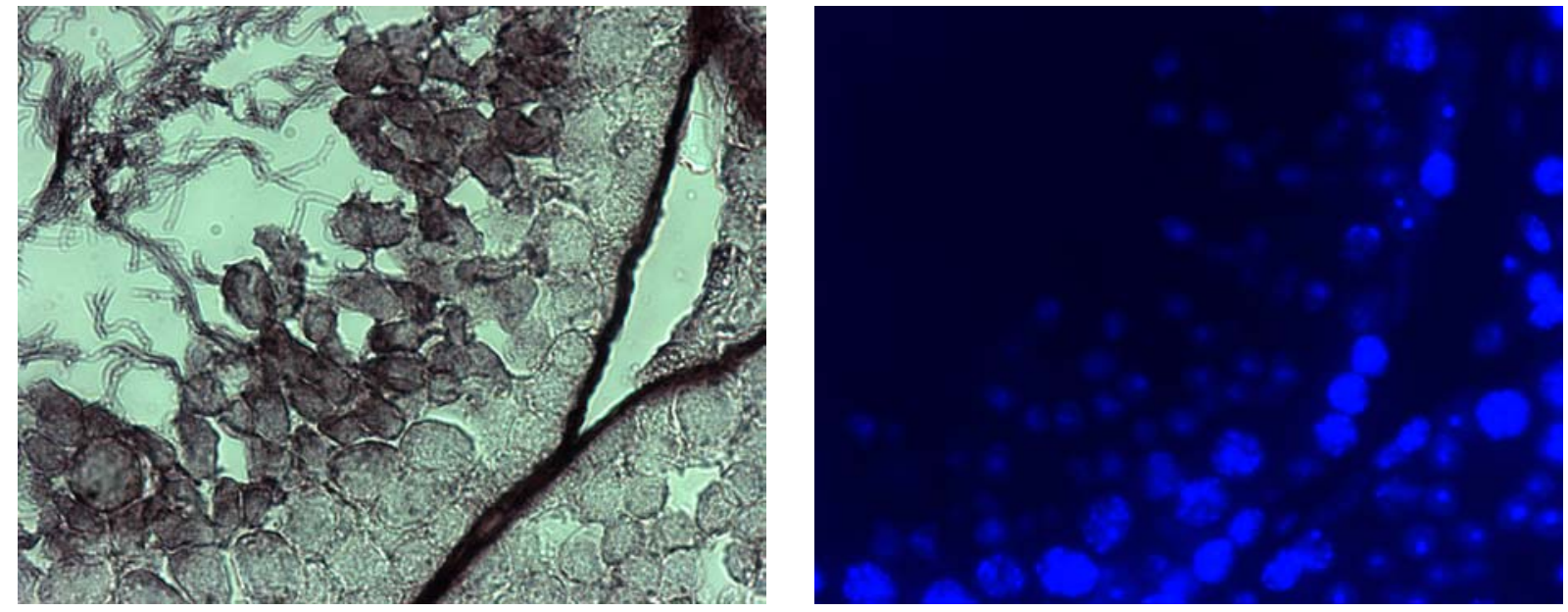

Stadium
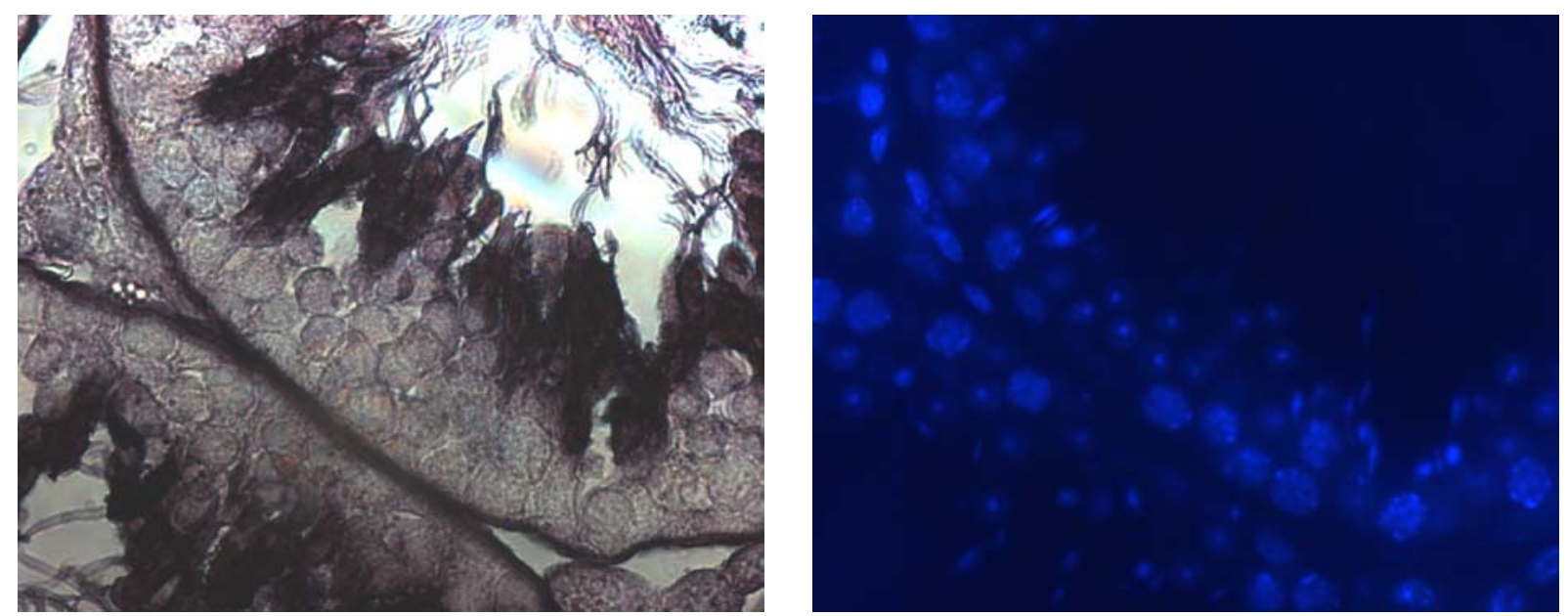

Abb. 3.12: Stadien-Bestimmung der Prm3 exprimierenden Zellen.

Immunodetektion auf den Testisschnitten mittels Prm3-Antikörper und AP-gekoppeltem Zweitantikörper (A). DAPI-Gegenfärbung den Kernen (B). Das Prm3-Protein kann in den Stadien IX bis VII detektiert werden (Spermatiden-Schritten 8-16).

\subsection{Subzelluläre Lokalisation des Prm3-Proteins in Säugerzellen}

Die immunohistochemischen Färbungen ließen eine zytoplasmatische Lokalisation des Prm3Proteins vermuten. Durch unterschiedliche Ansätze sollte dieser Aspekt weiter untersucht werden.

\subsubsection{Subzelluläre Lokalisation des Prm3-Proteins als GFP-Fusionsprotein}

Das Prm3-Gen der Maus wurde als C-terminales Fusionskonstrukt mit GFP-(,green fluorescent protein“) in den pEGFP-C1-Vektor (Clontech) kloniert. NIH3T3-Fibroblasten 
wurden mit diesem Konstrukt transient transfiziert. Als Kontrolle diente der pEGFP-C1 Vektor ohne Insert. Die Transfektion erfolgte auf speziellen Objektträgern mit angehefteter Kulturflasche (Nunc, Wiesbaden). Nach 24-48 h wurden die Zellen mit Methanol fixiert und im Fluoreszenzmikroskop (BX-60, Olympus) untersucht.
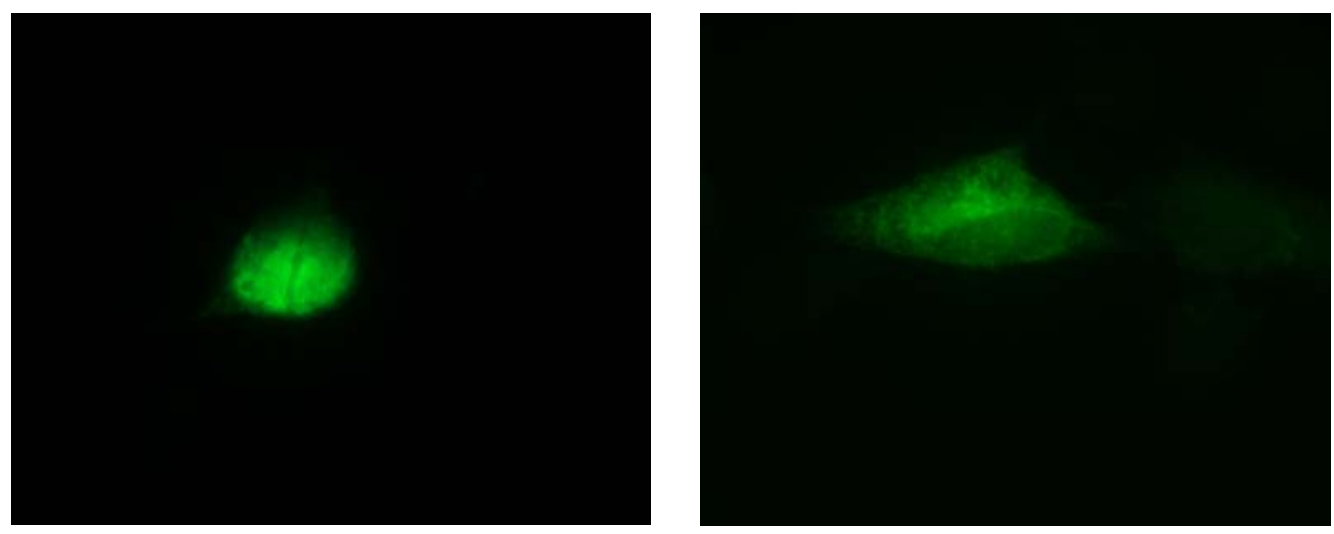

A
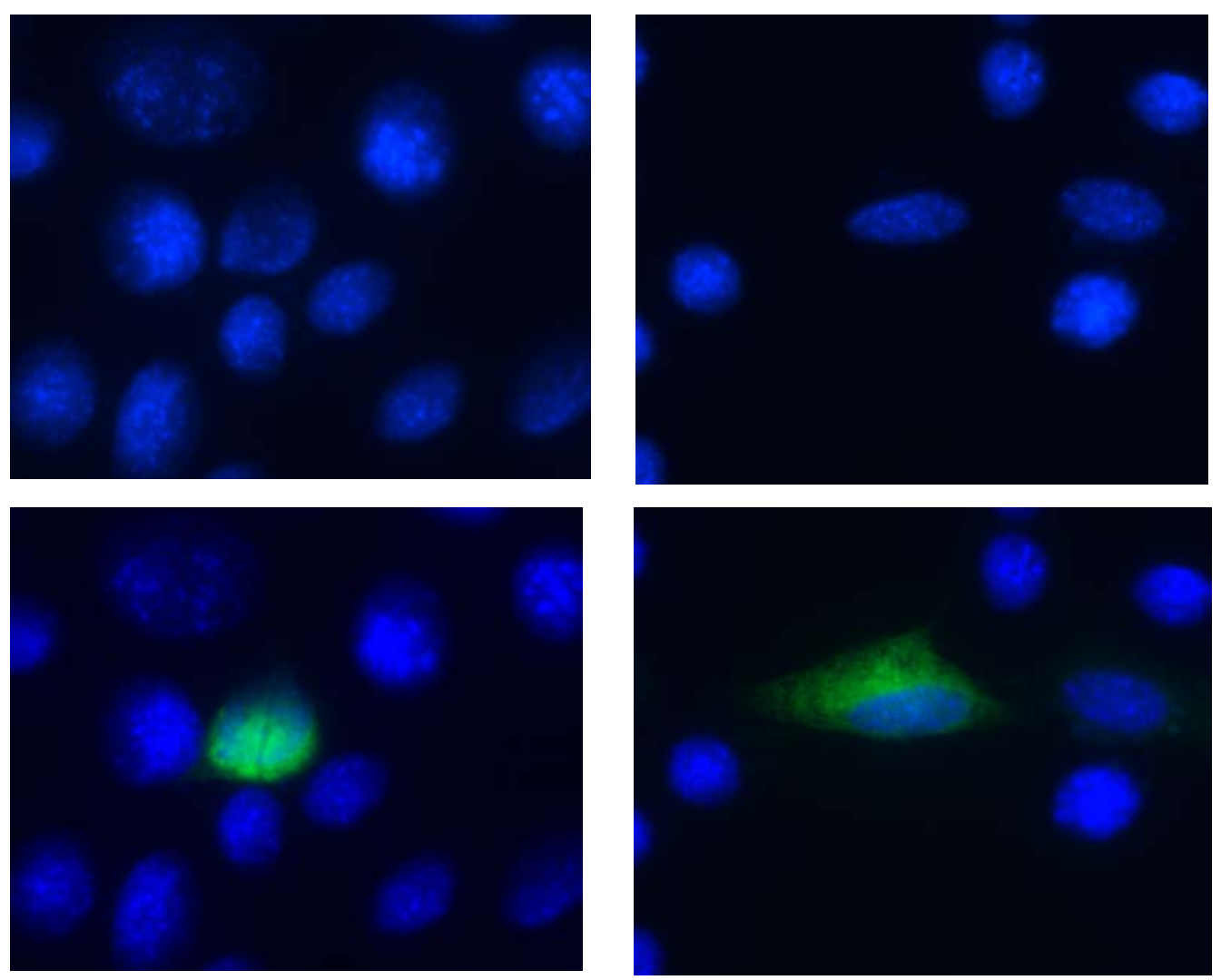

$\mathbf{C}$

Abb. 3.13: Subzelluläre Lokalisation des Maus Prm3-Proteins in NIH3T3-Fibroblasten. Die Zellen wurden mit einem pEGFP-C1-Prm3-Fusionskonstrukt transient transfiziert.

A Lokalisation vom pEGFP/Prm3-Fusionsprotein. B DAPI-Gegenfärbung der Zellkerne. C übereinander gelegte Bilder $\mathbf{A}$ und $\mathbf{B}$. 
Nach der Transfektion mit pEGFP-C1 waren das Zytoplasma und der Zellkern gleichmäßig gefärbt (nicht abgebildet). Dagegen zeigte sich nach der Transfektion mit Prm3-EGFP eine Lokalisation des Proteins in einigen Zellen überwiegend im Zellkern, in anderen Zellen überwiegend (aber nicht ausschließlich) im Zytoplasma (Abb. 3.13).

\subsubsection{Computergestützte Voraussage der subzellulären Lokalisation des Prm3-Proteins}

Das Programm PSORTII (http://psort.nibb.ac.jp/) berechnet aufgrund der Aminosäuresequenz eines Proteins die Wahrscheinlichkeiten für die Lokalisation des Proteins in den verschiedenen Zellkompartimenten. Für die Prm3-Sequenz der Maus wird eine 56,5\%ige Wahrscheinlichkeit für eine Kernlokalisation und eine 30,4\%ige Wahrscheinlichkeit für eine Lokalisation in den Mitochondrien errechnet.

\subsubsection{Subzelluläre Lokalisation des Prm3-Proteins in stabil transfizierten Zellen}

Die Zellinie Prm3/NIH3T3 ist eine stabil transfizierte Zellinie, die die Prm3-cDNA unter der Kontrolle des induzierbaren Metallothionin-Promotors exprimiert. Diese Zellinie wurde verwendet, um die Prm3-Lokalisation auch immunologisch zu analysieren. Die Zellen wurden wie oben (3.6.1) in speziellen Kulturflaschen kultiviert. Nach Induktion wurde das Prm3Protein mit dem aufgereinigten Prm3-Antikörper und FITC (Fluorescein Isothiocyanate)gekoppeltem Zweitantikörper detektiert. Die Analyse im Fluoreszenzmikroskop (BX-60, Olympus) zeigt eine überwiegende Lokalisation von Prm3 im Zytoplasma. Im Kernbereich ist nur eine ungleichmäßige Färbung (siehe Abb. 3.14, Bilder der rechten Spalte) sichtbar, und zwar an den Stellen wo keine DNA vorhanden ist. 

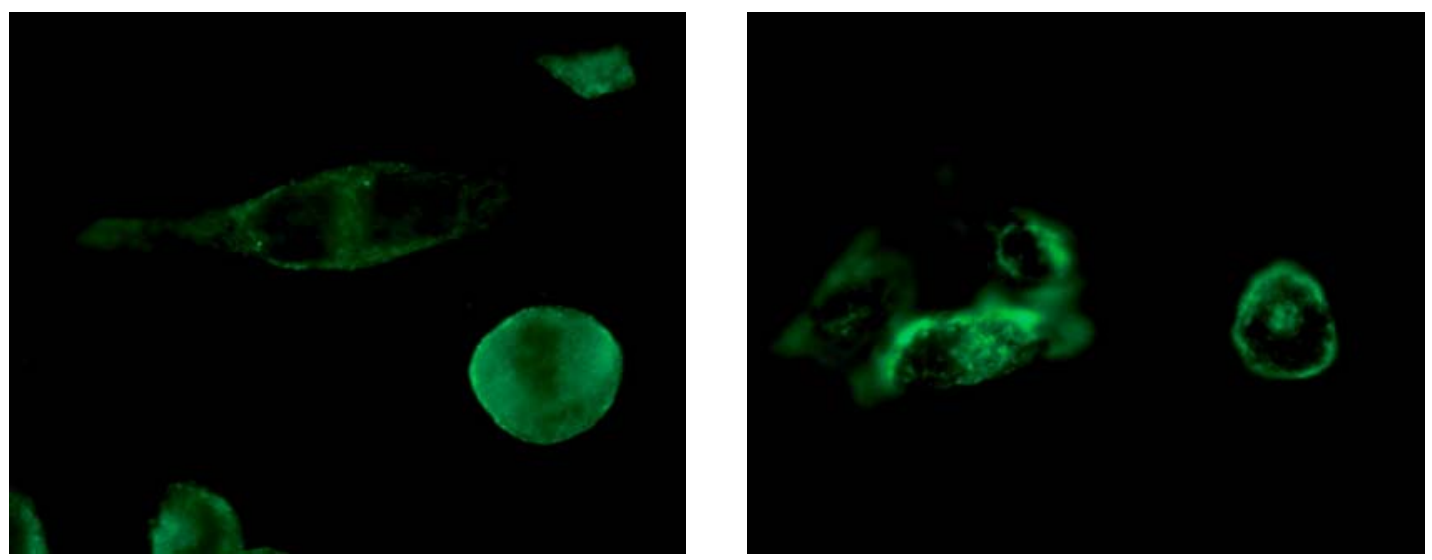

A
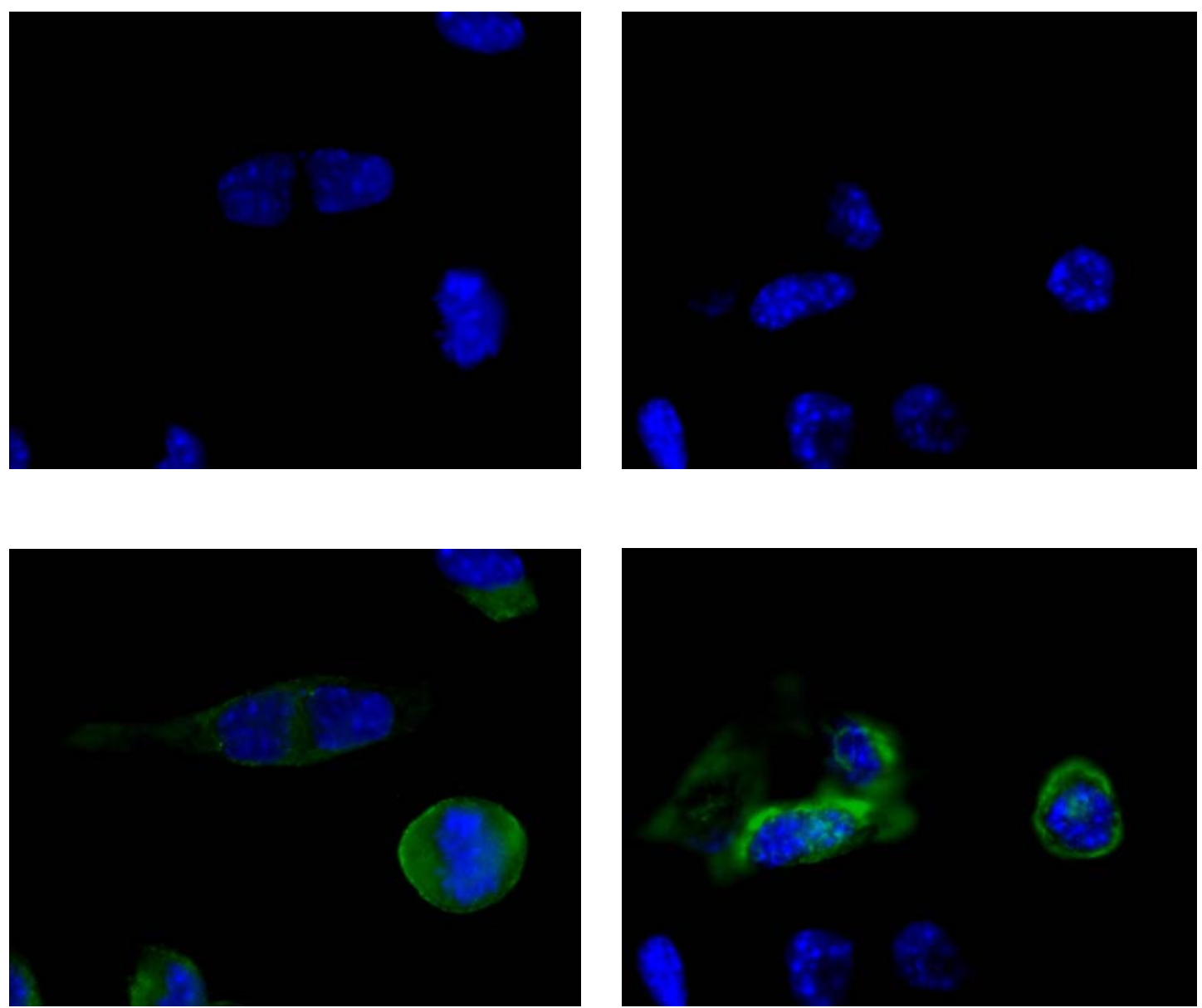

C

Abb. 3.14: Immundetektion des Prm3-Proteins in der Prm3/NIH3T3-Zellinie mit gereinigtem Antiserum (1:20 verdünnt) und cy3-gekoppeltem Zweitantikörper (Schaf-Anti-Kaninchen, 1:100 verdünnt).

A Die Prm3-Färbung befindet sich überwiegend im Zytoplasma. In einigen Zellen sind auch Bereiche des Zellkerns gefärbt (siehe Bilder in der rechten Spalte). B DAPI-Gegenfärbung der DNA. C übereinander gelegte Bilder $\mathbf{A}$ und $\mathbf{B}$. 


\subsubsection{Western-Blot-Analyse zur Lokalisation des Prm3-Protein}

Für eine weitere Analyse der subzellulären Lokalisation des Prm3-Proteins wurden Western-

Blots eingesetz. Dazu wurden separierte zytoplasmatische- und Kernprotein-Fraktionen aus Maus-Testis verwendet. Je $100 \mu \mathrm{g}$ der entsprechenden Extrakte (2.19.3, 2.19.4) wurden (wie in 3.2) in einer SDS-PAGE (2.20.1) aufgetrennt, auf Nitrocellulose geblottet (2.22.2.1) und mit dem Prm3-Antiserum detektiert (2.22.2.3). In beiden Fraktionen wurden Signale vergleichbarer Stärke detektiert (3.15). Auch im Gesamtprotein-Extrakt, der als Kontrolle mitgeführt wurde, konnte eine Pm3-Bande in ähnlicher Intensität nachgewiesen werden.

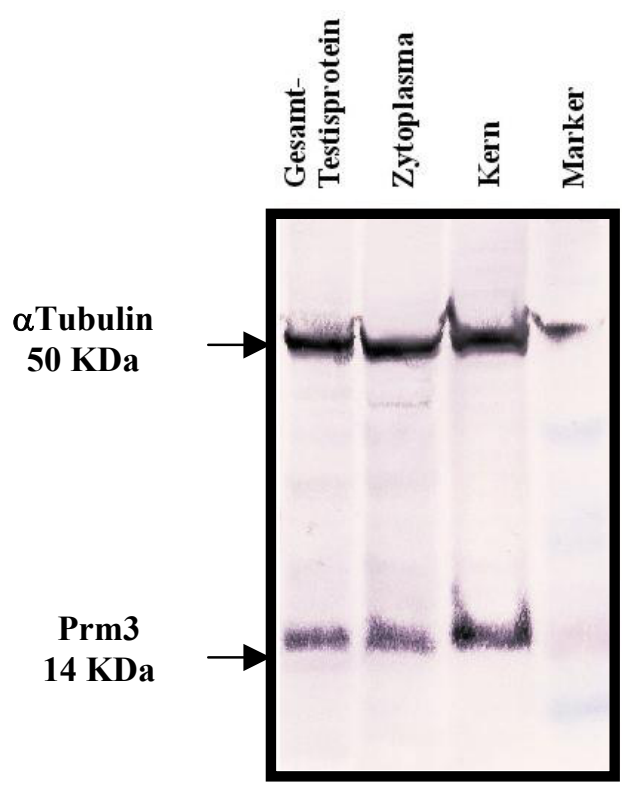

Abb. 3.15: Nachweis von Prm3 in subzellulären Fraktionen aus Maus-Testis.

Proteinextrakte aus Zytoplasma (Z)- und Kern-Fraktion (K) aus Maus-Testis, sowie von Gesamt-Testisprotein (T) wurden im Western-Blot analysiert. Die Detektion erfolgte mit 1:100 verdünntem Prm3-Antiserum und APgekoppeltem Ziege-anti-Kaninchen Zweitantikörper (1:15000). Das Prm3-Protein wird sowohl in der Kern- als auch in der Zytoplasma-Fraktion detektiert. Zur Kontrolle der Protein-Proben wurde eine Immundetektion mit anti- $\alpha$-Tubulin (1:2000) und AP-gekoppeltem Ziege-anti-Maus Zweitantikörper (1:15000) durchgeführt.

\subsection{Induktion von Apoptose durch Prm3-Expression}

Bei den Versuchen zur Produktion von rekombinatem Prm3-Protein hatten sich Hinweise ergeben, daß das Prm3-Protein eine toxische Wirkung auf die Wirtszelle haben könnte 
(Schlüter, 1996; Kämper, 2001). Um die Wirkung des Prm3-Proteins auf NIH3T3-Zellen zu analysieren, wurden die Zellen der stabilen Linie Prm3/NIH3T3 nach $\mathrm{ZnSO}_{4}$ Induktion (also maximaler Produktion von Prm3) mikroskopisch untersucht. (Abb. 3.16 zeigt die Expression des Prm3-Proteins in Extrakten dieser Zellinie: ohne Induktion und nach Induktion mit 40 und $60 \mu \mathrm{M} \mathrm{ZnSO}$ ). Als Kontrolle wurden nicht transfizierte NIH3T3-Zellen mit den gleichen Konzentrationen Zinksulfat inkubiert. Nach 72stündiger Induktion wurden die Zellen auf dem Objektträger für $10 \mathrm{~min}$ mit Methanol fixiert, mit DAPI angefärbt und mikroskopisch untersucht. In Abb. 3.17 kann man eine Fragmentierung von Zellkernen und die Bildung von sog. „,apoptotischen Körperchen“ (Martelli et al., 2001) beobachten. Zusätzlich wurden induzierte Zellen mit Trypan-Blau angefärbt. Tote Zellen zeigen hierbei eine blaue Färbung. Bei den $\mathrm{ZnSO}_{4}$ induzierten Prm3-NIH3T3-Zellen waren deutlich mehr Trypan-Blau gefärbte Zellen sichtbar als bei den Kontroll-Zellen.

Beide Versuche deuten darauf hin, daß die Prm3-Synthese in höheren Konzentrationen zu einem Absterben der Zellen führt.

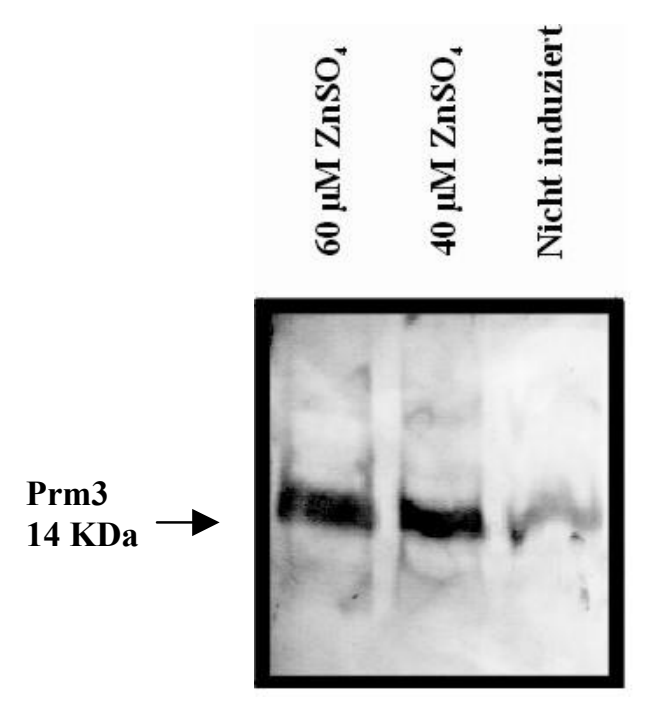

Abb. 3.16: Western-Blot mit Zellextrakten aus der Prm3/NIH3T3-stabilen-Linie nach Induktion mit $60 \mu \mathrm{M}$ und $40 \mu \mathrm{M} \mathrm{ZnSO}$. Nach der Induktion wurde eine starke Prm3-Protein-Expression nachgewiesen. Eine schwache Synthese des Prm3-Proteins ist auch in den nicht induzierten Zellen sichtbar. 
A
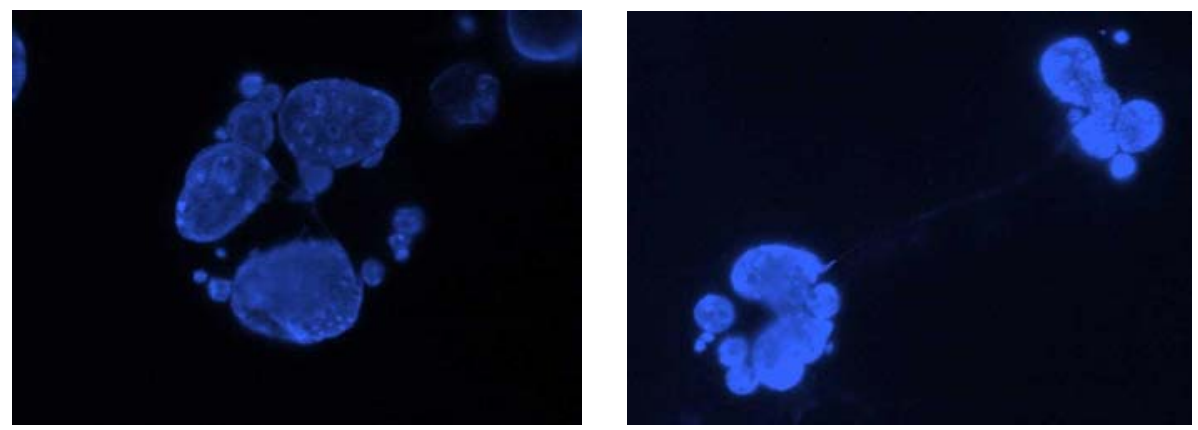

C
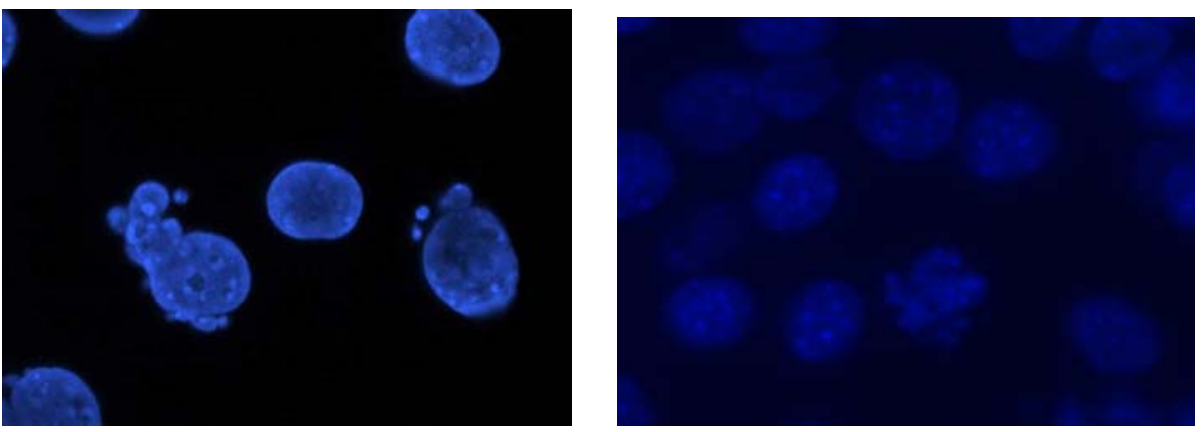

D

B
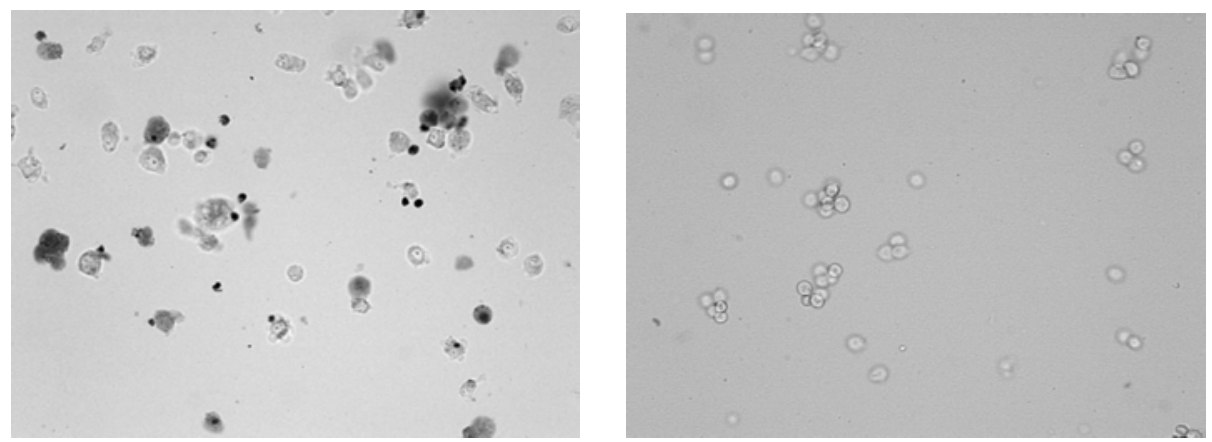

$\mathbf{F}$

Abb. 3.17: Apoptose nach Induktion der Prm3-Expression.

Prm3/NIH3T3 (A-C, E) und NIH3T3-Wildtyp-Zellen (D, F) wurden $72 \mathrm{~h}$ mit $\mathrm{ZnSO}_{4}$ inkubiert und mit DAPI (A-D) oder Trypan-Blau (E, F) gefärbt.

\subsection{Suche nach Prm3-Interaktionspartnern mit Hilfe des "Yeast-Two- Hybrid-Systems“}

Um mögliche Protein-Bindungspartner des Prm3-Proteins zu suchen und damit die Funktion des Prm3-Proteins zu charakterisieren, wurde das Yeast-Two-Hybrid-System (YTH) verwendet. Hierbei wurden zwei verschiedene Versionen des YTH angewendet. Im ersten Ansatz wurde Prm3 als Fusionsprotein der Gal4-DNA-Bindungsdomäne kloniert. Mit diesem Konstrukt wurde ein Hefestamm erzeugt (Prm3-pGBT9), in den die DNA einer Testis- 
Bibliothek, kloniert in pGAD10 (Matchmaker-Library, Clontech) transformiert wurde. In einem zweiten Ansatz wurden die Prm3-pGBT9-Zellen mit den Zellen einer prätransformierten Testis-Bibliothek fusioniert („,mating“").

\subsubsection{Klonierung des Prm3-Gens in den pGBT9-Vektor}

Das Prm3-Gen wurde mittels SacI und EcoRI aus dem Prm3-Klon P3woATG/pBSC ausgeschnitten. Dieses Fragment enthält bis auf die erste Aminosäure die gesamte kodierende Sequenz des Prm3 Gens. Das Fragment wurde mit aufgefüllter SacI-Schnittstelle in pGBT9 (PstI aufgefüllt und EcoRI) kloniert. Hierdurch entstand ein Fusionsprotein, das den Prm3Anteil N-terminal und die Gal4-DNA-bindende Domäne C-terminal trägt.

\subsubsection{Transaktivierungstest}

Um sicherzustellen, daß das erzeugte Prm3-pGBT9 Konstrukt allein keine transaktivierende Eigenschaft besitzt, wurde das Konstrukt allein in den Hefestamm CG-1945 transformiert. Anschließend wurden die Transformanten auf SD/-TRP-HIS-Selektivnährböden ausgestrichen. Die pGBT9/Prm3 Transformanten wuchsen nicht auf dem SD/-TRP-HISSelektivnährboden. Demzufolge konnte das Reportergen HIS3 nicht aktiviert werden. Das Fusionsprotein aus Prm3 und Gal4-DNA-BD war somit nicht transaktivierend und konnte als Köder im Yeast-Two-Hybrid-Screen verwendet werden.

\subsubsection{Bestimmung der Transformationseffizienz und der Anzahl der getesteten Klone}

Die Suche nach Prm3-Interaktionspartnern wurde in einem großen Transformationsansatz durchgeführt, in dem $100 \mu \mathrm{g}$ der pGAD-10/Testis-Matchmaker cDNA-Bank in den Hefestamm CG-1945-pGBT9/Prm3 transformiert wurde (2.26.5). Durch einen Kontrollausstrich eines kleinen Aliquots des Transformationsansatzes auf SD/-LEU-TRPPlatten (auf denen nur doppelt transformierte Hefezellen wachsen sollten) konnte die Transformationseffizienz berechnet werden: 
Transformationseffizienz $=(\mathrm{cfu} /$ Masse transformierter DNA $) \times\left(\mathrm{V}_{\text {gesamt }} / \mathrm{V}_{\text {Probe }}\right)$

Dabei sind

$$
\begin{aligned}
& \text { cfu =, ,colony forming units“ (= alle Kolonien, die beim Kontrollausstrich } \\
& \text { auf SD/-LEU-TRP-Platten gewachsen sind }) \\
& \mathrm{V}_{\text {gesamt }}=\text { Gesamtvolumen des Transformationsansatzes } \\
& \mathrm{V}_{\text {Probe }}=\text { Kontrollausstrich-Volumen }
\end{aligned}
$$

$\begin{array}{ll}\text { cfu } & 550 \\ \text { Masse transformierter DNA in } \mu \mathrm{g} & 100 \\ \mathrm{~V}_{\text {gesamt }} \text { in } \mu \mathrm{l} & 6.000 \\ \mathrm{~V}_{\text {Probe }} \text { in } \mu \mathrm{l} & 1 \\ \mathrm{~V}_{\text {gesamt }} / \mathrm{V}_{\text {Probe }} & 6.000\end{array}$

ergab sich eine Transformationseffizienz von $33.000 \mathrm{cfu} / \mu \mathrm{g}$ DNA. Da insgesamt $100 \mu \mathrm{g}$ DNA transformiert wurden, ergibt sich eine Gesamt-Anzahl von getesteten Klonen von 3,3 $\times 10^{6}$.

\subsubsection{Identifikation von HIS3-positiven Hefetransformanten}

CG-1945-Hefezellen (Histidin-auxotroph), die sowohl mit pGBT9/Prm3 (2.26.4) als auch mit Plasmiden der pGAD-10/cDNA-Bank (2.26.5) transformiert waren, wurden zur Identifikation von HIS3-positiven Transformanten auf Selektivnährböden ausgestrichen, denen neben den Aminosäuren Leucin und Tryptophan auch Histidin fehlte (SD-LEU-TRP-HIS). Auf diesen Nährböden sollten nur Hefezellen Kolonien bilden, die infolge einer Rekonstitution des GAL4-Transkriptionsaktivators zur Expression des HIS3-Gens fähig sind. Sie sind durch die Transformation und die Interaktion der beiden Fusionskonstrukte Histidin-autotroph geworden. Es wuchsen insgesamt vier Kolonien heran.

\subsection{5 $\beta$-Galaktosidase-Test der HIS3-positiven-Transformanten}

Die vier Histidin-autotrophen Klone wurden einem zweiten Selektionsverfahren, dem $\beta$-Galaktosidase-Test, unterzogen (siehe 2.26.7). Mit diesem Verfahren wurde die Aktivität der $\beta$-Galaktosidase bzw. die Expression des lacZ-Gens, die in diesem Hefestamm ebenfalls 
von dem intakten GAL4-Transkriptionsaktivator abhängig ist, geprüft. Keiner der getesteten HIS3-positiven Hefeklone war $\beta$-Galaktosidase-positiv: sie zeigten keine Blaufärbung.

\subsubsection{Screening einer YTH-Testis-cDNA-Bank durch Hefe "Mating"}

In einem zweiten Screening wurde eine prätransformierte Testis-cDNA-Bibliothek (Matchmaker-Testis-cDNA-Library, Clontech) verwendet. Dieses System bietet außer HIS und lacZ noch ein weiteres Reportergen, den ADE-Marker (Adenin). Die Selektion erfolgt also durch drei unabhängige Marker, wodurch das System sehr spezifisch sein sollte. Die Rate an falsch positiven Klonen beträgt laut Hersteller 5\%.

Nach dem "Mating" (2.29.10) wurden die Hefen auf SD-LEU-TRP-HIS-Platten (2.5.2) ausplattiert. Es wurden $3.12 \times 10^{7}$ Kolonien gescreent, insgesamt wuchsen ca. 300 Kolonien. Auf Minimalmedium SD-LEU-TRP-HIS-ADE (mit ADE-Selektion) und zusätzlich $\alpha$-galIndikator (2.5.2) wuchsen $110 \alpha$-gal-positive Kolonien (Abb. 318).

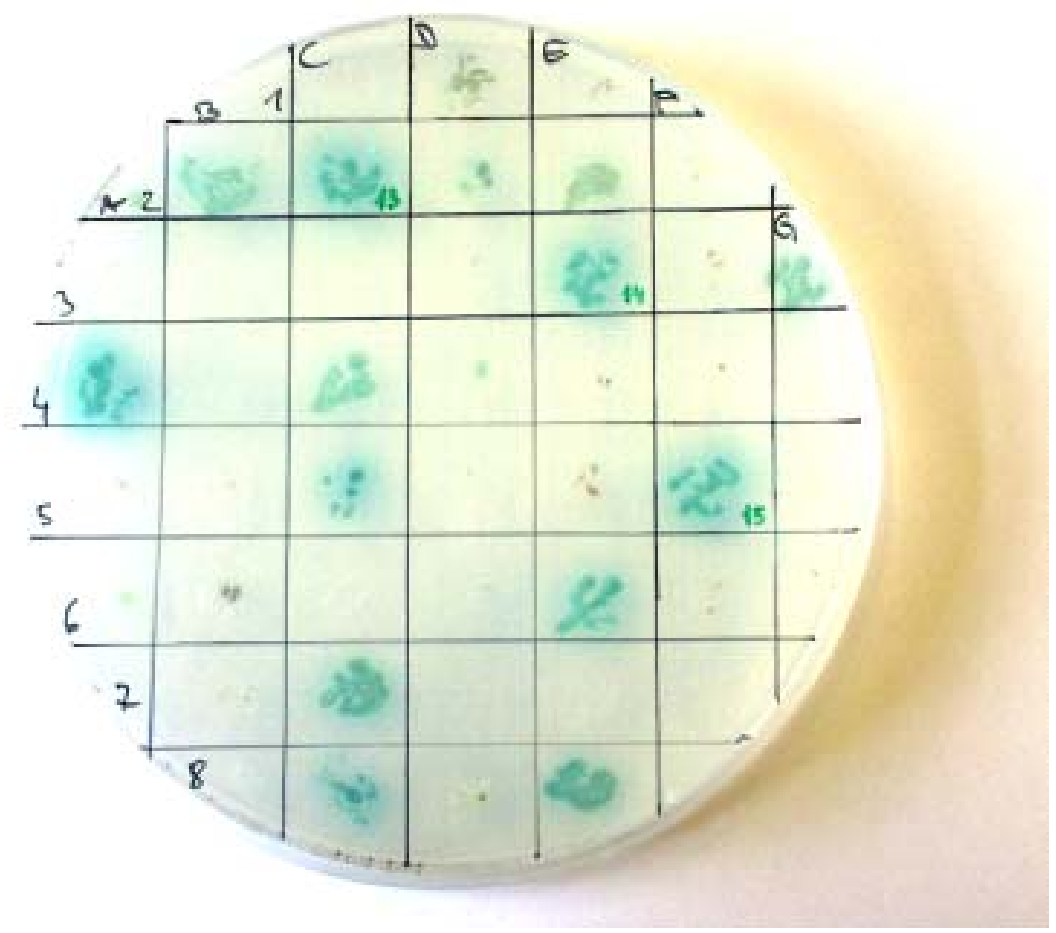

Abb.3.18: Blau/weiß-Selektion der auf SD-LEU-TRP-HIS-ADE/ $\alpha$-gal-Platten wachsenden Hefe-Klone. 


\subsubsection{Identifizierung der cDNA-Klone}

Um die erhaltenen cDNAs zu klonieren, wurde aus den Hefekolonien Plasmid-DNA isoliert. An dieser Plasmid-DNA, deren Ausbeute minimal war, wurde mit vektorspezifischen Primern (Y2H2 und Y2HAD3) eine PCR durchgeführt. Die Produkte wurden in den pGEM-T-EasyVektor kloniert und von beiden Enden ansequenziert. Die Sequenzen wurden mithilfe des BLAST-Programms (Altschul et al., 1990) gegen die GenBank-Sequenz abgeglichen.

Es wurden insgesamt 50 Klone sequenziert. Die Klone, die mehrfach unter den ScreeningProdukten auftauchten (s. Tabelle 3.1), wurden zur weiteren Analyse ausgewählt, nach Aktivierung der Reportergene überprüft (3.8.8) und in die Vektoren des Mammalian-TwoHybrid-Systems kloniert. Andere Klone tauchten nur einmal auf und wurden nicht ausgewählt.

\begin{tabular}{|l|l|l|l|l|}
\hline Name des Klons & GI-Code & Anzahl & $\begin{array}{l}\text { Länge des PCRs } \\
\text { Produkts }\end{array}$ & $\begin{array}{l}\text { Länge des sequen- } \\
\text { zierten Bereiches }\end{array}$ \\
\hline $\begin{array}{l}\text { JAB1 } \\
\text { Jun activator domain-binding protein }\end{array}$ & 3152933 & $17 \mathrm{x}$ & $\begin{array}{l}1,4 \mathrm{~Kb} \\
\text { gesamte cDNA }\end{array}$ & $1,4 \mathrm{~Kb}$ \\
\hline Similar to FLJ22316 (Nr. 62) & 16359291 & $11 \mathrm{x}$ & $1,5 \mathrm{~Kb}$ & $803 \mathrm{Bp}$ \\
\hline $\begin{array}{l}\text { mCDC47 (Nr. 40) } \\
\text { (Mitglied der Mcm Familie) }\end{array}$ & 20846808 & $2 \mathrm{x}$ & $750 \mathrm{Bp}$ & $489 \mathrm{Bp}$ \\
\hline $\begin{array}{l}\text { NAS-hypothetical protein (NR. 80) } \\
\text { Mus musculus RIKEN cDNA }\end{array}$ & 20858038 & $2 \mathrm{x}$ & $2 \mathrm{~Kb}$ & $400 \mathrm{Bp}$ \\
\hline $\begin{array}{l}\text { 1500002B03 gene (Nr.106) } \\
\text { Fragm. Ch.1 (Nr. 96) }\end{array}$ & 2036925 & $3 \mathrm{x}$ & $750 \mathrm{Bp}$ & $433 \mathrm{Bp}$ \\
\hline
\end{tabular}

Tab. 3.1: Im YTH gefundene putative Bindungspartner des Prm3-Proteins.

Die Bezeichnung der Klone ist der NCBI-Genbank-Datenbank entnommen. Der GI-Code identifiziert jede Sequenz eindeutig. Anzahl: Zahl der Wiederholungen des Klons im Pool von 50 zufällig ausgewählten HefeKlonen.

\subsubsection{Verifikation positiver Klone durch Segregation}

Um auszuschließen, daß die Aktivierung der Reportergene bei den 8 ausgewählten HIS3/Ade/lacZ-positiven Klonen allein durch das AD-Fusionsprotein (ohne Interaktionspartner) hervorgerufen wird, also nicht von einer Interaktion mit dem DNA-BD- 
Fusionsprotein abhängt, wurden die Klone nach Elimination des DNA-BD-Plasmids (siehe 2.26.8) erneut auf den LHA $\alpha$-gal-Mangelnährböden ausplattiert. Zwei Kolonien zeigten weiterhin $\alpha$-gal Aktivität, waren also falsch positive. Bei 6 Klonen fiel der Test negativ aus. Diese Klone wurden weiter im Mammalian Two Hybrid System überprüft.

\subsection{Mammalian-Two-Hybrid-System}

Die Versuche im Mammalian Two Hybrid System (MTH) dienten der Verifikation der Ergebnisse aus dem YTH.

Die im YTH positiv getesteten Klone sowie die Prm3-Sequenz mußten in den pM1-Vektor (als 3'-Fusionsprotein zur GAL-4-DNA-Bindungsdomäne) und in den pVP-FLAG5-Vektor (als 3'-Fusionsprotein zur VP16-Aktivierungsdomäne) umkloniert werden.

Prm3 wurde mit XbaI/BamHI aus einem Prm3-Klon ausgeschnitten, in dem direkt 3' vom ATG eine BamHI-Stelle eingefügt worden war (G. Schlüter, persönliche Mitteilung). Das Fragment wurde also ohne eigenes Start-Kodon in den GAL-4 Leserahmen des BamHI/XbaI geschnittenen pM1 bzw. den BglII/XbaI-geschnittenen pVP-FLAG-Vektor kloniert. Die zu testenden cDNAs (s. Tab. 3.1) aus der YTH-Matchmaker-Bibliothek wurden mit BamHI/XhoI aus pGAD-10 oder aus pGEM-T-Easy ausgeschnitten und ebenfalls in pM1 (BamHI/SalI) und pVP-FLAG5 (BgIII/SalI) kloniert. Die Klonierungen wurden durch Sequenzierung der Ligationsstellen kontrolliert. Für die pVP-FLAG5-Konstrukte wurde der pVP-FLAG5-sense-Primer benutzt. Dieser Primer bindet an die Sequenz der VP16Aktivierungsdomäne, die sich stromaufwärts des Polylinkers befindet. Für die pM-Konstrukte wurde der Y2H1DB-Primer eingesetzt, der an die Sequenz der DNA-Bindungsdomäne bindet.

\subsubsection{Transfektion der NIH/3T3-Fibroblasten}

Es wurden ca. 60.000 NIH3T3 Zellen/well in 12-well-Platten ausgesät und mit einer Mischung aus pM1- und pVP-FLAG5-Konstrukten und Reporterplasmiden (pGAL4-LUC und pCMV- $\beta$-GAL, s. 2.1.5) transfiziert. Als Positiv-Kontrollen dienten die Plasmide pGAL4/STAT2 sowie die Kombination pM1/BR-304 und pVP-HA/B202-NB. pGAL4/STAT2 trägt die GAL4-DNA-BD-Domäne und eine eigene Transaktivatordomäne und kann ohne Interaktion mit einem pVP-FLAG5-Konstrukt das Reportergen auf dem GAL4-Luc-Plasmid aktivieren. Auf den Plasmiden pM1/BR-304 und pVP-HA/B202-NB sind DNA-Bindungsdomäne (GAL4-DNA-BD in pM1) und Aktivierungsdomäne (VP16 in pVP- 
HA) voneinander getrennt und werden erst durch die Interaktion der beiden Polypeptide BR304 (Teil des BRCA1-Proteins) und B202-NB (Teil des BARD1-Proteins) verbunden (Wu et al., 1996). Die zu testenden Liganden wurden jeweils als M1 und als VP16-Konstrukt mit dem entsprechenden Prm3-Konstrukt als Partner getestet.

Als Negativkontrollen wurden pM2 und pVP-FLAG5 ohne Insert, pM2/Prm3 in Abwesenheit eines AD-Plasmids und pM2/Prm3 in Kombination mit dem pVP-FLAG5-Vektor (ohne Insert) transfiziert. Um die transfizierte DNA-Menge konstant zu halten, wurde ggf. pBluescript-SKII-DNA Plasmid zugefügt.

\begin{tabular}{|c|c|c|c|c|c|}
\hline & Ligand 1 & Ligand 2 & $\begin{array}{l}\text { Luciferase- } \\
\text { Aktivität in } \\
\text { RLU } \times 10^{3}\end{array}$ & $\begin{array}{l}\beta \text {-Gal- } \\
\text { Aktivität in } \\
\text { RLU } \times 10^{3}\end{array}$ & $\begin{array}{l}\text { Normalisierte } \\
\text { Luciferase- } \\
\text { Aktivität }\end{array}$ \\
\hline $\begin{array}{l}1 \text { Positiv- } \\
\text { kontrolle }\end{array}$ & pGEMT & GAL4/STAT2 & 115756,5 & 257,6 & 449 \\
\hline $\begin{array}{l}2 \text { Positiv- } \\
\text { kontrolle }\end{array}$ & B202-NB pVP & BR304 pM1 & 126347,5 & 325,6 & 387 \\
\hline $\begin{array}{l}3 \text { Negativ- } \\
\text { kontrolle }\end{array}$ & pGEMT & ------------ & 131,1 & 344,5 & 0,38 \\
\hline 4 & pM1 Prm3 & pVP JAB1 & 111,8 & 239,3 & 0,46 \\
\hline 5 & pVP Prm3 & pM1 JAB1 & 136,7 & 345,7 & 0,39 \\
\hline 6 & pM1 Prm3 & pVP Nr62 & 81,8 & 270,5 & 0,30 \\
\hline 7 & pVP Prm3 & pM1 Nr62 & 142,6 & 337,9 & 0,42 \\
\hline 8 & $\mathrm{pM} 1$ & pM1 Nr. 40 & 126,7 & 325,6 & 0,38 \\
\hline 9 & pVP Prm3 & pM1 Nr. 40 & 96,9 & 299,8 & 0,32 \\
\hline 10 & pM1 Prm3 & pVP Nr. 80 & 107,3 & 347,3 & 0,31 \\
\hline 11 & pVP Prm3 & pVP Nr. 80 & 112,6 & 296,4 & 0,38 \\
\hline 12 & pM1 Prm3 & pM1 Nr. 96 & 124,9 & 334,8 & 0,37 \\
\hline 13 & pVP Prm3 & pM1 Nr. 96 & 103,9 & 324,6 & 0,32 \\
\hline 14 & pM1 Prm3 & pVP Nr. 106 & 357,3 & 338,5 & 1,06 \\
\hline 15 & pVP Prm3 & pVP Nr. 106 & 397,3 & 345,8 & 1,15 \\
\hline 16 & pM1 leer & pVP Nr. 106 & 127,5 & 316,4 & 0,40 \\
\hline 17 & $\mathrm{pVP}$ leer & pVP Nr. 106 & 112,5 & 298,8 & 0,37 \\
\hline
\end{tabular}

Tab. 3.2 Transfektionsansätze und gemessene Luciferase- und $\beta$-Galaktosidase-Aktivitäten. $($ RLU $=$ relative Lichteinheiten, $\mathrm{RLU}_{\mathrm{LUC}} / \mathrm{RLU}_{\beta-\mathrm{GAL}}=$ normalisierte Luciferase-Aktivität) 
Tabelle 3.2 zeigt beispielhaft die Ergebnisse eines Transfektionsexperimentes. Die Ergebnisse für den Klon 106 zeigen eine schwache aber reproduzierbare Aktivierung an. Diese Transfektionen wurden zweimal wiederholt. Die Abb. 3.19 zeigt deshalb für diese Ergebnisse einen Fehlerbalken.

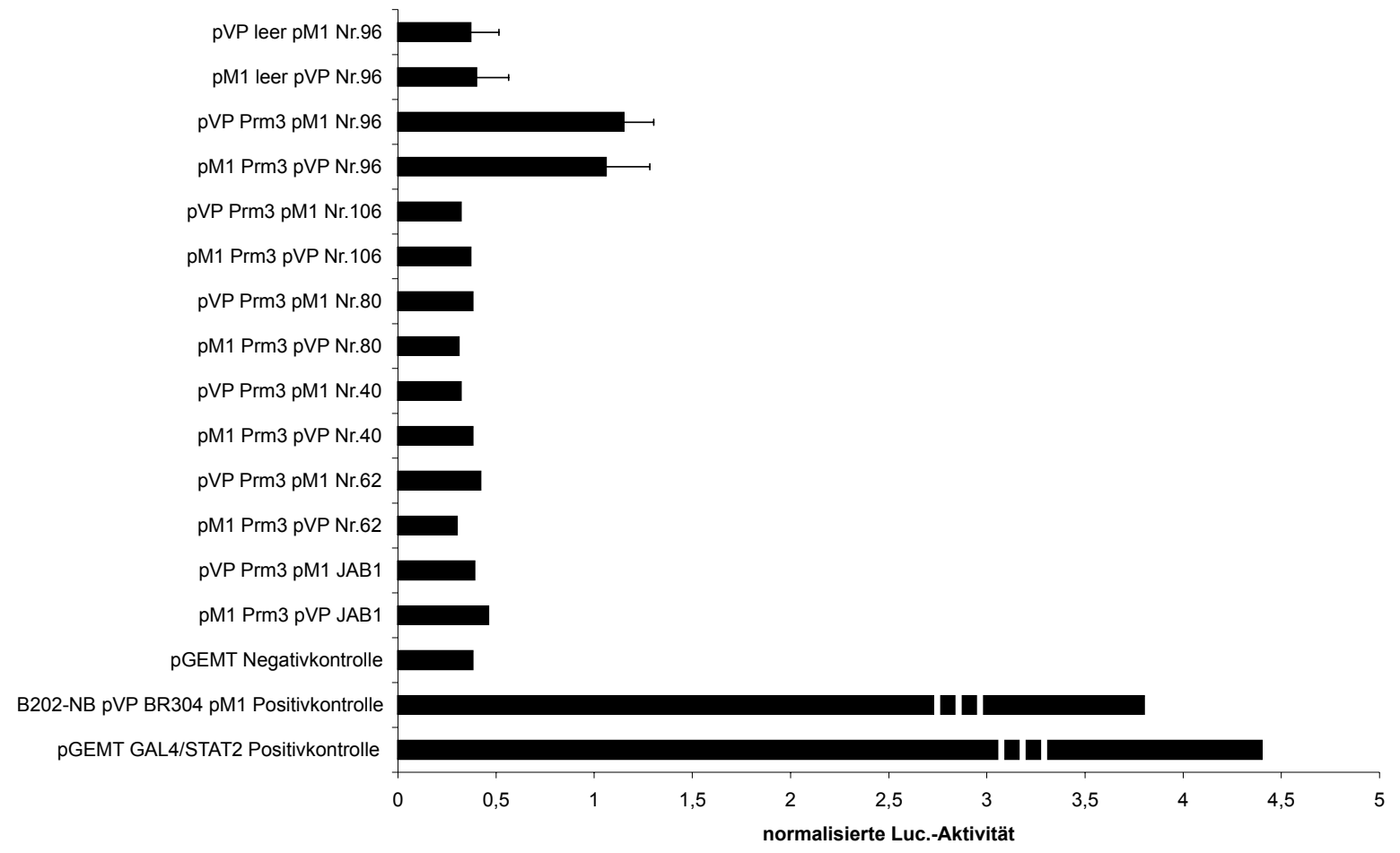

Abb. 3.19: Ergebnisse des Mammalian-Two-Hybrid-Experimentes zur Verifikation der Proteininteraktion.

Der Klon Nr. 96 zeigt eine signifikante Zunahme der Luciferase-Aktivität gegenüber dən Fontrollen. Die Transfektionsansätze sind vollständig in der Tabelle 3.1 dargestellt. Negativkontrollen wurden $n$ ur fiir den positiven Klon Nr. 96 zugefügt.

\subsection{Expression-Studien des Klons 96}

Für den Klon Nr. 96, der eine signifikante Aktivierung des Luciferase-Gens im MammalianTwo-Hybrid-Systems zeigte und damit als ein möglicher Interaktionspartner des Prm3Proteins angesehen werden muß, wurden Northern-Blot Experimente durchgeführt. Es wurde Testis-RNA aus Mäusen verschiedenen Alters, Testis-RNA von Maus-Mutanten mit Störungen der Spermatogenese (W/W $\mathrm{W}^{\mathrm{v}}$, Tfm/Y, LeyI-L, olt/olt und qk/qk) und RNA aus Zellinien, die sich aus verschiedenen testikulären Zelltypen ableiten, untersucht. Dies waren 
MA10 (Ledig Zellen), 15P1 (Sertoli Zellen), GC1 (Spermatogonien), GC2 (Spermatozyten) und GC4 (Spermatiden). Die LeyI-L-Mutante führt die Spermatogenese bis zum Stadium der frühen Pachytän-Spermatozyten durch. Andere Mutanten wurden bereits im Kapitel 3.3 beschrieben. Ein ca. 0,4 Kb große Transkript konnte in RNA aller untersuchter Altersstadien (Tag 15, 19, 25, 30), bei allen Mutanten und auch bei allen untersuchten Zellinien nachgewiesen werden (Abb.3.20).
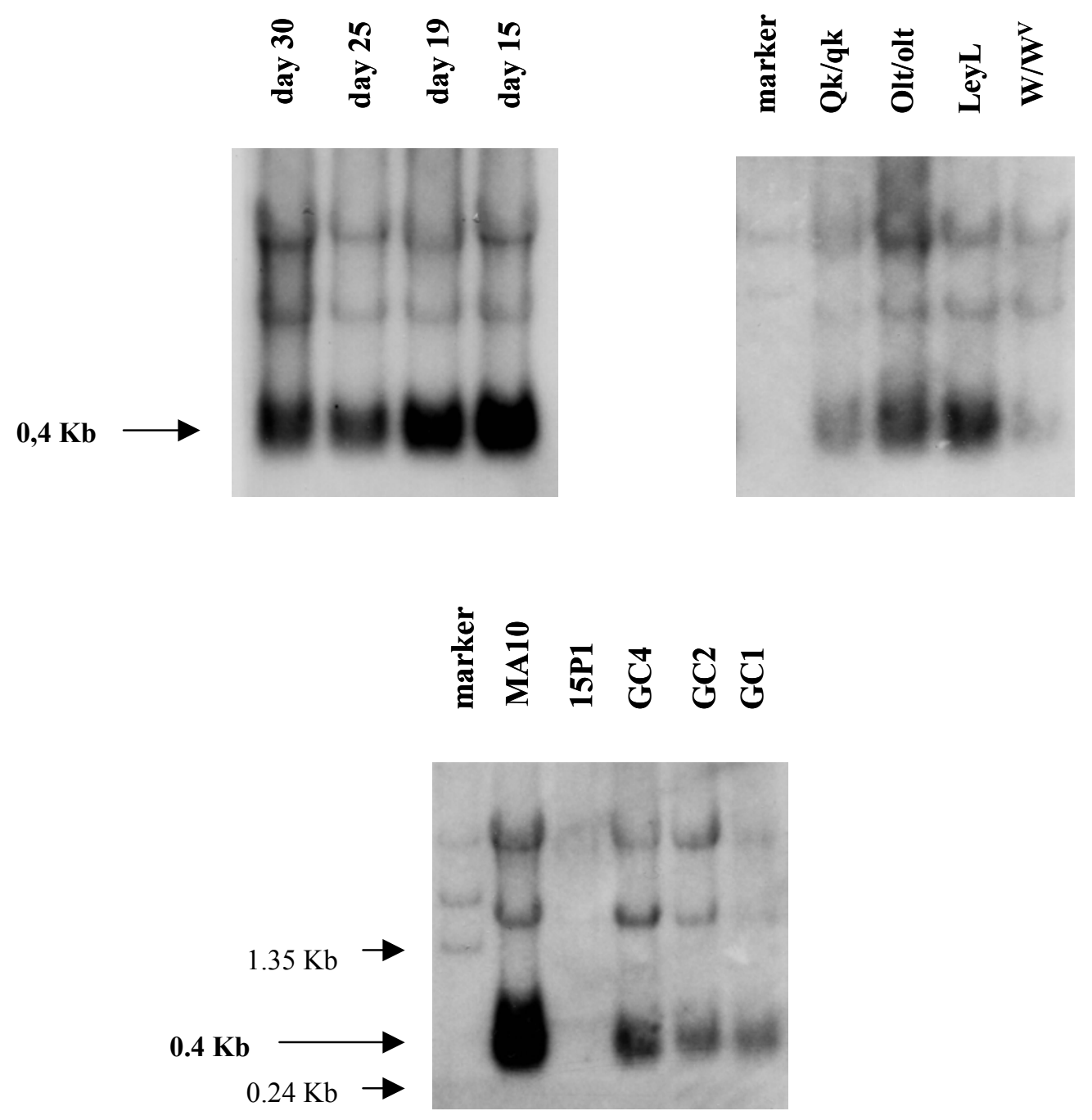

Abb. 3.20: Northern-Blot Analyse des Klon Nr.96.

Gesamt-RNA (je $20 \mu \mathrm{g}$ ) aus Testis-RNA von 15, 19, 25 und 30 Tage alten Mäusen, aus Testis von MausMutanten mit Störungen der Spermatogenese (qk/qk, olt/olt, Tfm/Y, LeyI-L und W/W ${ }^{\mathrm{v}}$ ) und RNA aus Zellinien (MA10, 15P1, GC1, GC2 und GC4) wurde nach denaturierender Gelelektrophorese auf Nitrocellulose geblottet und mit der cDNA-Sonde des Klons 96 hybridisiert. Die Expositionszeit des Autoradiogramms betrug 48 Stunden. Das Signal ist in allen Proben sichtbar. 


\subsection{Induzierbare Expression von Prm3 in transgenen Mäusen}

Zur Untersuchung der Eigenschaften des Prm3-Proteins sollten transgene Mäuse generiert werden, die eine aberrante Expression des Prm3-Gens zeigen. Da die Vermutung besteht, Prm3 könne in höheren Konzentrationen toxisch sein, wurde ein induzierbares System, das Tetracyclin-induzierbare Expression-System (Tet-System), verwendet (Gossen, und Bujard, 1992).

\begin{tabular}{|c|c|c|}
\hline Actin Promotor & tTA (tetR+VP16) & SV40 \\
\hline CMV Promotor & tTA (tetR+VP16) & SV40 \\
\hline
\end{tabular}

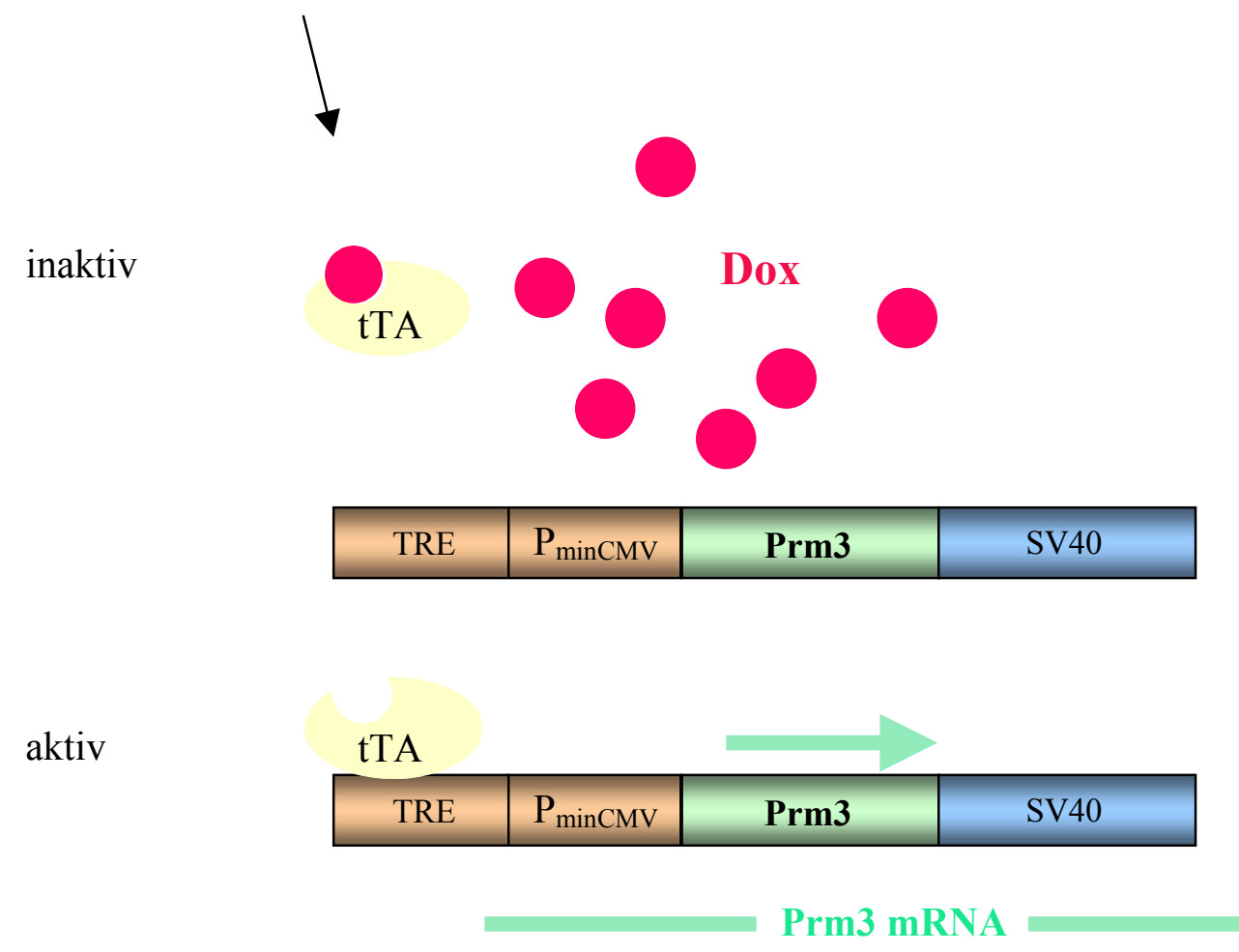

Abb.3.21: Schematische Darstellung des Tet-Systems.

Der Transkriptionsfaktor tTA (tetracycline-controlled Transactivator) bindet an das TRE (Tetracycline Responsive Element) in Abwesenheit von Tetrazyklin (oder Tetrazyklin-Derivaten) und aktiviert die Transkription des Zielgens. Zugabe von Dox verändert die Struktur von tTA und bewirkt seine Ablösung vom TRE. Dox - Doxyzyklin, ein Tetrazyklin-Derivat. 
Dieses System besteht aus einem Konstrukt mit der Sequenz des Zielgens (in diesem Fall Prm3), kloniert hinter einen synthetischen Promoter und einem Konstrukt zur Expression eines Transaktivators (tTA), der diesen Promotor aktiviert. Der Promoter besteht aus der TRE (Tetracyclin responsive element)-Sequenz, einem Heptamer der 19 Bp langen tetO-Sequenz (tet-Operator aus dem E. coli Tet-Operon) und dem CMV-Minimalpromotor.

Das Transaktivatorprotein (tTA) ist ein Fusionsprotein aus dem Tet-Repressor (TetR) des TetOperons von E. coli und der VP16-(Transkriptions)-Aktivatordomäne (Triezenberg et al., 1988) des Herpes simplex Virus. Die TetR-Domäne ändert ihre Struktur bei Zugabe von Tetrazyklin oder Tetrazyklin-Derivaten wie z.B. Doxyzyklin und wechselt dabei von der aktiven in die inaktive Konformation (siehe Abb. 3.21). Bei einer neueren Version des Transaktivators (rtTA) führt der Austausch von vier Aminosäuren zu einem umgekehrten Phänotyp: im Grundzustand ist das rtTA-Molekül inaktiv, durch Zugabe von Tetrazyklin wird es in den aktiven Zustand überführt.

\subsubsection{Klonierung des TRE-Prm3-Konstrukts}

Zur Herstellung des Konstruktes für die Mikroinjektion wurde die Prm3-Sequenz in den pTRE-Vektor (Clontech) kloniert. Die Prm3-cDNA wurde mit StuI (im Prm3 3'UTR) und EcoRI aus einem pBSC-Klon ausgeschnitten. Die Prm3-Sequenz wurde hinter den TREPromotor zwischen BamHI (mit Klenow-Enzym aufgefüllt) und EcoRI kloniert. Das vollständige Konstrukt wurde durch Sequenzierung überprüft. Für die Mikroinjektion wurde das Fragment (siehe Abb. 3.22) aus dem Vektor mittels XhoI und HindIII ausgeschnitten und aufgereinigt (2.28.1).

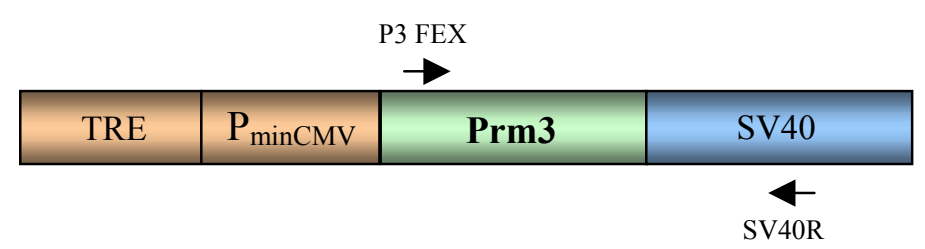

Abb. 3.22: Schematische Darstellung des TRE/Prm3 Konstruktes.

TRE (Tet-Response Element) und $\mathrm{P}_{\text {minCMV }}$ (CMV Minimalpromotor) mit einklonierter Prm3-Sequenz. Zur Stabilisierung der RNA enthält das Konstrukt einen SV40-3'UTR und ein Polyadenylierungssignal. Die Pfeile zeigen die zur Genotypisierung verwendeten PCR-Primer. 


\subsubsection{Transgene Tet-Responder Linien für TRE/Prm3}

Das TRE/Prm3-Konstrukt wurde in den paternalen Vorkern befruchteter Oozyten injiziert. Die mikroinjizierten Oozyten wurden anschließend in die Eileiter scheinschwangerer Mäuse transferriert. Die Nachkommen wurden im Alter von 21 Tagen auf Transgenität untersucht. Dafür wurden Dot-Blot- bzw. PCR-Experimente durchgeführt.

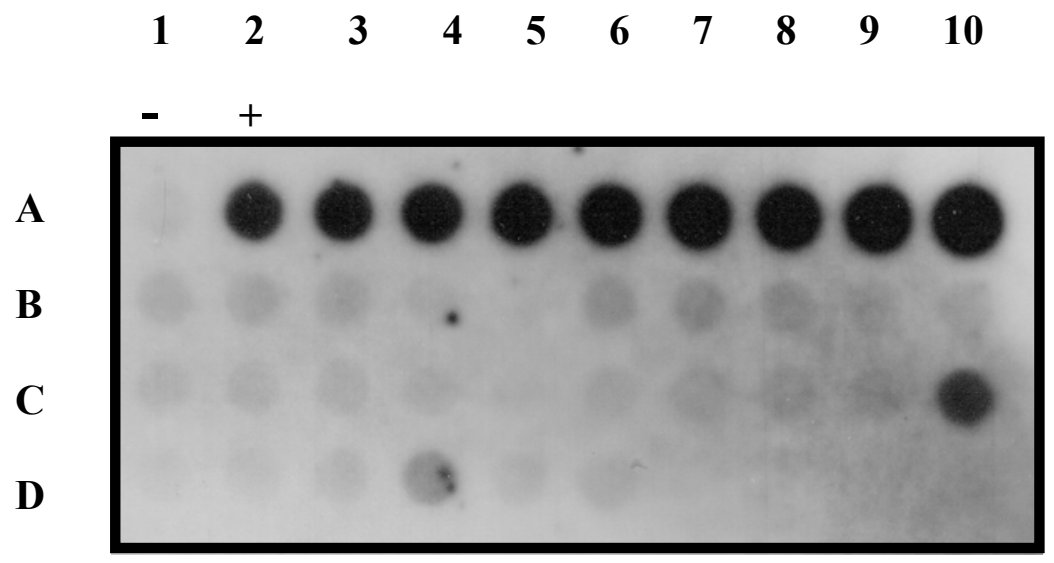

Abb. 3.23: Dot-Blot-Analyse der Tiere der F0-Generation für TRE-Prm3.

Je $20 \mu \mathrm{g}$ genomische DNA von 26 Tieren (Positionen B1-B10, C1-C10 und D1-D6) wurden auf Nitrozellulose geblottet und mit einer TRE-Sonde hybridisiert. Die oberste Reihe A1-A10 enthält eine Negativ- (-) und eine Positivkontrolle (+) (Z3/02, (Kämper, 2001)) aus genomischer DNA sowie eine Kontrollplasmidreihe (25$400 \mathrm{pg})$. Ein Tier (C10) wurde als positiv identifiziert.

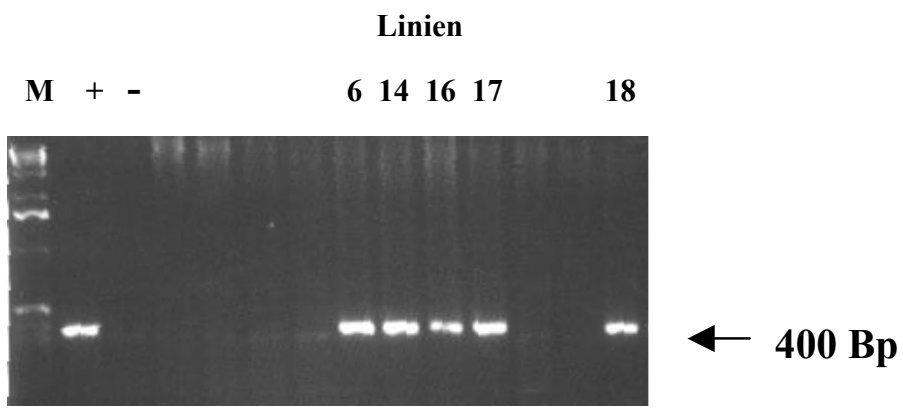

Abb. 3.24: PCR-Analyse der F0-Tiere für TRE-Prm3.

Je $1 \mu \mathrm{g}$ DNA wurde für eine PCR eingesetzt. Unter Verwendung der Prm3-spezifischen Primer P3FEX und SV40R wurde ein 400-Bp-großes Produkt amplifiziert. 5 Foundertiere zeigten die erwartete 400 Bp-große Bande. 0,1 ng DNA des TRE/Prm3 Konstrukts wurde als Positiv- und $1 \mu \mathrm{g}$ genomische Wildtyp-DNA als Negativkontrolle verwendet. ( $+=$ Positivkontrolle; $-=$ Negativkontrolle; $\mathrm{M}=$ DNA-Marker $)$ 
Es wurden insgesamt fünf unabhängige transgene Linien erzeugt. Die Abbildung 3.23 zeigt eine Dot-Blot-Analyse und 3.24 zeigt eine PCR-Analyse von Tieren der F0-Generation (Foundertiere). Das spezifische 400-Bp-große PCR-Produkt wurde in den Linien 6, 14, 16, 17 und 18 amplifiziert. Als Positivkontrolle wurde die PCR an 0,1 ng DNA des TRE/Prm3 Konstrukts durchgeführt. Alle Linien zeigten eine Transmission des Transgens an die Nachkommen.

\subsubsection{Test auf Regulierbarkeit der TRE-Prm3-Linien durch Transfektion von primären Ohrfibroblasten}

Anschließend wurde die in-vivo-Regulierbarkeit des TRE-Prm3-Konstrukts getestet. Es sollten die Linien ausgesucht werden, die die höchste Induktionsrate des Prm3-Transgens erzielen. Hierzu wurden für alle Linien primäre Ohrfibroblastenkulturen angelegt und mit der zweiten Komponente des Tet-Systems, dem Tet-Transaktivator, transient transfiziert. Auf diese Weise kann, ohne daß die Zucht doppelt transgener Linien abgewartet werden muß (Kistner et al., 1996), festgestellt werden, ob das Responder-Konstrukt in einer Weise integriert ist, die eine Dox-induzierbare Expression zuläßt.

\begin{tabular}{|c|c|c|c|c|c|c|}
\hline \multirow{3}{*}{$\begin{array}{l}\text { Linie } \\
\text { TRE6 }\end{array}$} & \multirow{2}{*}{\multicolumn{2}{|c|}{$\begin{array}{l}\text { ELISA-OD }_{405} / 100 \mu \mathrm{g} \\
\text { Protein } \\
\begin{array}{l}\text {-Dox } \quad+\text { Dox }\end{array}\end{array}$}} & \multirow{3}{*}{$\begin{array}{l}\text { ק-Gal-Aktivität } \\
\text { [RLU] +Dox } \\
\\
13660\end{array}$} & \multicolumn{2}{|c|}{$\begin{array}{l}\text { Korrigierte } \\
\text { ELISA-OD x 1000 } \\
\text { Aktivierungsfaktor }\end{array}$} & \multirow{3}{*}{$\begin{array}{l}\begin{array}{l}\text { Aktivierungs- } \\
\text { faktor }\end{array} \\
1.86\end{array}$} \\
\hline & & & & \multicolumn{2}{|c|}{-Dox $\quad+$ Dox } & \\
\hline & 92 & 50 & & 0,0067 & 0,0036 & \\
\hline TRE16 & 141 & 100 & 7332 & 0,0191 & 0,0136 & 1.40 \\
\hline TRE14 & 389 & 0,1 & 6200 & 0,0627 & 0,00001 & 6270000 \\
\hline TRE17 & 284 & 125 & 6064 & 0,0468 & 0,0206 & 2.27 \\
\hline TRE18 & 533 & 216 & 3930 & 0,1356 & 0,0549 & 2.46 \\
\hline
\end{tabular}

Tab. 3.3: ELISA-Werte der Proteinextrakte von Primären Fibroblasten den verschiedenen TRE-Mauslinien nach transienter Transfektion mit einem Transaktivatorkonstruktes (pTet-Off).

ODs wurden gemessen mit $100 \mu \mathrm{g}$ Protein pro Ansatz und einer Antiserum-Verdünnung von 1:4. Die OD-Werte von nichttransfizierten Kontroll-Zellen (Daten nicht gezeigt) wurden als 0-Wert von allen ODs abgezogen. 
Die Isolierung und Kultivierung primärer Fibroblasten wurde wie unter 2.26.2 beschrieben durchgeführt. Nachdem genug Zellen in Kultur gewachsen waren (mindestens vier Näpfe einer 12-Well Platte), wurden sie mit einem CMV/tTA-Konstrukt transfiziert. Zwei der vier Näpfe wurden gleich nach der Transfektion mit Dox inkubiert. 48 h später wurden die Zellen geerntet und das induzierte Prm3-Protein in den Proteinextrakten (2.19.1) mit Western-Blots und ELISA-Assays nachgewiesen. Um eine Normalisierung der Ergebnisse für die variable Transfektionseffizienz zu ermöglichen, wurde eine Kotransfektion mit dem CMV- $\beta$-GalPlasmid durchgeführt. Alle ODs wurden durch die $\beta$-Gal Aktivität der jeweiligen Kultur geteilt.

Tabelle 3.3 und Abb. 3.25 zeigen die ELISA-Ergebnisse für alle fünf transgenen Linien.

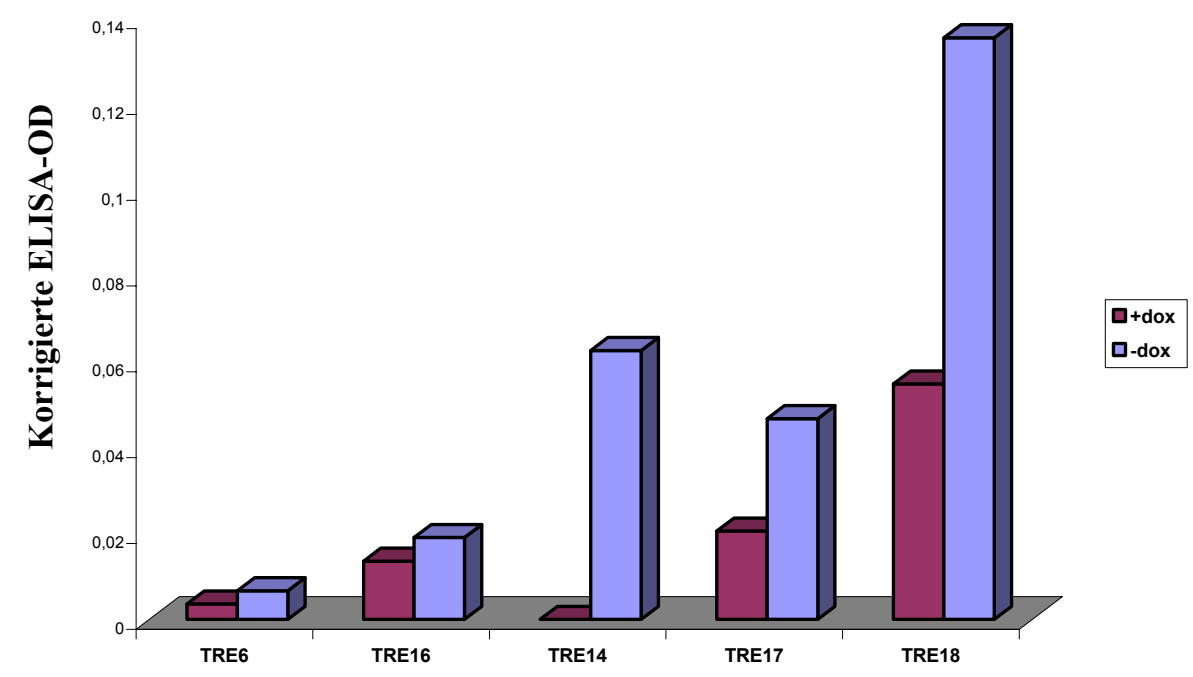

Abb. 3.25: Graphische Darstellung der ELISA-Werte aus Tab. 3.3..

Bei allen fünf transgenen Fo-Tieren konnte eine Synthese des Prm3-Proteins in den kultivierten Ohrfibroblasten nach der Transfektion mit dem Transaktivatorkonstrukt nachgewiesen werden. Alle Linien zeigten eine regulierbare, doxyzyklinabhängige Prm3Expression. Die Linie 18 zeigte den höchsten absoluten Wert für die Prm3-Expression, die Linie 14 zeigte den höchsten Aktivierungsfaktor. Drei Linien (Nr. 14, 17 und 18) wurden mit der Transaktivatorlinie weiterverpaart.

Neben den ELISA-Assays wurden auch Western-Blots aus den Proteinextrakten der Ohrfibroblastenkultur durchgeführt. $200 \mu \mathrm{g}$ Protein wurde im SDS-PAGE aufgetrennt, auf 
eine Nitrocellulosemembran transferriert und mit Prm3-Antiserum und AP-konjugiertem antiKaninchen Antikörper mittels NBT/BCIP Färbung detektiert. Wie auch im ELISA zeigten die Linien 14, 17 und 18 die stärkste Prm3-Induktion mit dem geringstem Hintergrund (siehe Abb. 3.26).

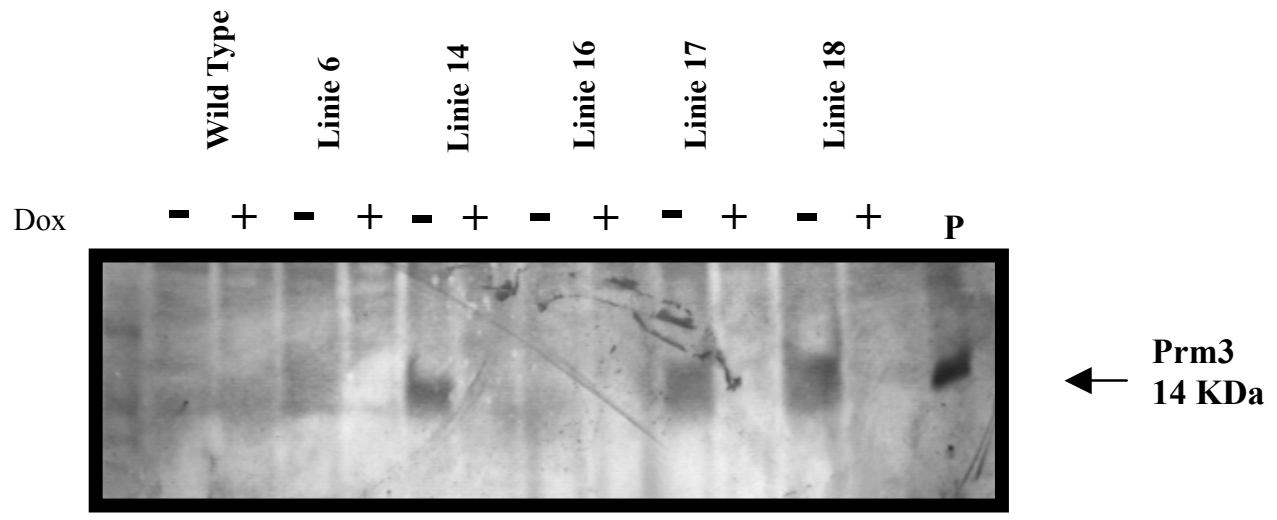

Abb. 3.26: Western-Blot Analyse der Prm3-Expression in Ohrfibroblasten der TRE/Prm3-Linien, transient transfiziert mit CMV-Tet-Off, behandelt mit und ohne Dox.

$200 \mu \mathrm{g}$ der Proteinextrakte der transient transfizierten Fibroblasten wurde mittels SDS-PAGE aufgetrennt, auf eine Nitrocellulose transferiert und mit Prm3-Antiserum und AP-konjugiertem-anti-Kaninchen Antikörper mittels NBT/BCIP Färbung detektiert. P = Positivkontrolle (Maus-Testis-Proteine, $100 \mu \mathrm{g}$ )

\subsubsection{Transgene Maus für den Tetracyclin-abhängigen Transaktivator tTA}

Neben den unter 3.10.1 beschriebenen Responder-Linien wurde als zweite Komponente des transgenen Tet-Systems eine Transaktivator-Linie benötigt. Von den Jackson Laboratories (Maine, USA) wurde die Linie CMV/tTA bezogen. Diese Linie war ursprünglich von Gossen und Bujard (1994) erzeugt und beschrieben worden. Laut Publikation ist das TransaktivatorProtein in allen Geweben anwesend, die stärkste Expression (und Aktivierung von Respondergenen) soll im Thymus, in der Skelettmuskulatur und in der Zunge zu finden sein.

Abb. 3.27: Schematische Darstellung des CMV-tTA-Konstrukts.

Der tTA-(Tetrazyklin-abhängige-Transaktivator)-Leserahmen wird vom ubiquitär aktiven CMV-Promotor reguliert. Eine SV40-3'UTR und ein Polyadenylierungssignal stabilisieren die mRNA. 


\subsubsection{Analyse der doppelt transgenen Tiere TRE/Prm3//CMV/tTA}

Die Nachkommen aus den Verpaarungen von TRE/Prm3 und CMV/tTA-Tieren wurden zunächst auf Transgenität für beide Konstrukte und dann im Western-Blot auf die Anwesenheit des Prm3-Proteins getestet. Dieses konnte lediglich in der Zunge nachgewiesen werden (Abb. 3.28). Auch im Thymus (laut Gossen und Bujard (1994) das Gewebe mit der stärksten tTA-Expression) konnte kein Prm3-Protein nachgewiesen werden (nicht abgebildet).

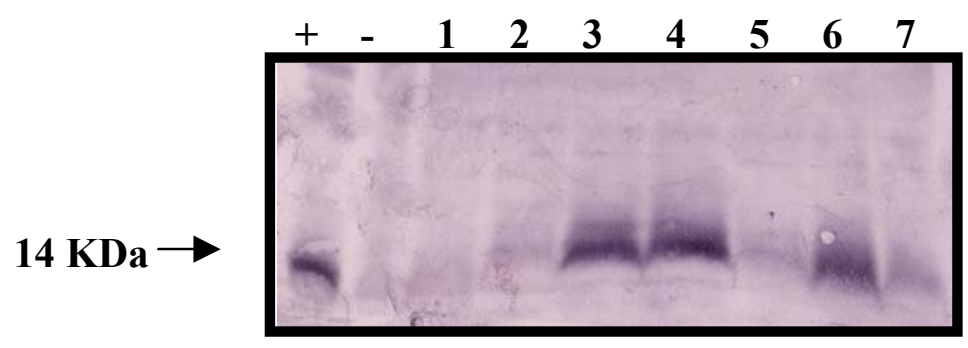

Abb. 3.28: Western Blot-Analyse der Zungen-Proteine von doppelt transgenen Tieren TRE/Prm $3 / / \mathrm{CMV} / \mathrm{tTA}$ (Spuren 3,4 und 6) und einfach transgenen (TRE/Prm3; 1,2,5 und 7).

Jeweils $100 \mu \mathrm{g}$ Protein wurde im Western-Blot eingesetzt. Proteinextrakte aus Wildtyp-Testis und Leber wurden als Positiv- bzw. Negativkontrolle verwendet. Ein starkes Prm3-Signal ist in den Spuren 3, 4 und 6 sichtbar. Ein schwaches Prm3-Signal in den einfach transgenen Tieren (1, 2, 5 und 7) spiegelt die „leaky“-Expression vom TRE-Promotor wieder.

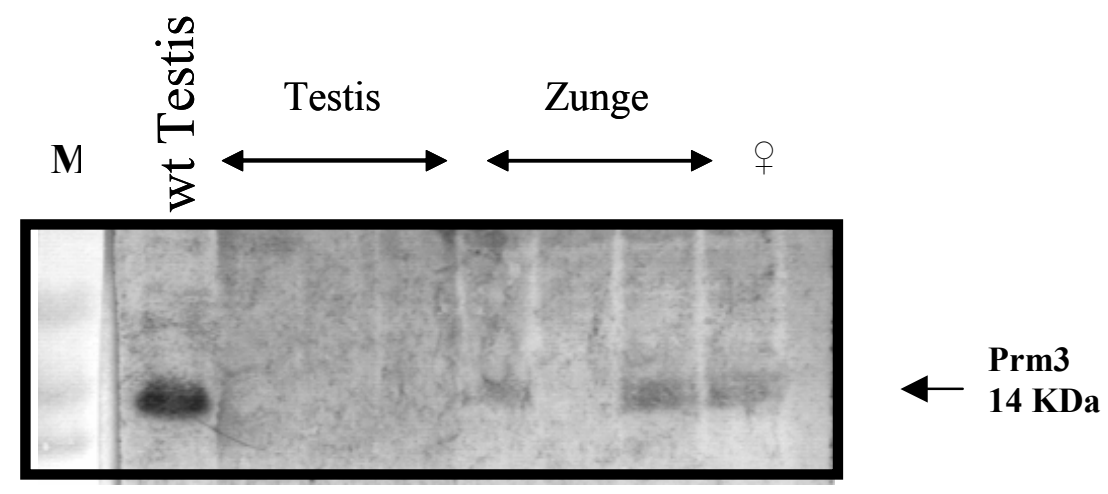

Abb. 3.29: Western Blot-Analyse für Zungen- und Testis-Proteine 23 Tage alter Mäuse aus der HeterozygotenVerpaarung TRE/Prm3 mit CMV/tTA.

Jeweils $100 \mu \mathrm{g}$ Protein wurde im Western Blot eingesetzt. Die Expression des Prm3-Proteins ist in der Zunge aber nicht im Testis der 23 Tage alten Mäuse sichtbar. Die Expression wurde auch in der Zunge eines weiblichen Tieres (+) detektiert. 
Als nächstes sollte festgestellt werden, ob das transgene Prm3-Protein auch im Testis (unabhängig vom endogenen Prm3) synthetisiert wird. Dazu wurden 23 Tage alten Mäuse getestet (das Prm3-Protein ist im Testis von Wildtyp-Mäusen erst ab Tag 25 anwesend). Wie in Abb. 3.29 sichtbar, konnte keine Prm3-Synthese im Testis 23 Tage alter männlicher Mäuse festgestellt werden.

Schließlich wurde die Regulierbarkeit der Prm3-Expression in den doppelt transgenen Mäusen getestet. Die Tiere der Linie TREPrm3//CMV/tTA wurden 5 Tage unter Dox gesetzt. Als Kontrolle diente ein doppelt-transgenes Tier ohne Dox-Behandlung. Zungen-Proteine wurden präpariert und auf Anwesenheit des transgenen Prm3-Proteins untersucht. Wie in Abb. 3.30 sichtbar, verursacht die Dox-Zugabe keine sichtbare Reduktion der Prm3Expression.

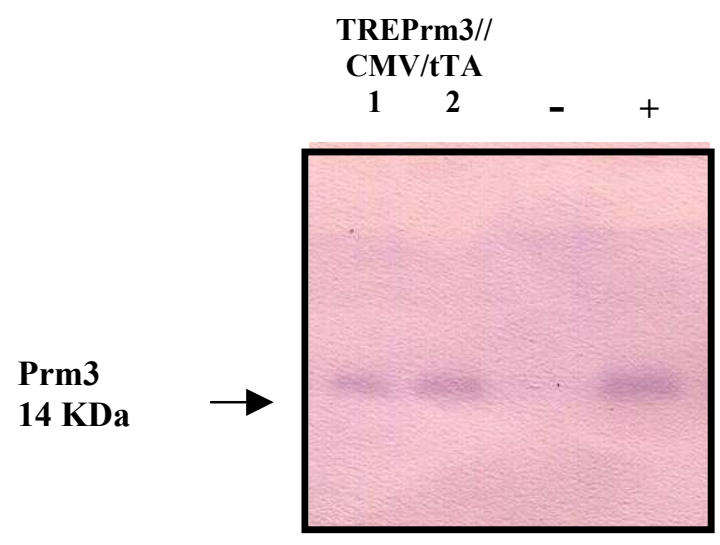

Abb. 3.30: Western-Blot-Analyse für Zungen-Proteine der doppelt transgenen Tiere TRE/Prm3//CMV/tTA mit oder ohne Dox-Zugabe.

In den Spuren 1 und 2 Extrakte von Dox-behandelten Tieren. - = Negativkontrolle (Proteine aus Wildtyp Zunge),$+=$ Positivkontrolle (Proteine von doppelt-transgenen Tier ohne Dox-Behandlung).

\subsubsection{Act/tTA-Aktivator-Linien}

Zwei weitere Transaktivator-Linien wurde von Dr. Antonio Servadio, Padua, bezogen. Bei diesen Linien ist die tTA-Sequenz hinter den humanen Actin-Promotor kloniert (Abb.3.31). In den transgenen Linien ergaben sich durch Positionseffekte unterschiedliche GewebsExpressionsmuster für das tTA-Transkript. Die beiden Linien Act45 und Act88 zeigen nach 
Angaben von Dr. Servadio eine hauptsächliche tTA-Aktivität im Testis, daneben auch im Gehirn und im geringen Maße im Ovar.

\begin{tabular}{|l|l|l|}
\hline Actin Promotor & tTA (tetR+VP16) & SV40 \\
\hline
\end{tabular}

Abb. 3.31: Schematische Darstellung des Act/tTA-Konstrukts.

Der tTA-(Tetrazyklin-abhängiger Transaktivator)-Leserahmen wird vom Actin-Promotor reguliert. Eine SV403'UTR und ein Polyadenylierungssignal stabilisieren die mRNA.

\subsubsection{Expressionsanalysen in Act/tTA transgenen Mäusen durch Northern-Blot- Analysen}

Gesamt-RNA wurde aus Leber, Niere, Gehirn, Lunge, Zunge und Testis transgener Mäuse der Linie Act88 präpariert und jeweils $20 \mu \mathrm{g}$ RNA in einer Northern Blot-Analyse eingesetzt. Das ca. 1,9 $\mathrm{Kb}$ große tTA-Transkript konnte in Testis und Gehirn detektiert werden (Abb. 3.32). Für die Hybridisierung wurde die tet-spezifische Sonde (2.8.3) verwendet.

Mu Te He Ni Mi Zu Ge Le Lu

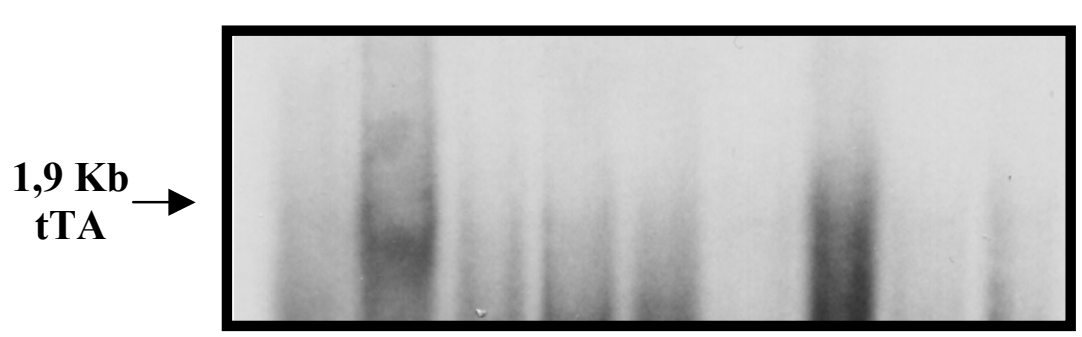

Abb. 3.32: Nachweis der Expression des Tet-Transaktivators in Act88-Tieren mit Hilfe eines Northern-Blots.

Es wurden je $20 \mu \mathrm{g}$ Gesamt-RNA aus Muskel, Testis, Herz, Niere, Milz, Zunge, Gehirn, Leber und Lunge aufgetragen und mit der Sonde TetR hybridisiert. Die tTA-Expression ist hauptsächlich im Testis und im Gehirn zu beobachten. 


\subsubsection{Untersuchungen der Act/tTA-transgenen Mäuse auf der Proteinebene}

Zum Nachweis des Tet-Transaktivatorproteins in Testisextrakten der Act/tTA-Linien wurden Western-Blots durchgeführt. Proteine aus Leber, Niere, Gehirn, Lunge, Zunge und Testis transgener Mäuse wurden isoliert und in einem Western-Blot unter Verwendung eines monoklonalen Antikörpers gegen das Tet-Protein (MoBiTec) analysiert. Das Tet-Protein konnte ausschließlich in der Zunge detektiert werden (Abb. 3.33).

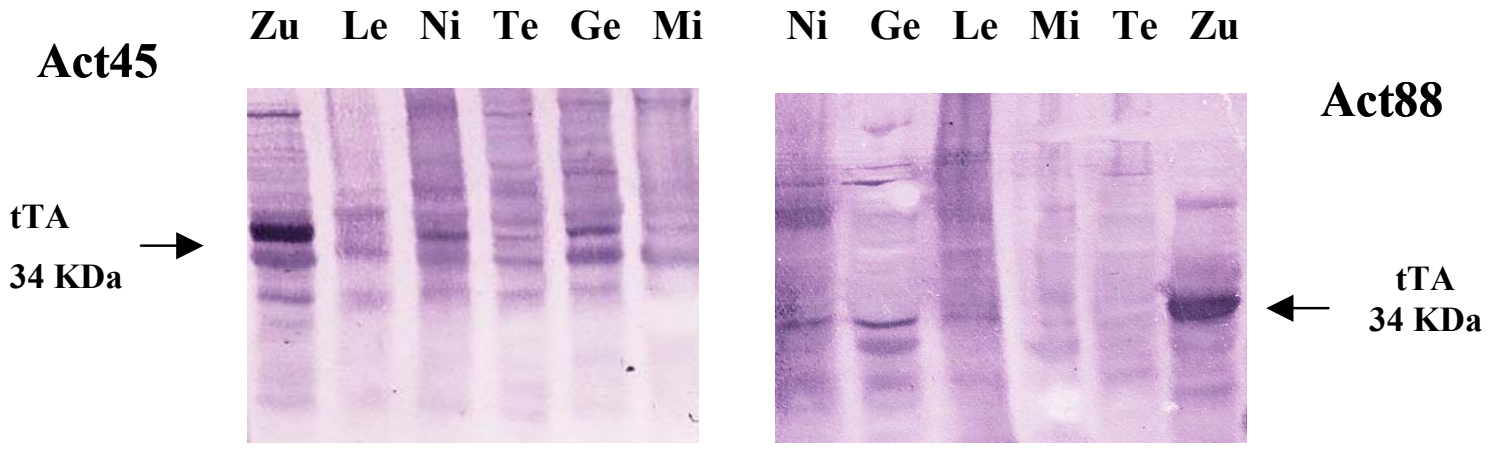

Abb. 3.33: Western-Blot-Analyse mit Proteinen aus Geweben der beiden Act-tTA-Linien (Act45 und Act88) unter Verwendung eines Tet-spezifischen Antikörpers.

Jeweils $100 \mu \mathrm{g}$ Protein verschiedener Gewebe der Linien Act45 und Act88 wurden im Western Blot eingesetzt. Die Expression des tTA-Proteins $(34 \mathrm{kDa}$ ) ist überwiegend in der Zunge sichtbar. (Zunge: $\mathrm{Zu}$, Leber: Le, Niere: Ni, Testis: Te, Gehirn: Ge und Milz: Mi).

\subsubsection{Western-Blot Analysen der doppelt transgenen Tiere TRE/Prm3//Act45}

Die Nachkommen aus den Verpaarungen von TRE/Prm3 und Act45-Tieren wurden zunächst auf Transgenität für beide Konstrukte getestet. Dann wurde im Western-Blot die Anwesenheit des Prm3-Proteins untersucht. Dieses konnte im Gehirn, im Testis und in der Zunge nachgewiesen werden (Abb. 3.34).

Als nächstes sollte festgestellt werden, ob das transgene Prm3-Protein im Testis (unabhängig vom endogenen Prm3) vorzeitig synthetisiert wird. Dazu wurden 22 Tage alte Mäuse getestet (das Prm3-Protein ist im Testis von Wildtyp-Mäusen erst ab Tag 25 anwesend). Wie in Abb. 
3.35 sichtbar, konnte keine Prm3-Synthese im Testis 22 Tage alter männlicher Mäusen festgestellt werden.

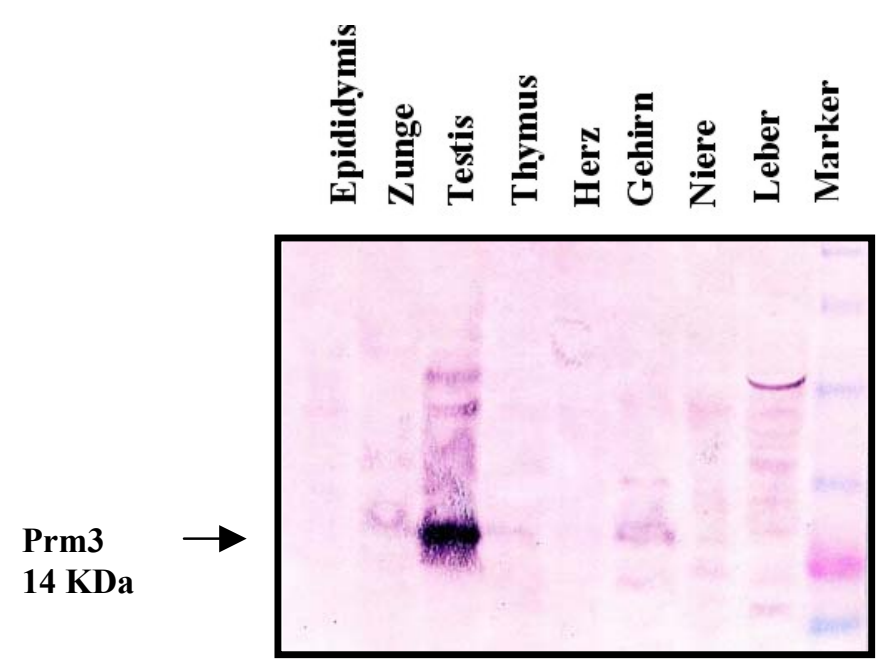

Abb. 3.34: Western-Blot-Analyse mit Proteinen aus Geweben der TRE/Prm3//Act45-Tiere unter Verwendung des Prm3-Antikörper.

Das Prm3-Signal ist stark im Testis und schwächer im Gehirn und Zunge sichtbar.

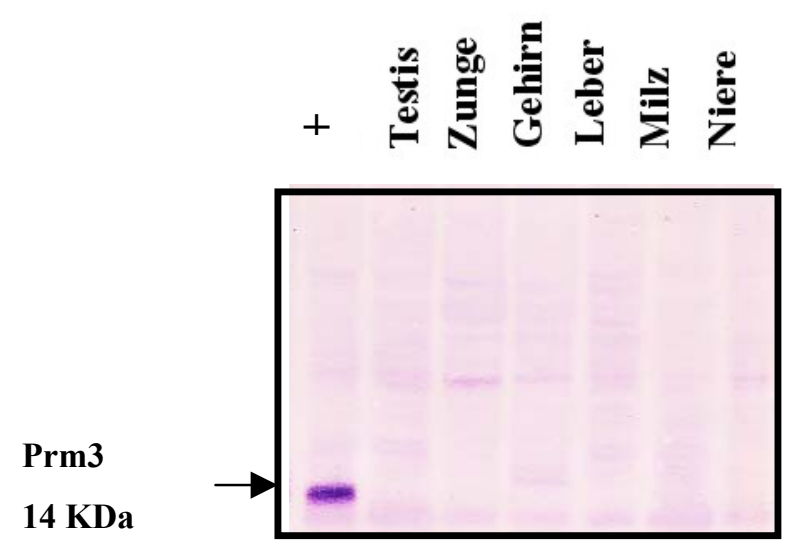

Abb. 3.35: Western-Blot-Analyse mit Proteinen aus Geweben von 22 Tage alten doppelt transgenen Tiere TRE/Prm3//Act45 unter Verwendung den Prm3-Antikörper.

Es konnte kein Signal für Prm3 nachgewiesen werden. Als Positiv-Kontrolle (+) wurden Proteine aus adultem Wildtyp Testis genommen. 


\subsubsection{Immundetektion des Prm3-Proteins auf Testis- und Epididymisschnitten doppelt transgener Tiere TRE/Prm3//Act45}

Durch eine immunohistochemische Färbung sollte die Lokalisation des Prm3-Proteins im Testisgewebe der TRE/Prm3//Act45-Tiere untersucht werden. Im Abb. 3.36 sind Querschnitte durch Maus-Tubuli verschiedener Stadien gezeigt. Eine Prm3-positive Reaktion konnte in den Stadien IX bis VII (Spermatiden Schritten 9 bis 16) festgestellt werden. Dies entspricht den Stadien, in denen das Prm3-Protein in Wildtyp-Mausgeweben exprimiert wird.

A

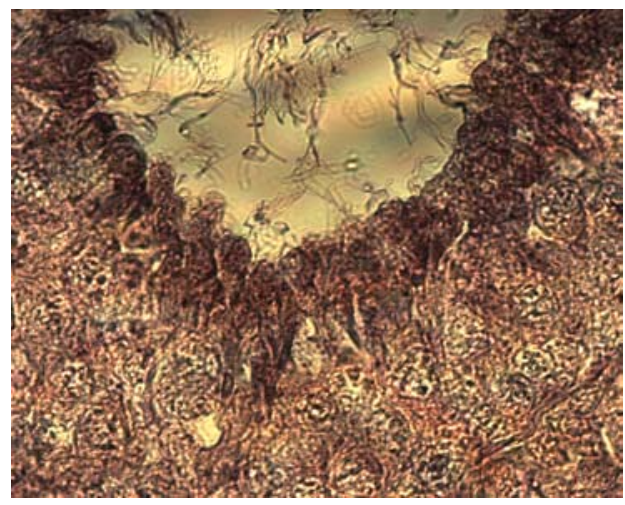

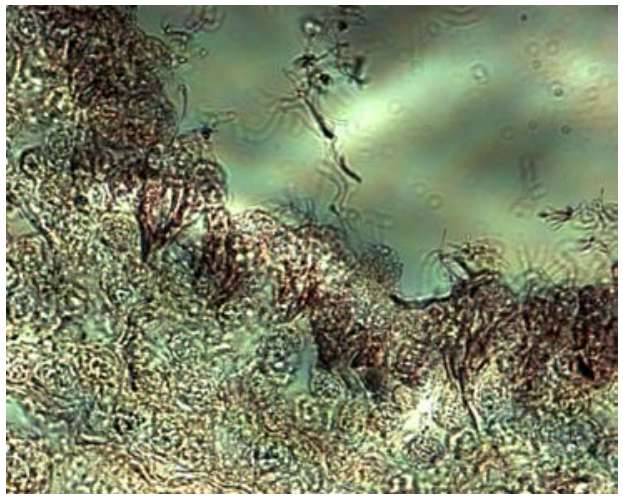

B

Abb.3.36: Immunohistochemische Lokalisierung des Prm3-Proteins TRE/Prm3//Act45 mit Hilfe des Prm3Antikörpers und des AP-gekoppeltem Zweitantikörpers.

Es konnte das Prm3-Protein ab Stadien IX detektiert werden.

Es wurde auch Epididymis aus TRE/Prm3//Act45-Mäusen immunohistochemisch untersucht (Abb.3.37 A-C). Es konnten große, runde Zellen festgestellt werden, die spezifisch gefärbt worden sind. Abb. 3.37 D zeigt zum Vergleich ein Schnitt durch Wildtyp-Epididymis. Es sind keine gefärbten Zellen zu sehen. 
A
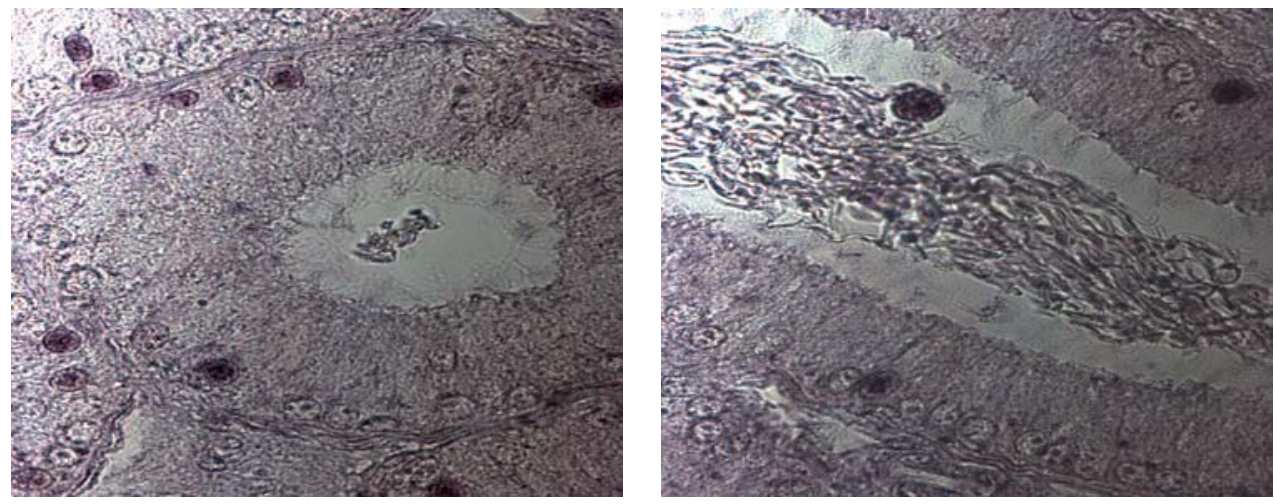

C

B
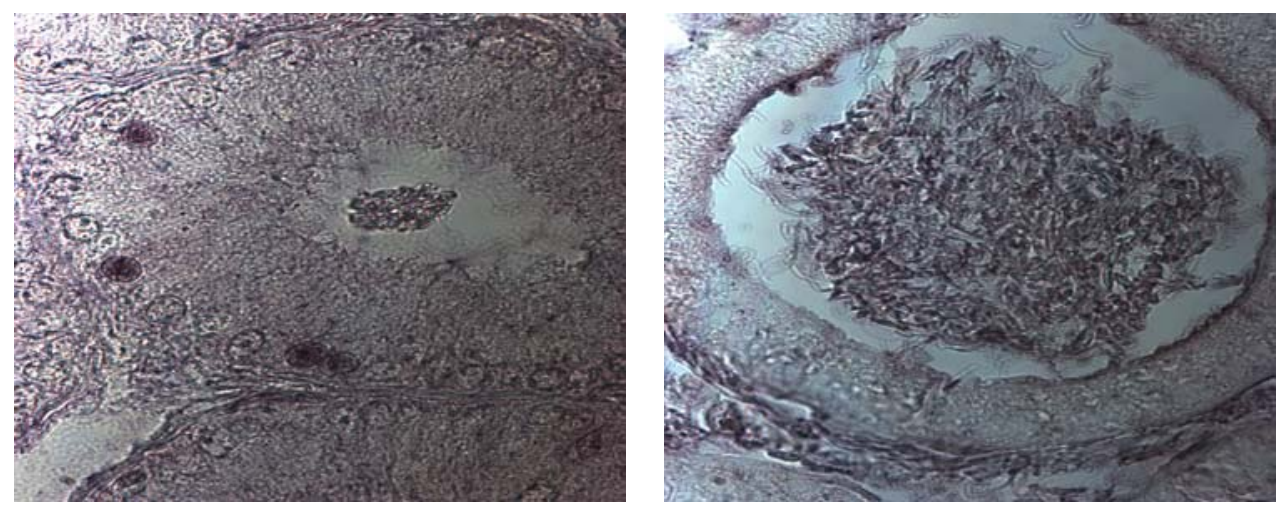

Abb. 3.37: Immunohistochemische Lokalisierung des Prm3-Protein in Epididymis von doppelt transgenen Mäuse (TRE/Prm3//Act45) und Wildtyp-Maus (D) mittels Prm3-Antikörpern und AP-gekoppeltem Zweitantikörper. Im Epididymis von doppelt transgenen Tieren konnten große, runde, gefärbte Zellen festgestellt werden (A-C), die im Epididymis von WT nicht gefärbt sind (D).

\subsection{Homologe Rekombination des Prm3-Gens}

Um die Funktion eines Gens in vivo zu untersuchen, kann in Mäusen mit Hilfe der homologen Rekombination ein Gen gezielt ausgeschaltet werden (Erzeugung von sog. „Knock-out Mäusen"). Die Inaktivierung des Gens erfolgt in embryonalen Stammzellen (ES-Zellen) unter Verwendung eines Targeting-Vektors vom Replacement-Typ: die Gen-Sequenz des nativen Allels wird gegen das Neomycin-Gen (Neo-Kassette) ausgetauscht (Ausubel et al., 1994; Capecchi, 1989), die für die positive Selektion der rekombinanten ES-Zellen (Resistenz gegen G418) nötig ist. Der Austausch erfolgt durch homologe Rekombination über genomische Fragmente, die die Neo-Kassette flankieren. Deren Gesamtgröße sollte $\geq 7 \mathrm{~Kb}$ betragen (Joyner, 2000), und sie müssen in korrekter Anordnung und Orientierung zur Zielgensequenz an die Neo-Kassette kloniert werden. 
Der Targeting-Vektor pTKneo (siehe. 2.8.2), dessen Gesamtgröße 8,3 Kb beträgt, basiert auf dem pBluescript-Vektor und enthält somit eine Ampicilin-Resistenz zur Selektion auf geeigneten Agarplatten (s. 2.5.1). Außer der Neo-Kassette, die einen Promotor und ein Polyadenylierungssignal der Phosphoglyceratkinase (PGK) besitzt, sind in dem Vektor zwei Kopien des Herpes simplex-Virus 1-Thymidinkinase-Gens (HSV-TK) in 5'-Richtung der Neo-Kassette vorhanden. Die TK-Gene dienen der Negativselektion der embryonalen Stammzellen in Gancyclovir-Medium. In 5'- und 3'- Richtung der Neo-Kassette befinden sich Polylinker-Sequenzen, die zur Klonierung der flankierenden genomischen Sequenzen dienen.

\subsubsection{Herstellung eines Prm3-Knock-out-Konstrukts}

Das Prm3-Gen kommt im Maus-Genom nur in einer Kopie vor („Single-copy-Gen“) und besteht nur aus einem einzigen Exon (Schlüter et al., 1996). Daher sollte die kodierende Sequenz von $330 \mathrm{Bp}$ vollständig entfernt werden.

Für die homologe Rekombination wurden zwei genomische Fragmente benutzt, die das Prm3Gen der Maus flankieren (3,5 Kb im 5' Richtung und 4,9 Kb im 3' Richtung von dem Gen). Durch die Verwendung isogener, d.h. aus dem gleichen Mausstamm wie die ES-Zellen stammender DNA, wird die Rekombinationsfrequenz erheblich gesteigert (Melton, 1994). Weil in der Umgebung des Prm3-Gens keine geeigneten Schnittstellen vorhanden waren, wurden Teile der nötigen Sequenzen mittels PCR an ES-Zell-DNA des Stammes 129/SvJ amplifiziert.

Unter Verwendung der Primer KOSacF und KOSpeR wurde aus ES-Zell-DNA ein ca. 3,5 Kb großes Fragment amplifiziert, das den 5'-Arm des Konstruktes bildete. Der Primer KOSacF enthält eine SacII-Schnittstelle, der Primer KONotR eine NotI Schnittstelle, so daß das amplifizierte Fragment mit diesen Enzymen gespalten und in den pTKneo Vektor einkloniert werden konnte. Zuvor wurde das Amplifikat in den pGEM-T Easy Vektor gebracht und durch Primer-Walking und Subklonierungen vollständig sequenziert. Ein 5'-wärts von Prm3 liegender Bereich von $\sim 900$ Bp enthielt 6 Punktmutationen und musste ersetzt werden. Dies konnte durch Austausch eines 1,6 Kb großen SpeI/AccI-Fragments (s. Abb. 3.38) gegen die entsprechende Sequenz aus einem P1-Klon (freundlicherweise von Dr. Adham zur Verfügung gestellt) erreicht werden. Anschließend konnte das gesamte 3,4 $\mathrm{Kb}$ lange Fragment mittels SacII- und NotI-Klonierung in den pTKneo Vektor integriert werden. 

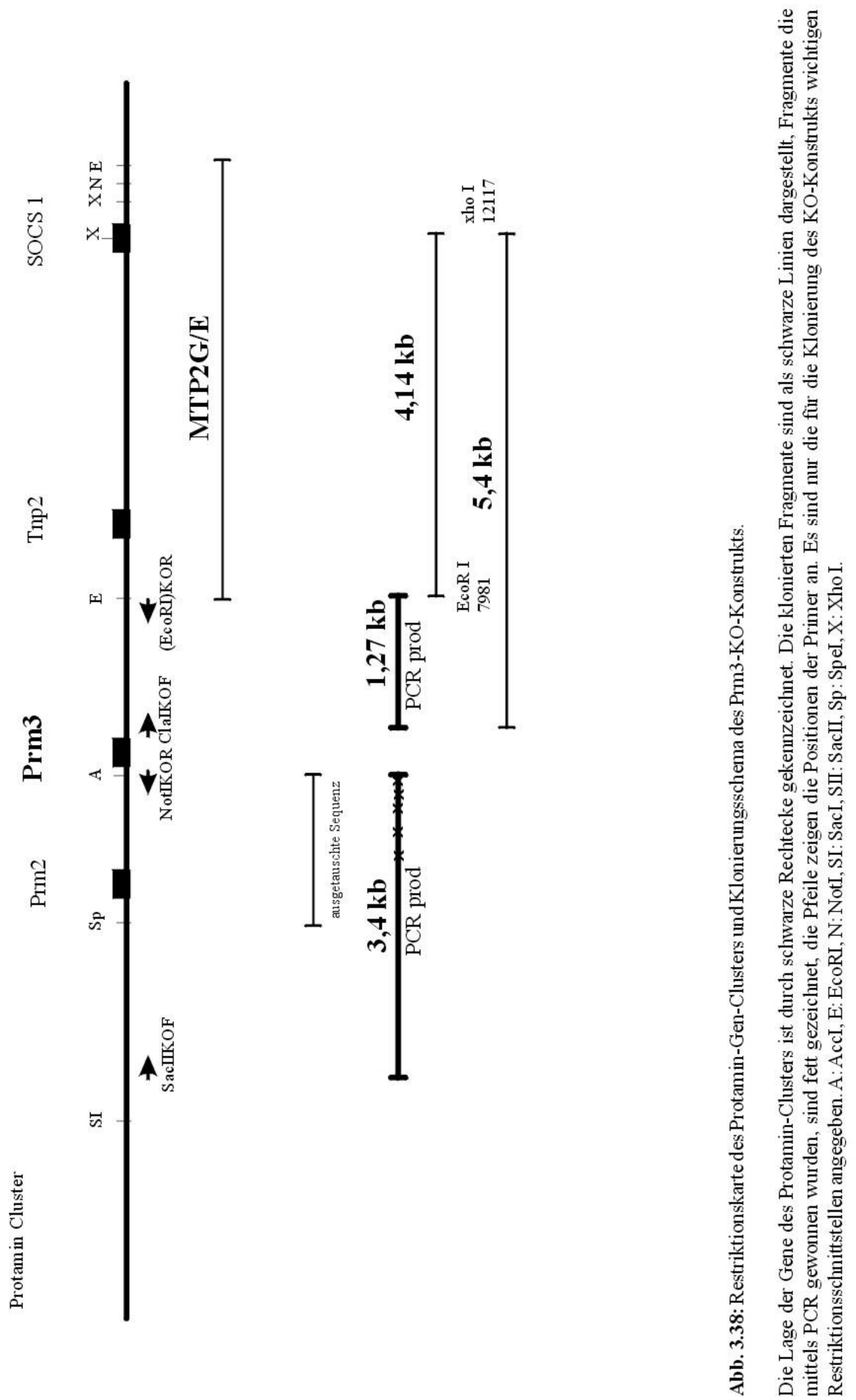


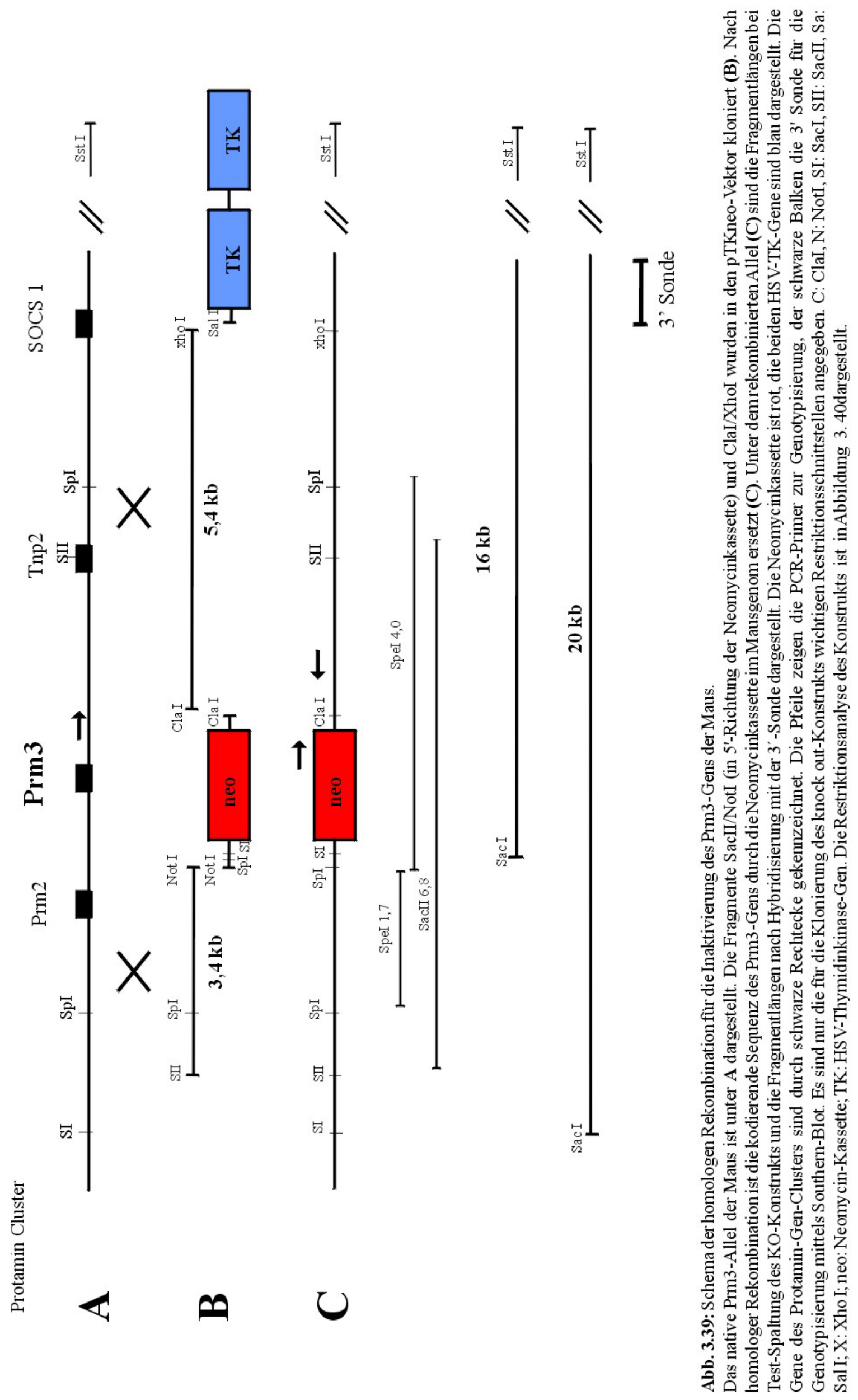


Der 3' Arm wurde zunächst im pBSC-Vektor vorbereitet. Ein 1,27 Kb großes PCR Produkt (Abb. 3.38) wurde mit den Primern KOClaF und KO(Eco)R amplifiziert, in den pGEMT Easy Vektor kloniert und sequenziert. Das Fragment wurde mit ClaI (für welches eine Schnittstelle im Primer vorhanden ist) und der nativen EcoRI-Stelle ausgeschnitten und in den pBSC Vektor kloniert. Das entstandene Konstrukt wurde mit EcoRI und NotI geöffnet und ein 4,1 $\mathrm{Kb}$ großes EcoRI/NotI-Fragment aus dem Klon MTP2G/E wurde einkloniert. Der auf diese Weise erhaltene $3^{\prime}$ Arm wurde mittels ClaI/XhoI in das KO-Konstrukt zwischen die ClaI/SalI Schnittstellen gebracht (s. Abb. 3.39). XhoI und SalI sind kompatible Enzyme, die gegenseitig ligierbare Überhänge erzeugen. Durch die Ligation gehen die Erkennungspalindrome der Ausgangssequenz verloren.

Um die Struktur des Konstrukts zu überprüfen, wurde die DNA mit XhoI, SpeI und SacII verdaut. SacII spaltet das Konstrukt in 3 Fragmente von 2,9 Kb, 6,8 Kb und 7,5 Kb. Der SpeIVerdau erzeugt 1,7 Kb, 4,0 Kb und 11,5 Kb große Fragmente. Die Schnittstellen sind in Abb. 3. 39 dargestellt.

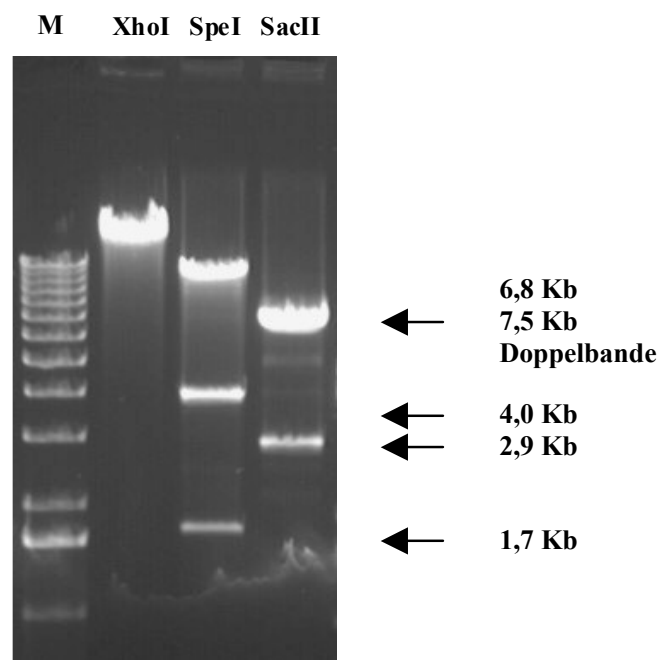

Abb. 3.40: Restriktionsanalyse des Prm3-KO-Konstrukts.

Die Prm3-KO-Konstrukt-DNA wurde mit XhoI, SpeI und SacII gespalten.

SacII spaltet das Konstrukt in drei Fragmente von 2,9 Kb, 6,8 Kb und 7,5 Kb. Die beiden letzten Fragmente sind in dem normalen Agarosegel nicht zu trennen. Der SpeI-Verdau erzeugt 1,7 Kb, 4,0 Kb und 11,5 Kb Fragmente. Die Schnittstellen sind in Abb. 3. 35 dargestellt.

Die Restriktion mit XhoI, das zur Linearisierung des fertigen Konstrukts dienen sollte, zeigt die Anwesenheit nur einer Restriktionsschnittstelle, sowie die Gesamtgröße des klonierten KO-Konstrukts von 17,1 Kb. M: Längestandard 
Die Restriktion mit XhoI, das für die Linearisierung des fertigen Konstrukts dienen sollte, zeigt nur eine Bande, mithin die Anwesenheit nur einer Schnittstelle, sowie die Gesamtgröße des klonierten KO-Konstrukts von 17,1 Kb. Die Restriktionsanalyse des Prm3-KOKonstrukts ist in Abb. 3.40 gezeigt.

\subsubsection{Herstellung von homolog rekombinierten ES-Zellen}

RI-ES-Zellen wurden wie unter 2.24.7.2 beschrieben mit $100 \mu \mathrm{g}$ linearisiertem KO-Konstrukt transfiziert. Bei erfolgreicher homologer Rekombination würde die gesamte kodierende Sequenz von Prm3 durch das Neomycin-Gen ersetzt werden (Abb.3.39). Nach der Kultivierung der ES-Zellen unter Neomycin- und Gancyclovir-Selektion wurden 120 doppeltresistente Klone isoliert (siehe 2.24.7.3). Die von Replica-Platten isolierte ES-Zell-DNA wurde mit SacI geschnitten und in einem genomischen Southern-Blot analysiert. Die Hybridisierung erfolgte mit der externen 400 Bp 3'-Sonde 0,4Xho (Abb. 3.39). Hierbei sollte das endogene Allel des Prm3 Gens eine ca. $20 \mathrm{~Kb}$ große Bande zeigen, beim homolog rekombinierten Allel sollte durch eine zusätzliche SacI-Schnittstelle im Targeting-Vektor ein zusätzliches, um 4 Kb kürzeres Fragment entstehen (Abb. 3.39).

Es wurde ein positiver Klon gefunden (Abb. 3.41). Der rekombinante ES-Zell-Klon wurde noch einmal kultiviert und es wurde neue DNA gewonnen, um in einem zweiten SouthernBlot die Rekombination zu bestätigen.

$\begin{array}{lllllll}110 & 111 & 112 & 113 & 114 & 115 & 116\end{array}$

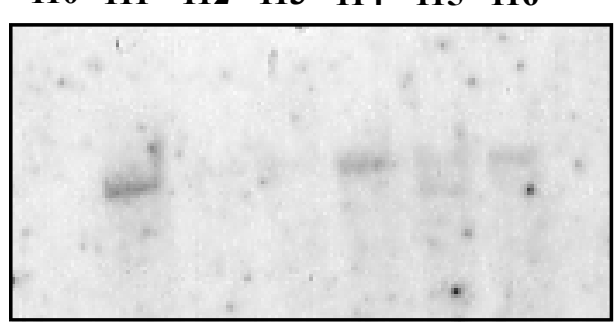

20 kb Wildtyp-Allel

$16 \mathrm{~kb}$ rekombinante-Allel

Abb. 3.41: Genotypisierung der ES-Zellklone mittels Southern-blot.

Die genomische ES-Zell-DNA wurde mit dem Enzym SstI enzymatisch gespalten, gelelektrophoretisch aufgetrennt und geblottet. Die Hybridisierung erfolgte mit der externen 0,4Xho-Sonde. Bei Klon 115 ist unterhalb der $20 \mathrm{~Kb}$ Wildtyp-Bande die rekombinante $16 \mathrm{~Kb}$ Bande zu erkennen. 


\subsubsection{Generierung von Prm3-defizienten Mäusen}

Die Injektion von rekombinanten ES-Zellen in Maus-Blastozysten und deren Transfer in pseudoschwangere Mäuse wurde von MitarbeiterInnen des Max-Planck-Instituts für Experimentelle Medizin, Göttingen, durchgeführt. 6 Mäuse mit 80-95\% Chimerismus wurden geboren und im hauseigenen Tierstall mit Tieren der Mauslinien C57/BL6 und 129/SvJ verpaart. Nachkommen werden im Alter von ca. 3-4 Wochen durch PCR-Analyse an DNA aus einer Schwanzbiopsie genotypisiert.

Die Genotypisierung der Nachkommen konnte im Rahmen dieser Arbeit nicht mehr durchgeführt werden. Allerdings wurde die dafür vorgesehene PCR etabliert. Dazu wurden drei verschiedene Primer eingesetzt, zwei aus dem nativen Prm3-Gen und einer aus der inserierten Neo-Kassette (s. Abb. 3.39). Die Primerkombination KOF3 / KOR3 ergibt ein Produkt für das native Allel von ca. 220 Bp. Mit dem reversen Primer neo R1 aus dem Targeting-Vektor und KOF3 entsteht ein Produkt von $420 \mathrm{Bp}$, so da $\beta$ mittels der amplifizierten Banden eine Genotypisierung zur Identifizierung heterozygoter Mäuse erfolgen kann.

Kurz vor Abgabe der Arbeit wurden die ersten F1-Würfe geboren. In zwei der Würfe waren alle Tiere braun. Dies bedeutet, daß die homolog rekombinierte ES-Zelllinie zu Bildung der Keimzellen beiträgt und mit größter Wahrscheinlichkeit eine Keinbahntransmission stattgefunden hat. 


\section{Diskussion}

\subsection{Prm3 und die Protamin/Transitionsprotein-Familie: ein Vergleich}

Im Rahmen der Spermatogenese werden eine Reihe von Genen aktiviert, die ausschließlich in den Zellen der männlichen Keimzellreihe gefunden werden. Ein wesentlicher Teil hiervon sind Strukturproteine (Protamine und Transitionsproteine), die Aufgaben bei der Kondensation des Spermatiden-Chromatins erfüllen. Diese Substitution der somatischen (und testisspezifischen) Histone durch keimzellspezifische Transitionsproteine und schließlich Protamine erfordert eine stringente zeitliche Orchestrierung der Abfolge der einzelnen RNAund Proteinsynthesen (Wouters-Tyrou et al., 1998). Wie in Tiermodellen gezeigt wurde, können Abweichungen im Expressionszeitpunkt als auch in der Menge der DNA-bindenden Proteine bedeutsame Konsequenzen (Lee et al., 1995; Wu et al., 2000; Yu et al., 2000; Giorgini et al., 2002) für die Spermatogenese mit sich bringen.

Prm3 ist als neues Gen im Protamin-Gencluster identifiziert wurden und nach ersten Befunden in die Familie der Protamine eingruppiert worden. Ein erster und wesentlicher Schritt zum Verständnis der Funktion von Prm3 war es daher, das Expressionsmuster von Prm3 auf mRNA- und Proteinebene genau zu analysieren.

\subsubsection{Vergleichende Analyse von mRNA- und Proteinexpression von Prm3 und anderen Mitgliedern der Protamin-Familie}

Bei der zeitlichen Zuordnung von Differenzierungsschritten und allgemeinen morphologischen Merkmalen unterschiedlicher Spermatogenese-Phasen benutzt man ein System, das die Zelltypen in bestimmte „Stadien“ einteilt. Innerhalb eines Querschnitts durch einen Tubulus semiferus kann man drei bis vier Etappen der Spermien-Entwicklung beobachten, die immer die gleiche räumliche Anordnung haben. Eine solche KeimzellGruppierung in einem Tubulus-Querschnitt nennt man ein Stadium. Bei der Maus kann man 12 Stadien abgrenzen (I-XII). Die Spermiogenese, die haploide Phase der Spermatogenese, unterteilt man noch zusätzlich in 16 Schritte. Eine komplette Serie der Entwicklungsetappen der Keimzellen in einem bestimmten Segment des Seminiferus epithelium nennt man einen Zyklus. Die Spermatogenese, das Entstehen von reifen Spermatozoen, benötigt in der Maus 
fast 4 Zyklen und dauert ca. 35 Tage. Ein Spermatogonium differenziert sich im ersten Zyklus (ca. 8,5 Tage, 207 \pm 6 Stunden) bis zu Zygotän-Spermatozyten und in dem zweiten bis zu sekundären Spermatozyten. In dem dritten Zyklus entwickeln sich die runden Spermatiden zu den elongierenden Spermatiden (Schritt 12), aus diesen entstehen schließlich in dem letzten Zyklus reife Spermien (ca. 4000 je Spermatogonium). In Abb. 4.1 wird eine schematische Darstellung den Stadien der Spermatogenese gezeigt. Alle weiter unten benutzten Stadienangaben beziehen sich auf dieses Einteilungssystem (Russel et al., 1990).

Die Transkription der Transitionsprotein- und Protamingene wurde in vielen Spezies detailliert untersucht. Hierbei sind die Ergebnisse der unterschiedlichen Arbeiten nicht immer einheitlich, was zum Teil auch auf die unterschiedlichen Methoden zurückzuführen ist. Mali et al. (1989) detektieren Tnp1-, Prm1- und Prm2-mRNA ab Stadium VII; Proteinsynthese findet in elongierenden oder elongierten Spermatiden statt.

Mittels in situ Hybridisierung wurde die Prm2-mRNA ab Tag 28 (auf dem Northern-Blot ab Tag 26), also ab ca. Stadium VII in runden Spermatiden detektiert (Iuchi et al., 2001). Aber es wurden auch Prm1-Transkripte in früheren Stadien nachgewiesen (Übersicht bei in Dadoune und Demoulin, 1993). Tnp2-mRNA wurde ab Stadium X beobachtet, jedoch wies Topaloglu (2001) Tnp2-mRNA schon am Tag 23 nach, was ca. dem Stadium IV entspricht. Morales et al. (1991) detektieren Tnp2 und Prm1 sogar ab Stadium I.

Auch das Erscheinungsmuster der entsprechenden DNA-bindenden Proteine ist nicht eindeutig beschrieben. Frühere Studien geben den Beginn der Translation der Transitionsproteine mit Stadium XII (Alfonso und Kistler, 1993), für Protamine mit Stadium IV an (Schritt 15, Spermatiden) (Bunick, 1990; Hecht, 1990;). Neuere immunohistochemische Studien zeigen Tnp2-Protein ab Stadium X. Auf dem Western-Blot wurde das Tnp2-Protein ab Tag 26 (ca. Stadium VII) (Topaloglu, 2001) beobachtet. Prm1- und Prm2-Proteine wurden ab Stadium X-XI bzw. ab Stadium XII (Lee et al., 1995) detektiert. Alle Autoren sind sich aber einig, da $\beta$ die in den runden Spermatiden vorbereiteten Transkripte erst in Form von Ribonukleoprotein-Partikeln (RNPs) im Zytoplasma gelagert und später translatiert werden. Im Fall der Transitionsproteine dauert die Lagerung ca. 3-4 Tage, die Protamin-Transkripte werden länger, nämlich ca. 7 Tage im Zytoplasma gelagert. Die Zeitabschnitte der Transkription und Translation dieser DNA-bindenden Proteine sind in der Abbildung 4.1 dargestellt und zusätzlich in der Tabelle 4.1 beschrieben. 

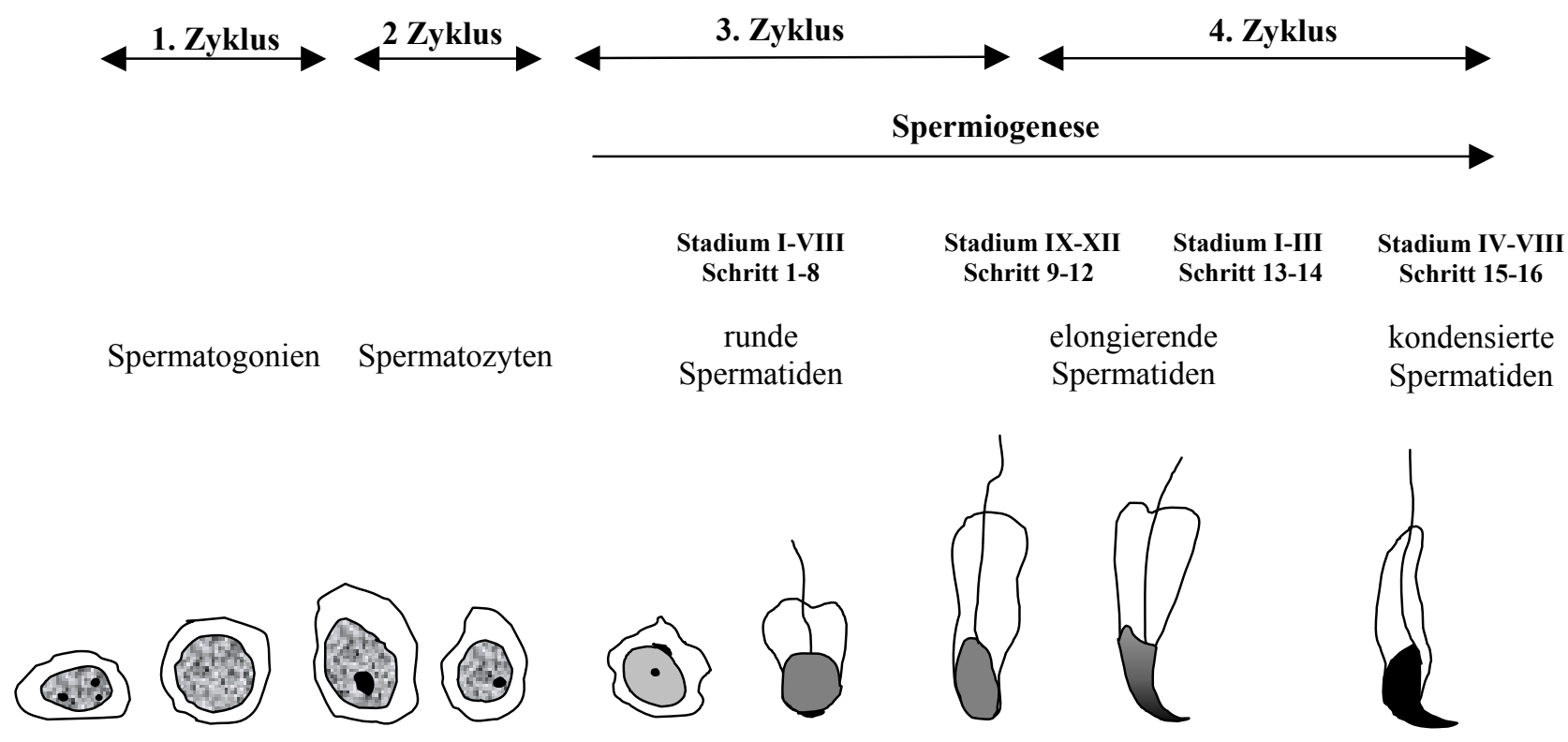

ca. Tag 20

ca. Tag 30

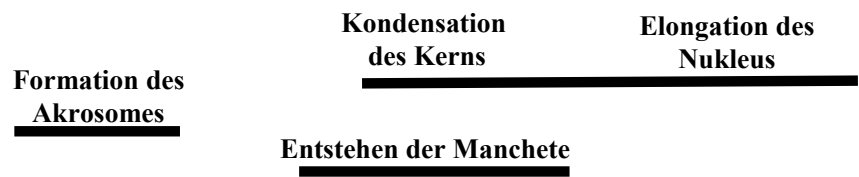

mRNA-Synthese

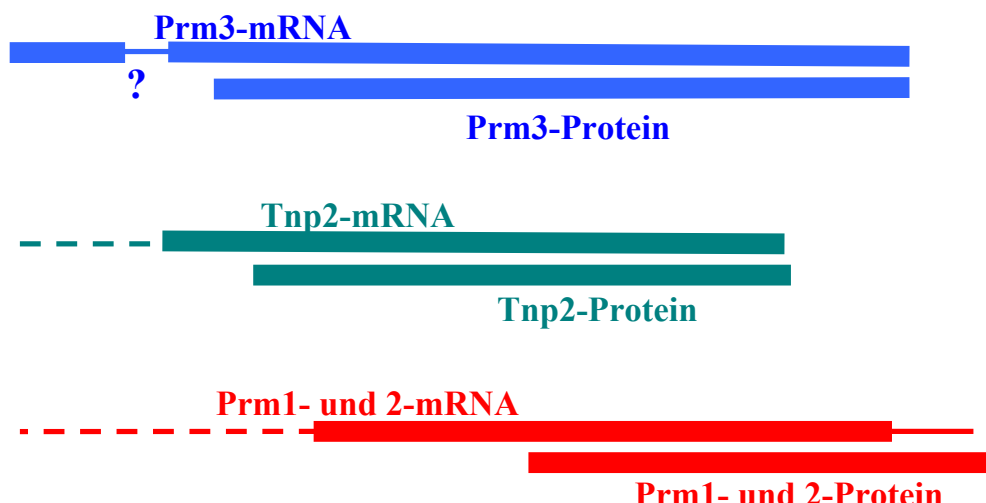

Abb. 4.1: Schematische Darstellung der Spermatogenese-Stadien. Unten: in den entsprechenden Zeitabschnitten lokalisierte einige wichtige Ereignisse der Spermiogenese als auch Transkriptions- und Translationsmuster einiger Gene, die während der Spermatogenese exprimiert werden. 
Auch viele andere Gene der haploiden Phase, wie auch in frühere Etappen der Spermatogenese unterliegen der translationalen Repression. Entsprechende Daten wurden für Y-box Proteine (Msy1, Mys2, Msy3 und Msy4), Proakrosin, Cyritestin, Hsp70t u.a. publiziert (Tab. 4.1).

\begin{tabular}{|c|c|c|}
\hline $\begin{array}{l}\text { Name des } \\
\text { Gens }\end{array}$ & Expression der mRNA & Expression des Proteins \\
\hline Tnp1 & Ab Schritt 7 (Heidaran et al., 1988) & Schritt 12 (Heidaran et al., 1988) \\
\hline Tnp2 & $\begin{array}{l}\text { ab Stadium X beobachtet } \\
\text { ab Tag 23, ca. Stadium IV Topaloglu } \\
(2001) \\
\text { ab Stadium I (Morales et al., 1991) }\end{array}$ & $\begin{array}{l}\text { von Stadium X bis zum Stadium I, in } \\
\text { Stadium II (Schritt 14) sinkt das } \\
\text { Proteinniveau } \\
\text { Schritt 12-14 (Alfonso und Kistler, 1993) } \\
\text { auf dem Western-Blot ab Tag } 26 \text { (ca. } \\
\text { Stadium VII) (Topaloglu, 2001) }\end{array}$ \\
\hline Prm1 & $\begin{array}{l}\text { Runde Spermatiden, (Hecht, 1986) } \\
\text { ab Stadium VII (Mali et al. 1989) } \\
\text { ab Stadium I Morales et al. (1991) }\end{array}$ & $\begin{array}{l}\text { Schritt 12-16 (Kleene, 1984) } \\
\text { (Meistrich, 1989) } \\
\text { (Mali et al., 1989) } \\
\text { (Biggiogera et al., 1992) }\end{array}$ \\
\hline Prm2 & $\begin{array}{l}\text { ab Tag } 28 \text { (auf dem Northern-Blot ab } \\
\text { Tag 26), ca. Stadium VII in runden } \\
\text { Spermatiden detektiert (Iuchi et al., } \\
\text { 2001). } \\
\text { Ab Schritt } 7 \text { elongierenden Spermatiden } \\
\text { (Übersicht in Braun, 1998) }\end{array}$ & $\begin{array}{l}\text { Schritt } 13 \text { (Balchorn et al., 1984; Meistrich, } \\
\text { 1989) } \\
\text { Schritte } 7 \text { bis } 14 \text { (Iuchi et al., 2001) }\end{array}$ \\
\hline $\begin{array}{l}\text { Msy1, } \\
\text { Msy3 }\end{array}$ & $\begin{array}{l}\text { Sehr schwach in Spermatogonien, stark } \\
\text { in Pachytän-Spermatozyten, runden und } \\
\text { elongierenden Spermatiden (Mastran- } \\
\text { gelo und Kleene, 2000) }\end{array}$ & Keine Angaben \\
\hline Msy2 & $\begin{array}{l}\text { Ab Anfang der Meiose (12 Tage alte } \\
\text { Mäuse) durch ganze Spermatogenese, } \\
\text { (Gu et al., 1998) }\end{array}$ & $\begin{array}{l}\text { Ab Pachytän-Spermatozyten, in runden } \\
\text { Spermatiden sehr stark und schwächer in } \\
\text { elongierenden Spermatiden (Oko et al., 1996) }\end{array}$ \\
\hline Msy4 & Keine Angaben & $\begin{array}{l}\text { Pachytän-Spermatozyten, runde Spermatiden } \\
\text { (Davies et al., 2000; Goirgini et al., 2002) }\end{array}$ \\
\hline Cyritestin & Ab Tag 14 (Linder et al., 1995) & $\begin{array}{l}\text { Ab Tag 17-18 (Linder et al., 1995; Forsbach } \\
\text { und Heinlein, 1998) }\end{array}$ \\
\hline Proakrosin & $\begin{array}{l}\text { späte Pachyten-Spermatozyten, (Kashi- } \\
\text { wabara et al., 1990; Kremling et al., } \\
\text { 1991a; Nayernia et al., 1992) }\end{array}$ & $\begin{array}{l}\text { runden Spermatiden, (Nayernia et al., 1992, } \\
\text { 1994) }\end{array}$ \\
\hline $\begin{array}{l}\text { Tenr } \\
\text { (testis nuclear } \\
\text { RNA binding } \\
\text { protein) }\end{array}$ & $\begin{array}{l}\text { Pachytän-Spermatozyten bis runde } \\
\text { Spermatiden (Schumacher et al., 1995) }\end{array}$ & $\begin{array}{l}\text { Runde und frühe elongierende Spermatiden } \\
\text { (Schumacher et al., 1995) }\end{array}$ \\
\hline $\begin{array}{l}\text { Hsp70t } \\
\text { (Heat shock } \\
\text { protein } 70 \mathrm{t})\end{array}$ & $\begin{array}{l}\text { Runde Spermatiden (Tsunekawa et al., } \\
\text { 1999) }\end{array}$ & 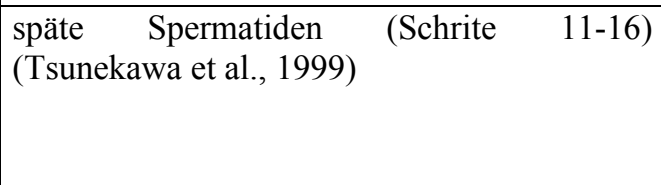 \\
\hline
\end{tabular}


Das Prm3-Gen wurde als neues Mitglied der Protamin-Genfamilie identifiziert (Schlüter, 1995). Es liegt inmitten des Protamin-Gen-Clusters, der bei allen bis jetzt untersuchten Spezies konserviert ist (Abb.1.1). Die Untersuchungen des Prm3-Expressionsmusters der Ratte und teilweise der Maus haben gezeigt, daß Prm3 in der haploiden Phase der Spermatogenese exprimiert wird (Schlüter und Engel, 1995; Schlüter et al., 1996; Schlüter, 1996). In der Ratte kann das $0,4 \mathrm{~Kb}$ große Prm3-Transkript ausschlie $\beta$ lich im Testis ab Tag 23 detektiert werden, also zu dem gleichen Zeitpunkt, an dem die Prm1-mRNA in der Ratte erscheint (Hecht et al., 1986). Die Prm3-Expression der Maus wurde in separierten Keimzellen und in verschiedenen Maus-Mutanten mit Spermatogenese-Störungen untersucht. Um die Prm3-Expression der Maus in den zeitlichen Rahmen der Spermatogenese einordnen zu können, wurde in dieser Arbeit ein detailliertes Prm3-Expressionsmuster auf RNA und Proteinebene dargestellt.

Durch Northern-Blot-Hybridisierungen an Gesamt-RNA aus Testes verschieden alter Mäuse (17-26 Tage) konnte das Prm3-Transkript erstmals in Testis 20 Tage alter Mäuse (ca. Schritt 1, runde Spermatiden) nachgewiesen werden (Abb.3.2). Man kann also die Expression des Prm3-Gens, ähnlich wie die der Transitionsprotein- und anderer Protamin-Gene, auf die haploide Phase der Spermatogenese eingrenzen. Western-Blots zeigen, daß das Prm3-Protein erst ab Tag 25 (p.n.) der Maus-Entwicklung (Abb.3.4), ausschließlich im Testis (Abb.3.3) nachweisbar ist. Auch in olt/olt- und qk/qk-Mäusen konnte das Prm3-Protein nachgewiesen werden. Die qk/qk-Mutante führt die Spermatogenese bis zu dem Stadium den elongierenden Spermatiden. Bei der olt/olt-Mutante ist die Spermatogenese in der Regel in runden Spermatiden unterbrochen. Lichtmikroskopische Betrachtungen zeigen aber, daß in einigen Tubuli dieser Mäuse elongierende Spermatiden vorkommen. Dieser Befund erklärt das Vorkommen von Prm3-Protein in olt/olt-Mäusen.

Durch die Immunodetektion auf Maus-Testisschnitten konnte der Beginn der Prm3-Synthese festgestellt werden. Es wurde eine Prm3 spezifische Immunfärbung in den Tubuli den Stadien VIII bis VI (Schritt 8-15 Spermatiden) gefunden. Das Stadium VII entspricht ca. dem Tag 27. Auf dem Westernblot wurde das Protein ab Tag 25 detektiert. Die Stadien der Spermatogenese kann man jedoch nicht genau den bestimmten Tagen zuordnen. Die Differenz von 2 Tagen kann man entweder mit unterschiedlichen Entwicklungen der untersuchten Tiere oder mit unterschiedlichen Empfindlichkeiten dieser beiden Methoden erklären. Es konnte also eine ca. 5-6tägige Verzögerung der Prm3-Synthese festgestellt werden. Das Prm3-Protein unterliegt genau wie andere Protamine einer Translationskontrolle. 
Um zu untersuchen, ob auch reife Spermien noch Prm3 enthalten, wurden Protein-Extrakte aus Epididymis, der verschiedene Reifungsstadien von Spermien enthält, und aus Spermien im Westernblot untersucht. Es konnte kein Prm3-Protein festgestellt werden (Abb.3.6). Auch die immunohistochemischen Studien auf den Epididymis-Schnitten zeigten kein Prm3-Signal (Abb. 3.11). Die Expression des Prm3-Proteins ist also auf die Spermatiden-Stadien beschränkt.

\subsubsection{Interspezies-Variabilität der Prm3-Expression}

Northern-Blot Analysen haben gezeigt, daß Prm3 im humanen Testis nur auf sehr geringem mRNA-Niveau exprimiert wird (Schlüter, 1996). Dies schließt aber eine Prm3Proteinbiosynthese nicht aus. Daher wurde mit Hilfe des nun vorhandenen Prm3-Antikörpers versucht, auch im menschlichen Testisgewebe Prm3-Protein nachzuweisen. Mit den für Maus-Westernblots üblichen Proteinmengen wurde kein Signal gefunden (Abb.3.6). Die Homologie zwischen Maus- und Mensch-Prm3 beträgt auf Protein-Ebene ca. 80\%. Es ist also nicht vollständig auszuschließen, daß die Homologie für eine Kreuzdetektion zu niedrig ist. Angesichts der geringen Transkriptmenge ist hingegen die Interpretation, daß im humanen Testis Prm3 nicht oder nur in sehr geringen Mengen vorkommt, plausibler.

Sowohl Tnp2 als auch Prm2 stellen Gene dar, die zwar ubiquitär vorhanden sind, aber nicht in allen Spezien (zumindest in vergleichbarer Stärke) exprimiert werden (Schlüter, 1996; Johnson et al., 1988a; Hecht, 1989; Maier et al., 1990). Das Prm2-Protein kann 2\% (Kaninchen) bis zu 75\% (Rhesus-Affe) der gesamten DNA-bindenden Proteine ausmachen. Die detektierten Unterschiede in der Transkriptmenge können von unterschiedlichen Transkriptionsraten oder aber von verschiedenen Transkriptstabilitäten herrühren.

Der letzte Punkt scheint insbesondere für Tnp2 zuzutreffen, da hier in Abhängigkeit von der Detektionsmethode Unterschiede im mRNA-Niveau gezeigt wurden (Wykes et al., 1995). Eine In-situ Hybridisierung nach schneller und drastischer Fixierung zeigte vergleichbare Mengen an Prm2- und Tnp2-Transkripten. In Northern-Blot Analysen ist die Tnp2-RNA nur nach langer Exposition sichtbar. Bei Prm3 scheinen die unterschiedlichen Transkriptmengen am ersten von der Transkriptionskontrole beeinfluss zu sein (siehe nächste Absatz). 


\subsubsection{Interspezies-Vergleich der Prm3-5'flankierenden Region und Vergleich mit anderen Protamin-Genen}

Mit Hilfe des TESS-Programms (http.//www.cbil.upenn.edu/tess/) wurde eine ComputerAnalyse eines 650 bp großen 5'flankierenden Bereichs des Prm3-Gens der Maus durchgeführt und dieses nach möglichen Transkriptionsfaktor-Bindungsstellen durchsucht. Aus dem Vergleich dieser Sequenz mit den korrespondierenden Bereichen des Prm3-Gens anderer Spezies und anderer testisspezifisch und haploid exprimierter Gene könnten konservierte Sequenzmotive identifiziert werden, die möglicherweise eine Rolle bei der Regulation der Prm3-Genexpression spielen. Die angegebenen Positionen der Bindungsstellen sind von dem ersten Transkriptionsstartpunkt der Ratte gezählt (Schlüter, 1996). In der angenommenen Promotor-Region des Prm3-Gens wurden potenzielle Bindungsstellen für folgende Transkriptionfaktoren gefunden, die in Abbildung 4.2 dargestellt sind:

- ATF/CREB, CREB beta (TGAGGTCA); Position der CRE Sequenz -64 bis -57 von Transkriptionsstartpunkt). Das TESS-Programm hat die CRE Sequenz als Bindungstelle für CREB-Faktor erkannt, er stellt aber keinen testisspezifischen Faktor dar.

- CAAT-binding faktor; Position der CAAT-box -144 bis -149 (Maus), -159 bis -164 (Ratte).

- YY1 (Ying Yang); Bindet an CCATCTTCC, Position der Bindungsstelle -208 bis -213 (Maus), -243 bis -248 (Ratte)

- MAZ (MYC-associated zinc finger protein) oder Pur1. Bindet an GGGAGGG, die sog. GAGA-box (Position -77 bis -83) (Kennedy et al., 1992). MAZ besitzt eine doppelte Rolle sowohl bei Initiierung und bei Terminierung der Transkription (Bossone et al., 1992). In Promotoren, die keine TATA-Box besitzen, soll die MAZ-Erkennungssequenz zusammen mit SP1-Bindungsstellen, die Bindungssequenz für TFIID (der Faktor der Transkription initiiert) darstellen (Parks und Shenk, 1996).

- Drei Sp1 Bindungsstellen in der Umgebung der MAZ Sequenz

- SRY (sex-determining regionY gene product). Unabhängig von der Sequenz erkennt SRY bestimmte Strukturen an DNA sog. "sharp angles" (Ferrari et al., 1992). 


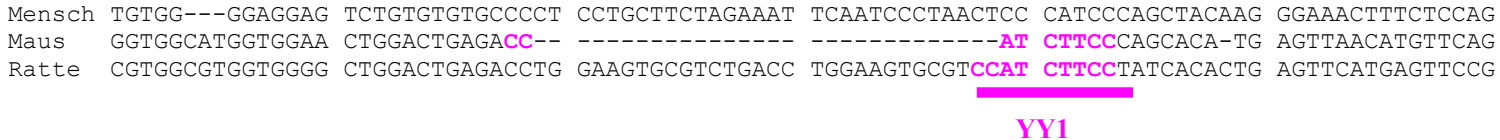

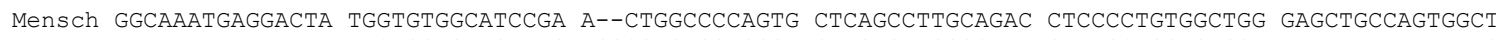
Maus ------------- --CTCCTCTAGTTTG TGCCCTCTCCAGCGT CTACTCTACCCCAAT CATTCCAGCTCAGC- -------------C

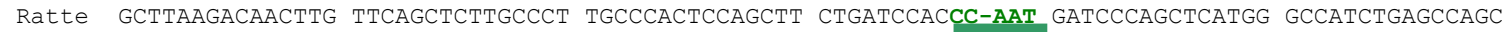

\section{CAAT-box}

Mensch GAgGtgtgagtTAAC TGTTGgCTCAgACCC AgGTTCCCAAGTGGg GATGGGCTC------ ----CCTTTGTGATG TCAGCATC------Maus AGGGTTCCTGGAAAA TGTAAGCATAGCTCC AAATTCTGGGGTGGG GGAGGGTGGTTCCTT GGAGCCTTTGTGAGG TCAGTGCCACACCCA Ratte AGgATTCCTGGAAAA TGTTAGCCTAGCTCC AAATTCTGGGGTGGG G-AGgGTGGTGCCTT GGAGCCTTTGTGAgG TCAGTGCCACACCCA

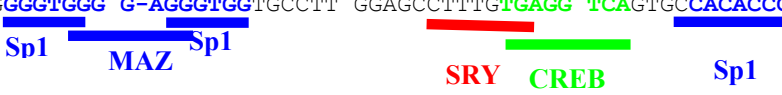

Mensch CTGCCCCCACTCGCA GCCCCTTCACCCACC GCCTCACCTCCTTGC CCAGAGAGACAGGCA ACGTAGACCATGGGT TCCCGCTGTGCCAAG Maus CCAGTCTCACACTCT CTCGCTACCCAGGCT GCCTC-CCTCCTAGT CCAGAGAGACAGGA- --GTGGGCGATGGGT TCCCGCTGTTCCAAG Ratte CTGGCCTCACATCCT CTCACT-CCCAGGCT GCCTC-CCTCCTAGT CCAGAGAGACAGGA- --GTGGGCGATGGGT TCCCGCTGTGCCAAG

Abb. 4.2: Vergleich der 5' nichttranslatierten Region des Prm3-Gens bei der Maus, der Ratte und dem Menschen. Die Bindungsstellen der Transkriptionsfaktoren sind farbig markiert und unterstrichen, die beiden Transkriptionsstartpunkte der Ratte wurden schwarz unterstrichen, das Translationsstartpunkt (ATG) rot markiert.

$\mathrm{Ob}$ und welche Funktion diese Faktoren in der Prm3-Expression spielen, muß durch weitere Experimente geklärt werden. Es fällt aber auf, daß all diese Konsensus-Sequenzen, die in der Maus und Ratte gefunden wurden, beim Menschen nicht vorhanden sind. Dies mag z.T. das niedrige Prm3-Transkriptionsniveau erklären.

In vielen in der Spermatogenese haploid exprimierten Gene, wie z.B. Prm1 und Prm2 der Maus (Johnson et al., 1988b), Tnp1 der Ratte (Heidaran et al., 1989), Prm1 des Bullen (Krawetz et al., 1988) und Tnp2 von Maus, Ratte und Bulle (Topaloglu, 2001), aber auch Proakrosin der Maus (Keime et al., 1990; Kremling et al., 1991b), konnten einige ubiquitäre Promotorelemente wie TATA- und CAAT-Box identifiziert werden (McKnight und Kingsbry, 1982). Bindungsstellen für die gewebespezifische Proteine der Y-box-Familie wurden in Promotoren von verschiedenen testisspezifischen Genen wie Prm1 (reviewed in Wolffe et al., 1992), Prm2 (Johnson et al., 1991), Cytochrom C (Yiu et al., 1997) und Proakrosin (Schulten et al., 2001)) gefunden. Es existieren aber auch Bindungsstellen für rein testisspezifische Faktoren. Das CRE (cAMP responsible element), an das verschiedene Proteine der CREB-Familie (CREB, CREM, ATF) binden, kommt oft in gewebsspezifischen Promotoren vor (Delmas et al., 1993). Der CREM $\tau$ (cAMP response element modulator) ist eine testisspezifische Isoform dieses Transaktivators. Das Fehlen von CREM $\tau$ verhindert die 
Transkription von in Prm1, Prm2 und Calspermin (Nantel et al., 1996). Schließlich stellt der Tet-1 Transkriptionsfaktor (Tamura et al., 1992) wahrscheinlich einen testisspezifischen Faktor dar.

Nimmt man an, daß der Prm3 Promoter - ähnlich wie bei den meisten gewebspezifischen Promotoren - sehr klein ist (der Abstand zum direkt 5'gelegenen Gen Prm2 beträgt bei der Maus nur $0,7 \mathrm{~Kb}$ ), und analysiert man diesen Bereich auf mögliche TranskriptionsfaktorBindungsstellen, so fällt auf, daß fast alle Motive fehlen, die bei anderen testisspezifischen Genen oder Protamin-Genen gefunden werden. Lediglich eine YY1-Stelle existiert im putativen Prm3 Promotor.

Es ist also anzunehmen, daß die oben beschriebene Variabilität der Prm3-Expression z.T. von Unterschieden in den Promotorregionen herrührt.

\subsection{Charakterisierung des Prm3-Proteins}

Aufgrund seines Expressionsmusters, seiner Lage im Protamin-Gen-Cluster (PGC) und der typischen translationellen Verzögerung zeigt Prm3 Ähnlichkeiten mit den anderen Protaminen und Transitionsproteinen. Andererseits weicht die Organisation des Gens für Prm3 (ein Exon, kein Intron) von der der anderen Gene im PGC ab. Vor allem aber codiert der offene Leserahmen von Prm3 für ein saueres, glutamat- und aspartatreiches Protein. Dies wäre ein gänzlich unerwarteter Befund für ein Mitglied der Protamin-Genfamilie. Eine alternative Interpretation dieser Daten könnte sein, daß das Prm3-Gen ein Retrotransposon darstellt, entstanden aus einem prozessierten Protamin-Transkript. Eine gewisse Unterstützung erfährt diese Interpretation aus der Tatsache, daß im Prm3-Gen ein zweiter, kürzerer ORF existiert (ausgehend von einem mehr 3' gelegenen ATG), der für ein basisches, argininreiches Protein codieren würde. Es war daher wichtig nachzuweisen, daß in der Tat ein entsprechendes, saueres Protein existiert. Zu diesem Zweck wurde Testis-Proteinextrakt durch IEF und anschließendem Immunoblot analysiert: Hier wurde die Existenz eines sauren Proteins (IP bei pH ca. 4,5) von entsprechender Größe (14 KDa) zweifelsfrei nachgewiesen. Es stellt sich die Frage, welche Funktion ein saueres Protein im Rahmen der Spermatogenese haben kann, wobei eine Funktion als DNA-bindendes Protein wie Prm1 oder Prm2 aufgrund der physikochemischen Eigenschaften unwahrscheinlich ist. 


\subsubsection{Versuche zur subzellulären Lokalisation von Prm3}

Über die Bestimmung der Lokalisation eines Proteins in der Zelle lassen sich Rückschlüsse auf die Funktion eines Proteins ziehen. Für das Prm3-Protein wurden hierzu mehrere unterschiedliche Ansätze benutzt.

Immunohistochemische Färbungen auf Maus-Testis Schnitten zeigten, daß das Prm3-Protein im Zytoplasma der elongierenden Spermatiden (Schritte 8 bis 15) zu finden ist. Es ist jedoch nicht eindeutig beurteilbar, ob die Färbung ausschließlich im Zytoplasma oder auch im Kern lokalisiert ist. In Western-Blot Experimenten mit fraktionierten Maus-Testis Extrakten (zytoplasmatische und Kernfraktionen) konnte in beiden Proteinextrakten Prm3 in vergleichbaren Mengen detektiert werden. Dies zeigt, daß Prm3 in beiden Kompartimenten vorhanden sein kann.

Auch Transfektionen mit Prm3-GFP Fusions-Genen ergab keine eindeutige Lokalisation. Immunohistochemische Färbungen bei stabilen Transfektanten weisen schließlich auf eine überwiegend zytoplasmatische Lokalisation hin, wobei im Kern hauptsächlich dort eine Färbung sichtbar ist, wo keine DNA vorliegt (ausgesparte Bereiche in der DAPI-Färbung).

\subsection{2 Überlegungen zur Funktion von Prm3}

Der saure Charakter und die diffuse intrazelluläre Lokalisation des Prm3-Proteins lassen eine Funktion ähnlich der von Prm1, Prm2 oder Tnp2 als sehr unwahrscheinlich erscheinen. Aufgrund seiner sauren glutamat- und aspartatreichen Domäne besitzt Prm3 Ähnlichkeit mit Proteinen der s.g. Poly A־-Familie, zu denen Nukleoplasmin, Nukleolin (C23) und Nukleophosmin (B23, numatrin, NO38) Nukleomorphin (Calmodulin-bindendes Protein (CaMBP) aus Dictyostelium discoidens (Myre, 2002) gehören. Alle Mitglieder dieser Familie besitzen eine oder mehrere saure Domänen mit 17 bis 100 Glutamaten und Aspartaten. Die beiden Aminosäuren können mehr als 25\% des gesamten Aminosäureanteils des Proteins ausmachen (Myre, 2002). Alle diese Proteine wurden (wie ihre Namen andeuten) zunächst im Nukleus oder Nukleolus gefunden. Nukleoplasmin spielt eine entscheidende Rolle beim Aufbau der Nukleosomen, indem es Histone bindet und auf DNA transferiert (Laskey et al., 1978; Earnshaw et al., 1980). Es ist aber auch an der Dekondensierung des SpermienChromatins nach der Fertilisation von Xenopus laevis Oozyten beteiligt (Philpott et al., 1991; 
Philpott und Leno, 1992). Nukleolin, das häufigste Protein im Nukleolus (Bugler et al., 1982), ist bei der Reifung des prä-rRNAs und deren Zusammenbau mit den ribosomalen Proteinen zu Ribonukleoproteinpartikeln (RNPs) beteiligt (Medina et al., 1995; reviewed in Ginisty et al., 1999).

Mittlerweile wurde für fast alle diese Proteine gezeigt, daß sie zwischen Kern und Zytoplasma hin- und herwechseln (,shutteln“) und Funktionen auch im Zellkern haben. Im Kern werden sie in Analogie zu Hsp70 im Zytosol als „molecular chaperone“ angesehen.

Aus dieser Parallele zu Prm3 ließe sich die Hypothese stellen, daß Prm3 ebenfalls als „chaperone“ an der Chromatin-Umstrukturierung beteiligt ist.

Allerdings ist für eine solche Aktivität immer eine Wechselwirkung zwischen Proteinen (z.B. Nukleoplasmin mit Histon H2A (Dingwall et al., 1987; Chen et al., 1994), Nukleolin mit Histon H1 (Erard, 1988), Nukleophosmin mit Histon H3 (Okuwaki, 2001)) notwendig. Für Prm3 konnten keine Interaktionspartner überzeugend nachgewiesen werden. Dazu wurde in zwei verschiedenen Yeast-Two-Hybrid-Banken gescrennt und zusätzlich wurden mehrere Kandidatengene (Nukleoplasmin, Msy2, Msy3) direkt im Mammalian-Two-Hybrid (MTH) System getestet. Der einzige Klon, der eine minimale Aktivierung im MTH-System zeigte und damit auf eine Interaktion mit Prm3 hinweist, war ein anonymer EST (Klon 96), der nach ersten Northern-Blot-Befunden sowohl prä- als auch postmeiotisch und in allen getesteten Mutanten exprimiert wird. Dieser Klon hat keine Ähnlichkeiten zu Histonen-Genen. Über die Funktion des entsprechenden Proteins ist nichts bekannt.

Ein weiteres Argument gegen die Einstufung von Prm3 als „molecular chaperone“ ist die geringe Größe des Proteins. Chaperone beinhalten üblicherweise mehrere Domänen, mit denen die Wechselwirkungen zu verschiedenen Proteinen und die Auf- und UmfaltungsAktivitäten vermittelt werden. Diese multidomäne Struktur fehlt Prm3.

Nukleolin, Nukleophosmin und andere Mitglieder der Poly A־-Familie besitzen u.a. Aufgaben im Nukleolus und wirken am „Ribosomen Assembly“ mit. Nukleolin hat Funktionen in der rRNA-Transkription, Reifung, der Ribosomen-Zusammensetzung und deren nukleozytoplasmatischen Transport (Xue, 1993; reviewed in Ginisty et al., 1999). Auch Nukleophosmin ist an der Reifung der präribosomalen Ribonukleoproteinpartikel (präRNPs) beteiligt (Li et al., 1996). Eine genauere Betrachtung nach immunohistochemischer Färbung der stabilen Prm3-exprimierenden Linie P3-8 zeigt ein Prm3 Signal vor allem dort, wo keine DAPI-Färbung zu sehen ist. Dies entspricht dem wahrscheinlichen Ort des Nukleolus. Es fällt auf, daß das Prm3-Protein kurz vor den Spermatogenese-Stadien auftaucht, in denen der 
Nukleolus abgebaut wird. Hier läßt sich spekulieren, ob Prm3 mit am Nukleolus-Abbau beteiligt ist (Biggiogera et al., 1994).

Eine weitere Hypothese zur möglichen Funktion von Prm3 ergibt sich aus seiner Ähnlichkeit zu Prothymosin $\alpha$. Dies ist ein kleines Protein (109 Aminosäuren), was zu 50\% aus Glutamat besteht. Auch Prothymosin $\alpha$ bindet an Histon H1 (Papamarcaki und Tsolas, 1994). GómezMárquez und Rodriguez (1998) schlagen vor, daß Prothymosin $\alpha$ Histon H1 vom Chromatin entfernt, und damit beim „Remodelling“ des Chromatins im Zuge von Transkription beteiligt sein könnte. Trumbore et al. (1997) zeigten, daß ein Großteil der Glutamat-Reste von Prothymosin $\alpha$ phosphoryliert ist, und stellt die Hypothese auf, daß dieses Protein als Energielieferant für die Chromatin-Umstrukturierungsprozesse dient. In der Tat ist die Hydrolysierungsenergie eines Glutamat-Phosphates höher als die eines Adenyl-Phosphates im ATP (Jencks, 1976). In Analogie hierzu ist denkbar, daß Prm3 als Energielieferant bei den energieverbrauchenden Prozessen der Chromatin-Kondensierung wirkt.

\subsection{Versuche zur Manipulation der Prm3 Expression in der Maus}

\subsubsection{Effekt von aberranter Expression}

Um die Funktion von Genen in vivo zu untersuchen, können neben Knockout Mäusen auch solche mit einer zeitlich oder örtlichen Deregulation der Genexpression eingesetzt werden. Aus dem Einfluss des Genproduktes auf den normalen Stoffwechsel können Rückschlüsse auf die Wirkungsweise des jeweiligen Genproduktes gezogen werden.

Dieser Weg kann sowohl in Zellkulturen als auch im (transgenen) Tier beschritten werden. In früheren Experimenten hatten sich Anhaltspunkte ergeben, daß Prm3 in E.coli und Hefe toxisch wirken könnte. Daher hatte Kämper (2001) den induzierbaren MetallothioninPromotor benutzt, um eine stabile, Prm3 exprimierende NIH3T3-Zelllinie zu erzeugen. In der normalen Kultur, ohne Induktion durch Zink und dem resultierenden Hintergrund-Niveau and Prm3 Expression, war diese Linie stabil und zeigte ein unauffälliges Wachstum. Erst nach der Induktion mit $\mathrm{Zn}^{2+}$ beginnen die Zellen massiv abzusterben. In der DAPI-Färbung ist eine Auflösung des Kernes in Subkompartimente, ähnlich den apopotischen Körperchen (Martelli, 2001) zu sehen. In ersten präliminären Experimenten wurde versucht, weitere apoptotische Marker nachzuweisen. Eine Messung der Caspase-Aktivität (durchgeführt bei Frau Dr. Nicole 
Happel, Labor Prof. Doenecke, Abteilung Molekularbiologie, Universität Göttingen) wurde eine auf das doppelte der Kontrolle erhöhte Caspase-Aktivität gefunden.

Diese Ergebnisse sind nur ein erstes Indiz auf eine mögliche Induktion von Apoptose durch eine ektopische Prm3 Expression.

Der zweite Weg, der Erzeugung von transgenen Tieren mit einer aberranten Expression von zu untersuchenden Genen, wurde auch für andere Gene, die an der Spermiogenes beteiligt sind, beschritten. So erzeugten Lee et al. (1995) transgene Mäuse, bei denen durch Austausch des Prm1 3'UTR gegen den hGH 3'UTR die Translationskontrolle der Prm1 mRNA aufgehoben war und das Prm1-Protein ca. eine Woche vor dem physiologischen Zeitpunkt synthetisiert wurde. In diesem Mausmodell wurde je nach Kopienzahl und Expressionsstärke des Transgens ein Spermatogenese-Arrest bei frühen oder späten Spermatiden beobachtet. Es wurde Prm2-Vorläufer Protein, nicht aber reifes Prm2 Protein gefunden. In einem ganz ähnlichen Modell wurde die Proteinexpression von MSY4 um einige Tage vorgezogen. Msy4 gehört zu der Y-box Familie und nimmt wahrscheinlich in der Transkriptions- und Translationskontrolle der Transitionsproteine und Protamine teil. Wurde die MSY4 Expression zeitlich vorgezogen, konnte eine drastische Reduktion der Translation von Protaminen und Transitionsproteine beobacht werden, die Differenzierung der Spermatiden war massiv gestört. Einige Tiere waren steril, bei anderen war die Spermienzahl reduziert und viele Abnormalitäten wurden beobachtet.

In der vorliegenden Arbeit sollte versucht werden, eine aberrante Expression (zeitlich vorgezogen in Keimzellen und ektopisch in somatischen Zellen) von Prm3 mithilfe des induzierbaren Tet-Systems zu erzielen. Die Technik des Tet-Systems wurde weiter oben erläutert (3.10). Konzeptionell bietet das Tet-System mehrere Vorteile gegenüber einer einfachen, Promotor getriebenen Expression des Transgens: erstens ist das Kontroll-Tier in diesem System nicht ein nicht-transgenes Wildtyptier sondern ein ebenfalls transgenes Tier, das aber nicht durch Doxycyclin Gabe induziert wurde. Kontrolle und experimentelles Tier sind deshalb genetisch (so gut wie) identisch und damit besser vergleichbar als transgene mit nicht-transgenen. Zweitens ist im Tet-System die Stärke der Transgenexpression regulierbar. Dies ist besonders dann interessant, wenn (wie bei Prm3 vermutet) das Zielgen toxisch sein könnte. 
Es wurden Mäuse mit einem TRE-Prm3 Konstrukt erzeugt (tet-responsive Promotor vor Prm3-Leserahmen kloniert). In Transfektionen von Ohrfibroblasten wurde gezeigt, daß das Transgen in diesen Linien durch den rtTA (den tetracyclinabhängigen Transaktivator) aktivierbar ist. Um Mäuse zu generieren, die Prm3 schon während der meiotischen Phase der Spermatogenese produzieren, wurde eine Aktivator-Linie benötigt, die rtTA in Keimzellen prämeiotisch exprimiert. Hierfür war eine Mauslinie mit dem Konstrukt pGK2-rtTA erzeugt worden. Diese Linie zeigte zwar eine testisspezifische rtTA-Expression, leider zeigte sich später in Verpaarungen mit Respondertieren, daß die pGK2-rtTA Linie nicht funktionell war, d.h. das Responder-Transgen nicht aktivieren konnte.

In weiteren Verpaarungen wurden kommerziell vertriebene Mäuse von den JacksonLaboratories benutzt, die tTA unter der Kontrolle des CMV-Promoters exprimieren. Diese Tiere sollten im Prinzip eine anähernd ubiquitäre Expression des Transaktivators zeigen, laut veröffentlichten Daten (Furth et al., 1994) aber am stärksten in Thymus, Haut und Testis. Hier war eine Prm3 Expression nur in der Zunge nachweisbar und diese war nicht durch Doxycyclin reprimierbar. Die Linie wurde deshalb nicht weiter verwandt.

Schließlich wurden zwei Linien von Dr. Antonio Servadio, Padua, bezogen, die tTA unter der Kontrolle des humanen $\beta$-Aktin Promotors exprimieren (Act45 und Act88). Durch Positionseffekte zeigen beide Linien unterschiedliche Expressionsmuster, beide aber auch (in unterschiedlichem Maße) tTA Expression im Testis. Leider existieren über diese Linien keine veröffentlichten Daten. Die tTA Expression im Testis ist lediglich durch LuciferaseAktivitätsmessungen in doppelt transgenen Kreuzungen mit Luciferase-Respondertieren gezeigt worden. Es ist noch unklar, in welchem Zelltyp im Testis die tTA Expression erfolgt. Eine genaue Charakterisierung dieser Linien, v.a. mit der Frage, welcher testikuläre Zelltyp tTA exprimiert, muss erst noch erfolgen.

Die ersten Nachkommen aus Verpaarungen mit Act45 konnten kurz vor Abschluss dieser Arbeit getestet werden. In 22 Tage alten Tieren ergab sich in Western-Blots kein Hinweis auf eine aberrante Prm3 Expression. Dagegen konnte Prm3 in Gehirn und in Zunge nachgewiesen werden. Immunhistochemische Färbungen zeigten im Epididymis auffällige, große runde Zellen, die sich intensiv mit dem Anti-Prm3-Antikörper anfärben lassen. Ansonsten waren aber keine histologischen Auffälligkeiten in den Tubuli oder in den Stadien der Spermatogenese sichtbar. Auch beim Auszählen der Spermien (aus Epididymis ausgewaschen) zeigten sich in den ersten Versuchen keine Unterschiede zwischen Wildtyp und doppelt transgenen Tieren. 
Weitere Arbeiten sind nötig, um die Verwendbarkeit dieser Kreuzungen für die Fragestellung des Projektes zu klären. Insbesondere scheint es problematisch, daß in diesen Linien der tTA benutzt wird, mithin der Aktivator konstitutiv aktiv ist und erst durch Doxycyclin reprimiert werden muss. Es wurde beschlossen, die ersten Nachkommen zunächst ohne Dox aufwachsen zu lassen, um die vermuteten toxischen Effekte einer aberranten Prm3 Expression nachweisen zu können. Doppelt transgene Tiere zeigten bislang keine Beeinträchtigungen. Verpaarungen jeweils einfach transgener Eltern ergaben zu 25\% doppelt transgene Nachkommen. Es ist bislang also kein Hinweis auf eine Toxizität von Prm3 zu sehen.

Da für den eigentlichen Ansatz dieses Versuches, nämlich der gezielten induzierbaren Überexpression von Prm3 in prämeiotischen Keimzellen, noch immer keine geeignete TetAktivator-Linie existiert, wurden mittlerweile transgene Mäuse für ein Konstrukt pGK2-M2 erschaffen. M2 ist eine neue Variante des rtTAs, die von einer größeren Zahl an Geweben toleriert wird (Uerlinger, 2000).

\subsubsection{Knockout Modele für spermatogenesespezifische Gene}

Die Generierung von Knockout-Mäusen, bei denen das zu untersuchende Gen durch homologe Rekombination entfernt oder inaktiviert ist, wird seit einigen Jahren zur Analyse der Genfunktion verwendet. Auch für Gene der Spermatogenese, inklusive der Gene der Protamin/Transitionprotein-Familie wurde dieser Ansatz erfolgreich genutzt.

Tnp1 ist das Hauptprotein (62\%) in den Schritten 12-13 der Maus-Spermatogenese. Tnp1 ${ }^{-/}$ Mäuse (Yu et al., 2000) produzieren normale Mengen von Spermatozoen, mit leichten morphologischen Veränderungen und deutlich reduzierter Motilität (nur $23 \%$ der Spermatozoen sind bewegungsfähig). Einige der Mäuse sind fertil (die Wurfgröße war von dem genetischen Hintergrund abhängig) aber 60\% den Tnp1-Null-Mutanten sind infertil. Alle $\operatorname{Tnp}^{1^{-/}}$Mäuse zeigen ab Schritt 12 ein auffälliges Kondensierungsmuster der Chromatin: die sog. "rod-like"-Strukturen im Chromatin sind doppelt so gro $\beta$ wie die feinen WildtypFibrillen. Die Spermatogenese wird vollständig durchlaufen. In Schritt 12-13 erhöht sich jedoch das Niveau von Tnp2 und des Prm2 Precursors, der später nicht zum reifen Prm2Protein prozessiert wird.

$T n p 2^{-/-}$Mäuse (Adham et al., 2001) können abhängig vom genetischen Hintergrund infertil sein oder vollkommen unauffällige Fertilität zeigen (gemischter Hintergrund C57BL/6J*x129/Sv: fertil; 129/Sv zu 100\% infertil). Ähnlich wie Tnp1 $1^{-/}$Mutanten zeigen 
diese Tiere Fehlbildungen des Spermienkopfes. Diese Abnormität wird jedoch nicht durch aberrante Chromatin-Kondensierung, sondern durch eine Deformation des Akrosoms verursacht. Die Bewegungsfähigkeit der Spermatozonen ist reduziert, die Menge an Tnp1Protein ist in den Tnp2 $2^{-/}$Mäuse erhöht.

Besonders die reziproke Erhöhung der Transitionsproteinspiegel bei den jeweiligen Knockout-Tieren scheint anzuzeigen, da $\beta$ ein Kompensationsmechanismus existiert, der (erfolglos?) versucht, den Mangel an einem durch Mehrsynthese des anderen auszugleichen. Ein solcher Kompensationsmechanismus und die offensichtliche Ähnlichkeit beider Knockout-Modelle ist erstaunlich vor dem Hintergrund der Befunde von Rao und Mitarbeitern, die gezeigt haben, daß Tnp1 in vitro die Schmelztemperatur von DNA reduziert und die Bindung der DNA in nukleosomalen Partikeln lockert (Singh und Rao, 1987; 1988), Tnp2 hingegen die Schmelztemperatur in vitro erhöht und die DNA in den Nukleosomen kompaktiert (Kundu und Rao, 1996).

Möglicherweise bezieht dieser hypothetische Kompensationsmechanismus auch die Protamine mit ein: in Tnp1-Mutanten ist die Expression von Prm2 und seinem Präkursor erhöht (im Tnp2-Knockout ist dies nicht untersucht), bei infertilen Männern ist nach de Yebra et al. (1993) die Prm1/Prm2 Relation gestört. Es muss offen bleiben, ob dies in der Tat ein funktionell relevanter Versuch der Kompensation von Minderexpression eines Faktors ist oder ob hier nur eine ungerichtete Überexpression ganzer Chromosomenabschnitte vorliegt, möglicherweise hervorgerufen durch den fehlerhaften Umbau des Chromatins. In diesem Fall müßte man erwarten, daß auch viele andere, nicht zum Funktionskreis der Spermatogenese gehörigen Gene, dereguliert werden. Mithilfe der modernen Expressionsprofiling-Methoden (cDNA-Arrays) ließe sich eine solche Frage angehen.

Auch für Prm1 und Prm2 wurde versucht, Knockout-Mäuse zu erzeugen (Cho et al., 2001). Männliche Chimären produzieren Spermien mit rekombinierten Prm1 oder Prm2 Allelen, diese Spermien gelangen aber nicht zur Befruchtung. Alle Nachkommen zeigten einen Wildtyp-Genotyp. Spermien von chimären Männchen wurden genotypisiert und morphologisch begutachtet. Hierbei fanden die Autoren, daß die Rate an Spermien aus dem homolog rekombinierten Mausstamm 129 mit der Rate an morphologisch auffälligen Spermien korreliert. Dies lässt vermuten, daß das Fehlen von Prm1 bzw. Prm2 zu Störungen in der Chromatinkondensierung und der Formation des Spermien-Nukleus führt. 
Beide Protamine scheinen also unerläßlich für die Bildung eines reifen und zur Fertilisierung geeigneten Spermiums zu sein.

Wie diese Beispiele zeigen, haben die zeitlich und räumlich Reihenfolge der Synthese der spermatidenspezifischen chromatinbindenden Proteine und die richtigen Mengenverhältnisse zwischen diesen, große Bedeutung für die Kondensation der DNA und die korrekte Bildung des Spermatozoons. Veränderungen in der Expression der Protamine scheinen deutlich stärkere Effekte mit sich zu bringen als die bei den Transitionsprotein-Genen. Trotzdem ist damit der Ablauf und Mechanismus der Chromatinkondensation in der Spermatogenese bei weiten noch nicht geklärt. Weitere Genprodukte müssen eine Rolle spielen.

Die Prm3-Knockout Maus konnte im Rahmen der vorliegenden Arbeit nicht mehr analysiert werden. Immerhin konnten bis zum jetzigen Zeitpunkt mehrere F1-Würfe erhalten werden, von denen einige Tiere aufgrund des Agouti-Fellmarkers eine Keimbahntransmission erwarten lassen. Über den möglichen Phänotyp einer Prm3-Knockout Maus kann nur spekuliert werden. Die Beobachtungen aus den bisher erzeugten Knockout Mäusen für Spermatogenese-spezifische Gene geben aber Anhaltspunkte, welche Effekte erwartet werden können. 


\section{$5 \quad$ Zusammenfassung}

In Rahmen dieser Arbeit wurde das Prm3-Gen der Maus untersucht.

- Die Expression des Prm3-Gens der Maus wurde auf RNA-Niveau detailliert untersucht. Prm3 wird testisch-spezifisch ab Tag 20 p.n. in elongierenden Spermatiden exprimiert.

- Ein polyklonales Kaninchen-Antiserum gegen ein Maus-Prm3/GST-Fusionsprotein wurde affinitätschromatografisch aufgereinigt. Mithilfe des aufgereinigten Antikörpers konnten immunohistochemische Untersuchungen durchgeführt werden.

- Das bislang hypothetische Prm3-Protein konnte als saures Protein von $14 \mathrm{KDa}$ charakterisiert werden. In immunhistochemischen Färbungen wurde das Prm3-Protein spezifisch in elongierenden und elongierten Spermatiden dargestellt. (Schritte 9 bis 15). Im Western-Blot ist das Prm3-Protein ab Tag 25 sichtbar. In humanem Testis konnte mit dem zur Verfügung stehendem Antikörper kein Prm3-Protein nachgewiesen werden.

- Über das Yeast-Two-Hybrid-System wurde nach Interaktionspartnern von Prm3 gesucht. Es wurde ein unbekannter EST Klon isoliert, dessen Interaktion mit Prm3 im MammalianTwo-Hybrid-System bestätigt werden konnte. Dieser Klon hybridisert mit einer 0,4 Kb großen cDNA im Testis. Es existieren keine weiteren Informationen über Eigenschaft oder Funktion des entsprechenden Gens.

- Die subzelluläre Lokalisation des Prm3-Proteins konnte nicht eindeutig geklärt werden. Es finden sich sowohl experimentelle Hinweise auf eine Kern- wie auf eine zytoplasmatische Lokalisation.

- In transgenen Mäusen sollte die Wirkung einer abberanten Expression von Prm3 studiert werden. Zur induzierbaren Expression sollte das Tet-Systems benutzt werden. Hier konnten zwar Responder-Mäuse erhalten werden. Bislang steht aber noch keine, eindeutig verwendbare Aktivatormaus (d.h. prämeiotische Keimzellexpression des Transaktivators) zur 
Verfügung. Erste Versuche mit einer tTA Linie, die zwar im Testis exprimiert, der exprimierende Zelltyp dort aber unklar ist, zeigten keine Abnormalitäten der Spermatogenese oder einer Reduktion der Spermien Zahl.

- Es wurde ein DNA-Konstrukt zur Herstellung von Prm3-knock out-Mäusen kloniert und hiermit homolog rekombinierte ES-Zellen erzeugt. Aus diesen ES-Zellen hergestellte Chimären haben mittlerweile F1 Tiere geworfen, von denen einige den agouti Fellmarker tragen, d.h. die Chimären das rekombinierte Allel in der Keimbahn weitergeben. 


\section{$6 \quad$ Literaturverzeichnis}

Adham, I.M., Szpirer, C., Kremling, H., Keime, S., Szpirer, J., Levan, G., Engel, W. (1991). Chromosomal assignment of four rat genes coding for the spermatid-specific proteins proacrosin (ACR), transition proteins 1 (TNP1) and 2 (TNP2), and protamine 1 (PRM1). Cytogenet Cell Genet.; 57(1): 47-50.

Adham, I.M., Nayernia, K., Burkhardt-Gottges, E., Topaloglu, O., Dixkens, C., Holstein, A.F., Engel, W. (2001). Teratozoospermia in mice lacking the transition protein 2 (Tnp2). Mol Hum Reprod. 7(6): 513-20.

Alfonso, P.J., Kistler, W.S. (1993). Immunohistochemical localization of spermatid nuclear transition protein 2 in the testes of rats and mice.

Biol Reprod. 48(3): 522-9.

Allen, M.J., Lee, C., Lee, J.D.4th., Pogany, G.C., Balooch, M., Siekhaus, W.J., Balhorn, R. (1993). Atomic force microscopy of mammalian sperm chromatin.

Chromosoma.;102(9): 623-30.

Altschul, S . F., Gish, W., Miller, W., Myers, E.W. and Lipman, D. J. (1990). Basic local alignment search tool.

J. Mol. Biol. 215: 403-410.

Ausubel, F.M., Breut, R., Kingston, R.E., Moore, D.D., Seidman, J.G., Smith, J.A. und Struhl, K. (1992).

Current Protocols in Molecular Biology, John Wiley \& Sons, Inc., USA.

Ausubel F.M., Brent R., Kingston R.E., Moore D.D., Seidman J.G., Smith J.A. und Struhl K. (1994).

Current Protocols in Molecular Biology, John Wiley \& Sons Inc., USA. 
Balhorn, R. (1982). A model for the structure of chromatin in mammalian sperm.

J Cell Biol. 93(2): 298-305.

Balhorn, R., Weston, S., Thomas, C., Wyrobek, A.J. (1984). DNA packaging in mouse spermatids. Synthesis of protamine variants and four transition proteins.

Exp Cell Res. 150(2): 298-308.

Bartel, P., Chien, C.T., Sternglanz, R., Fields, S. (1993). Elimination of false positives that arise in using the two-hybrid system.

Biotechniques. 14(6): 920-4.

Biggiogera, M., Muller, S., Courtens, J.L., Fakan, S., Romanini, M.G. (1992).

Immunoelectron microscopical distribution of histones $\mathrm{H} 2 \mathrm{~B}$ and $\mathrm{H} 3$ and protamines in the course of mouse spermiogenesis.

Microsc Res Tech. 20(3): 259-67.

Biggiogera, M., Martin, T.E., Gordon, J., Amalric, F., Fakan, S. (1994). Physiologically inactive nucleoli contain nucleoplasmic ribonucleoproteins: immunoelectron microscopy of mouse spermatids and early embryos.

Exp Cell Res. 213(1): 55-63.

Bolivar, F. und Beckmann, K. (1979). Plasmids of Escherichia coli as cloning vectors. Methods Enzymol. 68: 245-260.

Bossone, S.A., Asselin, C., Patel, A.J., Marcu, K.B. (1992). MAZ, a zinc finger protein, binds to c-MYC and $\mathrm{C} 2$ gene sequences regulating transcriptional initiation and termination. Proc Natl Acad Sci U S A. 89(16): 7452-6.

Bradford, M.M (1976). A rapid and sensitive method for the quantification of microgramm quantities of protein utilizing the principle of protein dye binding. Anal. Biochem. 72: 248254. 
Braun, R.E. (1998). Post-transcriptional control of gene expression during spermatogenesis. Semin.

Cell Dev Biol. 9(4): 483-9.

Brinster, R.L., Chen, H.Y., Trumbauer, M.E., Yaglr, M.K., Palmiter, R.D. (1985). Factors affecting the efficiency of introducing foreign DNA into mice by microinjecting eggs.

Proc. Natl. Acad. Sci. 82: 4438-4442.

Bronstein, J., Fortin, J.J., Voyta, J.C., Juo, R.R., Edwards, B.,Olesen, C.E., Lijam, N., Kricka, L.J. (1994). Chemiluminescent reporter gene assays: sensitive detection of the GUS and SEAP gene products.

Biotechniques 17(1): 172-174; 176-177.

Bugler, B., Caizergues-Ferrer, M., Bouche, G., Bourbon, H., Amalric, F. (1982). Detection and localization of a class of proteins immunologically related to a 100-kDa nucleolar protein. Eur J Biochem. 128(2-3): 475-80.

Bunick, D., Balhorn, R., Stanker, L.H., Hecht, N.B. (1990). Expression of the rat protamine 2 gene is suppressed at the level of transcription and translation.

Exp Cell Res. 188(1): 147-52.

Burfeind, P., Chernicky, C. L., Rininsland, F., Ilan, J. (1996). Antisense RNA to the type I insulin-like growth factor receptor suppresses tumor growth and prevents invasion by rat prostate cancer cells in vivo.

Proc. Natl. Acad. Sci. 93: 7263-7268.

Capecchi M.R. (1989). Altering the genome by homologous recombination, Science 244: 1288-1292.

Chen, H., Li, B., Workman, J.L. (1994). A histone-binding protein, nucleoplasmin, stimulates transcription factor binding to nucleosomes and factor-induced nucleosome disassembly. EMBO J. 13(2): 380 
Cho, C., Willis, W.D., Goulding, E.H., Jung-Ha, H., Choi, Y.C., Hecht, N.B., Eddy, E.M. (2001). Haploinsufficiency of protamine-1 or -2 causes infertility in mice.

Nat Genet. 28(1): 82-6.

Chomczynski, P. und Sacchi, N. (1987). Single-step method of RNA isolation by acid guanidinium thiocyanate-phenol-chloroform extraction.

Anal. Biochem. 162: 156-159.

Coolidge, C.J., Patton, J.G. (2000). A new double-stranded RNA-binding protein that interacts with PKR.

Nucleic Acids Res. 28(6): 1407-17.

Dadoune, J.P. und Demoulin, A. (1993). Structure and Functions of the Testis. In Reproduction in Mammals and Man. Edited by C. Thibault, M.C.Levasseur, R:F:F: Hunter. Ellipses, Paris.

Dagert, M. und Ehrlich, S.D. (1979). Prolonged incubation in calcium chloride improves the competence of Escherichia coli. cells.

Gene 6: 23-28.

Davies, H.G., Giorgini,F., Fajardo, M.A., Braun, R.E. (2000). A sequence-specific RNA binding complex expressed in murine germ cells contains MSY2 and MSY4.

Dev Biol. 221(1): 87-100.

Delmas, V., van der Hoorn, F., Mellstrom, B., Jegou, B., Sassone-Corsi, P. (1993). Induction of CREM activator proteins in spermatids: down-stream targets and implications for haploid germ cell differentiation.

Mol Endocrinol. 7(11): 1502-14.

Deryckere, F. und Gannon, F. (1994). A one-hour minipreparation technique for extraction of DNA-binding proteins from animal tissues.

Biotechniques. 16(3): 405. 
Dingwall, C., Dilworth, S.M., Black, S.J., Kearsey, S.E., Cox, L.S., Laskey, R.A. (1987). Nucleoplasmin cDNA sequence reveals polyglutamic acid tracts and a cluster of sequences homologous to putative nuclear localization signals.

EMBO J. 6(1): 69-74.

Earnshaw, W.C., Honda, B.M., Laskey, R.A., Thomas, J.O. (1980). Assembly of nucleosomes: the reaction involving X. laevis nucleoplasmin.

Cell. 21(2): 373-83.

Erard, M.S., Belenguer, P., Caizergues-Ferrer, M., Pantaloni, A., Amalric, F. (1988). A major nucleolar protein, nucleolin, induces chromatin decondensation by binding to histone $\mathrm{H} 1$. Eur J Biochem. 175(3): 525-30.

Feinberg, A.P. und Vogelstein, B. (1983). A technique for radiolabeling DNA restriction endonuclease fragments to high specific activity.

Anal. Biochem. 132: 6-13.

Ferrari, S., Harley, V.R., Pontiggia, A., Goodfellow, P.N., Lovell-Badge, R., Bianchi, M.E. (1992). SRY, like HMG1, recognizes sharp angles in DNA.

EMBO J. 11(12): 4497-506.

Fields, S. and Song, Q. (1989). A novel genetic system to detect protein-protein interactions. Nature, 340: 245-247.

Forsbach, A., Heinlein, U.A. (1998). Intratesticular distribution of cyritestin, a protein involved in gamete interaction.

J Exp Biol. 201 (Pt 6): 861-7.

Furth, P.A., St Onge, L., Boger, H., Gruss, P., Gossen, M., Kistner, A., Bujard, H., Hennighausen, L. (1994). Temporal control of gene expression in transgenic mice by a tetracycline-responsive promoter.

Proc Natl Acad Sci U S A. 91(20): 9302-6. 
Ginisty, H., Sicard, H., Roger, B., Bouvet, P. (1999). Structure and functions of nucleolin. J Cell Sci. 112 (Pt 6): 761-72.

Ginisty, H., Serin, G., Ghisolfi-Nieto, L., Roger, B., Libante, V., Amalric, F., Bouvet, P. (2000). Interaction of nucleolin with an evolutionarily conserved pre-ribosomal RNA sequence is required for the assembly of the primary processing complex.

J Biol Chem. 275(25): 18845-50.

Giorgini, F., Davies, H.G., Braun, R.E. (2002). Translational repression by MSY4 inhibits spermatid differentiation in mice.

Development. 129(15): 3669-79.

Gomez-Marquez, J., Rodriguez, P. (1998). Prothymosin alpha is a chromatin-remodelling protein in mammalian cells.

Biochem J. 333 (Pt 1): 1-3

Gossen, M. und Bujard, H. (1992). Tight control of gene expression in mammalian cells by tetracycline responsive promoters.

Proc. Natl. Acad. Sci. USA 89: 5547-5551.

Görg, A., Postel, W., Günter, S., Weser, J. (1995). Improved horizontal two-dimensional electrophoresis with hybrid isoelectric focusing in immobilized $\mathrm{pH}$ gradients in the first dimension and laying-on transfer to the second dimension. In: Electrophoresis 6: 599-604.

Gu, W., Tekur, S., Reinbold, R., Eppig, J.J., Choi, Y.C., Zheng, J.Z., Murray, M.T., Hecht, N.B. (1998). Mammalian male and female germ cells express a germ cell-specific Y-Box protein, MSY2.

Biol Reprod. 59(5): 1266-74.

Hanahan, D. (1983). Studies of transformation of E. coli with plasmids.

J. Mol. Biol. 166: 557-580. 
Hecht, N.B., Bower, P.A., Waters, S.H., Yelick, P.C., Distel, R.J. (1986). Evidence for haploid expression of mouse testicular genes.

Exp Cell Res. 164(1): 183-90.

Hecht, N.B. (1989). Molecular biology of structural chromosomal proteins of the mammalian testis. In Molecular Biology of Chromosome Fuktion, K.W. Adolph, ed., (Springer-Verlag, NewYork/Berlin/Heidelberg). 396-420.

Hecht NB. (1990). Regulation of 'haploid expressed genes' in male germ cells. J Reprod Fertil. 88(2): 679-93.

Heidaran, M.A., Kistler, W.S. (1987). Transcriptional and translational control of the message for transition protein 1, a major chromosomal protein of mammalian spermatids.

J Biol Chem. 262(27): 13309-15.

Heidaran, M.A., Showman, R.M., Kistler, W.S. (1988) A cytochemical study of the transcriptional and translational regulation of nuclear transition protein 1 (TP1), a major chromosomal protein of mammalian spermatids.

J Cell Biol. May; 106(5): 1427-33.

Heidaran, M.A., Kozak, C.A., Kistler, W.S. (1989). Nucleotide sequence of the Stp-1 gene coding for rat spermatid nuclear transition protein 1 (TP1): homology with protamine P1 and assignment of the mouse Stp-1 gene to chromosome 1.

Gene 75(1): 39-46.

Hogan, B., Beddington, R., Costantini, F. und Lacy, E. (1986). Manipulating the mouse embryo. Cold Spring Harbour, NY, USA: Cold Spring Harbour Press.

Iuchi, Y., Kobayashi, T., Kaneko, T., Takahara, M., Ogino, T., Fujii, J. (2001). Expression of a Y-box protein, YB2/RYB-a, precedes protamine 2 expression during spermatogenesis in rodents.

Mol Hum Reprod. 7(11): 1023-31. 
Jain, V.K. und Magrath, I.T. (1991). A chemiluminescent assay for quantitation of betagalactosidase in the femtogram range: application to quantitation of beta-galactosidase in lacZ-transfected cells.

Anal. Biochem. 199(1): 119-124.

James, P., Halladay, J., Craig, E.A. (1996). Genomic libraries and a host strain designed for highly efficient two-hybrid selection in yeast.

Genetics 144:1425-1436.

Johnson, P.A., Yelick, P.C., Liem, H., Hecht, N.B. (1988a). Differential distribution of the P1 and P2 protamine gene sequences in eutherian and marsupial mammals and a monotreme. Gamete Res. 19(2): 169-75.

Johnson, P.A., Peschon, J.J., Yelick, P.C., Palmiter, R.D., Hecht, N.B. (1988b). Sequence homologies in the mouse protamine 1 and 2 genes.

Biochim Biophys Acta. 950(1): 45-53.

Johnson, P.A., Bunick, D., Hecht, N.B. (1991). Protein binding regions in the mouse and rat protamine-2 genes.

Biol Reprod. 44(1): 127-34.

Joyner A.L. (2000). Gene Targeting, 2nd Edn., A Practical Approach, Oxford University Press, New York.

Kämper, M., (2001). Untersuchungen zur regulierbaren transgenen Expression von Ribozymen und „Antisense“-Transkripten mit dem Ziel einer Reduktion der Prm3Expression.

Dissertation, Math.-Nat. Fakultät der Georg-August-Universität zu Göttingen.

Kashiwabara, S., Baba, T., Takada, M., Watanabe, K., Yano, Y., Arai, Y. (1990). Primary structure of mouse proacrosin deduced from the cDNA sequence and its gene expression during spermatogenesis.

J Biochem (Tokyo). 108(5): 785-91. 
Keime, S., Adham, I.M., Engel, W. (1990). Nucleotide sequence and exon-intron organization of the human proacrosin gene.

Eur J Biochem. 190(1): 195-200.

Kennedy, G.C., Rutter, W.J. (1992). Pur-1, a zinc-finger protein that binds to purine-rich sequences, transactivates an insulin promoter in heterologous cells.

Proc Natl Acad Sci U S A. 89(23): 11498-502.

Kistner, A., Gossen, M., Zimmermann, F., Jerecic, J., Ullmer, C., Lübbert, H. und Bujard, H. (1996). Doxycycline-mediated quantitative and tissue-specific control of gene expression in transgenic mice.

Proc. Natl. Acad. Sci. USA 93: 10933-10938.

Kleene, K.C., Distel, R.J., Hecht, N.B. (1984). Translational regulation and deadenylation of a protamine mRNA during spermiogenesis in the mouse.

Dev Biol. 105(1): 71-9.

Krawetz, S.A., Connor, W., Dixon, G.H. (1988). Bovine protamine genes contain a single intron. The structures of the two alleles.

J Biol Chem. 5;263(1): 321-6.

Kremling, H., Keime, S., Wilhelm, K., Adham, I.M., Hameister, H., Engel, W. (1991). Mouse proacrosin gene: nucleotide sequence, diploid expression, and chromosomal localization. Genomics 11(4): 828-34.

Kremling, H., Flake, A., Adham, I.M., Radtke, J., Engel, W. (1991b). Exon-intron structure and nucleotide sequence of the rat proacrosin gene.

DNA Seq. 2(1): 57-60.

Kundu, T.K., Rao, M.R. (1996). Zinc dependent recognition of a human CpG island sequence by the mammalian spermatidal protein TP2.

Biochemistry. 35(49): 15626-32. 
Kwon, Y.K., Hecht, N.B. (1991). Cytoplasmic protein binding to highly conserved sequences in the $3^{\prime}$ untranslated region of mouse protamine $2 \mathrm{mRNA}$, a translationally regulated transcript of male germ cells.

Proc Natl Acad Sci U S A. 88(9): 3584-8.

Laird, P.W., Zijderveld, A., Linders, K., Rudnicki, M.A., Jaenisch, R. und Berns, A. (1991). Simplified mammalian DNA isolation procedure.

Nucleic Acids Res. 19: 4293.

Laskey, R.A., Honda, B.M., Mills, A.D. und Finch, J.T. (1978). Nucleosomes are assembled by an acidic protein which binds histones and transfers them to DNA.

Nature 275: 416-420.

Lee, K., Haugen, H.S., Clegg, CH, Braun, R.E. (1995). Premature translation of protamine 1 mRNA causes precocious nuclear condensation and arrests spermatid differentiation in mice. Proc Natl Acad Sci U S A. 92(26): 12451-5.

Lee, K., Fajardo, M.A., Braun, R.E. (1996). A testis cytoplasmic RNA-binding protein that has the properties of a translational repressor.

Mol Cell Biol. 16(6): 3023-34.

Li, Y.P., Busch, R.K., Valdez, B.C, Busch, H. (1996). C23 interacts with B23, a putative nucleolar-localization-signal-binding protein.

Eur J Biochem. 237(1): 153-8.

Linder, B., Bammer, S., Heinlein, U.A. (1995). Delayed translation and posttranslational processing of cyritestin, an integral transmembrane protein of the mouse acrosome. Exp Cell Res. 221(1): 66-72.

Maier, W.M., Nussbaum, G., Domenjoud, L., Klemm, U., Engel, W. (1990). The lack of protamine $2(\mathrm{P} 2)$ in boar and bull spermatozoa is due to mutations within the P2 gene. Nucleic Acids Res. 18(5): 1249-54. 
Mali, P., Kaipia, A., Kangasniemi, M., Toppari, J., Sandberg, M., Hecht, N.B., Parvinen, M. (1989). Stage-specific expression of nucleoprotein mRNAs during rat and mouse spermiogenesis.

Reprod Fertil Dev. 1(4): 369-82.

Martelli, A.M., Zweyer, M., Ochs, R.L., Tazzari, P.L., Tabellini, G., Narducci, P., Bortul, R. (2001). Nuclear apoptotic changes: an overview.

J Cell Biochem. 82(4): 634-46.

Mastrangelo, M.A., Kleene, K.C. (2000). Developmental expression of Y-box protein 1 mRNA and alternatively spliced Y-box protein 3 mRNAs in spermatogenic cells in mice. Mol Hum Reprod. 6(9): 779-88.

Matsushime, H., Jinno, A., Takagi, N., Shibuya, M. (1990). A novel mammalian protein kinase gene (mak) is highly expressed in testicular germ cells at and after meiosis.

Mol Cell Biol. 10(5): 2261-8.

McKnight, S.L. und Kingsbury, R. (1982). Transkriptional control signals of a eucariotic protein-coding gene.

Science 217: 316-324.

Medina, F.J., Cerdido, A., Fernandez-Gomez, M.E. (1995). Components of the nucleolar processing complex (Pre-rRNA, fibrillarin, and nucleolin) colocalize during mitosis and are incorporated to daughter cell nucleoli.

Exp Cell Res. 221(1): 111-25.

Messing, J. (1983). New M13 vectors for cloning.

Methods Enzymol. 101: 20.

Mills, N.C., Van, N.T., Means, A.R. (1977). Histones of rat testis chromatin during early postnatal development and their interactions with DNA.

Biol Reprod. 17(5): 760-8. 
Morales, C.R., Kwon, Y.K., Hecht, N.B. (1991). Cytoplasmic localization during storage and translation of the mRNAs of transition protein 1 and protamine 1, two translationally regulated transcripts of the mammalian testis.

J Cell Sci. 100 (Pt 1): 119-31.

Myre, M.A., O'Day, D.H. (2002). Nucleomorphin. A novel, acidic, nuclear calmodulinbinding protein from dictyostelium that regulates nuclear number.

J Biol Chem. 277(22): 19735-44.

Nantel, F., Monaco, L., Foulkes, N.S., Masquilier, D., LeMeur, M., Henriksen, K., Dierich, A., Parvinen, M., Sassone-Corsi, P. (1996). Spermiogenesis deficiency and germ-cell apoptosis in CREM-mutant mice.

Nature 380(6570): 159-62.

Nayernia, K., Burkhardt, E., Beimesche, S., Keime, S., Engel, W. (1992). Germ cell-specific expression of a proacrosin-CAT fusion gene in transgenic mouse testis.

Mol Reprod Dev. 31(4): 241-8.

Nelson, J.E., Krawetz, S.A. (1993). Linkage of human spermatid-specific basic nuclear protein genes. Definition and evolution of the P1-->P2-->TP2 locus.

J Biol Chem. 268(4): 2932-6.

Norander, J., Kempe, T. Messing, J. (1983). Construction of improved M13 vectors using oligodeoxynucleotide-directed mutagenesis.

Gene 26: 101-106.

Oko, R., Korley, R., Murray, M.T., Hecht, N.B., Hermo, L. (1996). Germ cell-specific DNA and RNA binding proteins p48/52 are expressed at specific stages of male germ cell development and are present in the chromatoid body.

Mol Reprod Dev. 44(1): 1-13.

Okuwaki, M., Matsumoto, K., Tsujimoto, M., Nagata, K. (2001). Function of nucleophosmin/B23, a nucleolar acidic protein, as a histone chaperone.

FEBS Lett. 506(3): 272-6. 
Papamarcaki, T., Tsolas, O. (1994). Prothymosin alpha binds to histone H1 in vitro. FEBS Lett. 345(1): 71-5.

Parks, C.L., Shenk, T. (1996). The serotonin 1a receptor gene contains a TATA-less promoter that responds to MAZ and Sp1.

J Biol Chem. 271(8): 4417-30.

Philpott, A., Leno, G.H., Laskey, R.A. (1991). Sperm decondensation in Xenopus egg cytoplasm is mediated by nucleoplasmin.

Cell 65(4): 569-78.

Philpott, A., Leno, G.H. (1992). Nucleoplasmin remodels sperm chromatin in Xenopus egg extracts.

Cell 69(5): 759-67.

Pires-daSilva, A., Nayernia, K., Engel, W., Torres, M., Stoykova, A., Chowdhury, K., Gruss, P. (2001). Mice deficient for spermatid perinuclear RNA-binding protein show neurologic, spermatogenic, and sperm morphological abnormalities.

Dev Biol. 233(2): 319-28.

Rapp, G., Klaudiny, J., Hagendorff, G., Luck, M. R., Scheit, K. H. (1989). Complete sequence of the coding region of human elongation factor 2 (EF-2) by enzymatic amplification of cDNA from human ovarian granulosa cells.

Biol. Chem. Hoppe-Seyler 370: 1071-1075.

Russell, L.D., Ettlin, R.A., Hikim, A.P.S. und Clegg, E. D. (1990). Histological and Histopathological Evaluation of The Testis.

Cache River Press. 120-161.

Saiki, R.K., Scharf, S., Faloon, F., Mullis, K.B., Horn, G.T., Ehrlich, H.A. und Arnheim, N. (1985). Enzymatic amplification of beta-globin genomic sequence and restriction site analysis for diagnosis of sickle cell anemia.

Science 230: 1350-1354. 
Sambrook, J., Fritsch, E.F. und Maniatis, T. (1989). Molecular cloning: a laboratory manual. 2. Auflage, Cold Spring Harbor, New York, USA.

Sanger, F., Nicklen, S. und Coulson, A.R. (1977). DNA sequencing with chain-terminating inhibitors.

Proc. Natl. Acad. Sci. USA 74: 5463-5467.

Sassone-Corsi, P. (1997). Transcriptional checkpoints determining the fate of male germ cells. Cell.; 88(2): 163-6.

Sassone-Corsi, P. (2002). Unique chromatin remodeling and transcriptional regulation in spermatogenesis.

Science. 296(5576): 2176-8.

Schlüter G, Kremling H, Engel W (1992). The gene for human transition protein 2: nucleotide sequence, assignment to the protamine gene cluster, and evidence for its low expression. Genomics. 14(2): 377-83.

Schlüter, G., Engel, W. (1995). The rat Prm3 gene is an intronless member of the protamine gene cluster and is expressed in haploid male germ cells.

Cytogenet Cell Genet. 71(4): 352-5.

Schlüter, G. (1996). Der Protamin Gencluster beim Säuger: Zur Struktur und Expression eines keimzellspezifischen Multi-Gen-Locus.

Dissertation, Math.-Nat. Fakultät der Georg-August-Universität zu Göttingen.

Schlüter, G., Celik, A., Obata, R., Schlicker, M., Hofferbert, S., Schlung, A., Adham, I.M., Engel, W. (1996). Sequence analysis of the conserved protamine gene cluster shows that it contains a fourth expressed gene.

Mol Reprod Dev. 43(1): 1-6.

Schmidt, E.E., Schibler, U. (1995). High accumulation of components of the RNA polymerase II transcription machinery in rodent spermatids.

Development. 121(8): 2373-83. 
Schulten, H.J., Nayernia, K., Reim, K., Engel, W., Burfeind, P. (2001). Assessment of promoter elements of the germ cell-specific proacrosin gene.

$J$ Cell Biochem. 83(1): 155-62.

Schumacher, J.M., Lee, K., Edelhoff, S., Braun, R.E. (1995). Distribution of Tenr, an RNAbinding protein, in a lattice-like network within the spermatid nucleus in the mouse.

Biol Reprod. 52(6): 1274-83.

Singh, J., Rao, M.R. (1987). Interaction of rat testis protein, TP, with nucleic acids in vitro. Fluorescence quenching, UV absorption, and thermal denaturation studies.

J Biol Chem. 262(2): 734-40.

Singh, J., Rao, M.R. (1988). Interaction of rat testis protein, TP, with nucleosome core particle.

Biochem Int. 17(4): 701-10.

Southern, E.M. (1975). Detection of specific sequences among DNA fragments separated by gel electrophoresis.

J. Mol. Biol. 98: 503-517.

Tamura, T., Makino, Y., Mikoshiba, K., Muramatsu, M. (1992). Demonstration of a testisspecific trans-acting factor Tet-1 in vitro that binds to the promoter of the mouse protamine 1 gene.

J Biol Chem. 267(7): 4327-32.

Topaloglu, Ö. (2001). Zur Transkriptions- und Translationskontrolle des Gens für Transitionsprotein 2 .

Dissertation, Math.-Nat. Fakultät der Georg-August-Universität zu Göttingen.

Triezenberg, S.J., Kingsbury, C., Mc Knight, S.L. (1988). Functional dissection of VP16, the transactivator of herpes simplex virus immediate early gene expression.

Genes \& Development 2: 718-729. 
Trumbore, M.W., Wang, R.H., Enkemann, S.A., Berger, S.L. (1997). Prothymosin alpha in vivo contains phosphorylated glutamic acid residues.

J Biol Chem. 272(42): 26394-404.

Tsan, J. T., Wang, Z. W., Hwang, L.Y., Bash, R. O. and Baer, R. (1997). Mammalian cells as hosts for two-hybrid studies of protein-protein interaction. In: Bartel, P. L. and Fiels, S. (ed): The yeast two hybrid system. New York, Oxford: Ox. Uni. Press., 217-232.

Tsunekawa, N., Matsumoto, M., Tone, S., Nishida, T., Fujimoto, H. (1999). The Hsp70 homolog gene, Hsc70t, is expressed under translational control during mouse spermiogenesis. Mol Reprod Dev. 52(4): 383-91.

Urlinger, S., Baron, U., Thellmann, M., Hasan, M.T., Bujard, H., Hillen, W. (2000).

Exploring the sequence space for tetracycline-dependent transcriptional activators: novel mutations yield expanded range and sensitivity.

Proc Natl Acad Sci U S A. 97(14): 7963-8.

Vogelstein, B. und Gillispie, D. (1979). Preparative and analytical pufification of DNA from Agarose.

Proc. Natl. Acad. Sci. USA 76: 615-619.

Ward, W.S. (1993) Deoxyribonucleic acid loop domain tertiary structure in mammalian spermatozoa.

Biol. Reprod. 48: 1193-1203

Weber, K. und Osborn, M. (1969). The reliability of molecular weight determinations by dodecyl sulfate-polyacrylamide gel electrophoresis.

J. Biol. Chem. 224: 4406-4412.

de Wet, J.R., Wood, K.V., Helinski, D.R., Deluca, M. (1986). Cloning firefly luciferase. Methods Enzymol. 133: 3-14. 
Wolffe, A.P., Tafuri, S., Ranjan, M., Familari, M. (1992). The Y-box factors: a family of nucleic acid binding proteins conserved from Escherichia coli to man.

New Biol. 4(4): 290-8.

Wouters-Tyrou, D., Martinage, A., Chevaillier, P., Sautiere, P. (1998). Nuclear basic proteins in spermiogenesis.

Biochimie. 80(2): 117-28.

Wu, L.C., Wang, Z.W., Tsan, J.T., Spillman, M.A., Phung, A., Xu, X.L., Yang, M.-C.W., Hwang, L.-Y., Bowcock, A.M., Baer, R. (1996). Identification of a RING protein that can interact in vivo with the BRCA1 gene product.

Nature Genet. 14: 430-440.

Wu, J.Y., Ribar, T.J., Cummings, D.E., Burton, K.A., McKnight, G.S., Means, A.R. (2000). Spermiogenesis and exchange of basic nuclear proteins are impaired in male germ cells lacking Camk4.

Nat Genet. 25(4): 448-52.

Wu, J.Y., Ribar, T.J., Means, A.R. (2001). Spermatogenesis and the regulation of $\mathrm{Ca}(2+)$ calmodulin-dependent protein kinase IV localization are not dependent on calspermin. Mol Cell Biol. 21(17): 6066-70.

Wykes, S.M., Nelson, J.E., Visscher, D.W., Djakiew, D., Krawetz, S.A. (1995). Coordinate expression of the PRM1, PRM2, and TNP2 multigene locus in human testis. DNA Cell Biol. 14(2): 155-61.

Xue, Z., Shan, X., Lapeyre, B., Melese, T. (1993). The amino terminus of mammalian nucleolin specifically recognizes SV40 T-antigen type nuclear localization sequences. Eur J Cell Biol. 62(1): 13-21.

de Yebra, L., Ballesca, J.L., Vanrell, J.A., Bassas, L., Oliva, R. (1993). Complete selective absence of protamine P2 in humans.

J Biol Chem. 268(14): 10553-7. 
Yiu, G.K., Murray, M.T., Hecht, N.B. (1997). Deoxyribonucleic acid-protein interactions associated with transcriptional initiation of the mouse testis-specific cytochrome c gene. Biol Reprod. 56(6):1439-49.

Yoshinaga, K., Nishikawa, S., Ogawa, M., Hayashi, S., Kunisada, T., Fujimoto, T., Nishikawa, S. (1991). Role of c-kit in mouse spermatogenesis: identification of spermatogonia as a specific site of c-kit expression and function.

Development 113(2): 689-99.

Yu, Y.E., Zhang, Y., Unni, E., Shirley, C.R., Deng, J. M., Russell, L.D., Weil M.M., Behringer, R.R., and Meistrich, M.L. (2000). Abnormal spermatogenesis and reduced fertility in transition nuclear protein 1-deficient mice.

PNAS . 97(9): 4683-4688.

Zhong, J., Peters, A.H., Lee, K., Braun, R.E. (1999). A double-stranded RNA binding protein required for activation of repressed messages in mammalian germ cells.

Nat Genet. 22(2): 171-4. 


\section{Publikation}

Schlüter, G., Boinska, D., Nieman-Seyde, S.C. (2000) Evidence for translational repression of the SOCS-1 major open reading frame by an upstream open reading frame.

Biochem Biophys Res Commun. 268(2): 255-61. 


\section{Danksagungen}

Herrn Professor Dr. W. Engel danke ich für die Bereitschaft, diese Arbeit zu betreuen. Darüber hinaus für seine hilfreichen Ratschläge und Anregungen, seine Geduld und die motivierende Arbeitsatmosphäre. Schließlich danke ich ihm für die zügige Korrektur dieser Arbeit.

Dr. Gregor Schlüter danke ich für die Überlassung des interessanten Themas und die Betreuung dieser Arbeit. Für die Diskussionen und Vorschläge, für die er trotz aller Umstände, Zeit gefunden hat. Des weiteren möchte ich mich für die Finanzierung dieser Arbeit bedanken. Besonderer Dank für seine Geduld in der letzten Phase des Zusammenschreibens. Das Erscheinen dieses Manuskriptes wäre ohne seine Hilfe fast nicht möglich gewesen.

Bei Özlem Topaloglu für die Unterstützung und das Einweisen in die Labor-Geheimnisse. Ihre ruhige und besonnene Art ist etwas Besonderes. Auch bei Martin Kämper für seine „Relaxtheit“, für die Hilfe und angenehme Atmosphäre. Den beiden zusammen danke ich für das „Erschaffen“ des besten Labors im ganzen Institut.

Auch Katayoon Shirneshan, Leonie Rieger, Gabi Gohla und Nicole Richter für die geselligen Momente im Labor-Leben und auch außerhalb. (Katy und Leonie zusätzlich für die schönen Mittagspausen).

Leonie, noch mal, jetzt für die Korrekturen (sie weißt bestimmt, daß es ETWAS gibt, um sich zu bedanken).

Auch Dr. Stephan Zimmermann danke ich für die Korrekturen, des weiteren für den Klon 115. Für die gemeinsame Zeit und für all die großen und kleinen Aufregungen, die das Leben erst interessant machen.

Dr. Peter Burfeind und allen anderen vom „Zytogenetik Flur“ für die schöne gemeinsame Zeit im Institut.

Den Tierpflegern danke ich für die Betreuung meiner Mauslinien und für die gute Zusammenarbeit.

Bei der ganzen „,polnische Truppe“: Asia, Ewelina, Ewa, Renata, Gosia, Monika, Paweł, Michał, Marcin, Tomek und Robert für die Abwechslungen, für die nette Zeit zwischen der ganzen Pipettiererei und vieles mehr. Dzięki za wspólne imprezy, za polską kolonię w Getyndze. Za wszystkie rozmowy o wyższości „dworu” nad „polem” (i odwrotnie). Będzie co wspominać.

Und bei meinen lieben Eltern natürlich, (aber daß versteht sich wohl von selbst). Dziękuję za wszystko, Kochani Rodzice. 


\section{Lebenslauf}

\section{Persönliche Daten:}

$\begin{array}{ll}\text { Name } & \text { Dagmara Boińska } \\ \text { Geburtsdatum } & \text { 19. November } 1974 \\ \text { Geburtsort } & \text { Toruń, Polen } \\ \text { Staatsangehörigkeit } & \text { polnisch } \\ \text { Familienstand } & \text { ledig }\end{array}$

\section{Schulausbildung:}

1981-1989

Besuch der Grundschule in Toruń, Polen

1989-1993

Besuch der V. Allgemeinbildenden

Oberschule in Toruń, Polen

Juni 1993

Abitur

\section{Studium:}

1993-1998

Studium an der Nicolaus Copernicus Universität in Toruń, Polen. Fakultät für Biologie und

Naturwissenshaften. Institüt für Allgemeine und Molekulare Biologie. Fachgebiet: Genetik.

Jan. - Dez. 1997 Studienaufenthalt in Göttingen, an der Georg-AugustUniversität, Experimentelle Arbeiten zur Diplomarbeit am Institut für Humangenetik unter der Leitung von Prof. Dr. W. Engel. Betreuer: Dr. Gregor Schlüter.

September 1998 Abschluß des Studiums der Biologie mit dem Diplom

Oktober 1998 Wissenschaftliche Angestellte am Institut für Humangenetik der Universität Göttingen.

Mai 1999 Beginn der experimentellen Arbeiten zur vorliegenden Dissertation. 